University of Louisville

ThinkIR: The University of Louisville's Institutional Repository

Electronic Theses and Dissertations

$5-2017$

\title{
Combating malignant melanoma with the multifaceted soy- dervied peptide lunasin.
}

Christopher Paul Shidal

University of Louisville

Follow this and additional works at: https://ir.library.louisville.edu/etd

Part of the Medical Pharmacology Commons

\section{Recommended Citation}

Shidal, Christopher Paul, "Combating malignant melanoma with the multifaceted soy-dervied peptide lunasin." (2017). Electronic Theses and Dissertations. Paper 2713.

https://doi.org/10.18297/etd/2713

This Doctoral Dissertation is brought to you for free and open access by ThinkIR: The University of Louisville's Institutional Repository. It has been accepted for inclusion in Electronic Theses and Dissertations by an authorized administrator of ThinkIR: The University of Louisville's Institutional Repository. This title appears here courtesy of the author, who has retained all other copyrights. For more information, please contact thinkir@louisville.edu. 


\title{
COMBATING MALIGNANT MELANOMA WITH THE MULTIFACETED SOY-DERIVED PEPTIDE LUNASIN
}

\section{By}

Christopher Paul Shidal

B.S., University of Kentucky, 2008

M.S., University of Louisville, 2014

\author{
A Dissertation \\ Submitted to the Faculty of the \\ School of Medicine of the University of Louisville \\ In Partial Fulfillment of the Requirements \\ For the Degree of
}

Doctor of Philosophy in Pharmacology and Toxicology

\author{
Department of Pharmacology and Toxicology \\ University of Louisville \\ Louisville, KY
}

May 2017 



\section{COMBATING MALIGNANT MELANOMA WITH THE MULTIFACETED SOY-DERIVED PEPTIDE LUNASIN}

By

Christopher Paul Shidal

\section{A Dissertation Approved on}

April 24, 2017

By the following Dissertation Committee:

Keith R. Davis, PhD

J. Christopher States, $\mathrm{PhD}$

Brian P. Ceresa, $\mathrm{PhD}$

Kavitha Yaddanapudi, PhD

Geoffrey J. Clark, PhD 


\section{ACKNOWLEDGMENTS}

I would like to thank my mentor, Dr. Keith R. Davis, for his guidance, patience, and support throughout this entire process. I would like to thank the committee members who agreed to serve on my graduate committee and offered invaluable advice and support. I would also like to acknowledge Christiane Hassel at the IU Flow Cytometry Core, Jim Powers at the IU Light Microscopy Imaging Center, and Sue Childress at the IU Medical Sciences program for their technical support and training used throughout this dissertation.

I extend a big thank you to all of my lab mates throughout the years; Elizabeth McConnell, Banu Vuyyuri, Numan Al-Rayaan, Bharat Devapatala, Calvin Koukam, and Amanda Lasnik for their friendship, training, and dedication to developing me as a scientist. Finally, I wish to thank all of my friends and family that have endured this journey with me, and especially my fiancée, Lauren Jones, for her unconditional love and unwavering support. 


\section{ABSTRACT \\ COMBATING MALIGNANT MELANOMA WITH THE MULTIFACETED SOY-DERIVED PEPTIDE LUNASIN}

Christopher P. Shidal

April 24, 2017

Lunasin is a 44 amino acid peptide that has been shown to have cancer chemopreventative and chemotherapeutic properties. This study investigated the potential utility of Lunasin as a chemotherapeutic in melanomas. Studies showed that Lunasin had little activity against established melanoma cell lines using adherent culture methods; however, Lunasin’s in vitro activity was significantly higher in nonadherent colony-forming assays and oncosphere formation. These results led to the investigation of whether or not Lunasin has selective effects on cancer initiating cells (CIC) that are known to be present in melanomas. It was revealed that Lunasin selectively inhibited the proliferation of high-ALDH expressing CICs, and prevented oncosphere formation. In vitro results were extended into mouse xenograft studies using parental cells and isolated CICs. Lunasin significantly inhibited tumor growth in both cases, with the highest inhibition being observed in tumors initiated by CICs while achieving an excellent safety profile. Lunasin reduced the invasive potential of CICs in vitro and in an in vivo experimental metastasis model. Mechanistic studies revealed that Lunasin may disrupt integrin signaling by inhibiting phosphorylations of the intracellular kinase FAK as well as altering the PI3K/AKT axis. Additionally, it was demonstrated that histone acetylation in $\mathrm{H} 3$ and $\mathrm{H} 4$ core histone are significantly altered in CICs treated with Lunasin. While histone acetylation is potentially involved in Lunasin's anticancer activity, the effects seen in these studies are mainly integrin-driven. These studies demonstrate that Lunasin has activity against putative CICs, and that Lunasin has potential utility as a therapeutic in treating malignant melanomas. 


\section{TABLE OF CONTENTS}

\section{PAGE}

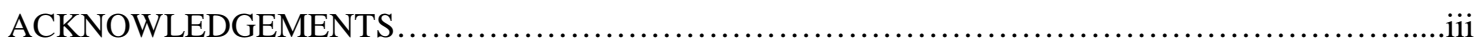

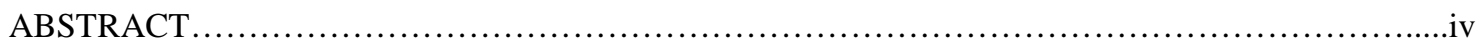

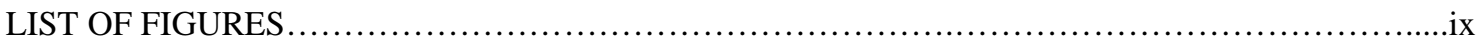

\section{CHAPTER}

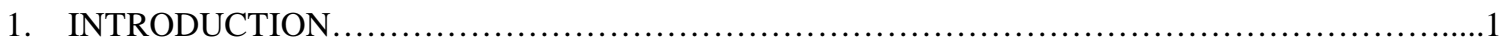

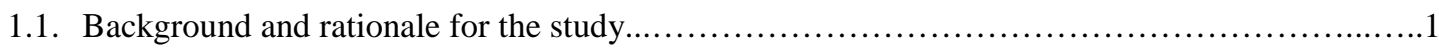

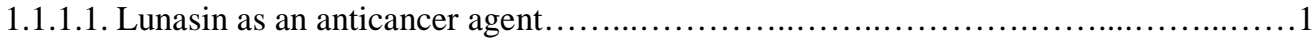

1.1.1.2. Integrins as a therapeutic target in melanoma patients.............................

1.1.1.3. Melanoma and the presence of melanoma stem cells................................8

1.1.1.4. Traditional approaches to treating melanomas and future perspectives..................12

1.2. Specific aims and goals of the dissertation..................................................

1.2.1.1. Identify the mechanisms in which Lunasin exerts its anticancer effects in

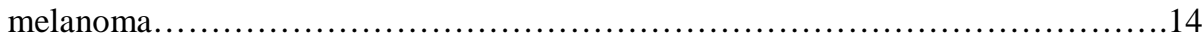

1.2.1.2. Evaluate the interaction between Lunasin and integrin subunits......................15

1.2.1.3. Investigate the antimetastatic effects of Lunasin......................................16

2. EXPERIMENTAL PROCEDURES AND METHODOLOGY .......................................17

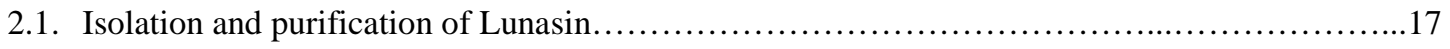

2.2. Cell culture and reagents...................................................................

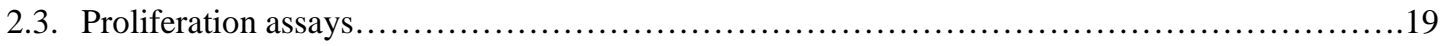

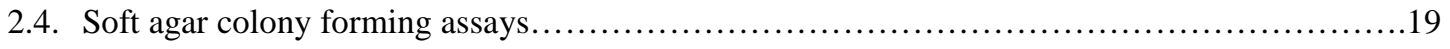

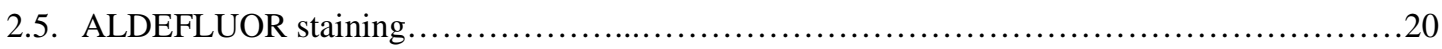

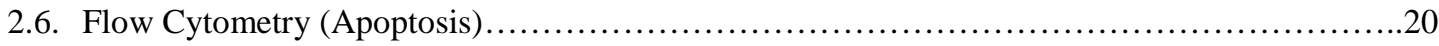

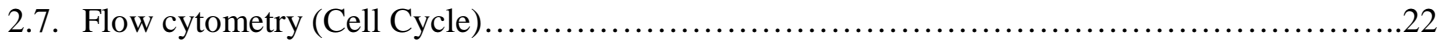

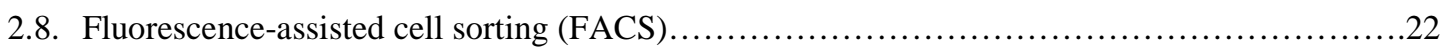




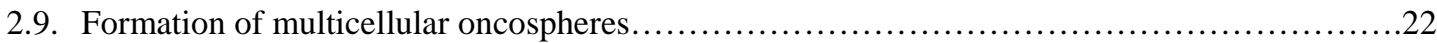

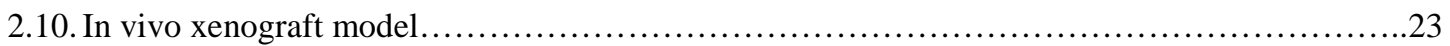

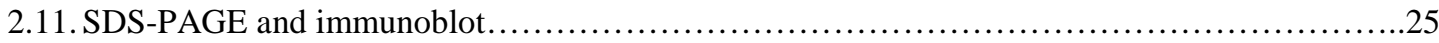

2.12. Non-steroidal anti-inflammatory drug (NSAID) toxicological panel and complete blood count

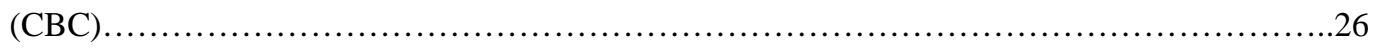

2.13. In vivo Limiting Dilution Assay and ALDH Activity in Primary Tumors......................27

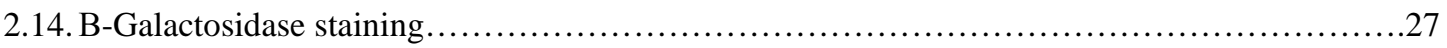

2.15. Liquid overlay generation of multicellular tumor spheres..................................28

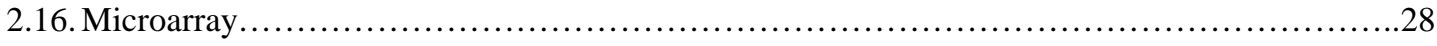

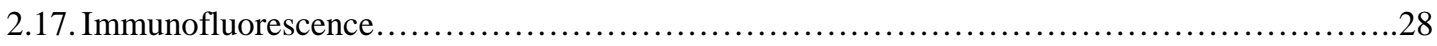

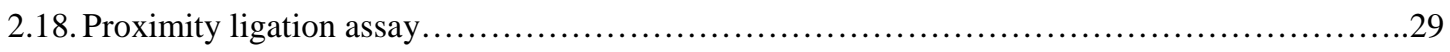

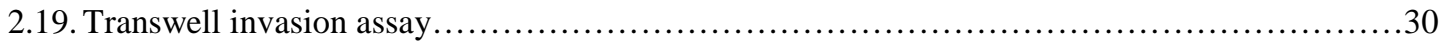

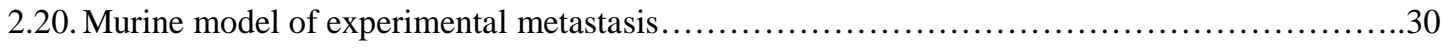

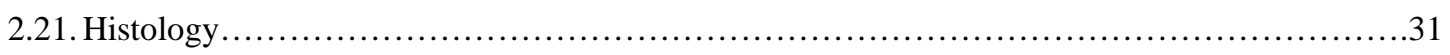

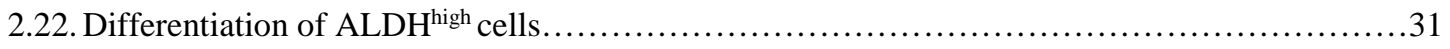

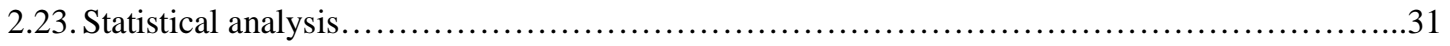

3. LUNASIN IS A NOVEL THERAPEUTIC FOR TARGETING MELANOMA STEM CELLS........33

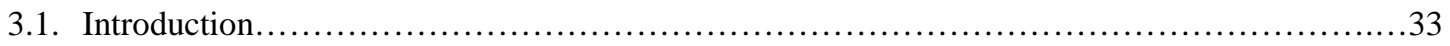

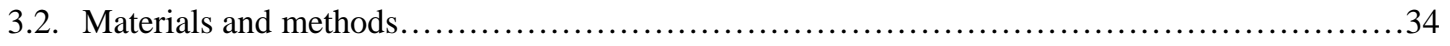

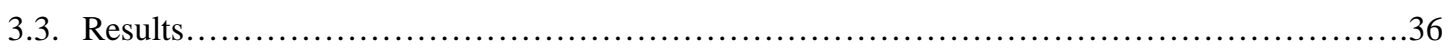

3.3.1.1. Lunasin inhibits anchorage-independent growth in human melanoma cell lines ......36

3.3.1.2. Lunasin inhibits tumor growth of melanoma cells in vivo .......................36

3.3.1.3. Lunasin reduces the melanoma CIC subpopulation in established cell lines ..........38

3.3.1.4. Lunasin suppresses the functional properties of melanoma CICs .....................41

3.3.1.5. Lunasin limits in vivo growth of tumors initiated by melanoma CIC-enriched

$\mathrm{ALDH}^{\text {high }}$ cells

3.3.1.6. Limiting dilution assays demonstrate differential growth patterns between $\mathrm{ALDH}^{\text {high }}$ and $\mathrm{ALDH}{ }^{\mathrm{low}}$ phenotypes..... . .44 
3.3.1.7. CIC markers are heterogeneously expressed in different melanoma cell lines.........46

3.3.1.8. Lunasin induces expression of differentiation markers in melanoma CICs .48

3.3.1.9. Lunasin did not induce a significant senescent response in ALDH ${ }^{\text {high }}$ melanoma

cells.

3.3.1.10. Lunasin may enhance the efficacy of vemurafenib in vemurafenib-resistant melanomas. 53

3.4. Discussion. .57

4. LUNASIN REDUCES THE METASTATIC POTENTIAL OF MALIGNANT MELANOMAS BY INHIBITING INTEGRIN SIGNALING AND ALTERING HISTONE ACETYLATION. .... .63

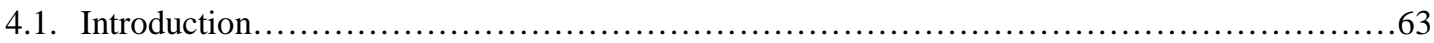

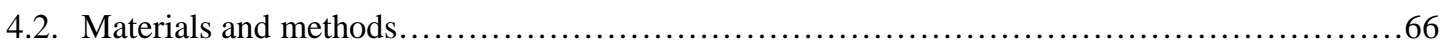

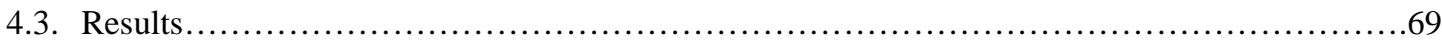

4.3.1.1. Microarray reveals Lunasin-targeted genes and identifies a unique gene signature in ALDH ${ }^{\text {high }}$ melanoma cells compared to parental cells

4.3.1.2. Lunasin uptake correlates with expression of $\alpha_{V}$ integrin subunits....................85

4.3.1.3. B16-F10 CIC populations were reduced with Lunasin treatment.....................86

4.3.1.4. Lunasin inhibits invasion of $\mathrm{ALDH}^{\text {high }}$ melanoma stem cells in vitro.................87

4.3.1.5. Lunasin abrogates pulmonary metastasis in vivo...............................89

4.3.1.6. Lunasin antagonizes integrin signaling through FAK/AKT/ERK and inhibits histone acetylation............................................................. 91

4.3.1.7. The RGD-domain is essential for Lunasin uptake and disrupting oncosphere formation. .93

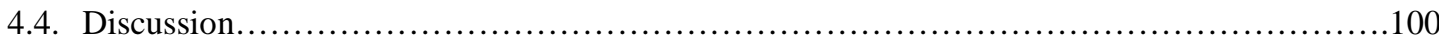

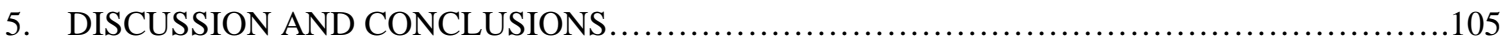

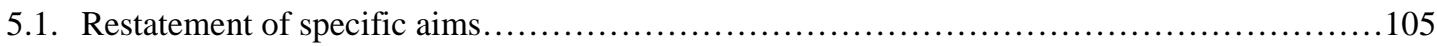

5.2. Summary of findings and impact of the work........................................... 105

5.3. Strengths and weaknesses of the dissertation............................................... 108

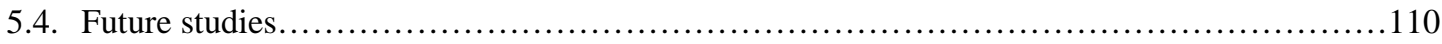




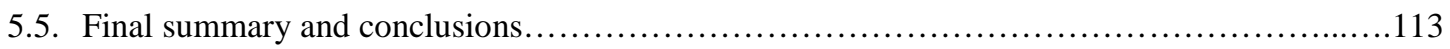

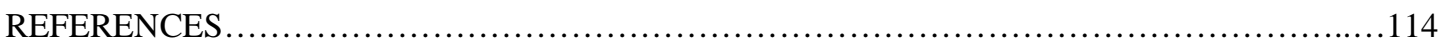

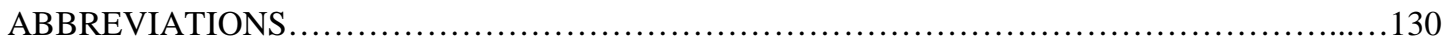

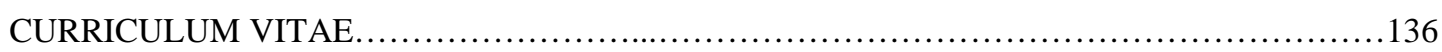




\section{LIST OF FIGURES}

\section{FIGURES}

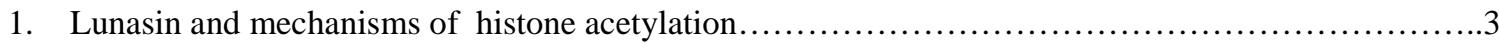

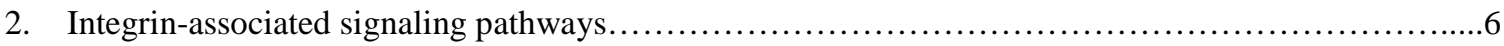

3. The cancer stem cell theory versus the stochastic model of cancer...................................

4. SDS-PAGE analysis of Lunasin purified from white flake.....................................18

5. SKMEL-28 cells stained with ALDEFLUOR reagent +/- DEAB ...............................21

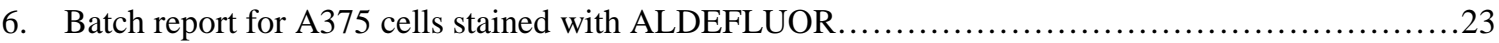

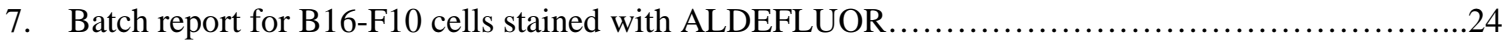

8. Lunasin did not have an antiproliferative effect on A375 or SKMEL-28 melanoma cells in adherent

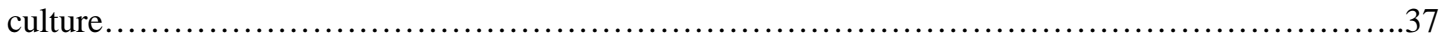

9. Lunasin did not induce apoptosis in parental melanoma cell lines...............................38

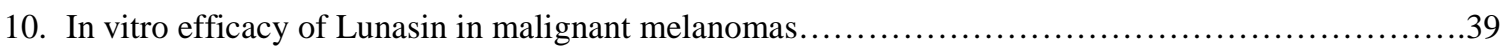

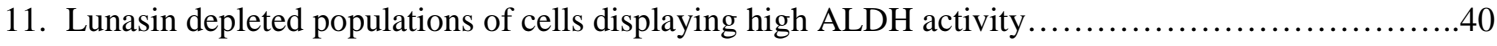

12. Lunasin reduced self-renewal capacity and oncosphere formation of CICs.........................42

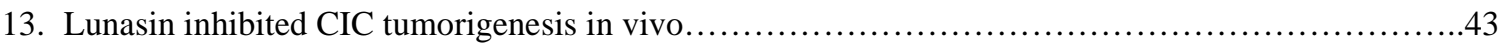

14. Long-term Lunasin treatment did not induce toxic side effects..................................44

15. Limiting dilution assays demonstrate the high tumorigenicity of A375 $\mathrm{ALDH}^{\text {high }}$ cells...............46

16. Differentiation of ALDH-sorted cells in culture...............................................49

17. CIC biomarkers are heterogeneously expressed in melanoma cell lines...........................51

18. Lunasin did not induce an apoptotic response in $\mathrm{ALDH}^{\text {high }}$ melanoma cells........................52

19. Lunasin modulated expression of melanocyte differentiation and stem-associated markers.............53

20. Lunasin did not induce a significant senescent response in A375 ${ }^{\text {high }}$ melanoma cells..................54

21. Combinations of Lunasin and vemurafenib yielded an additive interaction that may benefit treatment of chemoresistant populations of melanoma cells................................................55 
22. Lunasin in combination with vemurafenib kills A375 melanoma cells.............................56

23. Proposed mechanism for Lunasin’s activity in melanoma CICs...................................62

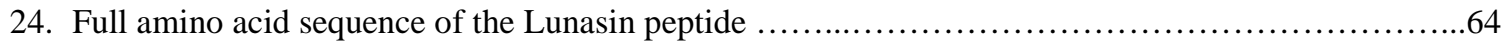

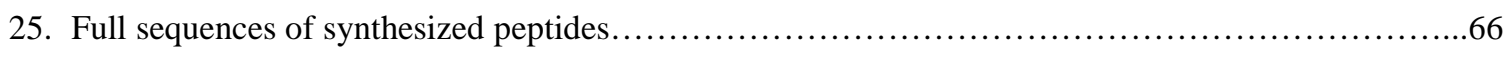

26. Validation of Lunasin antibody recognizing mutated peptides .................................66

27. RNA integrity values for genome-wide microarray analysis....................................67

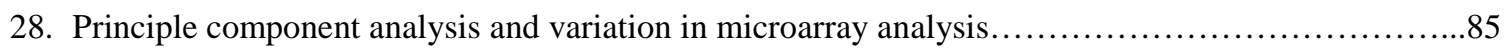

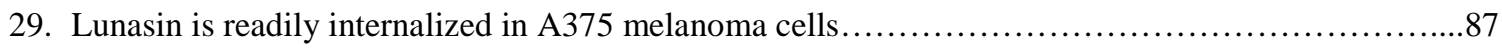

30. Lunasin disrupted oncosphere formation and reduces ALDH ${ }^{\text {high }}$ populations........................88

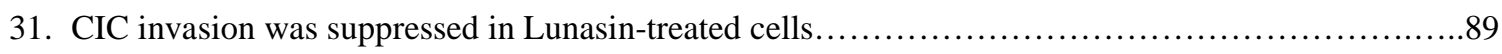

32. Lunasin reduced pulmonary metastases in vivo........................................91

33. Lungs resected from experimental metastasis in vivo model.................................93

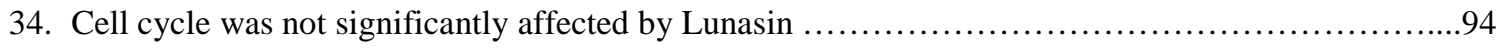

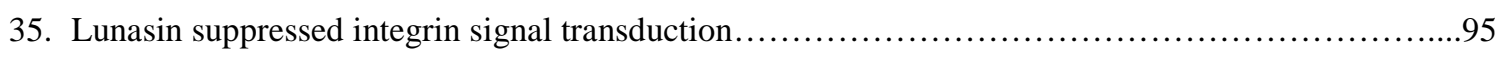

36. Lunasin inhibited phosphorylation of FAK, AKT, and ERK................................96

37. Lunasin modulates histone acetylation in melanoma CICs..................................97

38. Differential expression of integrin subunits by melanoma CICs..............................97

39. Lunasin's RGD motif is essential for disrupting oncosphere formation...........................98

40. Lunasin uptake is an integrin-dependent process.........................................99 


\section{LIST OF TABLES}

\section{TABLES}

PAGE

1. Microarray Analysis of Lunasin-treated A375 Cells..................................................... 72

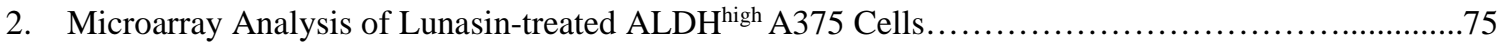

3. Microarray Analysis of Untreated Parental Versus ALDH ${ }^{\text {high }}$ A375 Cells............................80 


\section{CHAPTER 1: INTRODUCTION}

\subsection{BACKGROUND AND RATIONALE FOR THIS STUDY}

\section{Lunasin as an Anticancer Agent}

Consumption of high amounts of soy is prevalent in many Eastern cultures and has been linked by epidemiological studies to lower incidence of certain types of cancer [1-3]. Several components of soy have been attributed with its chemopreventative and chemotherapeutic properties including isoflavones [4], protease inhibitors [5], and bioactive peptides [6]. In combination, these components may work in a concerted effort to reduce carcinogenesis through several mechanisms of action. For example, genistein, a well-studied soy isoflavone, has been acknowledged to assert its anticancer effects through a variety of mechanisms including cell cycle arrest and induction of differentiation [7]. Bowman Birk Inhibitors (BBI) present in soy isolates perform an import action in the uptake and stability of bioactive peptides [8]. Lunasin, a 44 amino acid peptide encoded by the 2S Albumin gene in soy, has been reported to have several activities which may drive its anticancer effects; previous reports have shown that Lunasin functions as a histone acetyltransferase inhibitor [9] as well as an integrin antagonist [10]. With these studies in mind, using soy intake as a functional food seemingly has promising health benefits in preventing carcinogenesis. Additionally, investigating diet as a potential anticancer agent would appear an encouraging avenue for future therapeutic-based studies. This dissertation will specifically investigate the utility of the soy-derived peptide Lunasin as a chemotherapeutic agent against malignant melanomas.

Lunasin is a soy-derived peptide that has demonstrated anticancer, anti-inflammatory, antioxidant, and immunomodulatory activity [11-14]. Lunasin has been reported as a 43 amino acid fragment present in processed 2S albumin protein [15]; however, the Davis lab recently identified a native 44 amino acid sequence of Lunasin isolated from defatted soy flour consisting of the sequence: SKWQHQQDSCRKQLQGVNLTPCEKHIMEKIQGRGDDDDDDDDDN [16]. This 44 amino acid sequence was verified by subsequent studies by Serra et. al. [17]. Lunasin has been proposed to have three distinct domains that are responsible for its therapeutic and chemopreventive activity: an RGD sequence 
involved in internalization of the peptide via integrin binding, a poly-aspartic acid tail that binds lysine residues present in $\mathrm{H} 3$ and $\mathrm{H} 4$ histone tails, and a hypothesized chromatin binding domain $[9,18]$. Limited studies have described the direct chemotherapeutic effects of Lunasin against cancer as it is generally defined as a chemopreventive agent based on earlier studies by De Lumen and coworkers [9, 1922]. Thus, many questions remain about the number of cancer types sensitive to Lunasin, the possible mechanisms of Lunasin's anticancer effects, and to what extent Lunasin is involved with the tight correlation of soy consumption with a protective effect against certain cancer types [23-25].

Lunasin has been found to inhibit transformation induced by multiple carcinogens and viral oncogenes [9, 19, 26-28]. Moreover, studies in the Davis lab indicate Lunasin is able to inhibit transformation of mouse fibroblast cells induced by carcinogens present in cigarette smoke including cadmium and nicotine-derived nitrosamine ketones (unpublished data). The most discussed mechanism of action of Lunasin is the inhibition of histone acetyltransferases (HATs) and modulation of histone acetylation (Figure 1). The acetylation of core histones initiates the unwinding of tightly packed DNA from the nucleosome complex allowing for transcription of target genes. HAT inhibition alters normal acetylation patterns leading to hypoacetylation of histone tails, repressing transcription and can account for global cellular effects including proliferation, cell cycling, and apoptosis [29-31]. Although some evidence supports HAT inhibition as Lunasin's primary mechanism of action, to date, there have been no functional studies to support this hypothesis. Moreover, as new principal mechanisms of Lunasin action are still being discovered, it is not clear in the different experimental systems that have been studied whether histone acetylation is involved in all cases.

Studies in the Davis lab confirm a significant antiproliferative effect of Lunasin on non-small cell lung cancer (NSCLC), an effect which is mediated by disrupting cell cycle signaling [32]. Previous studies have suggested that Lunasin reduces cyclin-dependent kinase (CDK) levels, and may promote aspirininduced apoptosis in breast cancer models [33, 34]. Additionally, Lunasin was reported to induce apoptosis and alter expression of matrix adhesion proteins in metastatic colon cancer [35]. Lunasin was recently shown to suppress FAK/ERK/NF-אB signaling in human colon cancer as well as potentiate the antiproliferative and antimetastatic effects of oxaliplatin [36]. 
Sadly, many plant-derived compounds (e.g. curcumin) are quickly metabolized or excreted resulting in poor bioavailability; however, Lunasin is active and bioavailable in humans consuming physiologically relevant amounts of soy [37]. In this study, volunteers were orally dosed with Lunasin (155.5 mg/day) in 50 grams (g) soy protein for 5 consecutive days. De Mejia et al. revealed Lunasin is orally bioavailable; however, incomplete gastrointestinal (GI) absorption resulted in a low concentration (71.0 ng/mL or approximately $14 \mathrm{nM}$ ) of Lunasin in plasma samples [37].
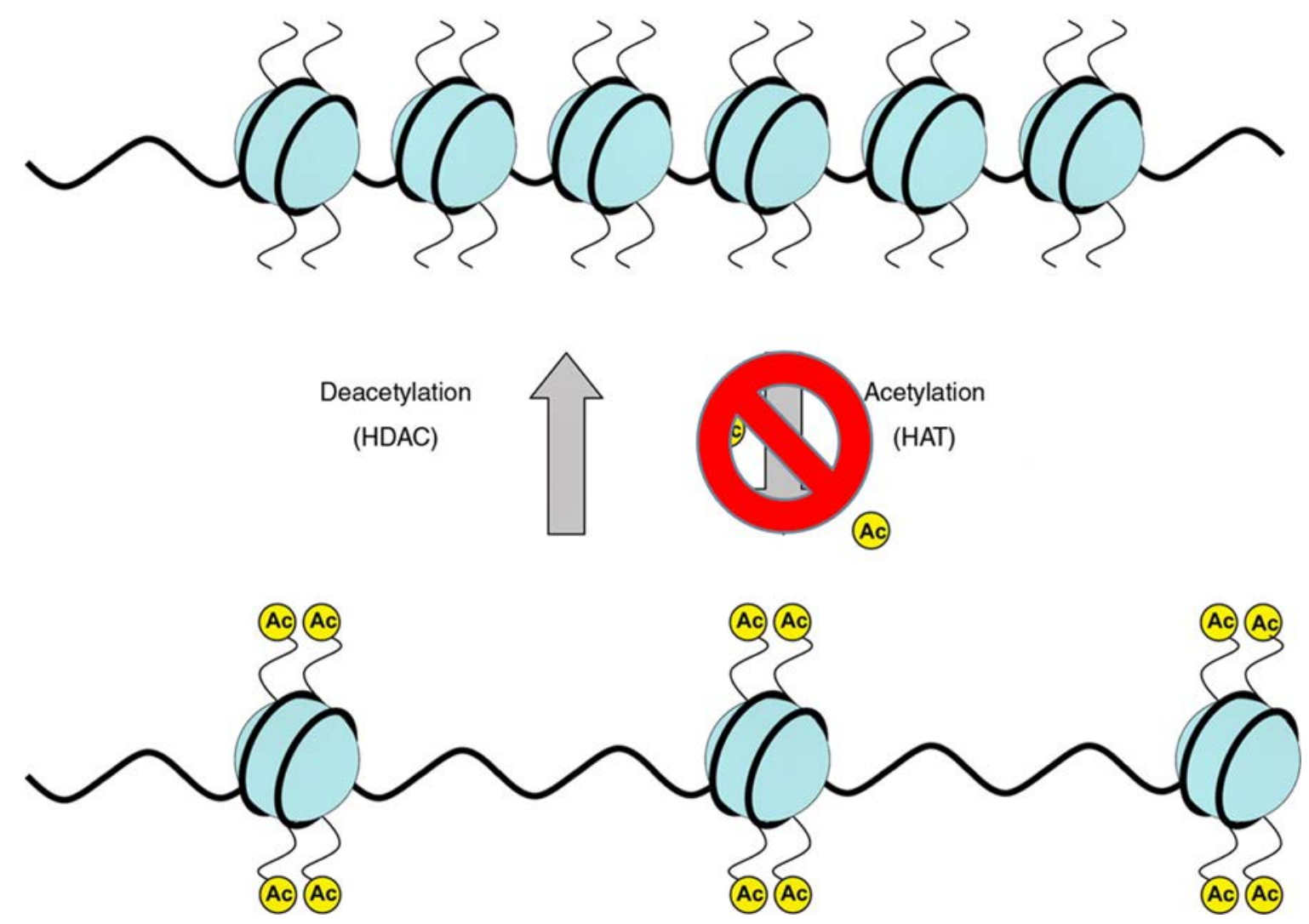

Figure 1: Proposed mechanism in which Lunasin decreases histone acetylation. The poly-aspartic acid tail of the Lunasin peptide may inhibit binding of HATs to lysine residues on core histone H3 and H4 tails. This effect disrupts the normal cycles of histone acetylation/deacetylation and subsequently represses transcription of target genes. Transcriptional machinery is unable to initiate transcription when chromatin is tightly wound around the nucleosome complex (top). Histone acetylation allows for the unwinding of chromatin and exposes sights of transcriptional regulation (bottom). 
Prior studies suggest that Lunasin interacts with a specific subset of integrin subunits, as supported by a 2012 study by De Mejia and coworkers [12]. Furthermore, recent studies suggest that internalization of Lunasin is mediated by $\alpha_{v} \beta_{3}$ integrins via clathrin and caveolin-mediated endocytosis [38]. Proximity ligation assays (PLA) verify that the specific integrin subunits $\alpha_{v}, \alpha_{5}, \beta_{1}$ and $\beta_{3}$ network with the Lunasin peptide [10]. In normal cells, integrins mediate cell-cell and cell-matrix adhesions by recognizing binding motifs (i.e. RGD) as well as cooperating with growth factor receptors to induce proliferative and survival signaling [39, 40]. The ubiquitous activity of integrin signaling provides an interesting target for cancer prevention and treatment because many of these pathways are deregulated in cancer and result in uncontrolled proliferation and metastasis. More specifically, this dissertation aimed to elucidate the effects of Lunasin on downstream pathways associated with integrin signaling and how disrupting these pathways can therapeutically benefit melanoma patients.

Perhaps the most intriguing aspect of the Lunasin peptide is the fact that it has been shown to have immunomodulatory properties as well as those previously mentioned. Having a therapeutic with several mechanisms may lower the possibility of chemoresistance due to the upregulation of pathways associated with the inhibition of oncogenic pathways caused by chemotherapeutic agents as seen in B-Raf targeted therapies (i.e. vemurafenib). In one study, Lunasin was shown to increase antigen specific T cells when mice were challenged with allergen, while also suppressing inflammatory cytokines through NF-кB inhibition [41]. A subsequent study demonstrated that Lunasin provided a significant advantage in dendritic cell activation and maturation and conferred an enhanced immune response to viral challenge in a similar murine model [42]. Relevant to melanoma, Lunasin in combination with cytokines (IL-2 and IL12) synergistically enhanced NK cell-mediated cytotoxicity leading to significantly improved tumoricidal activity both in vitro and in vivo [13]. Lunasin, when introduced into a host, induces an immune response as indicated by the use of multiple antibodies raised in both rabbit and mouse models [16]; thus, Lunasin could be considered an antigenic peptide. Perhaps, the introduction of an immunogenic peptide such as Lunasin promotes the mobilization of cells involved in innate immunity (NK cells, etc.) in order to combat tumor-associated molecules; though, this hypothesis is only speculator at this point, and subsequent studies on the precise mechanisms of Lunasin's immunomodulatory functions are necessary. 
Studies utilizing Lunasin have demonstrated its significant benefit in several cancer models; however, specific mechanisms of action and their induced response in cancer cells is only beginning to become clear. Without functional studies to investigate the precise activity of mechanisms such as integrin antagonism or histone acetylation, it is difficult to target the exact cause of Lunasin's anticancer activity. This dissertation aims to explore the functional domains of the Lunasin peptide while also expanding the knowledge of its chemotherapeutic potential in preclinical models of human melanoma with a strong emphasis on understanding the interactions between Lunasin's RGD domain and integrin subunits on the extracellular matrix (ECM).

\section{Integrins as a targeted therapy in melanoma patients}

Integrins are vital to many cellular processes, and remain an important and underexplored target for cancer therapies (Figure 2). Recent studies utilizing RGD peptides have shown targeting of integrins as a viable treatment alternative in melanoma therapy by inhibiting tumor angiogenesis, growth, and metastasis [43-45]. Integrins are heterodimeric membrane proteins primarily implicated in cell adhesion and migration [46, 47]; yet, integrins have also been reported to be intimately involved in cell growth, differentiation, and survival [48, 49]. Integrin heterodimers are composed of a single $\alpha$-subunits and a single $\beta$-subunits, of which there are 18 and 8 variations, respectively. These $\alpha$ - and $\beta$-subunits comprise the 24 heterodimeric proteins known in humans [50], and make integrin signaling flexible yet highly intricate [51]. Furthermore, integrin expression profiles in vitro can vary largely depending upon the type of adhesion (adherent cells versus cells in suspension) [52], and can result in recruitment of very different subsets of proteins. Proteins attracted to different adhesion structures (e.g. paxillin) can produce diverse yet specific signaling cascades.

By categorizing NSCLC lines based on integrin expression profiles, studies have associated explicit integrin subunits with Lunasin sensitivity [10]. Moreover, it was shown that Lunasin exerts its anticancer effects in NSCLC by reducing activating phosphorylations of v-akt murine thymoma viral oncogene homolog 1 (AKT), focal adhesion kinase (FAK), and interactions of $\beta$-subunits with integrinlinked kinase (ILK), thereby altering signaling pathways downstream of integrin-ligand binding [10]. 
In melanoma models, the integrin $\alpha \mathrm{v} \beta 3$ is currently the predominant target for therapeutic applications of integrin antagonists. Integrin $\alpha v \beta 3$ is expressed at low levels in non-transformed epithelial cells relative to melanoma cells [53], as $\alpha v \beta 3$ expression has been related to metastatic potential and dissemination of melanoma neoplasms to a metastatic phenotype $[54,55]$. Crosstalk between integrins and growth factor receptors has been well documented [56, 57]. Enhanced cancer cell survival has been attributed to a number of interactions between integrin signaling and other pathways including increased BCL-2 expression, PI3K-AKT activation, or NF- $\kappa B$ signaling [58-60]. This dissertation proposed that in melanoma models, similar to recent findings in NSCLC [10], Lunasin binds $\alpha v \beta 3$ integrins through its RGD domain and inhibits proproliferative and prosurvival signaling.

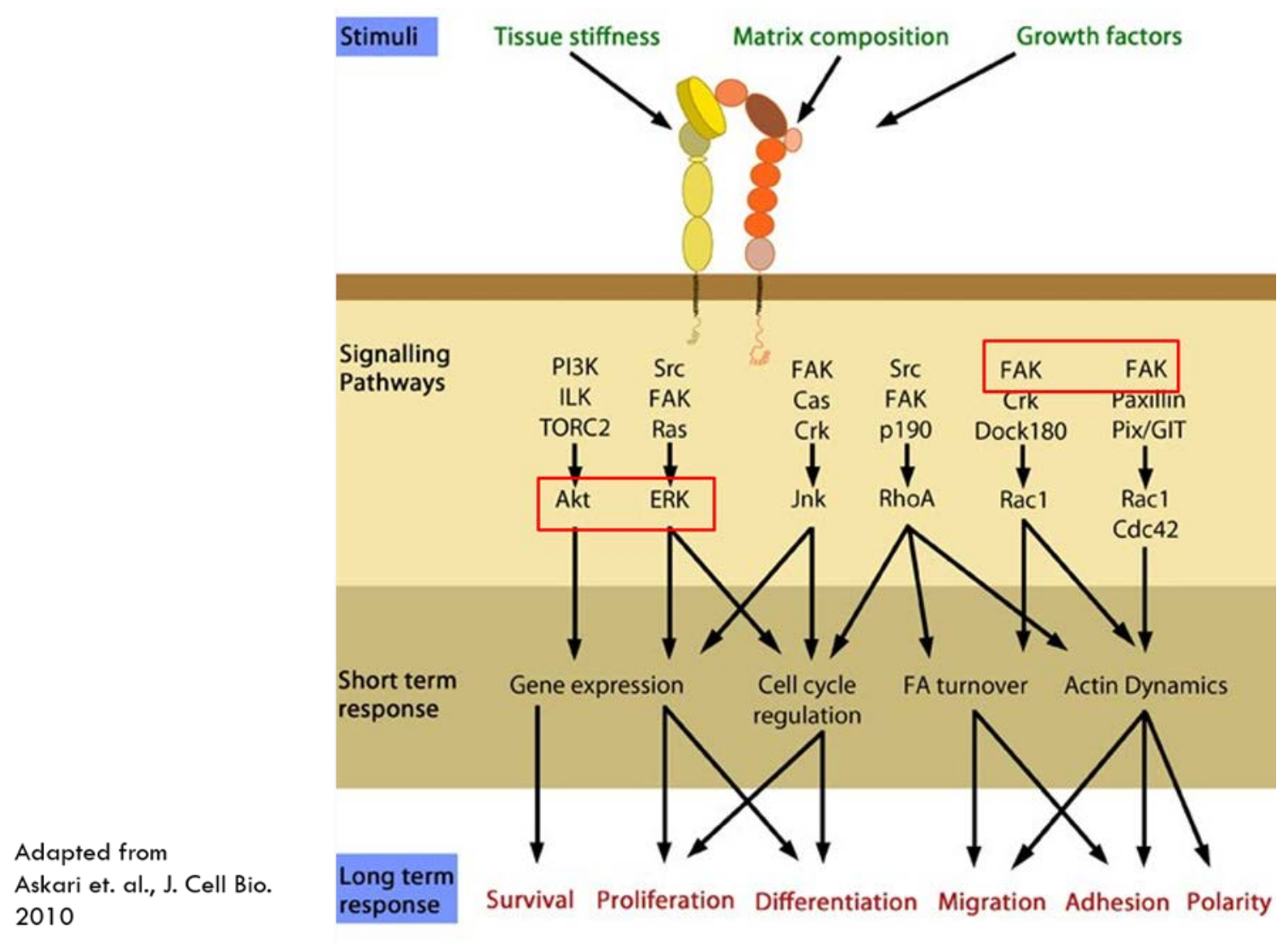

Figure 2: Integrin-associated signaling pathways and the cellular effects associated with integrin signal transduction. Integrin signaling is ubiquitous in that several intracellular kinases (and their effector proteins) are involved in signal transduction. These transduction pathways elicit various cellular effects 
including proliferation, differentiation, and migration, to name a few. Specific kinases highlighted in this dissertation are enclosed in red boxes.

Certain integrins have specific roles in melanoma; for instance, it has been shown that $\alpha_{4} \beta_{1, \text { a }}$ homing molecule on leukocytes that binds VCAM-1, is absent on melanocytes, yet present in melanoma cultures [61]. Consequently, $\alpha_{4} \beta_{1}$ may help melanomas mimic hematopoietic cells by enabling melanoma migration into tissues that expressing VCAM-1 [62]. Other integrins implicated in melanoma are $\alpha_{3} \beta_{1}$ and $\alpha_{5} \beta_{1}$, which were elevated in metastatic melanoma tissue. Furthermore, $\alpha_{1} \beta_{1}, \alpha_{2} \beta_{1}$ and $\alpha_{6} \beta_{1}$ integrin subunits were found to be reduced in metastatic versus primary melanoma [61]. However, roles of integrins in CICs are somewhat ambiguous. Recent studies show that integrin subunits may be a viable marker for CICs and may be responsible for stem cell pool maintenance and differentiation mediated by FAK [63, 64], but the specific functions of integrins in CICs when compared to non-CICs have yet to be elucidated. CICs are proposed to be more tumorigenic based on properties such as chemoresistance, immune evasion, and self-renewal capabilities [65, 66]. Whether integrins, through mechanical adhesion or signal transduction mechanisms, play a central role in these cellular processes is a major focus of this dissertation.

Cilengitide, a cyclic RGD (cRGD) peptide, has been used to treat glioblastoma and is the first integrin inhibitor to be used in Phase III clinical trials [67]. Unfortunately, cilengitide had minimal clinical efficacy as a single agent in treating malignant melanoma [68]. Clinicians noted a significant decrease of $\alpha_{\mathrm{v}} \beta_{3}$ expression in cilengitide-treated melanoma patients. Interestingly, the sole responder to cilengitide treatment had no tumoral $\alpha_{v} \beta_{3}$ expression. Additional clinical trials utilizing integrin-targeted therapeutics in combination with standard treatments have yielded disappointing results [69, 70]; despite promising preclinical data [71-73]. Despite not obtaining a significant difference, the treatment arm combining standard-of-care chemotherapy and anti-integrin targeted therapy trended toward improved overall survival in addition to having a favorable kinetic profile [69]. Furthermore, targeting of integrin subunits explicitly expressed on cancer cells may represent a dynamic solution to reducing off-site, adverse side effects generally seen with traditional chemotherapy. Using integrin antagonists to suppress angiogenesis as well as integrin-associated signaling cascades may prove useful in the future as novel therapeutic strategies that 
do not simply target the bulk of rapidly proliferating tumor cells. The multiple modes of action of Lunasin may provide a substantial boost in antitumor efficacy over more traditional integrin-targeted therapies.

\section{Melanoma and the presence of melanoma stem cells}

Skin cancers account for nearly half of all diagnosed cancer cases in the United States and have increased in frequency over the last thirty years [74]. Melanoma is estimated to account for 76,000 new cancer cases in 2014 [75]. Despite being less frequent than other skin cancers, nearly 75\% of skin cancer deaths are attributed to melanoma [75]. Even more unnerving, NCI’s Surveillance, Epidemiology, and End Results (SEER) program estimates cases of melanoma have nearly tripled in the past thirty years increasing from 7.9 (per 100,000) in 1975 to 22.7 in 2011, while 5-year survival rates remain constant. Early detection and diagnosis is paramount for overall survival with 5-year survival rates of $98 \%, 62 \%$, and $16 \%$ for localized, regional, and distant diseases, respectively [75]. Epidemiological studies have shown that the single greatest risk factor for melanomagenesis is UV exposure [76]; however, heredity has been reported to be involved in up to $12 \%$ of melanoma cases [77]. Classification of melanomas (reviewed in [78]) relies on a staging system which incorporates tumor thickness, presence of ulcerations, mitotic rate, and the existence of metastasis. If diagnosed at an early stage, melanoma is a highly curable disease; however, progression from the radial to vertical growth phase indicates the ability to invade surrounding tissues and potential for metastatic dissemination [79].

Continued research of melanoma has provided several "cracks in the armor" of metastatic melanoma leading to the development of several targeted therapies that aim to inhibit proliferation, metastasis, and angiogenesis of primary and secondary tumors. One such targeted therapy is vemurafenib, which decreases melanoma cell viability and proliferation resulting in tumor regression and increasing overall mean survival time [80, 81]. Vemurafenib targets a mutated form of the B-Raf protein found in approximately $60 \%$ of melanomas in which a V600E substitution leads to constitutive Raf signaling within the mitogen-activated protein kinase (MAPK) cascade [82]. In the majority of patients harboring this mutation, mean survival time has been improved with vemurafenib; however, after initial tumor regression, many patients experience recurrence of tumors that are vemurafenib-resistant [83-85]. Conferred resistance to vemurafenib may occur through a number of mechanisms including, but not limited to, 
feedback activation of epithelial growth factor receptor (EGFR), upregulation of other Raf proteins, or upregulation of N-Ras [85-87].

One explanation for the reformation of palpable tumors with chemoresistance is the presence of CICs within the bulk tumor population. The presence of CICs and their origin have become a topic of debate [88-92]. According to the cancer stem cell theory, a subset of cells within the tumor population have properties that resemble physiological stem cells including the ability to self-renew while also giving rise to daughter cells that differentiate to reform heterogeneous tumor populations [88] (Figure 3). The present study will show that CICs exist within established melanoma cell lines at a relatively high rate, and that this subset of cells displays enhanced tumorigenicity and invasiveness.

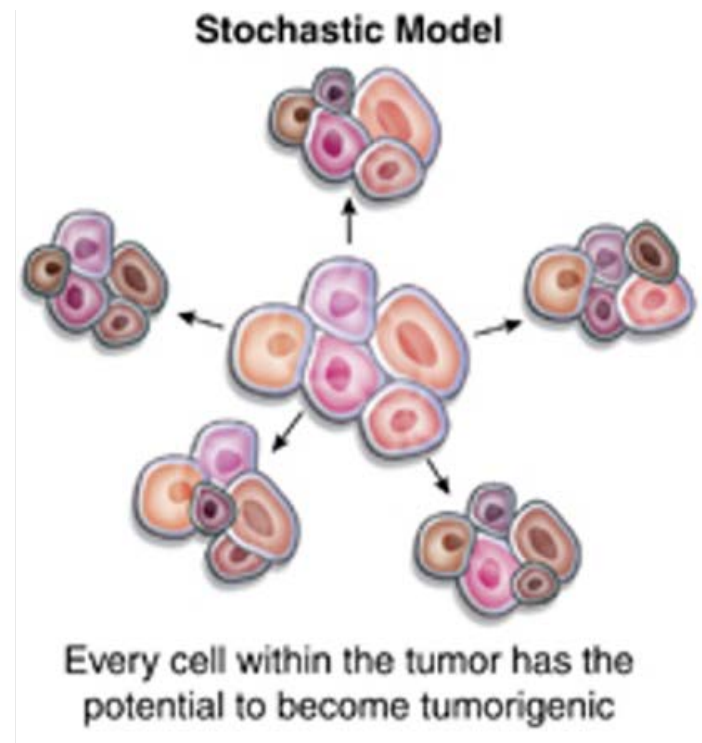

Adapted from Girouard S. and Murphy G., Laboratory Investigation 2011

\section{Cancer Stem Cell Model}

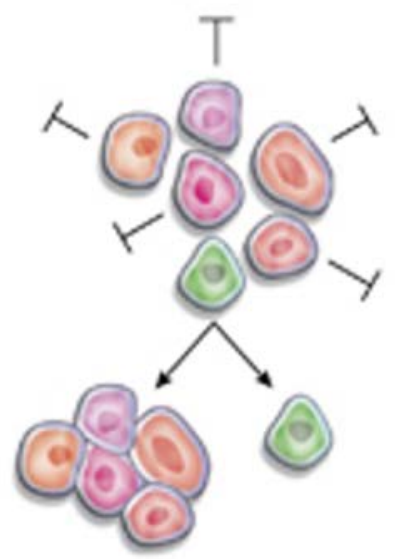

Only a subset of tumor cells, known as cancer stem cells, is tumorigenic, and these cells are defined by their capacity for self-renewal and differentiation plasticity

Figure 3: Stochastic model compared to the cancer stem cell model. The stochastic model of tumorigenesis argues that all individual cells within a tumor population have the intrinsic ability to form a tumor. The cancer stem cell hypothesis states that only a subset of tumor cells have the capacity for reforming heterogeneous tumor populations. The cancer stem cell hypothesis has recently become a topic of debate. While several models seem to appropriately fit the cancer stem cell hypothesis, several researchers have provided evidence suggesting some models do not follow this model. 
Discovery of melanoma cells with stem cell-like plasticity was initially found in patient tumors overexpressing CD20 and CD133 [93, 94]. CD20 is a membrane-spanning surface molecule generally found on B lymphocytes; per se, it is the molecular target for therapeutic monoclonal antibodies (e.g. rituximab) for treatment of select leukemias and lymphomas. CD133 (prominin-1) is a membranespanning protein of no known function that is classified as a marker for primitive hematopoietic and neural stem cells. These subsets of cells were found to have properties of stem cells as well as enhanced ability to form palpable tumors in immunodeficient mice. Ensuing studies verify ATP-binding cassette sub-family B member 5 (ABCB5), a drug transporter playing a key role in chemoresistance, and Low-Affinity Nerve Growth Factor Receptor (LNGFR/CD271), a member of the tumor necrosis factor (TNF) receptor family involved in survival and differentiation of neurons, as viable CIC biomarkers [66, 95]. However, scientists are slow to embrace this concept for a number of valid reasons. One concern remains the standardization of techniques for identifying and propagating cancer stem cells. Serial dilution and transplantation of CICs into NOD/SCID mice has long been the gold standard for determining stem cell populations; however, spheroid assays in addition to genetic lineage tracing provide in vitro assays for CIC classification [89].

To make matters more complicated, some evidence supports plasticity of differentiated cancer cells in a breast cancer model [96]. By reverting to a dedifferentiated phenotype, stem-like cells arise de novo in response to environmental cues [96]. These data support the theory of bidirectional movement between stem and non-stem compartments, and have serious implications on the plasticity of cells in cancer models as well as subsequent therapeutic strategies. The phenomenon of "phenotype switching" has also been reported in melanomas [97]. The hypothesis proposed by Hoek and his coworkers suggests that cells within a tumor may be able to undergo a change between invasive and proliferative phenotypes depending on environmental cues and genetic alterations. Additional publications have aimed to refute the claim that melanoma "fits" the cancer stem cell theory. Quintana et. al. recently reported that nearly 1 in every 4 melanoma cells may be able to produce a palpable tumor in vivo; however, the percentage of tumorigenic melanoma cells was highly variable depending upon the immune status of the host animal [98]. This report questions whether or not cancer stems cells are a rare subpopulation despite the fact that the rarity of CSCs, according to the CSC theory, has yet to be truly defined [99, 100]. 
Although populations of stem cell-like cells are recognized in melanoma cell lines, the frequency of these cells is highly variable, ranging from less than $1 \%$ up to nearly $25 \%[66,98]$. The incidence of cancer stem cells seems dependent upon the in vivo model, the biomarker used for identification, and the tumor microenvironment $[62,101]$. Conflicting reports indicate that tumor samples enriched for CIC markers have enhanced tumor forming capacity. Quintana [98] showed tumorigenic cells are phenotypically heterogeneous in melanomas, as significant in vivo tumor growth was marginal based on select CIC biomarkers. Despite these findings, numerous studies report superior tumor forming capabilities of cells enriched for melanoma stem cell biomarkers including ABCB5 [102], CD133 [94], CD271 [95], and ALDH (aldehyde dehydrogenase) [103].

ALDH is a family of detoxifying enzymes responsible for metabolism of certain alkylating agents such as cyclophosphamide. Enrichment for melanoma initiating cells by intracellular ALDH staining (protocol reviewed in [104]) has come with mixed reviews; however, most evidence supports ALDH as a CIC biomarker [103, 105-107]. ALDH expression has also successfully been used to detect CICs in breast and colon cancer models $[108,109]$. The use of ALDH as a biomarker is based on its involvement in vitamin A metabolism [110]. ALDH has also been researched as a therapeutic target in human melanomas and its inhibition has been shown to decrease melanoma cell tumorigenicity and metastasis [111], indicating a primary role in melanomagenesis and progression. Interestingly, ALDH-high cells may also serve a role as an adjuvant in vaccine-based therapies for melanoma [112].

Throughout this dissertation, ALDH-high fractions of cells derived from several melanoma lines were utilized to assess the effects of Lunasin on melanoma CICs compared to "bulk" tumor cells with the ALDH-low phenotype. The complex mechanisms underlying the contributions of ALDH in CIC function have yet to be fully elucidated. While the work presented in this dissertation does not immediately delve into these intricacies regarding ALDH function in CICs, it will serve as a foundation for using ALDH as a CIC biomarker and supports the notion that ALDH-high cells harbor a highly tumorigenic and invasive population of melanoma cells. In order to indisputably determine whether melanomas follow a hierarchal or stochastic model of tumorigenesis, additional research must be conducted using a standardized and well defined classification and identification system for CSCs. Simply collecting cells based on a single biomarker will most likely not suffice, but long-term propagation in an in vivo system may help categorize 
subsets of tumors cells in terms of tumorigenic capacity and self-renewal. Data presented throughout this dissertation and how it relates to what is currently known about the CSC theory (Reviewed in [113]) will be discussed in subsequent chapters of this work.

\section{Traditional approaches to treating melanomas and future perspectives}

It is becoming clear that late-stage and recurrent melanoma may be due to the presence of melanoma stem cells which repopulate the heterogeneity of melanoma tumor tissues throughout the body. An emerging issue in treatment strategies involving late-stage cancers is the fact that traditional chemotherapeutic agents (e.g. alkylating agents) can actually expand the CIC compartment while simultaneously causing an initial regression of the primary tumor [114-116]. Recent studies have found that several traditional chemotherapies, including many used in the treatment of malignant melanomas, can increase the number of cells in the CIC compartment [117-120]. In addition to selecting for CICs, these chemotherapeutic regimens can increase genetic instability leading to phenotypic abnormalities such as increased invasiveness or enhanced tumorigenicity [121]. Therefore, the strategy of using differentiationinducing agents to reduced CIC populations prior to, in combination with, or immediately following therapeutic intervention is an emerging area of research [122].

The standard protocol for treating melanoma has largely depended on the stage at diagnosis; early melanomas (stage I and II) can generally be surgically resected without fear of recurrence [123, 124]. However, late stage (stage III and IV) melanomas are treated much more aggressively and traditional treatment usually includes surgical resection, radiation, chemotherapy, or a combination of these therapies [123, 124]. Dacarbazine, temazolomide, cisplatin, and paclitaxel have primarily been used as the chemotherapeutic arm of traditional treatment strategies [125-127]. While these therapies have been shown to induce apoptosis in many melanomas and provide relief in the form of an initial tumor regression, many patients will experience recurrence and subsequent metastasis of chemoresistant tumor populations within months of treatment; patients with stage IV melanomas given the standardized treatment of care (i.e. dacarbazine) had median overall survival times ranging from 5.6 - 7.8 months and a response rate of only 7 $-12 \%$ [83, 128-131]. These facts, taken in conjunction with the high cytotoxicity and ongoing list of 
adverse effects of traditional anticancer pharmacologics, make it very clear to see why the demand for efficacious yet safe treatment options are needed.

The past decade has seen the implementation of several novel strategies for the treatment of late stage melanomas including targeted therapy (e.g. vemurafenib) [132] and immunotherapies, which consist of several subcategories including adoptive cell transfer [133], oncolytic viral therapy [134], and checkpoint blockade (e.g. nivolumab) [135]. Due to the strong immunogenicity of melanomas [136], the use of immunotherapies for modulating melanoma progression has received strong interest from researchers and pharmaceutical companies and will likely be a major focus moving forward. While immunotherapies have shown great promise in clinical trials [137-139], the fact that these drugs are just now being implemented clinically raises the question as to whether these agents can sustain improved patient responses and increased overall survival rates. Therefore, the continual development of novel antimelanoma drugs is necessary to combat this particularly deadly and inherently common disease. With respect to Lunasin, a particularly intriguing aspect of the recent development and approval of immunotherapies is the fact that Lunasin has been shown to enhance components of both innate and adaptive immunity [13, 41, 42]. While strategies dedicated to eliciting cell-mediated immune responses seem to be receiving heightened interest, inducing an overall immune response by activating several constituents of the immune system may provide a more robust antitumor effect. At the very least, it will be interesting to see what the future holds for immunomodulatory therapies, and whether or not they become a mainstay in anticancer treatments. 


\subsection{SPECIFIC AIMS AND GOALS OF THE DISSERTATION}

\section{Overall Goals}

The principle goal of this dissertation is to expand upon the existing knowledge that Lunasin has significant anticancer activity. Initial data from the Davis lab indicated that Lunasin may have potential utility against NSCLC. The hypothesis of this dissertation extends upon previous studies in the Davis lab to suggest that Lunasin may have potential clinical utility against melanoma. Malignant melanoma cell lines derived from both human and murine origins were used to investigate the functional effects on cancer cells when they are treated with Lunasin, and additionally, to demonstrate through preclinical studies that these effects could provide a potential therapeutic benefit in clinical applications. Initially, it was observed that Lunasin had a modest effect in vitro; however, these effects were more robust in vivo. The importance of CICs in melanoma mortality [140] led to the question as to whether or not Lunasin might have a selective effect on this population of cells. This was especially important due to the problematic and challenging nature of melanoma recurrence and chemoresistance due to the presence of CICs [140]. A principle goal of this study was to characterize the effects of Lunasin on melanoma cells through analysis of proliferative, apoptotic, differentiation, and senescence markers. Previously described mechanisms of Lunasin's anticancer activity including alterations in histone acetylation and integrin signaling were investigated to reveal which mechanism(s) was responsible for the effects seen in melanoma models. The

driving hypothesis of this study is that Lunasin decreases tumorigenicity and proliferation of melanoma cell lines by inhibiting integrin signal transduction.

Recent findings in NSCLC [10] indicated that Lunasin's interaction with integrins comprised a significant portion of its anticancer activity; therefore, those studies were used as a stepping stone to further explore melanoma as a model to discover novel functions of the Lunasin peptide. Because of the central role of both CICs and integrins in metastatic dissemination [62], it was imperative to assess whether Lunasin, through its changes in integrin signal transduction and selective targeting of CICs, would significantly suppress metastatic outgrowth in a murine model of metastasis. In terms of clinical relevance, the use of Lunasin as an adjuvant in combination with the commonly prescribed B-Raf inhibitor vemurafenib was utilized to assess any additional gain in therapeutic benefit. Taken together, it was expected that these findings would advance Lunasin as a potential drug candidate for further development, 
not only in malignant melanoma, but in malignant diseases in which the presence of CICs has the potential to cause patient relapse.

Specific Aims

\section{Identify the mechanisms in which Lunasin exerts its anticancer effects in melanoma}

Sub Aim A. Assess the ability of Lunasin to reduce populations expressing CIC and stem-associated markers

Sub Aim B. Characterize the effects of Lunasin on CICs through analysis of proliferative, apoptotic, and differentiation markers

Lunasin's effects on melanoma had yet to be documented prior to the Davis lab’s initial study [141]; however, the recent findings in NSCLC would suggest that these effects are conserved throughout many different cancer cell types. It was revealed that NSCLC proliferation was significantly inhibited when cancer cells were treated with Lunasin, and additionally, that this effect was differentially dependent upon expression of specific integrin subunits [10]. These results would suggest that integrin signaling is strongly linked to the initial results which demonstrated that Lunasin diminished the ability of cells to form colonies in soft agar as well as had a very modest effect on melanoma cells in proliferation assays. Firstly, this dissertation aimed to identify and characterize the effects that Lunasin had on parental melanoma cells through assessment of markers for proliferation, apoptosis, differentiation, and senescence. Secondly, this work planned to identify whether or not Lunasin had a significant effect on biomarkers for melanoma CICs including ALDH, CD271, and CD133. Categorizing these effects as described would justify subsequent aims geared toward elucidating specific mechanisms of Lunasin in melanoma CICs.

\section{Evaluate the interaction between Lunasin and integrin subunits}

Sub Aim A. Specify the explicit integrin subunits interacting with Lunasin and identify the downstream mediators of integrin signal transduction

Sub Aim B. Mutate the Lunasin peptide to discriminate the effects caused by histone acetyltransferase inhibition and integrin antagonism

Sub Aim C. Genome-wide microarray analysis to discover Lunasin associated gene targets

Recent work in the Davis laboratory has focused on using NSCLC as a model to investigate the specific mechanisms in which Lunasin exerts its effects on cancer cells. It was observed that in NSCLC, 
integrin signaling was significantly suppressed in cells treated with Lunasin. Using these results as a stepping stone, it was next investigated if these effects were conserved in models of melanoma. Therefore, this dissertation proposed to investigate the interactions between RGD-recognizing integrin subunits and the Lunasin peptide as well as assessed the downstream effects through integrin-associated intracellular kinases (e.g. FAK) caused by this interaction. Because Lunasin has been reported to have significant effects on global histone acetylation patterns [142], it was next asked whether these effects could be driven by alterations in chromatin structure (via histone acetylation) compared to suppressed integrin signaling. Using synthesized peptides with mutated activity domains, this study aimed to test whether the RGD domain or the poly-aspartic acid tail were necessary for Lunasin’s activity in melanoma.

Integrin signal transduction has been linked to several oncogenic signaling pathways [143]; for example, integrins have been shown to cooperate with the MAPK signaling cascade [144]. The ubiquitous nature of integrin-mediated signaling makes it difficult to accurately pinpoint precise mechanisms involved in Lunasin’s activity. Thus, a genome-wide microarray screen was employed in order to distinguish any signaling pathways that may overlap with either integrin signal transduction or histone acetylation causing the effects observed in previous studies. Using Lunasin as a tool to probe for novel therapeutic targets or identify connected hubs of proteins associated with these targets may allow researchers to explore this multifaceted peptide as a viable treatment option for malignant melanoma.

\section{Investigate the antimetastatic effects of Lunasin}

Metastatic dissemination due to circulating tumor cells that have undergone epithelial to mesenchymal transition (EMT) is the foremost reason for poor prognosis due to the high mortality rates caused by secondary tumor growth [145]. Prevention of initial metastatic seeding and sequential colonization of distant tissues is at the forefront of several clinical trials, and remains a major focus for oncologists and researchers [146, 147]. Even after metastatic outgrowth from the primary tumor, shrinkage of these initial lesions and prevention of metastatic spread can successfully improve overall patient survival. Therefore, it was next investigated whether or not Lunasin could provide any antimetastatic benefit in a syngenic model of experimental metastasis. These data, if supportive of the proposed hypothesis, could potentially provide significant clinical implications for the development of Lunasin as an adjuvant therapy in malignant diseases. 


\section{CHAPTER 2: EXPERIMENTAL PROCEDURES AND METHODOLOGY}

\subsection{Lunasin Isolation and Purification}

Lunasin was isolated from "white flake,” a product resulting from the flaking and defatting of soybeans via hexane extraction. The extraction and purification was scaled and performed by Kentucky BioProcessing (KBP) as previously described [16]. Briefly, Lunasin was extracted from defatted soy flour in a 12.5: 1 ratio of extraction buffer $(20 \mathrm{mM}$ sodium phosphate/150 mM NaCl/20 mM ascorbic acid/10 mM sodium metabisulfite, $\mathrm{pH}$ 7.4) to soy flour. This solution was mixed for one hour at room temperature. A diatomite filter aid (Advanced Minerals Corporation) was added to the solution after mixing, and the mixture was then passed through a filter press (ErtelAlsop, $1 \mu \mathrm{m}$ filter pads). The filter cake was dried and once again washed with extraction buffer, and the resulting mixture was added to the initial extract. Anion exchange chromatography was performed at Kentucky BioProcessing using a 20x13 cm Q-Sepharose FF column on a Pharmacia $10 \mathrm{~mm}$ BioProcess System Skid after both column and skid were sanitized with 1 $\mathrm{N} \mathrm{NaOH}$ and preconditioned with equilibration buffer (20 mM sodium phosphate/150 mM NaCl, pH 7.4). Clarified extracted was applied to the column for a residence time of approximately $3 \mathrm{~min}$, and washed with 14.8 CV (column volumes) of equilibration buffer. Lunasin was eluted using a linear gradient of sodium chloride $(0.29-0.48 \mathrm{M}, \mathrm{pH}=7.4)$, and the Lunasin-containing fractions were filtered through a 0.2 $\mu \mathrm{m}$ capsule filter. Dithiothreitol (DTT) was added to the fraction containing Lunasin to a final concentration of $2 \mathrm{mM}$, and the mixture was mixed at room temperature for one hour. DTT-containing fractions were then subjected to ultrafiltration using $30 \mathrm{kDa}$ polyethersulfone membranes and a Sartorious Sartocon Slice unit (Sartorious Stedium Biotech). The final step in the purification process utilized reverse-phase chromatography (RPC) using a 10x9.2 cm Source RPC column on an AKTA pilot system (GE Healthcare). Fractions were applied to the column with a residence time of precisely $2.5 \mathrm{~min}$. and subsequently washed with equilibration buffer followed by a step elution process using $20 \%$ up to $100 \%$ elution buffer (17 mM sodium phosphate/127.5 mM NaCl/15\% n-propanol/pH 7.4) in which the $100 \%$ buffer was the Lunasin-containing fraction. This fraction was concentrated using a $0.5 \mathrm{~m}^{2} 2 \mathrm{kDa}$ cellulose 
cassette (Sarorious Stedium Biotech). RPC elution buffer was replaced with $50 \mathrm{mM}$ sodium phosphate (pH 7.4) via diafiltration, and passed through a $0.2 \mu \mathrm{m}$ filter. Sodium dodecyl sulfate polyacrylamide gel electrophoresis (SDS-PAGE) analysis indicate these Lunasin preparations have $>99 \%$ purity (Figure 4). Subsequent experiments utilizing Lunasin as a treatment used these stock preparations, which had been diluted to a final concentration of $4.7 \mathrm{mg} / \mathrm{mL}$ of Lunasin (in $50 \mathrm{mM}$ sodium phosphate) in $10 \mathrm{~mL}$ sterile glass vials and stored at $4^{\circ} \mathrm{C}$.

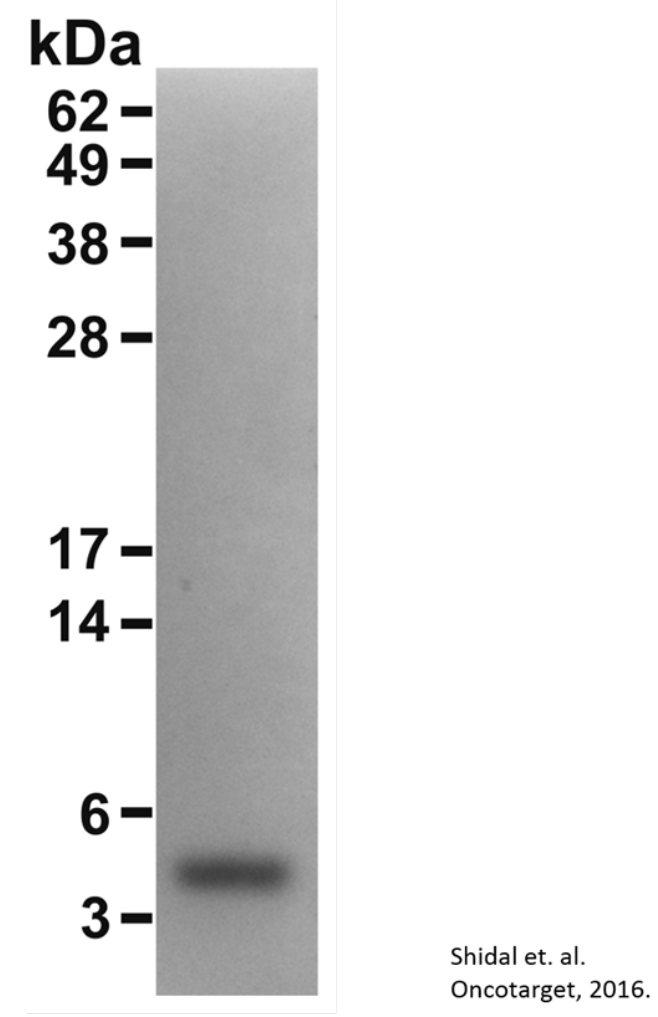

Figure 4: SDS-PAGE analysis of lunasin purified from soybean white flake. A total of $5 \mu \mathrm{g}$ total protein was subjected to SDS-PAGE using a 15\% gel (BioRad) followed by staining with Coomassie Brilliant Blue (BioRad). Labels indicate migration of SeeBlue Plus2 (Life Technologies) protein standards.

\subsection{Cell Culture and Reagents}

B16-F10, SKMEL-28, and A375 cell lines were obtained from American Type Culture Collection (Rockville, MD), and further authenticated by short tandem repeat profiling (Promega). Cells were monitored for mycoplasma contamination every 6 months. All cell lines were grown in Dulbecco’s 
Modified Eagles Medium (DMEM) supplemented with 10\% Fetal Bovine Serum (FBS), Penicillin (100 $\mathrm{U} / \mathrm{mL})$, and Streptomycin $(100 \mu \mathrm{g} / \mathrm{mL})$. Cells were incubated at $37^{\circ} \mathrm{C}$ at $5 \% \mathrm{CO}_{2}$ and sub-cultured every $72 \mathrm{~h} . \mathrm{ALDH}^{+}$cells were purified by fluorescence-activated cell sorting (FACS) and were grown in DMEM/F-12 serum-free media containing 1x N-2 Supplement (Gibco) $10 \mathrm{ng} / \mathrm{mL}$ basic fibroblast growth factor (Gibco), and $10 \mathrm{ng} / \mathrm{mL}$ epidermal growth factor (Gibco). For soft agar assays, DMEM media (Invitrogen) powder was reconstituted in ultrapure water (500 mL) and supplemented with $20 \%$ FBS, Penicillin (200 U/mL), and Streptomycin $(200 \mu \mathrm{g} / \mathrm{mL}$ ). Vemurafenib (a selective B-Raf inhibitor) was obtained from Selleck Chemicals (PLX4032, RG7204). Vemurafenib was dissolved in dimethyl sulfoxide (DMSO) at a stock concentration of $1 \mathrm{mM}$ and stored at $-20^{\circ} \mathrm{C}$ until use. The A375R cell line was created in the Davis lab to mimic acquired vemurafenib resistance. A375R cells are derived from A375 melanoma cells which were cultured in $1 \mu \mathrm{M}$ vemurafenib for 4 weeks. The resulting cell phenotype had decreased sensitivity to vemurafenib compared to parental A375 cells.

\subsection{Proliferation Assays}

Manufacturer protocols were followed to determine the effects of Lunasin on melanoma cell proliferation (Promega Cell titer-96 Aqueous Reagent). Initial seeding densities were standardized at 7.5x $10^{3}$ cells $/ \mathrm{cm}^{2}$ in $100 \mu \mathrm{L}$ culture media. Briefly, cells were plated and incubated at $37^{\circ} \mathrm{C}, 5 \% \mathrm{CO}_{2}$ for $4 \mathrm{~h}$. Media were drained from each well and replaced with media containing varying concentrations of vehicle, Lunasin, or vemurafenib. Treatment media were replaced every $24 \mathrm{~h}$ during the $72 \mathrm{~h}$ treatment period. After $72 \mathrm{~h}$ of treatment, wells were drained of expired media and refilled with $100 \mu \mathrm{L}$ of fresh media. 20 $\mu \mathrm{L}$ of [3-(4,5-dimethylthiazol-2-yl)-5-(3-carboxymethoxyphenyl)-2-(4-sulfophenyl)-2H-tetrazolium (MTS) reagent was added to each well and the plate was incubated for 2-3 h. Absorbance was read at 490 nm on a plate reader (Biotek Instruments). Average absorbance of media containing no cells (i.e. background absorbance) was subtracted from all absorbance values. Absorbance values were then normalized to control and expressed as percent control \pm s.d.

\subsection{Soft Agar Colony Forming Assay}

A lower, cell-free layer of $0.5 \%$ Bacto agar and cell culture media (1:1 suspension) was plated in 6-well tissue culture plates and allowed to solidify at room temperature in a laminar flow cabinet. An upper layer of $0.35 \%$ agar and culture media (1:1) containing 1000 melanoma cells plus vehicle, Lunasin or 
vemurafenib was plated over the solid lower layer. Plates were incubated at $37{ }^{\circ} \mathrm{C}$ and $5 \% \mathrm{CO}_{2}$ for $10-18$ days until colonies grew to approximately $100 \mu \mathrm{m}$ in diameter. After seeding, plates were fed with culture media containing vehicle (PB) or Lunasin twice weekly. Plates were stained with crystal violet solution (0.005\%; Sigma-Aldrich), photographed, and scanned (1000 dpi; EPSO Expression 1680 scanner). Average colony size and total colony area for each sample were analyzed using Image-J software (National Institutes of Health).

\subsection{ALDEFLUOR Staining}

The ALDH positive population was identified using a commercial kit (ALDEFLUOR ${ }^{\mathrm{TM}}$, Stem Cell Technologies) according to manufacturer’s directions. A375, SKMEL-28, and B16-F10 cells were grown to approximately 80\% confluence in DMEM cell culture medium and treated with Lunasin for $24 \mathrm{~h}$.

Cells $\left(1 \times 10^{6}\right.$ cells $\left./ \mathrm{mL}\right)$ were washed and resuspended in ALDEFLUOR ${ }^{\mathrm{TM}}$ Assay Buffer. ALDEFLUOR ${ }^{\mathrm{TM}}$ reagent $(5 \mu \mathrm{L} / \mathrm{mL})$ was added to the cell suspension. The sample was mixed, and a portion was added to a fresh tube containing the N,N-diethylaminobenzaldehyde (DEAB) inhibitor. Another portion was placed in a fresh tube for staining with $10 \mu \mathrm{g} / \mathrm{mL}$ propidium iodide (PI). Samples were incubated in $37^{\circ} \mathrm{C}$ for 45 min and mixed occasionally by inversion. Flow cytometry was performed using FACS Calibur (BD Biosciences). A representative histogram showing SKMEL-28 melanoma cells stained with ALDEFLUOR reagent is presented in Figure 5.

\subsection{Flow Cytometry (Apoptosis)}

Annexin V binding assays were conducted using FITC conjugated antibodies against phosphatidylserine (BD Bioscience) and propidium iodide to measure rates of apoptosis and cell death. Cells were harvested and resuspended in 1x binding buffer (0.1 M HEPES, pH 7.4; 1.4 M NaCl; 25 mM $\mathrm{CaCl}_{2}$ ) at a concentration of $1 \times 10^{6}$ cells per mL. Briefly, $1 \times 10^{5}$ melanoma cells were incubated with 100 $\mu \mathrm{M}$ Lunasin for $24 \mathrm{~h}$. After the $24 \mathrm{~h}$ treatment, cells were harvested using enzyme-free dissociation media (TrypLE, Life Technologies), counted, and subjected to staining. Cells were suspended in $0.5 \mathrm{~mL}$ binding buffer and stained with $5 \mu \mathrm{L}$ PI, $5 \mu \mathrm{L}$ Annexin antibody, or both for 15 min at room temperature. Gates were set based on controls (unstained, PI only, Annexin only), and compensation controls were performed in FlowJo V10 (FlowJo, LLC). 1x10 ${ }^{4}$ events were collected per run on a FACS Calibur flow cytometer (BD Biosciences). 
For identifying ALDH ${ }^{\text {high }}$ cells, melanoma cells were assayed for high ALDH activity as described above (Section 2.5). ALDH ${ }^{\text {high }}$ and $\mathrm{ALDH}^{\text {low }}$ melanoma cells were sorted using a MoFlo cell sorter (Beckman Coulter) or a FACS Aria II with FACS Diva software (BD Biosciences). Sorted ALDH ${ }^{\text {high }}$ cells $\left(1 \times 10^{3}\right.$ cells/mL) were plated in low-attachment 6-well plates (Corning) in DMEM/F-12 serum-free media. Cells were either treated with Lunasin $(100 \mu \mathrm{M})$ or vehicle and labelled with Annexin V or PI. Labelled cells were analyzed by flow cytometry using FACSCalibur (BD Biosciences) as outlined above.
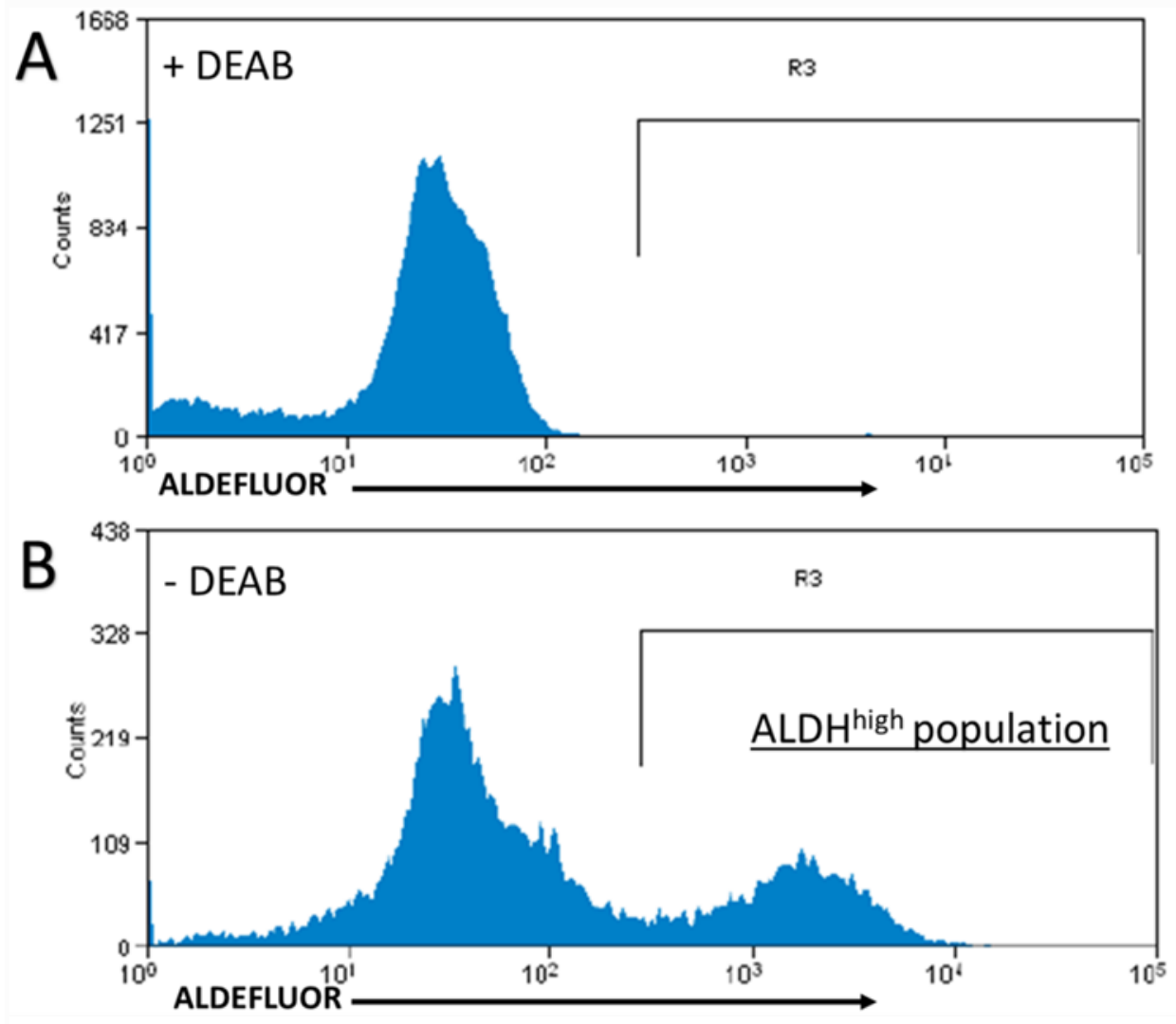

Shidal et. al. Oncotarget, 2016.

Figure 5: SKMEL-28 cells stained with ALDEFLUOR reagent +/- DEAB. SKMEL-28 melanoma cells were grown in adherent culture, harvested, and stained for ALDH activity. This histogram represents a typical ALDH staining profile for the SKMEL-28 cell line run on a MoFlo cell sorter, and shows subpopulations both negative (A) and positive (B) for ALDH activity. 


\subsection{Flow Cytometry (Cell Cycle)}

Cell cycle analysis was performed on synchronized melanoma cells; cells were serum starved for $72 \mathrm{~h}$ and then released by addition of 10\% FBS culture media containing Lunasin or vehicle for $24 \mathrm{~h}$. $1 \times 10^{6}$ cells were harvested and resuspended in $200 \mu \mathrm{L}$ of PBS. Cells were slowly added to $4 \mathrm{~mL}$ ice cold $70 \%$ ethanol for overnight fixation at $-20^{\circ} \mathrm{C}$. After fixation, cells were spun down at $300 \mathrm{xg}$ for $10 \mathrm{~min}$ and resuspended in $0.5 \mathrm{~mL}$ of PI master mix ( $40 \mu \mathrm{g} / \mathrm{mL}$ PI, $100 \mu \mathrm{g} / \mathrm{mL}$ DNase in PBS) and incubated at $37^{\circ} \mathrm{C}$ for 30 min prior to flow analysis using a BD FACS Calibur. Resulting data were analyzed using FlowJo V10 cell cycle analysis tool.

\subsection{Fluorescence-assisted Cell Sorting}

Cell sorting was performed on a Beckman MoFlo or BD Aria II instrument equipped with a 20 milliwatt blue argon laser (488 nm) using the ALDEFLUOR ${ }^{\mathrm{TM}}$ kit as previously described (Section 2.5). $\mathrm{ALDH}^{\text {high }}$ and $\mathrm{ALDH}{ }^{\mathrm{low}}$ fractions were detected using a FITC filter set (530/30 emission) on FL-1 (FITC) channel and collected for subsequent in vitro and in vivo experiments. Sorted cells were confirmed to be positively stained for ALDH by fluorescent microscopy on a Nikon NiE microscope (Nikon) under a 488 nm laser and GFP (530/20) filter set. Batch sorting reports derived from Aria II FACS equipment are provided to represent typical staining profiles for A375 (Figure 6) and B16-F10 (Figure 7) melanoma cell lines. Melanoma cells which do not express ALDH (i.e. ALDH-negative) are captured in the left gate (set by the DEAB control), and those staining for high ALDH activity are captured in the gate to the right. Cells which express intermediate (i.e. between the left and right gate) levels of ALDH represent an ALDHpositive population that did not demonstrate a one log shift in fluorescence, and thus, were not isolated in our ALDH ${ }^{\text {high }}$ sorted fractions.

\subsection{Formation of Multicellular Oncospheres}

B16-F10, A375 and SKMEL-28 melanoma cells were sorted for ALDH activity as described above. ALDH ${ }^{\text {high }}$ cells were sorted using a MoFlo flow cytometer (Beckman Coulter) or a FACS Aria II (BD Biosciences). Gates were set based upon DEAB controls for each cell line and reflected at least a onelog shift between negatively and positively stained cells. Sorted cells were cultured in low-adherent T-25 flasks (Corning) in DMEM/F-12 serum-free media at a density of $1 \times 10^{3}$ cells $/ \mathrm{mL}$. Cultures were grown for up to 14 days and treated with fresh media containing either Lunasin $(100 \mu \mathrm{M})$ or vehicle twice per 
week. Oncospheres $(>100 \mu \mathrm{m})$ were harvested and passed through a $70 \mu \mathrm{m}$ nylon filter (BD Biosciences) to remove single cells and small cell clumps. Spheres were imaged and analyzed using Image-J software [148].
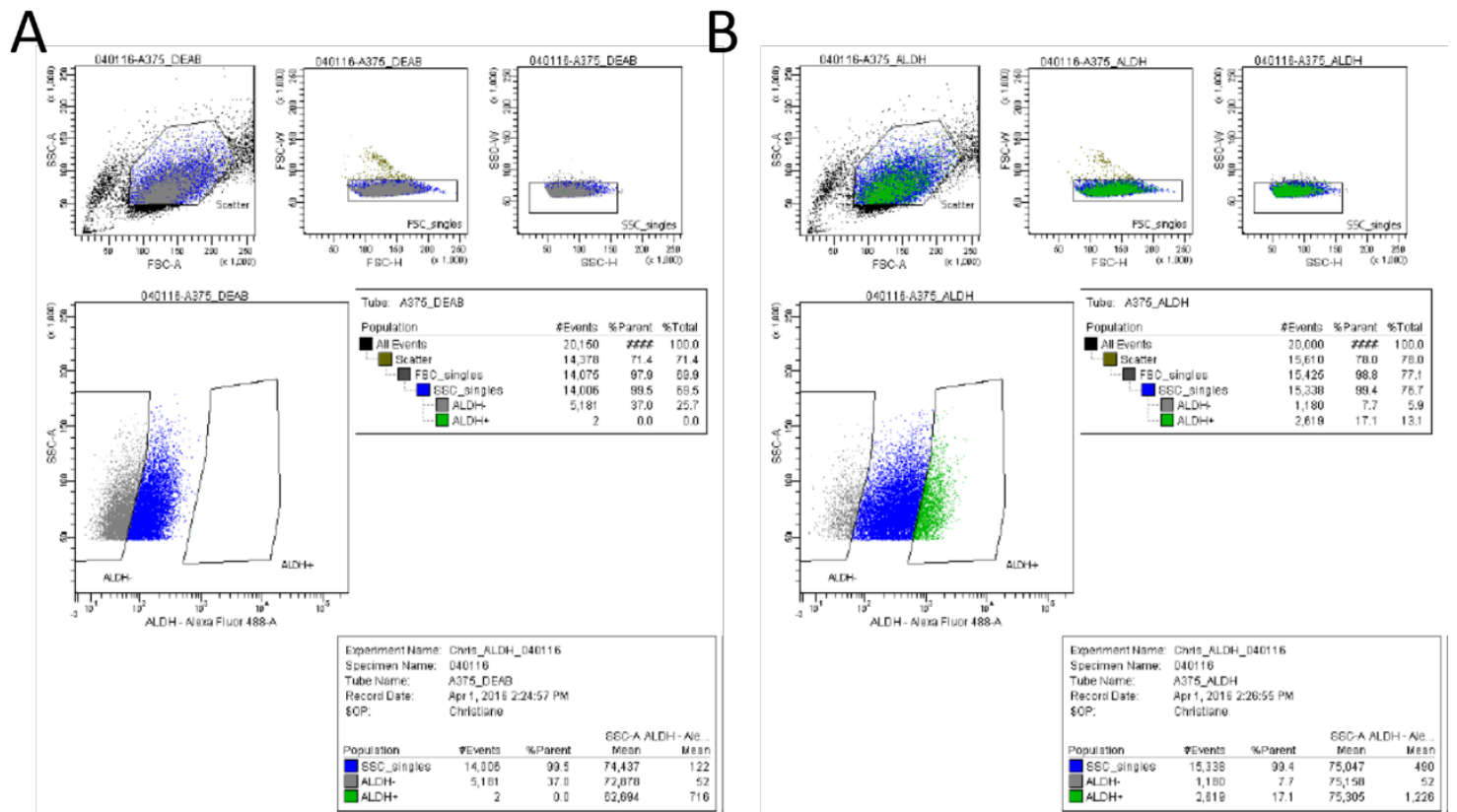

Figure 6: Batch report for A375 melanoma cells stained with ALDEFLUOR reagent. Parental A375 cell lines were subjected to FACS after being stained with ALDEFLUOR reagent. DEAB was used as a negative control in order to set appropriate gates for ALDH-negative cells (A). ALDH ${ }^{\text {high }}$ cells reflect at least a one log shift in fluorescence intensity (B). Sorted cells were analyzed and isolated using a BD Aria II FACS and batch reports were generated using FACS Diva software.

\subsection{In vivo Xenograft Model}

Male athymic nude mice (Jackson \#002019) were used at 6-8 weeks of age. All mice were handled in accordance with the Association for Assessment and Accreditation of Laboratory Animals Care international guidelines with the approval of the appropriate Institutional Animal Care and Use Committees at the University of Louisville (protocol \#12091) and Indiana University, Bloomington (Protocol \# 14-019- 
4). Mice were injected subcutaneously (s.c.) with $2.5 \times 10^{6}$ A375 cells in phosphate buffered saline (PBS; $100 \mu \mathrm{L}$ ) on the right hind flank. Mice received daily intraperitoneal (i.p.) injections of either Lunasin (30 $\mathrm{mg} / \mathrm{kg}$ ) or vehicle (PB) starting the same day that cells were implanted and repeated until mice were sacrificed. Noticeable tumor formation was observed approximately 14 days post-injection and measured every other day thereafter. Experimental endpoint was set at tumor volumes exceeding $20 \mathrm{~mm}$ in diameter ( $\sim 2 \mathrm{~cm}^{2}$ total area) or upon ulceration of tumor tissues. At endpoint, mice were sacrificed, and organs and whole blood samples were taken for subsequent analyses.

A
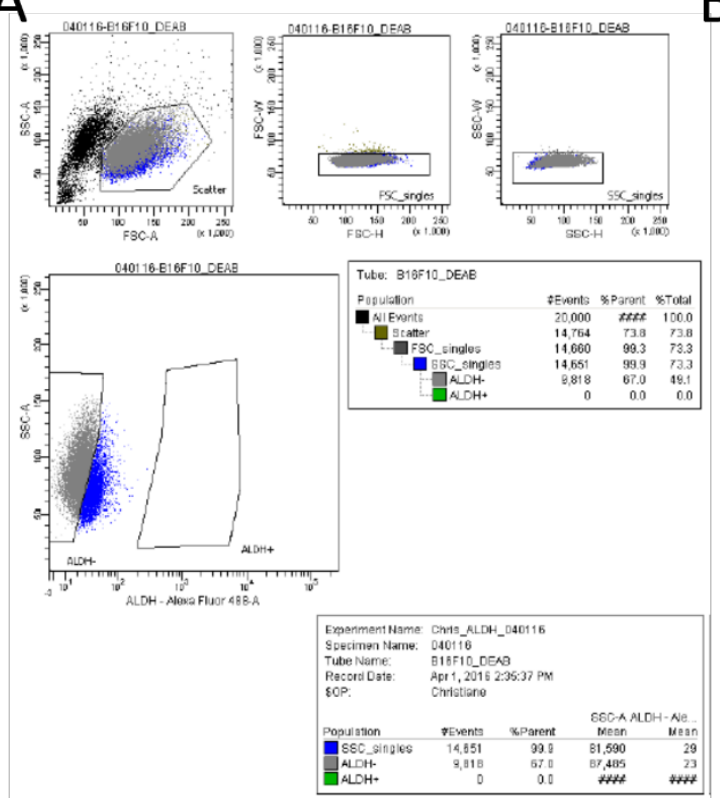

B
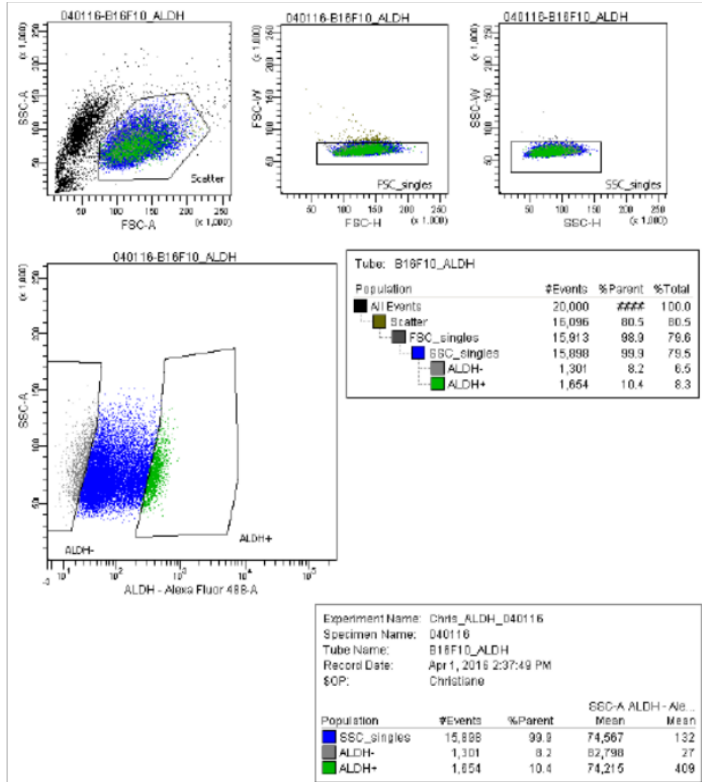

Figure 7: Batch report for B16-F10 melanoma cells stained with ALDEFLUOR reagent. Parental B16-F10 cell lines were subjected to FACS after being stained with ALDEFLUOR reagent. DEAB was used as a negative control in order to set appropriate gates for ALDH-negative cells (A). ALDH ${ }^{\text {high }}$ cells reflect at least a one log shift in fluorescence intensity (B). Sorted cells were analyzed and isolated using a BD Aria II FACS and batch reports were generated using FACS Diva software.

To test the in vivo properties of CICs, ALDH ${ }^{\text {high }}$ A375 cells were sorted as described above. ALDH $^{\text {high }}$ cells were suspended in Hank’s Balanced Salt Solution (HBSS) +calcium +magnesium 
(Invitrogen) and mixed at a ratio of 1:1 with Matrigel (growth factor reduced, without phenol red; BD Biosciences). A total of $100 \mu \mathrm{L}$ of this Matrigel-cell suspension containing $1 \times 10^{4}$ melanoma cells was implanted s.c. on the dorsal side of the athymic nude mice. Tumor size was monitored thrice weekly until animals were sacrificed due to tumor burden. Tumor volume $[\mathrm{V}=\mathrm{L} \times \mathrm{W} 2 \times(\pi / 6)]$ was determined by measuring the greatest linear dimensions in length (L) and width (W).

\subsection{SDS-PAGE and Immunoblot}

Cultured cells were treated with $100 \mu \mathrm{M}$ Lunasin or vehicle and harvested by using enzyme free dissociation buffer (TrypLE, Gibco) to minimize protein degradation. Cells were pelleted by centrifugation at $300 \mathrm{xg}$ and resuspended in appropriate amounts of RIPA buffer (250 mM Tris-HCl, pH 7.5, $5 \mathrm{mM}$ EDTA, 750 mM NaCl, 0.5\% Lauryl sulfate, 2.5\% Deoxycholic acid, 5\% Igepal CA-630, Protease inhibitor cocktail containing 4-(2-aminoethyl) benzenesulfonyl fluoride (AEBSF), pepstatin A, bestatin, leupeptin, aprotinin and trans-epoxysuccinyl-L-leucyl-amido(4-guanidino)-butane (E-64) (Sigma-Aldrich). Protein concentrations of cell lysates were determined by a bicinchoninic acid (BCA) assay (Thermo Fisher Scientific, Waltham, MA). Total protein ranging from 20 - $40 \mu$ g were loaded in $10 \%$ polyacrylamide gels (BioRad, Hercules, CA) and resolved at 100 volts for $1 \mathrm{~h}$. The protein was then transferred to a polyvinylidene difluoride (PVDF) membrane (BioRad) at 350 milliamps (mA) for $1 \mathrm{~h}$. Membranes were stained with Ponceau S (BioRad) to ensure equal loading and transfer of protein into the membrane. In some cases, PVDF membranes were then cut into halves, leaving two duplicate membranes that were subsequently probed for various proteins. In some cases, images of immunoblots presented in this dissertation represent chemiluminescent signal resulting from these duplicate membranes. Individual PVDF membranes were blocked with 5\% bovine serum albumin (BSA) or non-fat dry milk for $1 \mathrm{~h}$. After several washing steps in Tris Buffered Saline with $0.1 \%$ Tween (TTBS), primary antibodies were incubated with the PVDF membrane at $4{ }^{\circ} \mathrm{C}$ overnight with constant agitation. Lysates were probed with antibodies that recognize human Microphthalmia-associated transcription factor (MITF, Cell Signaling \#12590), Tyrosinase (EMD Millipore \#05-647), poly ADP ribose polymerase (PARP, Santa Cruz \#sc-7150), Caspase-3 (Santa Cruz \#sc-56055), NANOG (EMD Millipore \#MABD24), $\beta$-Actin (Santa Cruz \#sc47778), phosphorylated AKT (Cell Signaling \#9916S), phosphorylated FAK (Cell Signaling \#9330S), phosphorylated ERK 1/2 (Cell Signaling \#4094), H3K9 (EMD Millipore \#07-352), H4K12 (EMD 
Millipore \#04-119), H4K8 (EMD Millipore \#07-328), and H3K14 (EMD Millipore \#07-353) diluted in TTBS at 1:1000 - 1:2000 v/v. After three washes in TTBS, secondary antibodies at 1:10,000 dilutions (Cell Signaling) were incubated with the membrane for $1 \mathrm{~h}$ at RT. Electrochemiluminescent (ECL) substrate and enhancer solutions (Thermo Fisher) were allowed to activate horseradish peroxidase (HRP) signal on membrane for 2-3 min; Chemiluminescence was developed on x-ray film and/or detected using a ChemiDoc station (BioRad). In some cases, membranes were stripped using a harsh stripping buffer (0.5 M Tris HCL, $\mathrm{pH}=6.8,10 \%$ SDS, 1\% 2-mercaptoethanol). Briefly, PVDF membranes were allowed to incubate in an appropriate amount of stripping buffer in a dry incubator (Thermo Fisher) for approximately $20 \mathrm{~min}$ at $50^{\circ} \mathrm{C}$ under constant agitation. After removal of the antibodies, membranes were washed in TTBS at least 5 times for a minimum of 5 min per wash. To ensure removal of all primary and secondary antibodies, ECL substrate was applied to the stripped membrane as described above. After a 2-3 min incubation with ECL substrate, membranes were reimaged to confirm the efficient removal of all antibodies. In some cases, a second incubation with stripping buffer was necessary to remove all bands from previously imaged membranes. Efficiently stripped membranes were blocked in an appropriate blocking buffer as described above, and subsequently probed using a different primary antibody. All band densities, including the loading control ( $\beta$-Actin), were normalized to vehicle-treated cells and are shown above the appropriate representative protein band.

\subsection{Non-steroidal anti-inflammatory drug (NSAID) Toxicological Panel and Complete Blood Count}

\section{(CBC)}

Whole blood was drawn from athymic nude mice by cardiac puncture immediately following $\mathrm{CO}_{2}$ asphyxiation and collected in serum separator tubes (BD Biosciences) or EDTA coated collection tubes (BD Biosciences). Aliquots of whole blood $(25 \mu \mathrm{L})$ were collected in EDTA coated tubes and sent to the Research Resources Center (RRC) at the University of Louisville for CBC analysis. After 1 h postcollection, whole blood collected in serum separator tubes were centrifuged for $10 \mathrm{~min}$ at 10,000 xg. 250 $\mu \mathrm{L}$ of serum was removed from each sample, collected in a $1.5 \mathrm{~mL}$ Eppendorf tube, and send to the RRC facility for NSAID toxicological analysis. Liver damage was assessed by levels of alanine aminotransferase (ALT), aspartate aminotransferase (AST), and alkaline phosphatase (ALKP). Kidney damage was assessed by level of blood urea nitrogen (BUN) and creatinine (CREA). 


\subsection{In vivo Limiting Dilution Assay and ALDH Activity in Primary Tumors}

In order to determine the viability of using ALDH as a practical biomarker for identifying CICs, in vivo limiting dilution assays were employed. A375 melanoma cells were isolated by FACS based on $\mathrm{ALDH}^{\text {high }}$ and $\mathrm{ALDH}^{\text {low }}$ activity as described above (Section 2.5). These cells were counted and assessed for high viability (> 95\%) by trypan blue exclusion assays. Cells were resuspended in HBSS and mixed in a 1:1 ratio of Matrigel as previously described in this chapter (Section 2.10). Dilutions of 100, 1,000, and 10,000 cells were s.c. injected into the hind flanks of athymic nude mice in a total volume of $100 \mu \mathrm{L}$. Tumor growth initiated by both $\mathrm{ALDH} \mathrm{H}^{\text {high }}$ and $\mathrm{ALDH}^{\text {low }}$ cells was observed for each dilution group. Upon experimental endpoint, tumors were excised, and subjected to collagenase treatment to dissociate primary tumors to single cell suspensions. After resection, tumor tissues were minced using a scalpel and incubated at $37^{\circ} \mathrm{C}$ with dissociation media (DMEM/F12 containing $1 \mathrm{mg} / \mathrm{mL}$ collagenase, $20 \mu \mathrm{g} / \mathrm{mL}$ DNase, and $1 \%$ penicillin/streptomycin) for up to $4 \mathrm{~h}$. Samples were strained using a $70 \mu \mathrm{m}$ nylon filter to remove aggregates of tumor tissue and collect single cells into a $15 \mathrm{~mL}$ conical tube. Samples from ALDH ${ }^{\text {high }}$ and $\mathrm{ALDH}^{\text {low }}$ tumors were pooled before analysis of ALDH activity. Samples from each group were counted and assessed for viability by trypan blue exclusion assays, and subjected to staining for ALDH activity as previously described. In order to discriminate mouse from human cells, all samples were labelled with a human-specific antibody against CD147 (BioLegend). Positively-gated CD147 cells were then analyzed for ALDH activity by ALDEFLUOR ${ }^{\mathrm{TM}}$ staining as previously described.

\subsection{4 $\beta$-Galactosidase Staining}

Senescence-associated (SA) $\beta$-Galactosidase staining (Cell Signaling) was utilized to assess the degree of cellular senescence induced by Lunasin treatment; vemurafenib was used as an experimental control. Melanoma cells were plated at $1 \times 10^{5}$ cells per well in 6-well culture plates (Corning) and treated with vehicle (PB), $100 \mu \mathrm{M}$ Lunasin, or $1 \mu \mathrm{M}$ vemurafenib for up to $24 \mathrm{~h}$. Treated cells were washed twice with PBS, and incubated with 1x fixative solution for 15 min at RT. Cells were again washed twice with PBS and incubated with $1 \mathrm{x}$ staining solution $\left(\mathrm{pH}\right.$ 6.0) overnight in a dry incubator at $37^{\circ} \mathrm{C}$. Staining was analyzed and imaged using an EVOS light microscope. A total of 500 cells were counted from 5 independent fields and averaged for the total number of stained (blue) cells. The mean number of 
positively stained cells was averaged from three independent experiments and represented as a percentage \pm s.d.

\subsection{Liquid Overlay Generation of Multicellular Tumor Spheres}

Cell culture plates (96-well, Corning) were coated with $100 \mu \mathrm{L}$ per well of a 1:1 mixture of warmed DMEM culture media and cell culture-grade agarose (1.5\% final concentration) and allowed to air dry at RT. $1 \times 10^{3}$ A375 and A375R melanoma cells were plated in $100 \mu \mathrm{L}$ of DMEM culture media containing vehicle, $100 \mu \mathrm{M}$ Lunasin, $1 \mu \mathrm{M}$ vemurafenib, or a combination of vemurafenib and Lunasin. Cells were allowed to grow in an incubator at $37^{\circ} \mathrm{C}$ and $5 \% \mathrm{CO}_{2}$ for up to $96 \mathrm{~h}$. Tumor sphere measurements were taken after the formation of multicellular spheres ( 72 - $96 \mathrm{~h}$ ), and measured for up to an additional $96 \mathrm{~h}$ after sphere formation using ImageJ software (National Institutes of Health, NIH). Tumor sphere diameters were measured and plotted as mean sphere diameter \pm s.d.

\subsection{Microarray}

Parental A375 cells and A375 ALDH ${ }^{\text {high }}$ cells from three independent cultures were treated with vehicle or $100 \mu \mathrm{M}$ Lunasin for $72 \mathrm{~h}$ in adherent and nonadherent conditions, respectively. After treatment, cells were harvested, homogenized, and RNA was extracted using the RNeasy Mini Kit (Qiagen) complemented with the QIAshredder kit (Qiagen). RNA concentration was quantitated using a Nanodrop 1000 system (Thermo Fisher) and quality was analyzed by an Expert 2100 BioAnalyzer (Agilent). All RNA used had RNA integrity numbers (RIN) of 8 or greater. cDNA was generated using the Ovation Pico WTA V2 system (NuGen), and analyzed for integrity on the Bioanalyzer. Fragmentation and labeling of 5 $\mu \mathrm{g}$ total DNA was carried out using an Encore Biotin Module (NuGen) which is optimized for use with Affymetrix gene chips. Hybridization and raw data analysis were carried out by staff at the University of Louisville Microarray Core (Louisville, KY). Gene expression and analysis were performed using MetaCore software (Thomson Reuters) with a fold-change cut-off of $1.3(\mathrm{p}<0.05)$.

\subsection{Immunofluorescence Microscopy}

A375 cells were plated in DMEM culture media at a density of 1 x $10^{4}$ cells per well in an 8chambered microscope slide. Cells were allowed to adhere for $4 \mathrm{~h}$ before removal of media and replacement with media containing vehicle (PB) or $100 \mu \mathrm{M}$ Lunasin. Cells were allowed to incubate with treatment media for up to $24 \mathrm{~h}$. Cells were washed with PBS, fixed with $4 \%$ paraformaldehyde, and 
permeabilized with $0.1 \%$ Triton X-100. Cells were incubated at $-20^{\circ} \mathrm{C}$ in $100 \%$ methanol before blocking with $1 \%$ bovine serum albumin. Cells were incubated with anti-Lunasin (1:1000) rabbit polyclonal antibody [16] and anti- $\alpha_{V}(1: 100)$ mouse monoclonal antibody (Santa Cruz \#376156) in blocking solution. Following overnight incubation, cells were washed and incubated with appropriate secondary antibodies conjugated to AlexaFluor-488 or AlexaFluor-647 fluorophores (Jackson ImmunoResearch). After washing, mounting media containing DAPI (Thermo Fisher) was dropped onto slides, and a cover slip was sealed on top of the slide using clear fingernail polish prior to fluorescent analysis. Images were taken on a Nikon NiE upright microscope using Nikon Elements software (Nikon).

For Lunasin uptake experiments, the same protocol was followed; however, time points were standardized at $0,5,10,30$, and 60 min post-treatment. Additionally, A375 melanoma cells were treated with both Lunasin containing the native (RGD) sequence as well as a mutated (RAD) peptide at a concentration of $100 \mu \mathrm{M}$. Melanoma cells were again fixed and labelled with Lunasin monoclonal antibody, counterstained with DAPI, and imaged on a Nikon NiE fluorescent microscope using Nikon Elements software.

\subsection{Proximity ligation assay (PLA)}

A375 ALDH ${ }^{\text {high }}$ cells were isolated by FACS as described in Section 2.5. Following isolation, $\mathrm{ALDH}^{\text {high }}$ cells were treated for $24 \mathrm{~h}$ with $100 \mu \mathrm{M}$ Lunasin. Treated cells were washed twice with PBS, plated on glass coverslips coated with poly-lysine (Sigma), and allowed to air dry in a biological safety cabinet. Coverslips were washed twice with PBS for 5 min per wash and fixed in 4\% paraformaldehyde (PFA) for 10 min. Coverslips were then washed three times with PBS for 5 min per wash and permeabilized using $0.5 \%$ Triton X-100 in PBS for 10 min. After permeabilization, cells were washed three times with TTBS for 5 min per wash, and blocked in 1\% BSA in TTBS. Cells were incubated overnight at $4{ }^{\circ} \mathrm{C}$ with appropriate antibody combinations against Lunasin [16], phosphorylated focal adhesion kinase (FAK, Abcam \#ab4803), integrin-linked kinase (ILK, Cell Signaling \#3862), and integrin $\alpha_{\mathrm{V}}$ (Cell Signaling \#4711), $\beta_{1}$ (Abcam \#ab134179), and $\beta_{3}$ (Millipore \#AB2984) subunits as described [10]. Antibodies were then labelled using the Duolink in situ red starter kit (Sigma) following the recommended manufacturer's protocol, and subsequently imaged on a Nikon NiE upright microscope with Nikon 
Elements software. Exposure settings were kept consistent throughout image collection. Fluorescence analysis of the resulting images representing a single layer was analyzed using ImageJ software (NIH).

\subsection{Transwell invasion assay}

A375 and B16-F10 cells were plated in 6-well culture plates at a density of $1 \times 10^{5}$ cells per well in $2 \mathrm{~mL}$ of DMEM culture media. After $4 \mathrm{~h}$, the media were removed and replaced with media containing vehicle or $100 \mu \mathrm{M}$ Lunasin for $24 \mathrm{~h}$. After treatment, cells were washed once with PBS, and harvested with TrypLE dissociation media (Gibco). Cells were counted and viability was assessed by trypan blue exclusion assay; > 95\% viability was observed for all samples. Cells were replated at a density of $1 \times 10^{5}$ viable cells in serum-free DMEM culture media containing vehicle or Lunasin into a transwell Boyden chamber (pore size $=8 \mu \mathrm{m}$ ) coated with Matrigel basement membrane (Corning). The bottom chamber was filled with DMEM culture media containing 10\% FBS to promote invasion from the top chamber. After $24 \mathrm{~h}$ at $37^{\circ} \mathrm{C}$, cells were removed from the top chamber by using a cotton-tipped swab, and cells adhered on the bottom layer of the insert were fixed in $100 \%$ methanol and stained in a $1 \%$ Toluidine Blue in $1 \%$ borax solution. After several washes in distilled water, membranes were allowed to air dry, mounted onto slides with mounting solution, covered, and sealed with a $60 \mathrm{~mm}$ cover slip and clear fingernail polish. A total of 5 fields per insert were counted and averaged to obtain the average number of cells per field.

\subsection{Murine model of experimental metastasis}

All mice were handled in accordance with the Association for Assessment and Accreditation of Laboratory Animals Care international guidelines with the approval of the appropriate Institutional Animal Care and Use Committees at Indiana University, Bloomington (Protocol \# 14-019-4). B16-F10 cells (2.5

x $10^{5}$ ) were suspended in $100 \mu \mathrm{L}$ phosphate buffered saline (PBS) and injected intravenously (i.v.) into 4-6 week old, female C57Bl/6 mice (Harlan) via the lateral tail vein. Immediately following transplantation of melanoma cells, mice were dosed with Lunasin (30 mg / kg) or vehicle by intraperitoneal (i.p.) injection. Mice received daily i.p. injections of Lunasin or vehicle until the end of the experiment 18 days posttransplantation of cells. Upon sacrificing the mice, lungs were resected and imaged using a Leica M205 Stereoscope (Leica). Tissues were fixed in $10 \%$ formalin for $72 \mathrm{~h}$ and processed for subsequent histological staining. 


\subsection{Histology}

After fixation in $10 \%$ formalin, lungs were transferred to $70 \%$ ethanol and stored overnight at room temperature. Tissues were dehydrated through a series of graded alcohols, and infiltrated with paraffin (Electron Microscopy Sciences). Tissues were embedded in paraffin and sectioned (thickness $=7$ $\mu \mathrm{m})$ on a microtome. Sections were transferred to SuperFrost Plus slides (Fisher) and allowed to dry overnight on a slide warmer (Fisher). Paraffin removal was initiated by several washes in xylene, and followed by rehydration of the tissues in a series of graded alcohols. Tissues were stained in hematoxylin and eosin (H\&E) solutions followed by a clearing solution of xylene. After staining, Permount ${ }^{\mathrm{TM}}$ mounting medium (Fisher) was applied to each slide and covered with a $60 \mathrm{~mm}$ cover slip (Fisher). Slides were allowed to dry at room temperature overnight and then placed in a drying oven until completely dry. Images of H\&E stained slides were taken using a Leica M205 Stereoscope (Leica) as well as an EVOS light microscope (Life Technologies). Macrometastases were counted under 4.32x magnification on the Leica M205 Stereoscope. Micrometastases were counted from H\&E stained non-sequential sections ( $\mathrm{n}=$ 5) from each tissue sample using an EVOS light microscope. Images were subsequently analyzed for total tumor area using ImageJ software (NIH).

\subsection{Differentiation of ALDH ${ }^{\text {high }}$ cells}

$\mathrm{ALDH}^{\text {high }}$ and $\mathrm{ALDH}{ }^{\text {low }}$ cells were isolated from A375 and SKMEL-28 cell lines as described above. These cells were counted, assessed for viability by trypan blue exclusion, and plated into 6-well cell culture plates at a density of $1 \times 10^{5}$ cells per well in fresh DMEM culture media. Cells were allowed to grow in standard growth conditions in an incubator for up to 7 days. ALDH activity was assessed on day 3 and on day 7 and subsequent analysis was performed to assess the proportion of cells remaining in the $\mathrm{ALDH}^{\text {high }}$ compartment using methods previously described in Section 2.5. Analysis was performed using FlowJo V10 software using gates set upon a DEAB negative control.

\subsection{Statistical Analysis}

GraphPad Prism 5.0 software (GraphPad Prism Software, Inc., La Jolla, CA) was used for all statistical analyses. For all in vitro studies, two-group comparisons between control and test samples were done by two-tailed student's t-tests and represent data from three independent experiments. For experiments in which a significant difference was observed, p-values are provided above the statistically 
significant (from control group) treatment group. If statistical significance is observed between experimental groups, an asterisk will be used to denote significance between the indicated treatment groups. P-values between groups which were not determined to be statistically significant are not provided in their respective figures. For the in vivo tumor measurement studies, group comparisons were done using two-way ANOVA. For all tests, statistical significance was assumed when $p<0.05$. In vitro results are shown as means \pm s.d. In vivo experiments were analyzed using GraphPad Prism ANOVA analysis tool are shown as means \pm s.e.m. Mean tumor volumes for individual days were compared by unpaired student's t test $(\mathrm{p}<0.05)$ to determine significance between control and treatment groups. Experimental metastasis data were analyzed for significance using two-tailed student's t-tests. Interactions between Lunasin and vemurafenib were determined to be antagonistic $(<1)$, additive (1), or synergistic $(>1)$ by calculating the Drewinko Index (DI). All samples were normalized to appropriate controls and applied to the formula DI $=\frac{\left(S F^{1}\right)\left(S F^{2}\right)}{S F^{3}}$ in which $\mathrm{SF}^{1}$ is equal to the surviving fraction of $\operatorname{drug}^{1}, \mathrm{SF}^{2}$ is equal to the surviving fraction of drug ${ }^{2}$, and $\mathrm{SF}^{3}$ is equal to the surviving fraction of the combination of drug ${ }^{1}$ and $\operatorname{drug}^{2}$. 


\section{CHAPTER 3: LUNASIN IS A NOVEL THERPEUTIC TARGETING MELANOMA STEM CELLS}

\subsection{INTRODUCTION}

Nearly 20\% of all Americans will develop some form of skin cancer during their lifetime [149]. Annual treatment costs for skin cancers are estimated at $\$ 8.1$ billion; approximately $\$ 4.8$ billion and $\$ 3.3$ billion for non-melanoma and melanoma skin cancers, respectively [150]. Although less frequent than non-melanoma skin cancers, rates of melanoma are steadily rising and account for nearly all skin cancerassociated deaths [74]. Recurrent disease is the major cause of morbidity and mortality associated with melanoma. Although significant progress has been made in preventing or delaying disease, additional nontoxic approaches are needed to reduce the risk of recurrence. Studies in preclinical models of carcinogenesis have shown that an enrichment of melanoma CICs is likely to occur after conventional chemotherapeutic regimens, implicating CICs in treatment resistance and cancer recurrence [151-154]. Thus, successful elimination of CICs, along with the proliferating bulk tumor melanoma cells could be an effective therapeutic strategy to achieve higher rates of complete remission, especially in patients with late stage melanoma.

Melanoma CICs have been shown to represent about 1-25\% of all tumor cells and can form tumors by injection of a single cell [98]. Identification of a universal biomarker for CICs remains a major research focus [155]; however, most markers appear to be model specific. Melanoma cells with stem celllike plasticity were initially discovered in patient tumors that overexpressed CD20 [93] and CD133 [94]. These subsets of cells displayed characteristics of stem cells and an enhanced ability to form palpable tumors in immunodeficient mice. Ensuing studies have identified ABCB5 [66] and CD271 [95] as potential melanoma CIC biomarkers. More recently, melanoma cells expressing Aldehyde Dehydrogenase (ALDH) have been shown to display stem cell-like properties with enhanced in vivo tumorigenic capacity [103]. Other studies utilizing solid tumor models of the colon [108], breast [109], and lung [156] provide further evidence for utilizing expression levels of ALDH as a CIC marker. This hypothesis is supported by data showing ALDH1 expression correlates with poor prognosis in breast [157], ovarian [158], and lung [159] 
cancers, and that ALDH is critical in the development and differentiation of hematopoietic stem cells [160, 161] by modulating retinoid signaling through the conversion of vitamin A (retinol) to retinoic acid [162], a ligand for downstream nuclear receptors retinoic acid receptor (RAR) and retinoid X receptor (RXR) [163].

Lunasin has three putative functional domains including an aspartic acid tail, an RGD domain, and a chromatin-binding helical domain $[15,16]$. Lunasin has been shown to exhibit robust chemopreventive and chemotherapeutic activities [9, 11-14]. Lunasin has chemotherapeutic activity both in vitro and in vivo in various cancer models, including colon [35, 36, 164] and breast [34] cancer. Previous studies have established a novel functional role for Lunasin in decreasing proliferation of NSCLC cells by suppressing integrin signaling through $\alpha_{v} \beta_{3}[10,165]$. This finding is consistent with results from previous studies that demonstrated that Lunasin is internalized via $\alpha_{v} \beta_{3}$ integrin $[12,38]$. When compared to melanoma cells, the expression of $\alpha_{v} \beta_{3}$ integrins are lower in non-transformed epithelial cells [53]; the expression levels of $\alpha_{v} \beta_{3}$ correlate with the metastatic potential and the conversion of melanoma neoplasms to a metastatic phenotype [55].

In light of recent studies that clearly link integrin-matrix interactions to cancer cell survival [166] (including the maintenance and survival of CICs through integrin-FAK signaling [64, 167-174]), it seemed logical to ask whether Lunasin can target melanoma CICs and, if yes, is this anti-CIC activity critical for its in vivo antitumorigenic effects. This dissertation will aim to show, for the first time, that Lunasin specifically targets ALDH ${ }^{\text {high }}$ CICs in human melanoma cell lines. Lunasin treatment decreases the expression of surrogate CIC markers in vitro and reduces their in vivo tumorigenicity. Lunasin treatment significantly reduces formation of CIC-enriched melanoma oncospheres and more importantly, induces expression of melanocyte-associated differentiation markers while suppressing stem-associated factors. Taken together, these results delineate the ability of Lunasin to regulate melanoma CIC properties and provide a compelling argument for developing Lunasin as a therapeutic agent to reduce melanoma recurrence.

\subsection{MATERIALS AND METHODS}

\section{Isolation and purification of Lunasin}

Isolation and purification of Lunasin was performed as described in Section 2.1. These Lunasin stock preparations were used throughout the work in this dissertation. 


\section{ALDH assay}

ALDH activity was assessed using the ALDEFLUOR kit (StemCell Technologies) as described in Section 2.5. FACS was performed to isolate fractions of cells based on ALDH activity as previously described in Section 2.5 .

\section{Annexin V binding assays}

Apoptosis was assessed using a commercially available Annexin V binding assay (BD

Biosciences) as described in Section 2.6.

\section{Melanoma oncosphere culture}

Generation of melanoma oncospheres from sorted cells was performed as described in Section 2.9.

\section{Xenograft experiments}

Subcutaneous xenograft models to assess tumor growth characteristics of parental and ALDH ${ }^{\text {high }}$ melanoma cells were utilized as described in Section 2.10.

\section{In vivo limiting dilution assay}

In order to investigate the tumorigenic properties and frequency of CICs in ALDH-sorted compartments, A375 cells were subjected to FACS as described in Section 2.5. These cells were then injected s.c. at various dilutions in order to determine the extent of their tumorigenic potential as outlined in Section 2.10.

\section{Immunoblot analysis}

Lysate preparation, SDS-PAGE, and immunoblot analysis were performed as outlined in Section 2.11 .

\section{Toxicological analysis}

Kidney and liver function as well as complete blood analysis were evaluated by NSAID toxicological and CBC panels as previously described in Section 2.12 .

\section{SA $\beta$-Galactosidase staining}

A375 ALDH ${ }^{\text {high }}$ cells were isolated by FACS and subsequently treated with vehicle, Lunasin, or vemurafenib. After $24 \mathrm{~h}$ treatment, cells were stained as described in Section 2.14. 


\section{Liquid overlay generation of multicellular tumor spheres}

Liquid overlay was used to help characterize the interaction between vemurafenib and Lunasin as described in Section 2.15.

\section{Statistical analysis}

Statistical analysis of data presented in Chapter 3 was performed as described in Section 2.23.

\subsection{RESULTS}

\section{Lunasin inhibits anchorage-independent growth in human melanoma cell lines}

Previous studies of NSCLC demonstrated that Lunasin had a modest or no effect on most cell lines when grown under standard adherent culture conditions whereas all cell lines tested were sensitive under non-adherent conditions [165]. It was found that this was also the case with human melanoma cell lines. A375 and SKMEL-28 cells did not show any decrease in proliferation when treated with a concentration range of 10 to $100 \mu \mathrm{M}$ over three days when assayed using a standard MTS-based assay (Figure 8). Additionally, no indication of apoptosis in parental A375 or SKMEL-28 melanoma cells was observed (Figure 9) when cells were treated with Lunasin and subjected to labelling using an Annexin V binding assay (Figure 9A-D). No significant induction of cleaved caspase 3 or PARP was observed following treatment with Lunasin for $24 \mathrm{~h}$ in either cell line (Figure 9E). However, A375 and SKMEL-28 melanoma cells exhibited a significant dose-dependent decrease in colony formation in soft agar assays upon exposure to Lunasin (Figure 10). When compared to cells treated with vehicle alone; colony formation by A375 cells was reduced by 37\% upon treatment with Lunasin (100 $\mu \mathrm{M})$ (Figure 10A, 10B, and 10E), while Lunasin-treated SKMEL-28 cells exhibited a 23\% inhibition of colony formation (Figure 10C, 10D and 10F). The size of colonies formed by single melanoma cells was also decreased upon exposure to Lunasin (Figure 10A-D). These results establish that Lunasin inhibits anchorage-independent growth of melanoma in vitro and provides the first demonstration that Lunasin may offer potential therapeutic effects on human melanoma cells.

\section{Lunasin inhibits tumor growth of melanoma cells in vivo}

To evaluate whether the inhibition of in vitro anchorage-independent growth of melanoma cells can be recapitulated in vivo, tumor xenografts were generated by s.c. implantation of A375 cells in athymic 
nude mice. Tumor cell implantation was followed by concurrent and subsequent daily i.p. injections of Lunasin (30 mg/kg body weight). Dosing was determined by a combination of previous in vivo experiments [175] with the objective of obtaining a significant host response while minimizing toxicity, and established dosing regimens for previously established biologics (e.g. cilengitide). While no significant reduction in palpable tumor formation was observed, a significant reduction in the tumor growth rate was observed in the Lunasin-treated mice when compared to mice injected with vehicle alone (Figure 10G). Tumors were measured at 14 days after initial implantation; however, it was observed that mice in the Lunasin-treated group displayed tumors that were significantly smaller $\left(<50 \mathrm{~mm}^{3}\right)$ and difficult to measure due to their small size and lack of depth. Mice treated with Lunasin over a 34 day period exhibited significant reductions in tumor volume (55\%) and total tumor mass (46\%) when compared to those measured in the vehicle-treated mice (Figure 10G and 10H). This model established that Lunasin was biologically active in athymic nude mice, and its anticancer effects persists in vivo.

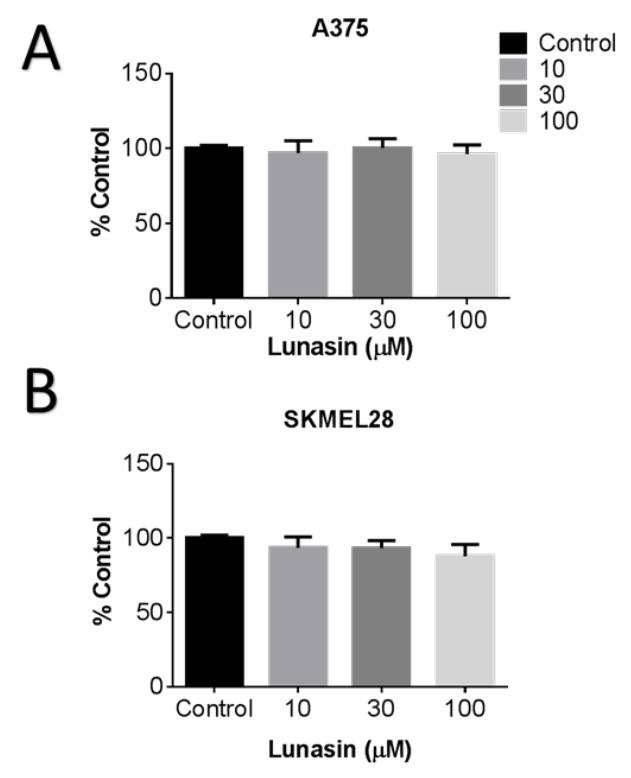

Figure 8: Lunasin did not have an antiproliferative effect on A375 or SKMEL-28 melanoma cells in adherent culture. Parental A375 (A) and SKMEL-28 (B) cells were plated and treated with vehicle or varying concentrations of Lunasin for up to $72 \mathrm{~h}$. It was observed that Lunasin treatment caused no significant antiproliferative effect on these cell lines when utilizing the MTS/MTT tetrazolium-based proliferation assay in an adherent format. These data are consistent with the modest effects observed when 
several NSCLC, breast, and colon cancer cell lines were treated with Lunasin at similar concentrations. Graphs were generated using data gathered from three independent experiments, and statistical analysis was performed by student's t-test. P-values of less than 0.05 were considered statistically significant.
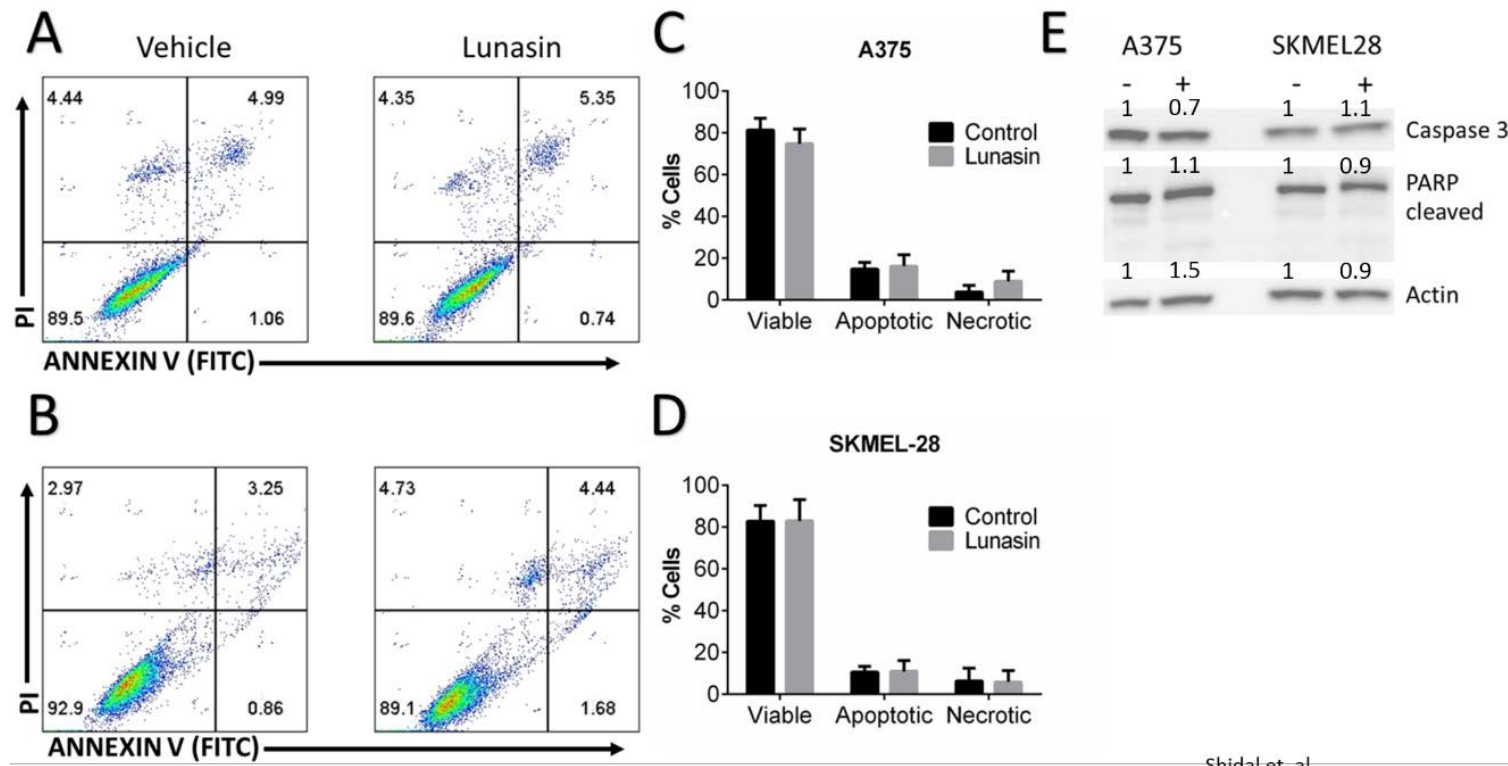

Figure 9: Lunasin did not induce apoptosis in parental melanoma cell lines. A375 (A, C) and

SKMEL-28 (B, D) cell lines were treated with Lunasin $(100 \mu \mathrm{M})$ for $24 \mathrm{~h}$, and subsequently analyzed for apoptosis. No significant induction of apoptosis or necrosis was observed with Lunasin treatments. These results were corroborated by findings that Lunasin did not increase levels of cleaved PARP and active Caspase 3 when assessed by immunoblot analysis (E). Data were gathered from three independent experiments, and analyzed using FlowJo V10. Statistical significance between control and Lunasin treatment groups was determined by student's t-test $(\mathrm{p}<0.05)$.

\section{Lunasin reduces the melanoma CIC subpopulation in established cell lines}

ALDH is an intracellular enzyme highly expressed by stem-like cells [176] and recent studies suggest that high ALDH activity is a property of CICs in human melanoma [103]. To measure ALDH activity in melanoma cells, ALDEFLUOR reagent was used. ALDEFLUOR is a commercially available molecule that freely diffuses into cells and is a substrate for the ALDH enzyme. ALDH cleaves ALDEFLUOR and yields a fluorescent product that can no longer diffuse across the cell membrane. ALDH activity within the cells is then assayed by incubating cells with a fluorescent ALDH substrate followed by 
flow cytometry. For this assay, ALDH ${ }^{\text {high }} \mathrm{CICs}$ were identified by comparing the fluorescence in a test sample to that in a control sample containing DEAB, a specific inhibitor of ALDH. These data demonstrate that treatment of A375 melanoma cells with Lunasin $(100 \mu \mathrm{M})$ for $24 \mathrm{~h}$ significantly reduced the size of the ALDH ${ }^{\text {high }}$ CIC subpopulation (Figure 11A - 11C). Similarly, SKMEL-28 ALDH ${ }^{\text {high }}$ subpopulations were reduced after a $24 \mathrm{~h}$ treatment with Lunasin (Figure 11D-11F). Immunofluorescence analyses for the ALDH marker expression corroborated the findings that Lunasin treatment dramatically diminished the ALDH expression levels in both A375 and SKMEL-28 melanoma cells and significantly reduced the ALDH $^{\text {high }}$ subpopulation (Figure 11A-11F).
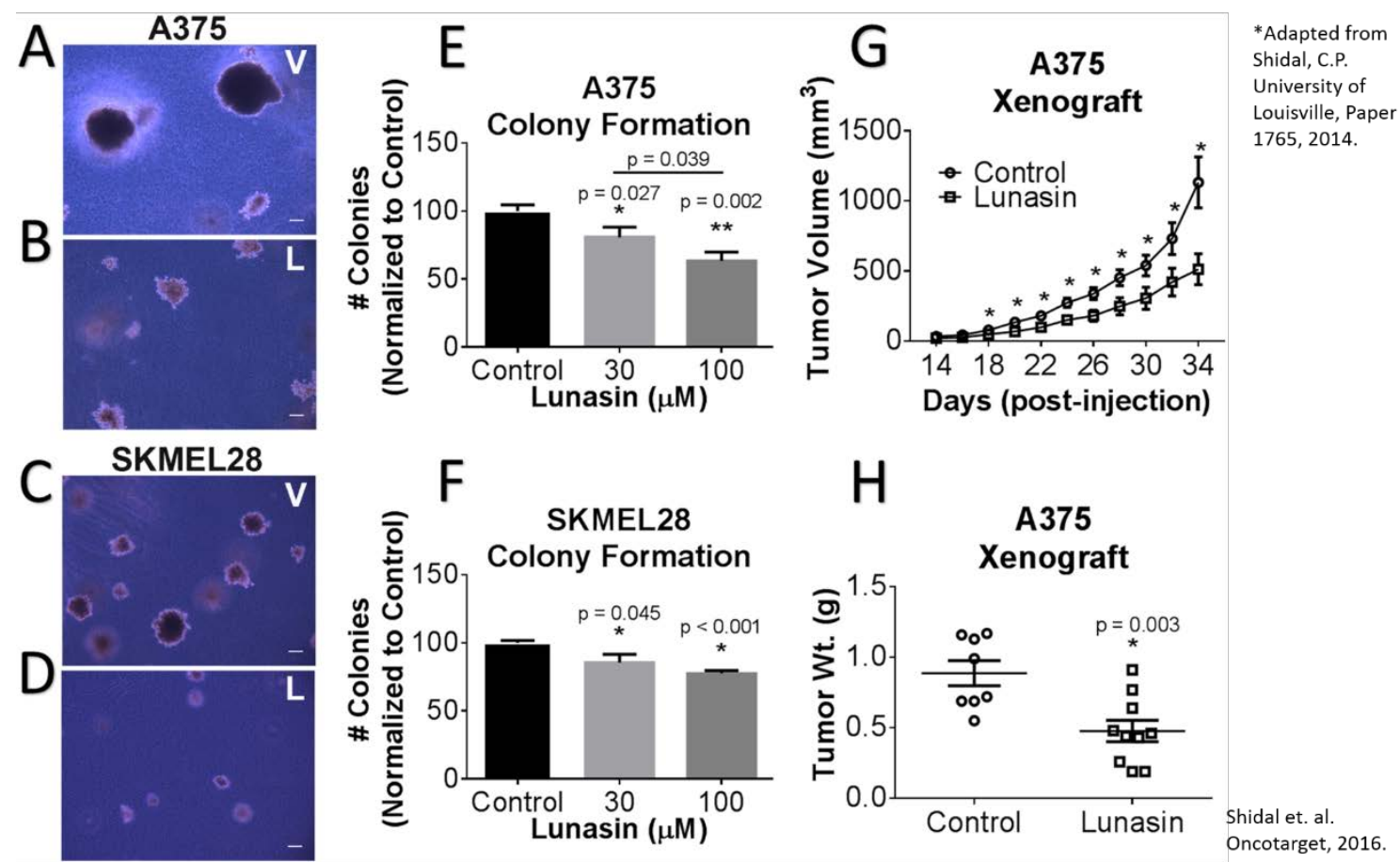

Figure 10: In vitro efficacy of Lunasin in malignant melanomas. Representative images of colonies grown in soft agar for vehicle-treated (A, C) and Lunasin-treated (B, D) A375 (A,B) and SKMEL-28 (C,D) cells (magnification at 40x). Scale bars on images represent $100 \mu \mathrm{m}$. Anchorage-independent growth conditions sensitized melanoma cells to Lunasin resulting in a significant decrease in colony formation in A375 (E) and SKMEL-28 (F) cells. Statistical significance between treatment groups is denoted by an asterisks $(*)$ and p-values are provided for each significant difference. Two asterisks $(* *)$ signifies a difference between $30 \mu \mathrm{M}$ and $100 \mu \mathrm{M}$ Lunasin treatment groups. Data are presented as mean \pm s.d. from three independent experiments. For xenograft studies, 2.5 X $10^{6}$ A375 cells were injected s.c. into nude 
mice and subsequently treated with vehicle $(\mathrm{PB})(n=8)$ or Lunasin $(n=10)$ for a total of $34 \mathrm{~d}$. Lunasin reduced tumor volume by 55\% (G) and wet tumor weight by 46\% (H). Lunasin-treated mice differed significantly in tumor volume $(\mathrm{p}<0.001)$ from control treated mice as assessed by GraphPad ANOVA analysis. The corresponding reductions in wet tumor weights were determined to be significant by unpaired student's t-test $(\mathrm{p}=0.003)$ and statistical significance is denoted by an asterisk. In vivo data are presented as mean \pm s.e.m.

\section{A375}

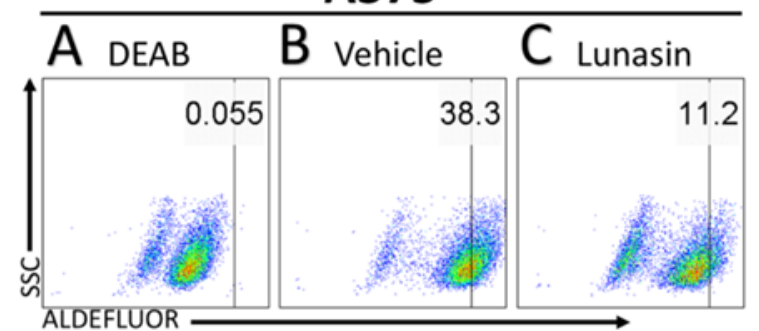

ALDEFLUOR
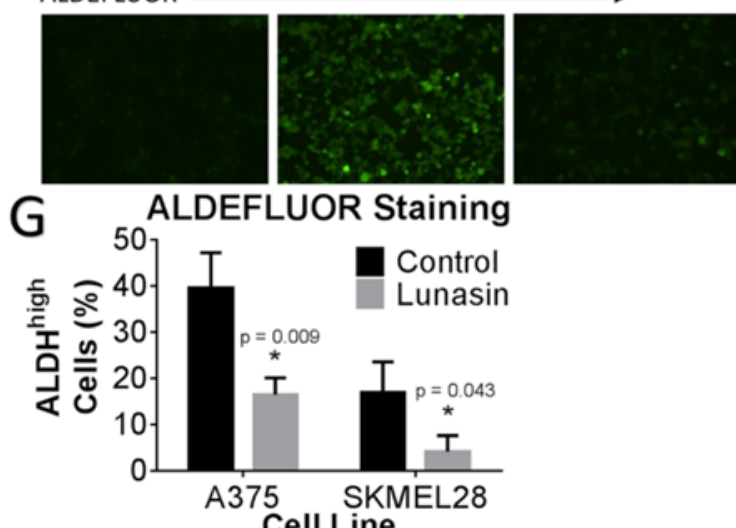

SKMEL28

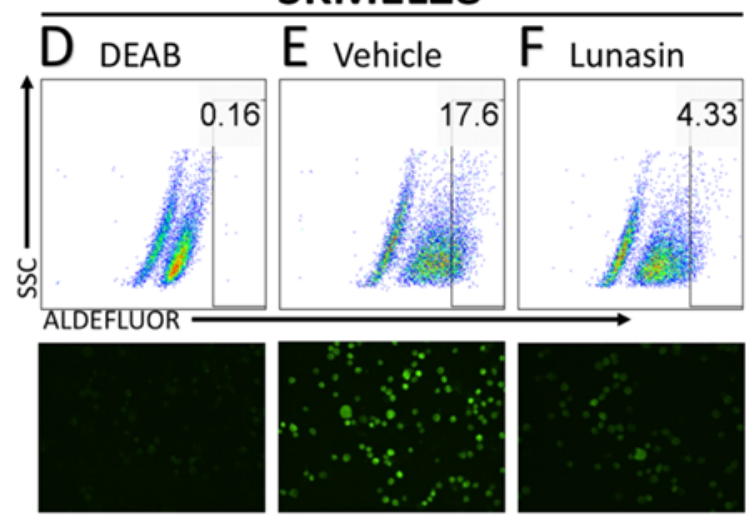

Figure 11: Lunasin depleted populations of cells displaying high ALDH activity. A375 and SKMEL-

28 cells showed a substantial decrease in ALDH positive populations when treated with Lunasin for $24 \mathrm{~h}$.

DEAB was used as a negative control, and served as a tool for gating ALDH negative populations.

Representative flow cytometry plots and corresponding fluorescent microscopy images were taken $24 \mathrm{~h}$ post-treatment and provided for DEAB (A, D), control (B, E), and Lunasin-treated (C,F) groups. Lunasin reduced the number ALDH ${ }^{\text {high }}$ cells in A375 and SKMEL-28 cell lines when compared to vehicle-treated cells (G). Statistical significance was determined from three independent experiments and assessed by student t-test $(\mathrm{p}<0.05)$. Fluorescence microscopy images were taken at 40x magnification. Data are presented as mean \pm S.D and represent data gathered from three independent experiments. Statistical 
analyses were performed using student's t-test with p-values of less than 0.05 being considered statistically significant.

\section{Lunasin suppresses the functional properties of melanoma CICs}

CICs are characterized by having stem cell-like properties, including the ability to self-renew. Oncosphere formation assays have been widely used to measure the functional activity of CICs, and previous studies have indicated that the ALDH ${ }^{\text {high }}$ melanoma cells represent the CIC-enriched compartment [103]. To determine the effects of Lunasin on melanoma CIC functional properties, clonogenic and sphere formation assays were performed using isolated $\mathrm{ALDH}^{\text {high }}$ A375 and SKMEL-28 melanoma cells. Stringent assay conditions in which spheres (floating) and colonies (formed in soft agar) are all of clonal origin were first established. Under these conditions, Lunasin treatment (100 $\mu \mathrm{M})$, when compared to control vehicle treatment, significantly inhibited sphere establishment in ALDH ${ }^{\text {high }}$ A375 melanoma cells and in ALDH ${ }^{\text {high }}$ SKMEL-28 melanoma cells (Figure 12A-C). Similarly, when compared to vehicle-treated cells, Lunasintreatment at both $30 \mu \mathrm{M}$ and $100 \mu \mathrm{M}$ drug doses significantly affected colony forming ability in purified ALDH $^{\text {high }}$ A375 melanoma cells (Figure 12D, 12E, and 12H) as well as in ALDH ${ }^{\text {high }}$ SKMEL-28 cells (Figure 12F, 12G, and 12I). Collectively, these results indicate that treatment with Lunasin negatively regulates melanoma CIC functional properties in vitro. In these assays, it was demonstrated that Lunasin functionally represses the clonogenic ability of melanoma CICs by inhibiting their potential to form oncospheres in non-adherent conditions as well as self-renewal capacity when suspended in soft agar.

\section{Lunasin limits in vivo growth of tumors initiated by melanoma CIC-enriched ALDH ${ }^{\text {high }}$ cells}

It was further investigated if the anti-CIC activity of Lunasin in melanoma cells in vitro translated into better therapeutic efficacy against in vivo melanoma CIC-initiated tumor growth. ALDH ${ }^{\text {high }}$ A375 cells isolated from the parental line were subcutaneously injected into the dorsal side of nude mice and subsequently treated via the intraperitoneal route with $30 \mathrm{mg} / \mathrm{kg}$ of Lunasin or vehicle control as described in Section 2.5. All mice eventually formed palpable tumors regardless of treatment group; however, a significant reduction in the tumor growth rate was observed in the Lunasin-treated group when compared to that in vehicle treated mice (Figure 13A and B). Notably, tumor volumes in Lunasin-treated mice were reduced by 73\% ( $<$ 0.001; Figure 13A) upon experimental endpoint (i.e. 38 days post-transplantation). Also, wet weights of tumors isolated from Lunasin-treated groups were reduced by $67 \%$ when compared to 
tumor weights from vehicle-treated mice ( $\mathrm{p}<0.001$; Figure 13B) upon experimental endpoint.

Additionally, a significant lag time until palpable tumors $\left(>50 \mathrm{~mm}^{3}\right)$ were formed was observed in the Lunasin-treated group when compared to vehicle-treated animals.

It was evaluated if any toxicological effects are associated with chronic Lunasin treatment. Mice receiving Lunasin treatment did not display significantly altered liver enzymes or creatinine levels when compared to the control group; however, significantly lower BUN levels were observed in Lunasin-treated mice (Figure 14A-B). Additionally, CBC analysis showed no significant difference in blood cell counts between vehicle-treated and Lunasin-treated mice (Figure 14C-E). These studies indicate that melanoma CICs were very sensitive to Lunasin treatment in vivo, and that this treatment regimen resulted in minimal toxicity.
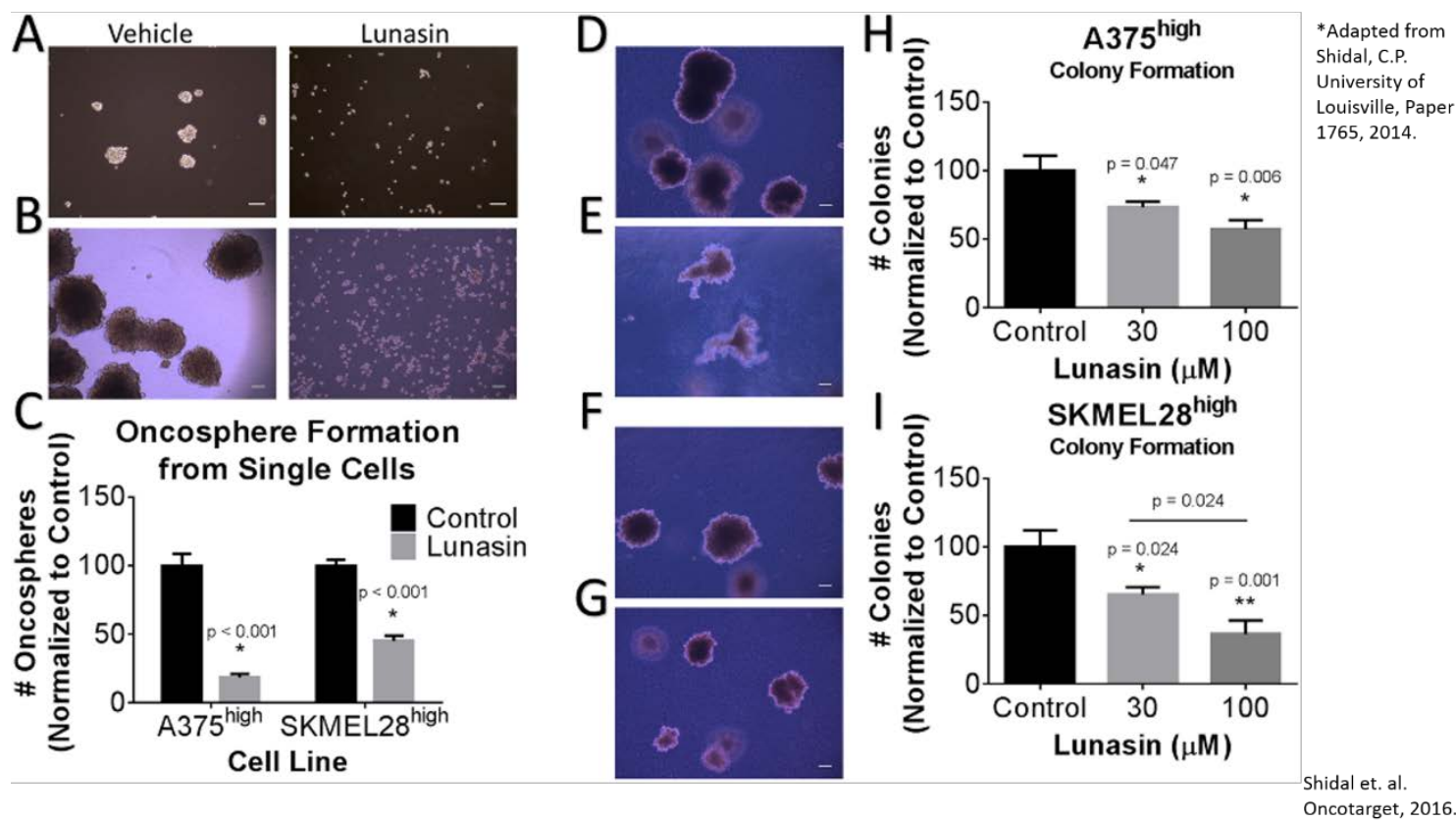

Figure 12: Lunasin reduced self-renewal capacity and oncosphere formation of CICs. ALDH ${ }^{\text {high }}$ populations of melanoma cells were plated in low adherent culture for $21 \mathrm{~d}$ and treated with vehicle or Lunasin twice weekly. Representative images taken at $7 \mathrm{~d}(\mathbf{A})$ and $21 \mathrm{~d}(\mathbf{B})$ illustrate the ability of Lunasin to disrupt sphere formation of A375 ALDH ${ }^{\text {high }}$ melanoma cells. Lunasin treatment decreased sphere formation by $81 \%$ and 55\% in A375 ALDH $^{\text {high }}$ and SKMEL-28 ALDH ${ }^{\text {high }}$ cell lines, respectively (C). $\mathrm{ALDH}^{\text {high }}$ melanoma cells showed increased sensitivity to Lunasin versus their parental counterparts when treated in soft agar. Lunasin-treated ALDH ${ }^{\text {high }}$ cells derived from A375 and SKMEL-28 lines demonstrated 
a decreased ability to form colonies in soft agar. Representative images for A375 and SKMEL-28 colonies treated with vehicle (D, F) or Lunasin (E, G) illustrate the morphological differences between treatment groups. The number of colonies formed by Lunasin-treated cells were decreased in size and density in ALDH $^{\text {high }}$ fractions of A375 (H) and SKMEL-28 (I) cell lines. Significance $(\mathrm{p}<0.05)$ was determined from three independent experiments and assessed by student's t-test $(\mathrm{p}<0.05)$. Scale bars on images represent $100 \mu \mathrm{m}$. All representative images were taken at 40x magnification. Data are presented as mean \pm s.d.
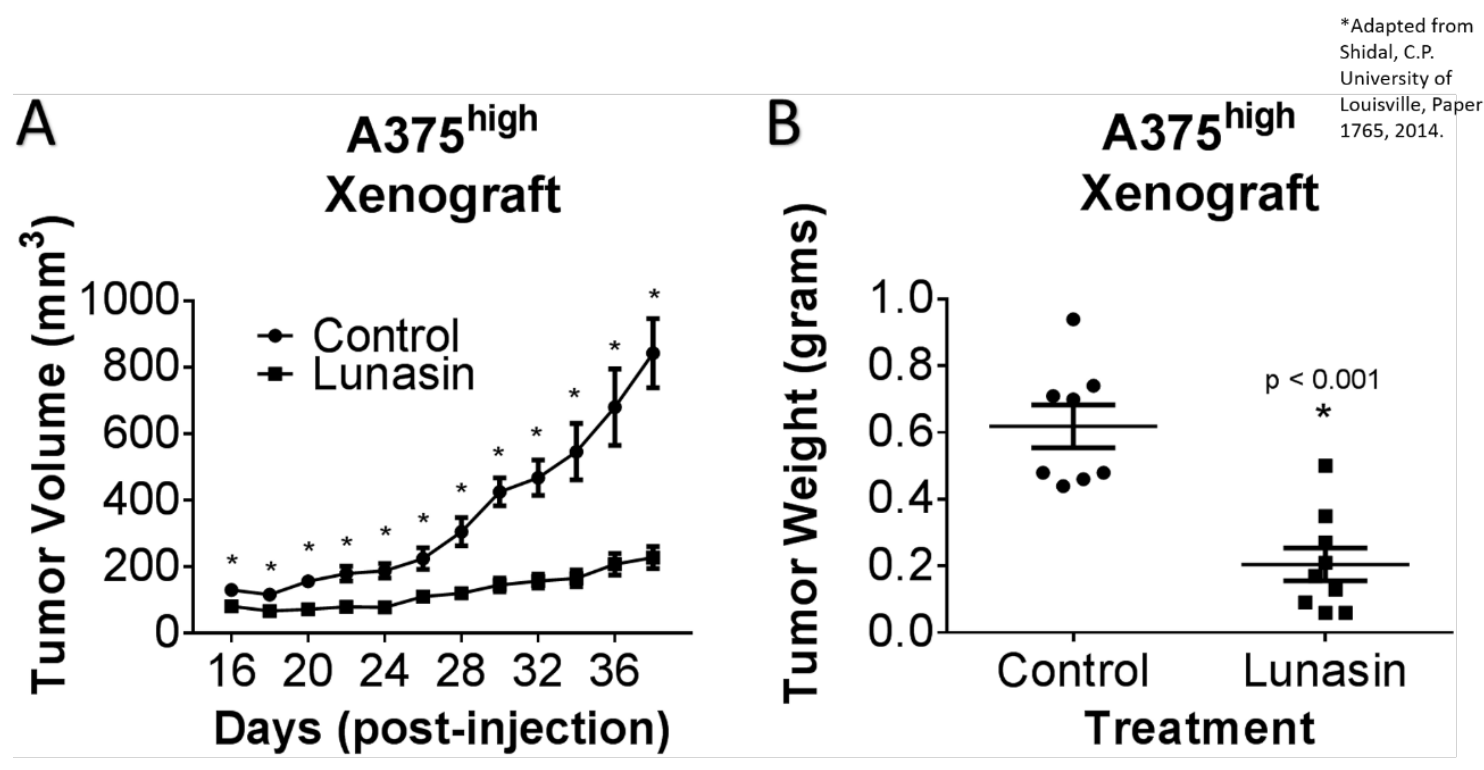

Shidal et. al.

Oncotarget, 2016.

Figure 13: Lunasin inhibited CIC tumorigenesis in vivo. Athymic nude mice were injected s.c. with 1 x $10^{4}$ A375 ALDH ${ }^{\text {high }}$ cells and subsequently dosed with $30 \mathrm{mg} / \mathrm{kg}$ of Lunasin or vehicle every day for 38 d. Upon endpoint, average tumor volumes in Lunasin-treated mice $(n=9)$ were significantly lower compared to mean tumor volume in vehicle-treated mice $(n=8)(A)$. Upon resection of tumor tissues, wet tumor weights were determined (B). Statistical significance between mean tumor volumes of control and treatment groups was determined using GraphPad ANOVA analysis tool $(\mathrm{p}<0.05)$. Wet tumor weights determined at experimental endpoint were determined to be statistically significant by student's t-tests, and significant differences are denoted by an asterisk (*). Data are represented as mean \pm s.e.m. 

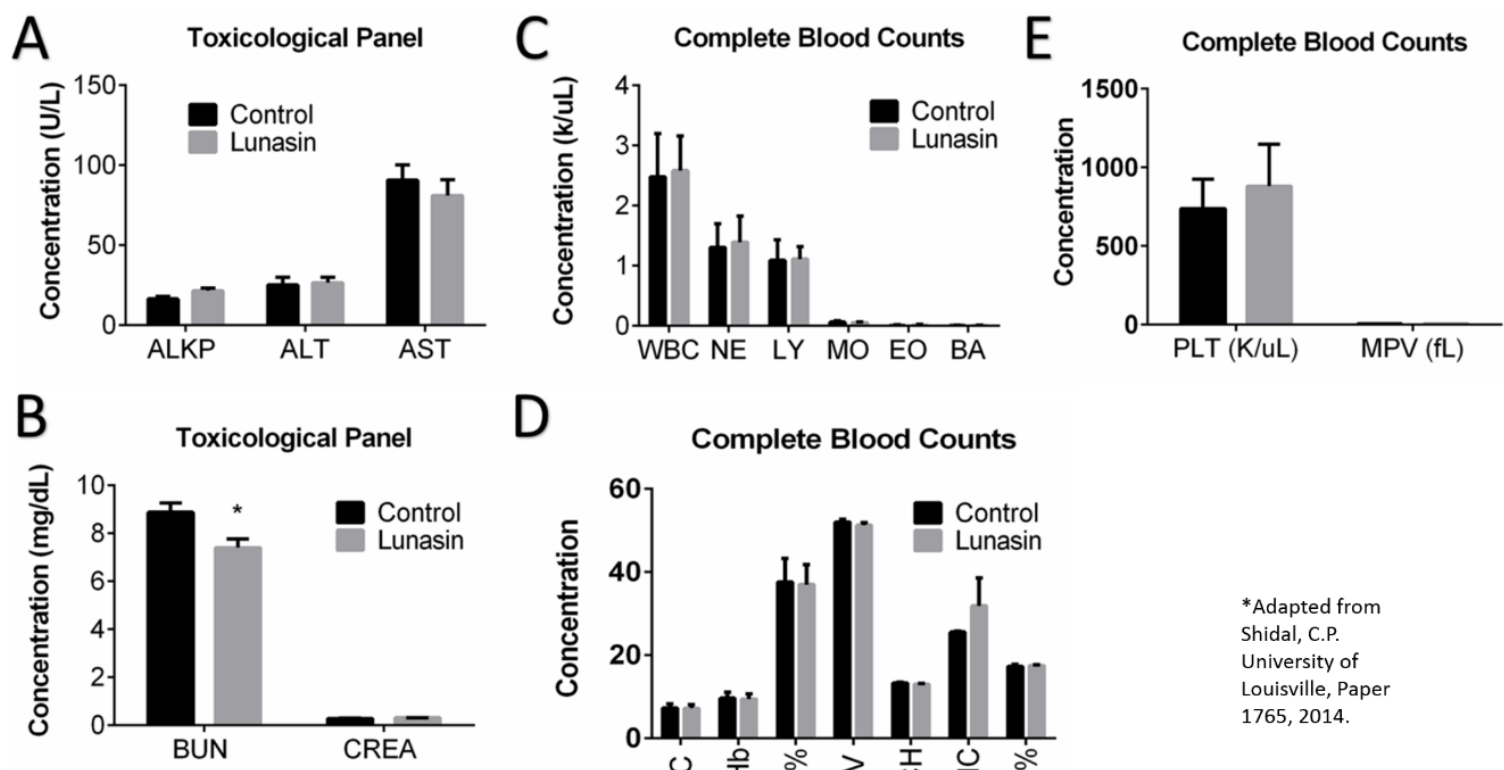

D

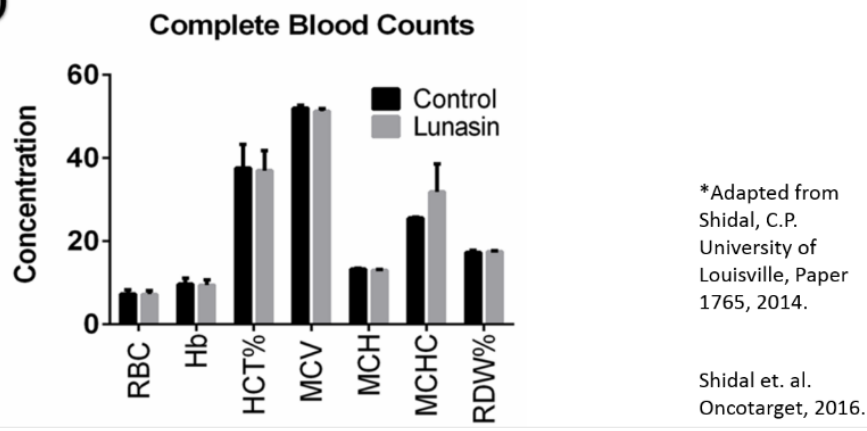

Figure 14: Long-term Lunasin treatment did not induce toxic side effects. Nude mice were treated with Lunasin (30 mg/kg) for several weeks. Upon experimental endpoint, blood serum and whole blood fractions derived from mice in the Lunasin and control groups $(\mathrm{n}=17)$ were analyzed for liver $(\mathbf{A})$, kidney (B) and CBC (C-E) toxicity, respectively. A significant decrease in BUN was observed in Lunasin-treated mice. Liver and kidney function did not appear to be affected by long-term Lunasin treatment. Statistical significance between Lunasin and control groups was determined by student’s t-test $(\mathrm{p}<0.05)$.

\section{Limiting dilution assays demonstrate differential growth patterns between ALDH $^{\text {high }}$ and ALDH ${ }^{\text {low }}$ phenotypes}

To assess in vivo tumorigenicity of ALDH-sorted populations derived from A375 melanoma cells, varying concentrations of cells were injected into nude mice (Figure 15). All mice injected with ALDH ${ }^{\text {low }}$ cells produced tumors when injected with $1 \times 10^{3}$ and $1 \times 10^{4}$ cells; however, only $2 / 3$ mice injected with $1 \times 10^{2} \mathrm{ALDH}^{\text {low }}$ cells produced tumors. All mice transplanted with $\mathrm{ALDH}^{\text {high }}$ cells produced palpable tumors (9/9). Although the sample size in these experiments was not large enough to produce a statistical significance in tumor formation, a significant difference in tumor growth curves between ALDH ${ }^{\text {high }}$ and ALDH $^{\text {low }}$ cells was observed (Figure 15A-C) when tumor growth rates were analyzed by GraphPad ANOVA analysis tool as described in Section 2.5. When $1 \times 10^{2} \mathrm{ALDH}^{\text {high }}$ cells were injected into mice, 
tumors formed quicker and had higher proliferation rates when compared to tumors initiated by ALDH ${ }^{\text {low }}$ cells $(\mathrm{p}<0.007)$. Despite this statistically significant difference, these results were potentially driven by one large tumor produced in the ALDH ${ }^{\text {high }}$ group. Conversely, ALDH ${ }^{\text {low }}$ cells had higher proliferative capacity when compared to ALDH ${ }^{\text {high }}$ cells when $1 \times 10^{4}$ cells were transplanted $(\mathrm{p}<0.001)$. The intermediate dilution of $1 \times 10^{3}$ cells produced no observable differences in tumor growth $(\mathrm{p}=0.98)$. Representative images demonstrate the differences in final tumor size between tumors initiated by $\mathrm{ALDH}^{\text {high }}$ and $\mathrm{ALDH}{ }^{\text {low }}$ cells (Figure 15D-F).

Tumors initiated by ALDH ${ }^{\text {high }}$ cells had a higher propensity to stay in the ALDH ${ }^{\text {high }}$ compartment when compared to tumors initiated by $\mathrm{ALDH}^{\text {low }}$ cells

With the observable differences in tumor growth rates from limiting dilution assays, it was next investigated whether or not the proportion of $\mathrm{ALDH}^{\text {high }}$ cells would significantly vary between tumors initiated by ALDH ${ }^{\text {high }}$ and ALDH ${ }^{\text {low }}$ phenotypes (Figure 15G). In order to discriminate between human melanoma cells with elevated ALDH activity and mouse cells which may also have intrinsic ALDH activity, human cells were selected for by using a human-specific PE-conjugated antibody against CD147 (top). This allowed for the gating and analysis of ALDH activity in only A375-derived cells (bottom). Cells dissociated from tumors initiated by ALDH ${ }^{\text {high }}$ melanoma cells had a population with high ALDH activity which represented $6.24 \%$ of $\mathrm{PE}^{+}$cells. In $\mathrm{ALDH}^{\text {low }}$ initiated tumors, high ALDH activity was seen in only $1.25 \%$ of $\mathrm{PE}^{+}$cells. These data raise several questions as to the function and responses of melanoma CICs to the surrounding microenvironment, and whether bulk tumor cells play a major role in the differentiation and self-renewal of these stem-like cells.

In vitro, a small population of cells with low ALDH activity derived from both A375 and SKMEL-28 melanoma cell lines had the intrinsic capability to (de)differentiate to form ALDH ${ }^{\text {high }}$ cells (Figure 16). ALDH ${ }^{\text {high }}$ and $\mathrm{ALDH}^{\text {low }}$ cells were monitored for up to a week in serum-free stem cell media in low-adherent culture conditions following FACS. After 3d and 7d in culture, cells were stained with ALDEFLUOR reagent and reanalyzed for the percentage of cells displaying high ALDH activity. Samples derived from A375 (Figure 16A) and SKMEL-28 (Figure 16B) showed a significant portion of ALDH ${ }^{\text {high }}$ cells had differentiated into the ALDH ${ }^{\text {low }}$ compartment. Unexpectedly, it was also observed that some cells isolated in the $\mathrm{ALDH}^{\text {low }}$ compartment had the ability to undergo a phenotype switch into the ALDH ${ }^{\text {high }}$ 
compartment. Whether this phenomenon is due to the high plasticity and heterogeneity of melanoma cells, a byproduct of using cultured cell lines, or the fact that these studies used a singular marker to define a complex hierarchy of cells has yet to be determined. Additional studies to define the cellular hierarchy and differential capacity to differentiate and dedifferentiate between melanoma stem cells and bulk tumor cells are necessary to 1) determine if melanoma truly fits the model proposed by the cancer stem cell theory, 2) determine if cultured cell lines truly represent the heterogeneity of primary melanoma tissues, and 3) determine if ALDH is a practical biomarker for potential CIC identification.

\section{CIC markers are heterogeneously expressed in different melanoma cell lines}

Although ALDH was used as a surrogate marker for identification and isolation of melanoma CICs, this study aims to investigate whether or not other potential biomarkers for CICs were present in the melanoma cell lines used. Flow cytometry was used to assessed the level of expression of several cancer stem cell biomarkers reported for melanomas and for other cancer models including CD44/CD24, CD133, and CD271 (Figure 17). These data indicate that both A375 and SKMEL-28 cells have a highly abundant population of cells with a CD44 $/$ CD24- phenotype (Figure 17A). Conversely, both cells lines failed to show populations of cells that were labelled with a CD133 antibody (Figure 17B). Differential expression of CD271 was observed between A375 (93\%) and SKMEL-28 (28.1\%) cell lines suggesting that melanomas display high heterogeneity even between commonly used cell lines (Figure 17C).
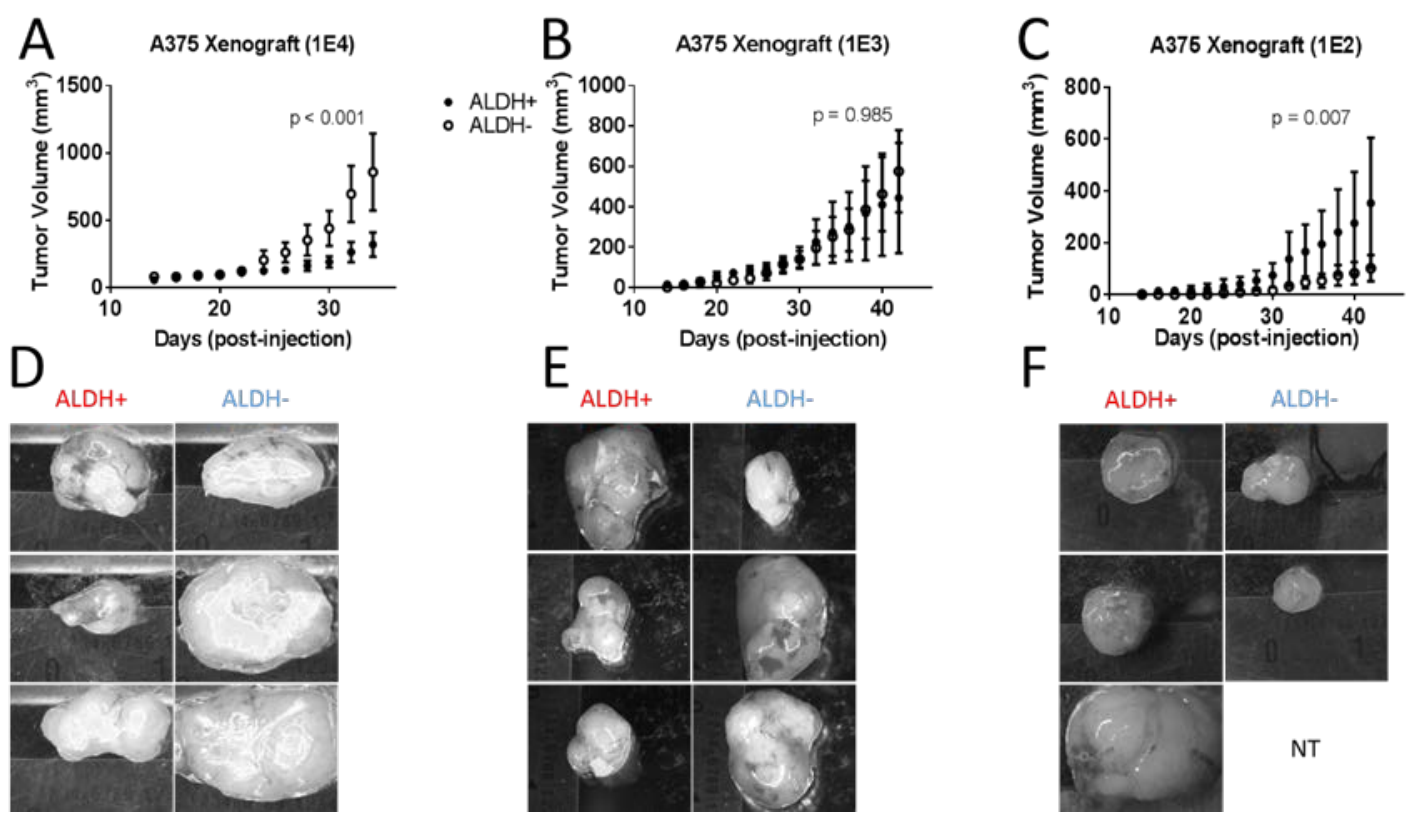

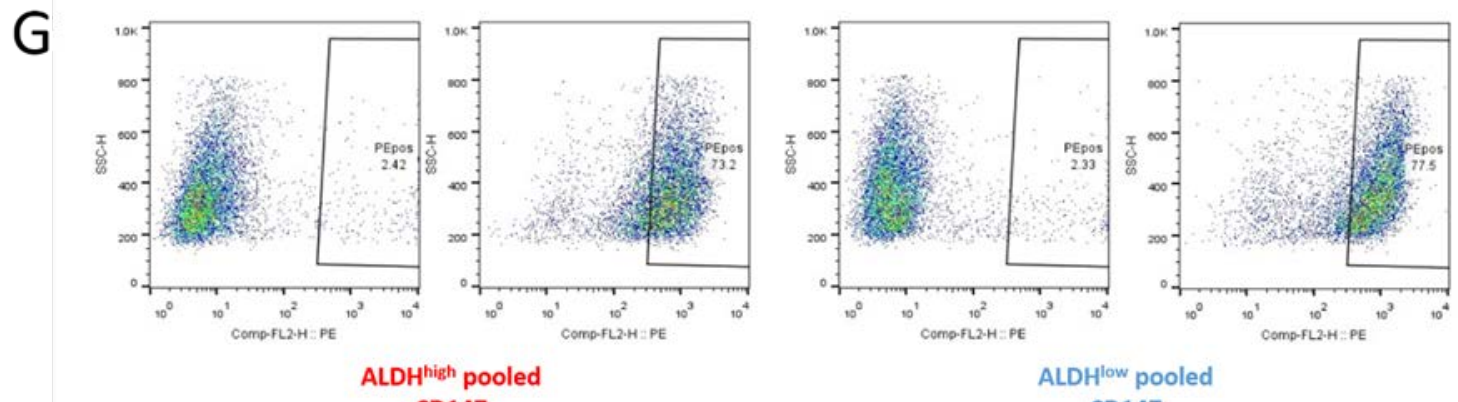

CD147
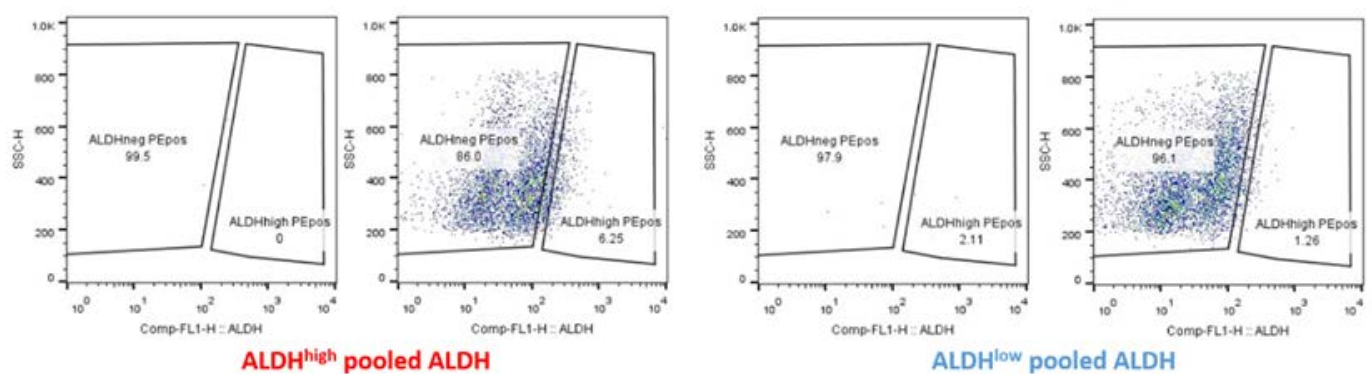

Figure 15: Limiting dilution assays demonstrate the high tumorigenicity of A375 ALDH ${ }^{\text {high }}$ cells.

Xenografted A375 ALDH ${ }^{\text {high }}$ and ALDH ${ }^{\text {low }}$ melanoma cells were observed for differences in tumor proliferation and tumorigenicity when injected into nude mice at decreasing dilutions (A-C). ALDH ${ }^{\text {high }}$ cells produced tumors in all mice injected (9/9 total), and were tumorigenic with cell dilutions down to 100 cells. ALDH ${ }^{\text {low }}$ cells also displayed high tumorigenicity yet, only produced 2/3 tumors in nude mice when injected with 100 cells. Tumor growth rates were also dilution-dependent; ALDH ${ }^{\text {low }}$ cells proliferated much more quickly at a lower cell dilution $\left(1 \times 10^{4}\right)$, but less rapidly at higher concentrations $\left(1 \times 10^{2}\right)$ when compared to ALDH ${ }^{\text {high }}$ cells. No significant difference was observed between growth curves at the intermediate dilution $\left(1 \times 10^{3}\right)$. NT = no tumor. Statistical analyses were performed using GraphPad ANOVA analysis tool with statistical significance considered when $\mathrm{p}<0.05$. Representative images of tumors derived from both ALDH-sorted groups in dilutions of $1 \times 10^{4}(\mathrm{D}), 1 \times 10^{3}(\mathrm{E})$, and $1 \times 10^{2}(\mathrm{~F})$ are shown to illustrate the differential growth patterns of tumors initiated by each phenotype (zoom $=4.32 \mathrm{x})$. Tumors initiated by $1 \times 10^{2} \mathrm{ALDH}^{\mathrm{low}}$ and $\mathrm{ALDH}{ }^{\text {high }}$ melanoma cells were dissociated, counted, and pooled to generate samples subsequently analyzed for ALDH activity. ALDH ${ }^{\text {high }}$ and ALDH ${ }^{\text {low }}$ cells of human origin (i.e. A375 melanoma cells) were labelled with an anti-CD147 antibody (G, top). $\mathrm{PE}^{+}$cells were analyzed for ALDH activity; Tumor cells derived from the ALDH ${ }^{\text {high }}$ phenotype had a higher proportion of cells 
remaining in the $\mathrm{ALDH}^{\text {high }}$ compartment (6.25\%) when compared to tumors initiated by ALDH ${ }^{\text {low }}$ melanoma cells (1.26\%) (G, bottom).

\section{Lunasin induces expression of differentiation markers in melanoma CICs}

To test if the Lunasin-induced decrease in CIC function is due to induction of apoptotic cell death in the isolated CICs, cell viability and apoptosis assays (Annexin V/PI staining) were performed following Lunasin treatment on isolated ALDH ${ }^{\text {high }}$ cells. Interestingly, these assays failed to detect any significant reduction in cell viability with Lunasin treatment in $\mathrm{ALDH}^{\text {high }}$ CICs obtained from either A375 or SKMEL28 cell lines when compared to that in vehicle-treated ALDH ${ }^{\text {high }}$ CICs (Figure 18A and 18B). Consistent with these results, there was no apparent difference in the protein expression of apoptotic signaling mediators, PARP and Caspase-3 in vehicle and Lunasin-treated ALDH ${ }^{\text {high }}$ CICs from both A375 and SKMEL-28 melanoma cell lines (Figure 18C). Caspase-3 is cleaved (i.e. activated) in response to activation of the apoptotic cascade and in turn, cleaves PARP to carry out cellular deconstruction. Thus, the absence of active Caspase-3 and cleaved PARP in Lunasin-treated samples indicates that apoptosis was not induced.

Recent studies established that reduced expression of MITF yielded G1-arrested cells with an invasive stem cell-like phenotype, whereas high MITF expression generated either proliferating cells or cells with a differentiated pigment-producing phenotype depending on the status of MITF's posttranslational modifications $[177,178]$. Other studies provide supportive evidence to this claim and show that TGF- $\beta$ signaling can mediate MITF expression, which is critical for the generation and maintenance of melanoma stem cells [179]. In accordance with these reported studies, the authors observed a reduced expression of MITF in CIC-enriched ALDH ${ }^{\text {high }}$ A375 and SKMEL-28 cells in comparison to MITF expression in ALDH ${ }^{\text {low }}$ A375 and SKMEL-28 cells (Figure 19A). 

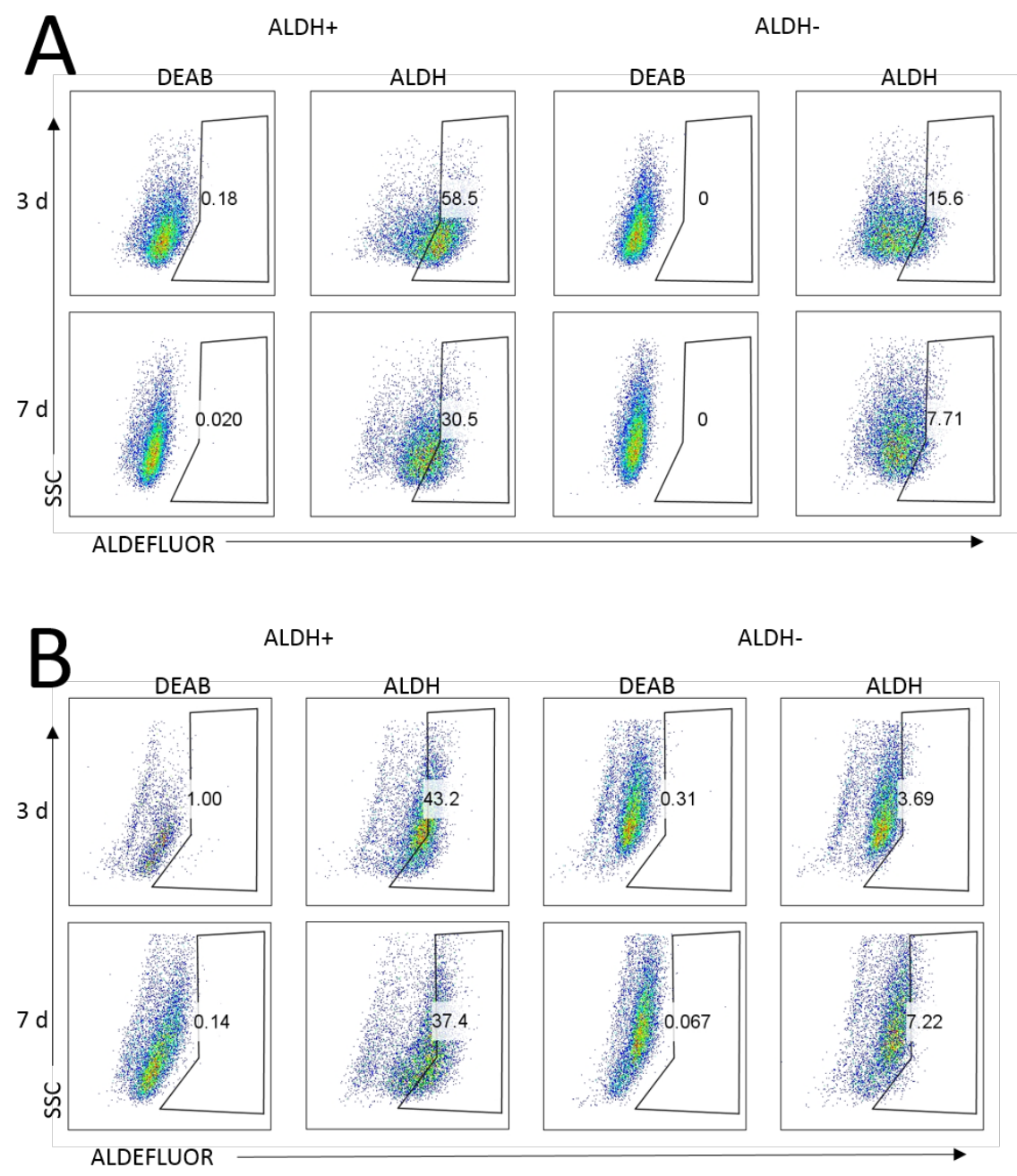

Figure 16: Differentiation of ALDH ${ }^{\text {high }}$ cells derived from A375 and SKMEL-28 melanoma lines.

Sorted melanoma cells were replated in normal culture media and cultured in 6-well culture dishes for up to 7 d. Cells were assayed for ALDH activity at day 3 (top) and day 7 (bottom). After sorting, ALDH ${ }^{\text {high }}$ cells represented a significantly smaller proportion of cells in both A375 (A) and SKMEL-28 (B) after only 3 days in culture and $\mathrm{ALDH}^{\text {high }}$ populations further decreased in both cell lines at day 7. Interestingly, it was observed that a small population of ALDH ${ }^{\text {low }}$ cells had the capacity to revert back to an ALDH ${ }^{\text {high }}$ phenotype in both cell lines.

Whether or not Lunasin treatment can modulate MITF expression in CICs and thereby, trigger a phenotypic switch in CICs that will ultimately drive the Lunasin exposed melanoma CICs towards 
differentiation was next investigated. To test this hypothesis, ALDH ${ }^{\text {high }}$ cells isolated from A375 and SKMEL-28 melanoma lines were cultured in the presence or absence of Lunasin (100 $\mu \mathrm{M})$ for $24 \mathrm{~h}$ under serum-free, non-adherent culture conditions. Lunasin-treated and vehicle-treated cultures were then analyzed for MITF protein expression as well as for the expression of its downstream differentiationassociated protein, Tyrosinase. It was observed that Lunasin treatment increased the expression of MITF and Tyrosinase proteins in A375- and SKMEL-28-derived ALDH ${ }^{\text {high }}$ cells compared to vehicle-treated controls (Figure 19B). Additionally, Lunasin-treated ALDH ${ }^{\text {high }}$ cells from both A375 and SKMEL-28 melanoma lines showed reduced expression of the stem-associated transcription factor, NANOG (Figure 19C). Taken together, these experiments provide substantial experimental evidence to support the notion that Lunasin treatment negatively influenced melanoma CICs’ tumorigenicity and self-renewal abilities by regulating MITF signaling, one of the key drivers in inducing a differentiated phenotype in melanoma CICs, as well as suppressing levels of the key stemness factor Nanog.

\section{Lunasin did not induce a significant senescent response in $A L D H^{\text {high }}$ melanoma cells}

A375 melanoma cells were sorted based on ALDH activity. These cells were treated with vehicle, Lunasin, or vemurafenib for 24 h. Representative images for positively-stained melanoma cells in vehicle, Lunasin, and vemurafenib-treated samples are shown (Figure 20A). No significant difference in positively stained cells (Figure 20B) between vehicle or Lunasin treatment groups ( $p=0.09)$ was observed. The positive control, vemurafenib, induced a significant senescent response in nearly $25 \%$ of all cells, and represented a significant increase from control and Lunasin-treated cells ( $\mathrm{p}<0.001)$. 


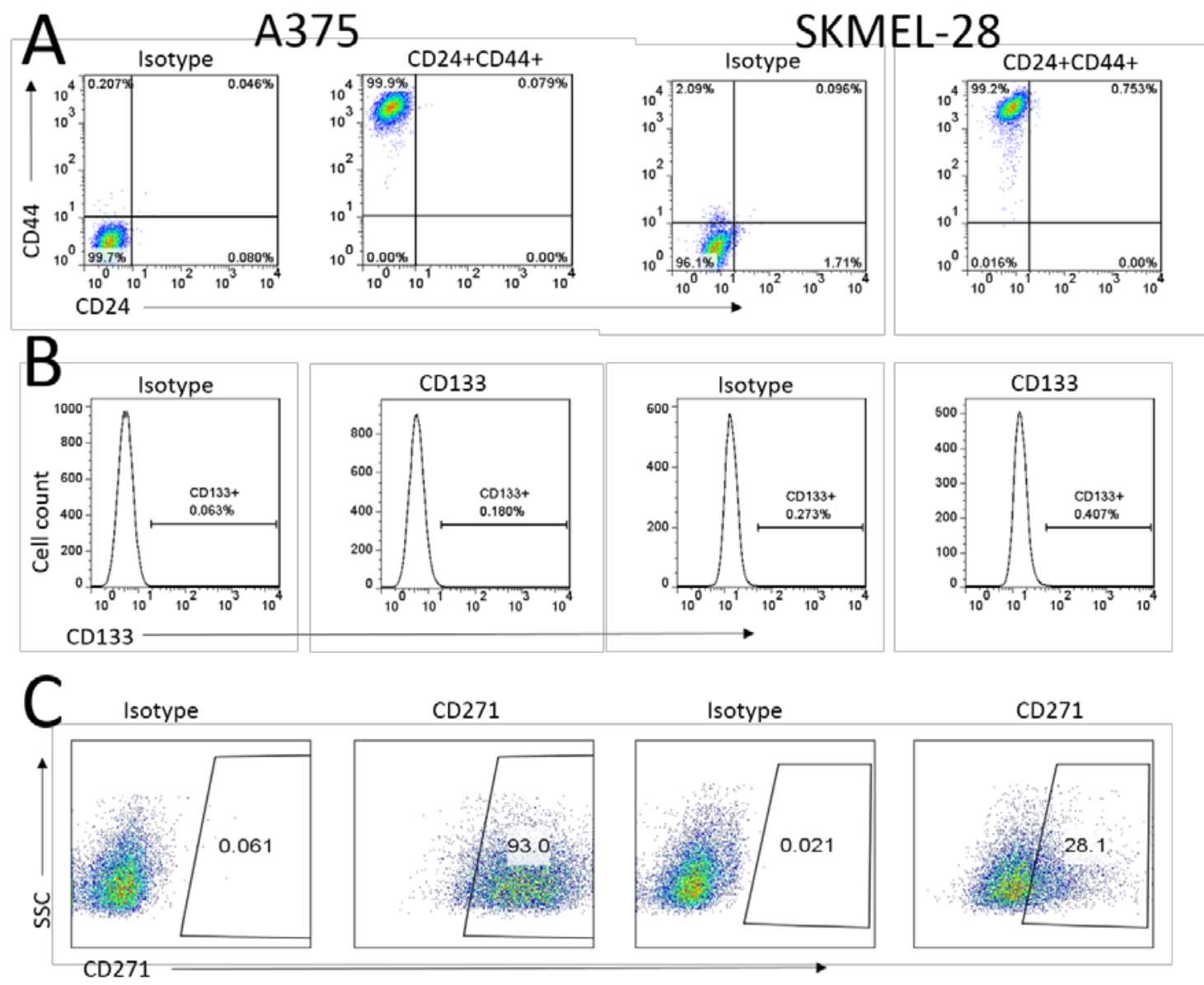

Figure 17: CIC biomarkers are heterogeneously expressed in melanoma cell lines. Utilizing flow cytometry A375 (left) and SKMEL-28 (right) melanoma cell lines were labelled and assessed for expression of commonly used CIC identification markers. Both cell lines had an abundant CD44+CD24population (A). Neither cell line had a significant population of cells that express the CD133 CIC biomarker (B). When A375 cells were labelled with anti-CD271 antibody, it was observed that the majority of the cells were CD271 ${ }^{+}$; however, in the SKMEL-28 cell line, only a small proportion (28.1\%) expressed CD271 (C). Isotype controls were represented by the appropriate host-specific PE- and APCconjugated $\operatorname{IgG}_{1}$ antibodies. 

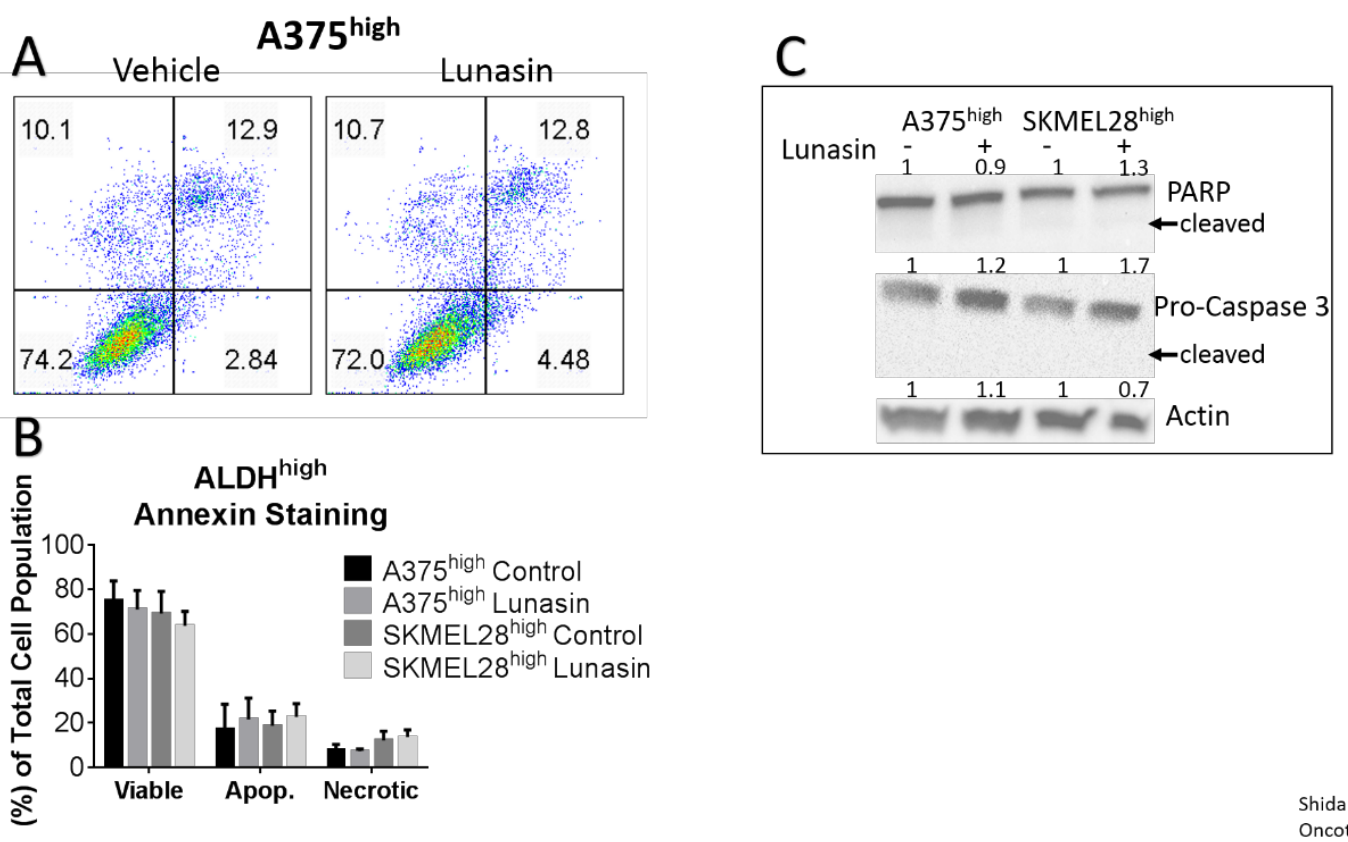

Shidal et. al. Oncotarget, 2016

Figure 18: Lunasin did not induce an apoptotic response in $A L D H^{\text {high }}$ melanoma cells. Annexin V

binding assays were used to assess apoptotic populations of melanoma cells sorted for high ALDH activity and subsequently treated with Lunasin or vehicle for 24 h. Representative flow cytometry plots for A375 $\mathrm{ALDH}^{\text {high }}$ cells in each treatment group are shown (A). No significant decrease in cell viability of ALDH ${ }^{\text {high }}$ subpopulations derived from A375 or SKMEL-28 cells were observed when stained with Annexin V/ PI. Additionally, there was no observed significant increase in apoptotic or necrotic populations after Lunasin treatment (B) when compared to control. It was further confirmed that Lunasin did not induce apoptosis by immunoblot analysis for the apoptotic markers active Caspase-3 and cleaved PARP, which were absent in both control and Lunasin-treated samples (C). Significance was determined by student's t-test from three independent experiments with a p-value of $<0.05$ representing statistical significance from control samples. Data are represented as mean \pm s.d. 


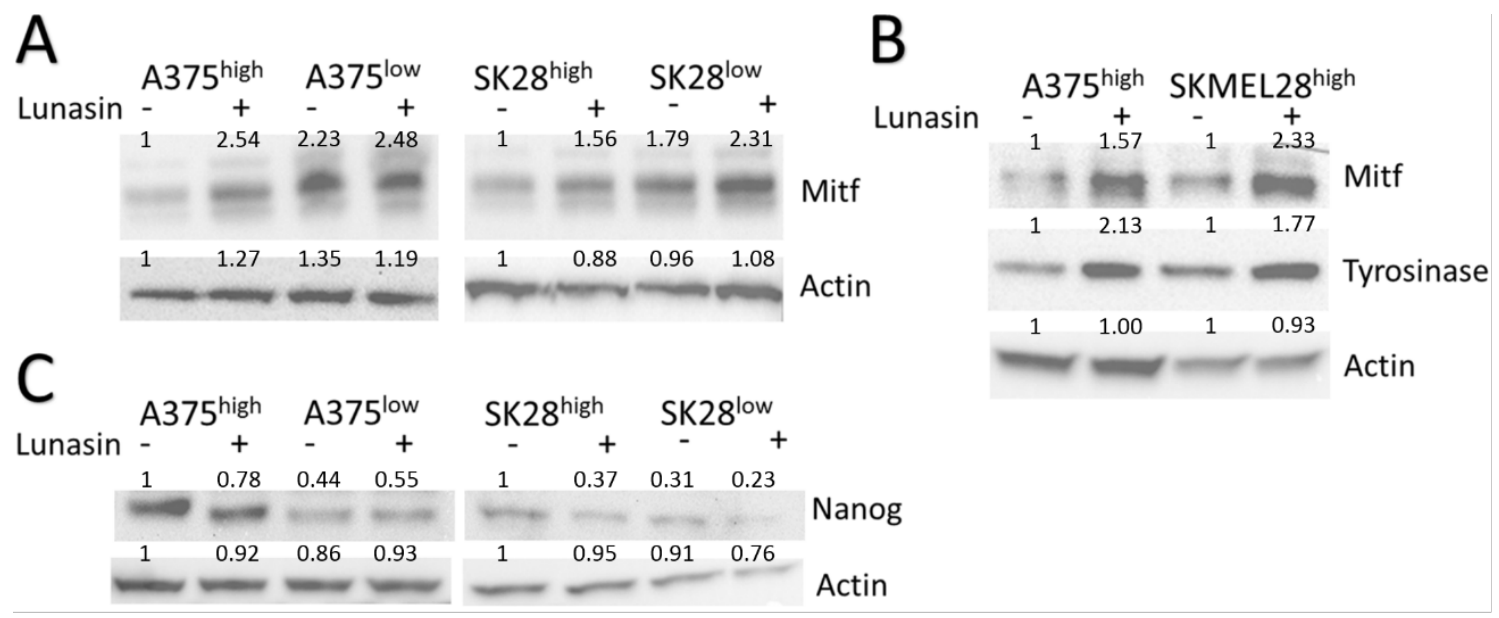

Shidal et. al.

Oncotarget, 2016

\section{Figure 19: Lunasin modulated expression of melanocyte differentiation and stem-associated}

markers. Sorted subpopulations of $\mathrm{ALDH}^{\mathrm{low}}$ and $\mathrm{ALDH}{ }^{\text {high }}$ cells displayed differential expression of the melanocyte-associated transcription factor MITF, with $\mathrm{ALDH}^{\text {low }}$ cells expressing higher levels of MITF than ALDH ${ }^{\text {high }}$ populations in both A375 and SKMEL-28 cell lines (A). MITF and the downstream melanocyte differentiation marker Tyrosinase were strongly induced in ALDH ${ }^{\text {high }}$ cells treated with Lunasin for $24 \mathrm{~h}$ (B). Immunoblot analysis revealed that NANOG, a stem-associated marker, was repressed in Lunasin-treated ALDH $^{\text {high }}$ samples (C). Actin was used as a loading control.

\section{Lunasin may enhance the efficacy of vemurafenib in vemurafenib-resistant melanomas}

Proliferation (Figure 21A), colony-forming (Figure 21B), and liquid overlay assays (Figure 21C) were performed on parental A375 cells and vemurafenib-resistant A375R cells. In MTS assays, a significant decrease in the number of viable A375 cells when $300 \mathrm{nM}$ vemurafenib was combined with 10 and $100 \mu \mathrm{M}$ Lunasin $(\mathrm{p}<0.05)$ was observed. In A375R cells, a significant decrease in viable cell counts in combinations of $100 \mu \mathrm{M}$ Lunasin and several concentrations of vemurafenib $(\mathrm{p}<0.05)$ was observed. Similarly, a significant difference in the ability of A375 cells to form colonies in soft agar at concentrations of 30 and $100 \mu \mathrm{M}$ Lunasin alone and $100 \mu \mathrm{M}$ Lunasin in combination with 300 and $1000 \mathrm{nM}$ vemurafenib $(\mathrm{p}<0.05)$ was observed. While Lunasin did not cause a significant decrease in colony formation in A375R cells, it did significantly reduce colony formation when A375R cells were treated in combination with 300 
$\mathrm{nM}$ and $1000 \mathrm{nM}$ vemurafenib (Figure 21B). Interestingly, the authors observed that when A375R cells were grown in anchorage-independent culture conditions (i.e. suspended in soft agar), they were much more sensitive to vemurafenib when compared to adherent culture. Liquid overlay assays were utilized to generate multicellular oncospheres and assess their growth characteristics after treatment with combinations of Lunasin and vemurafenib. Lunasin $(100 \mu \mathrm{M})$ did not significantly decrease the total area of the oncospheres in either A375 or A375R cells; vemurafenib-treated cells were significantly smaller in total area in both A375 and A375R cells ( $\mathrm{p}<0.05)$. However, when Lunasin was combined with vemurafenib, sphere area was significantly decreased in both A375 $(\mathrm{p}<0.001)$ and A375R $(\mathrm{p}=0.04)$ tumor spheres (Figure 21C) compared to vemurafenib controls. For each assay described, DI values were calculated based on the effect of each drug on melanoma cell proliferation. It was observed that Lunasin had an additive effect (DI values between 0.9 and 1.1) when used in combination with vemurafenib for all of the aforementioned assays.
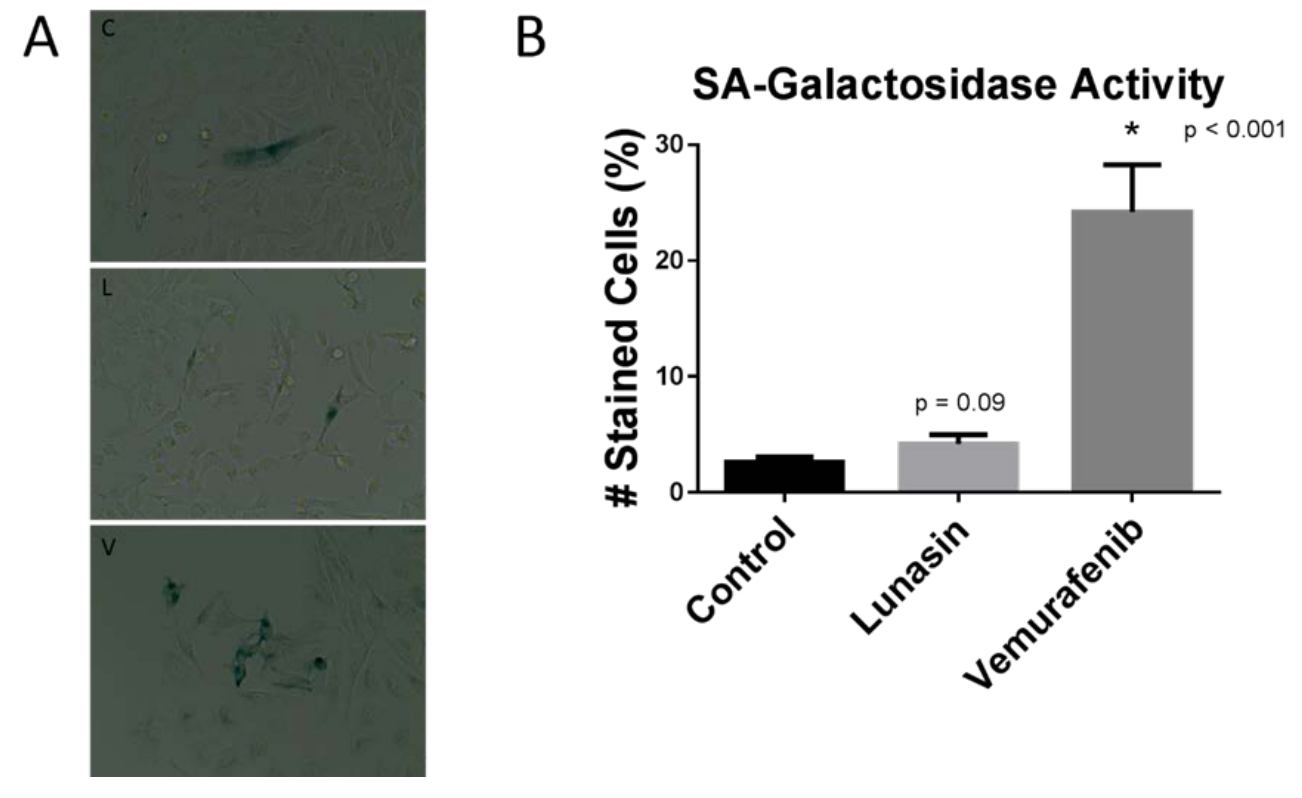

Figure 20: Lunasin did not induce a significant senescent response in A375 ALDH ${ }^{\text {high }}$ melanoma cells. When A375 ALDH ${ }^{\text {high }}$ cells were treated with vehicle, Lunasin, and vemurafenib, no observable increase in senescence between control (2.6\%) and Lunasin-treated (4.2\%) samples was detected, despite a modest increase in cells staining positive for $\beta$-Galactosidase activity in the Lunasin-treated cells (A,B). Vemurafenib was statistically significant from both groups with nearly $25 \%$ of cells staining positive after a 
$24 \mathrm{~h}$ treatment. Representative images for each treatment group are shown at 200x magnification (A) and represent data from two independent experiments. Statistical analysis was performed using student's t-test with a p-value of less than 0.05 considered statistically significant.
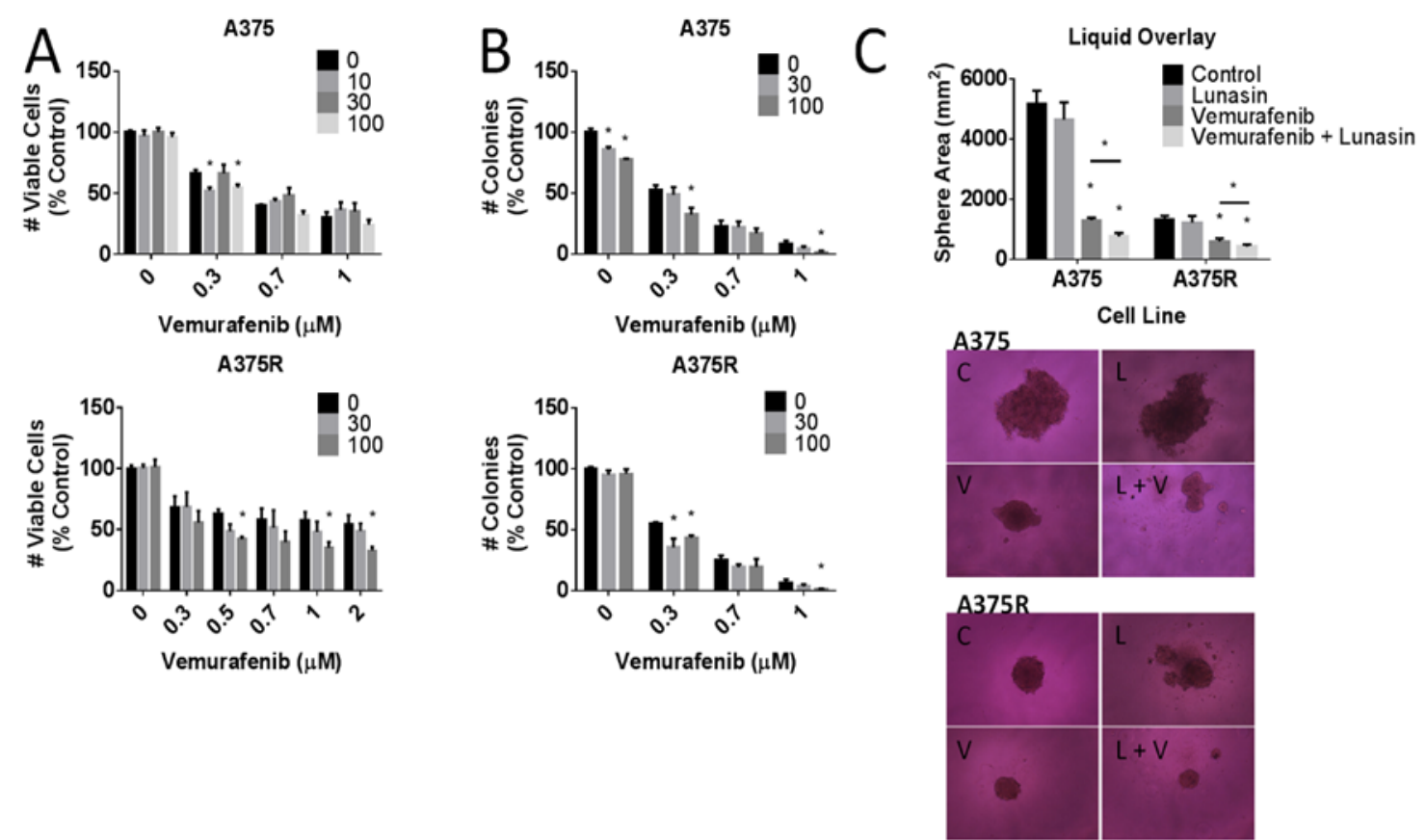

Figure 21: Combinations of Lunasin and vemurafenib yielded an additive interaction that may benefit treatment of chemoresistant populations of melanoma cells. A375 and A375R (i.e. vemurafenib-resistant) cells were treated with combinations of vemurafenib and Lunasin and efficacy was assessed by MTS (A), soft agar (B), and liquid overlay assays (C). C = control, L = Lunasin, $\mathrm{V}=$ vemurafenib, $\mathrm{V}+\mathrm{L}=$ combination. Concentrations of Lunasin are indicated in the respective graph legends (A, B). Significant differences between control and treatment groups were determined by student's t-test and were observed for several combination treatments as denoted by asterisks (*). Results represent data taken from three independent experiments and are expressed as mean \pm s.d. Representative images for liquid overlay assays were taken at 100x magnification.

In Annexin V binding assays, a significant decrease in cell viability ( $\left.\mathrm{PI}^{-} \mathrm{A}^{-}\right)$was observed in cells treated with $1 \mu \mathrm{M}$ vemurafenib and $1 \mu \mathrm{M}$ vemurafenib in combination with $100 \mu \mathrm{M}$ Lunasin after $72 \mathrm{~h}$ of treatment (Figure 22). No significant differences in viable $\left(\mathrm{PI}^{-} \mathrm{A}^{-}\right)$, apoptotic $\left(\mathrm{PI}^{-} \mathrm{A}^{+} / \mathrm{PI}^{+} \mathrm{A}^{+}\right)$, or necrotic $\left(\mathrm{PI}^{+} \mathrm{A}^{-}\right)$populations were observed between treatment groups and control samples at either $24 \mathrm{~h}$ or $48 \mathrm{~h}$ time 
points. At $72 \mathrm{~h}$, a significant increase in cells positively stained with $\mathrm{PI}\left(\mathrm{PI}^{+} \mathrm{A}^{-}\right)$was observed in cells treated with a combination of Lunasin and vemurafenib when compared to vehicle-treated cells indicating that Lunasin may increase necrotic cell death in A375 cells treated with vemurafenib (Figure 22A). Representative dot plots for A375 cells treated with vehicle, Lunasin, vemurafenib, and combination therapy demonstrate the potential of Lunasin in conjunction with vemurafenib (Figure 22B). Combined with the results from the in vitro proliferation assays, it would seem logical that Lunasin may lend some therapeutic benefit as an adjuvant therapy in melanoma patients receiving vemurafenib treatment.

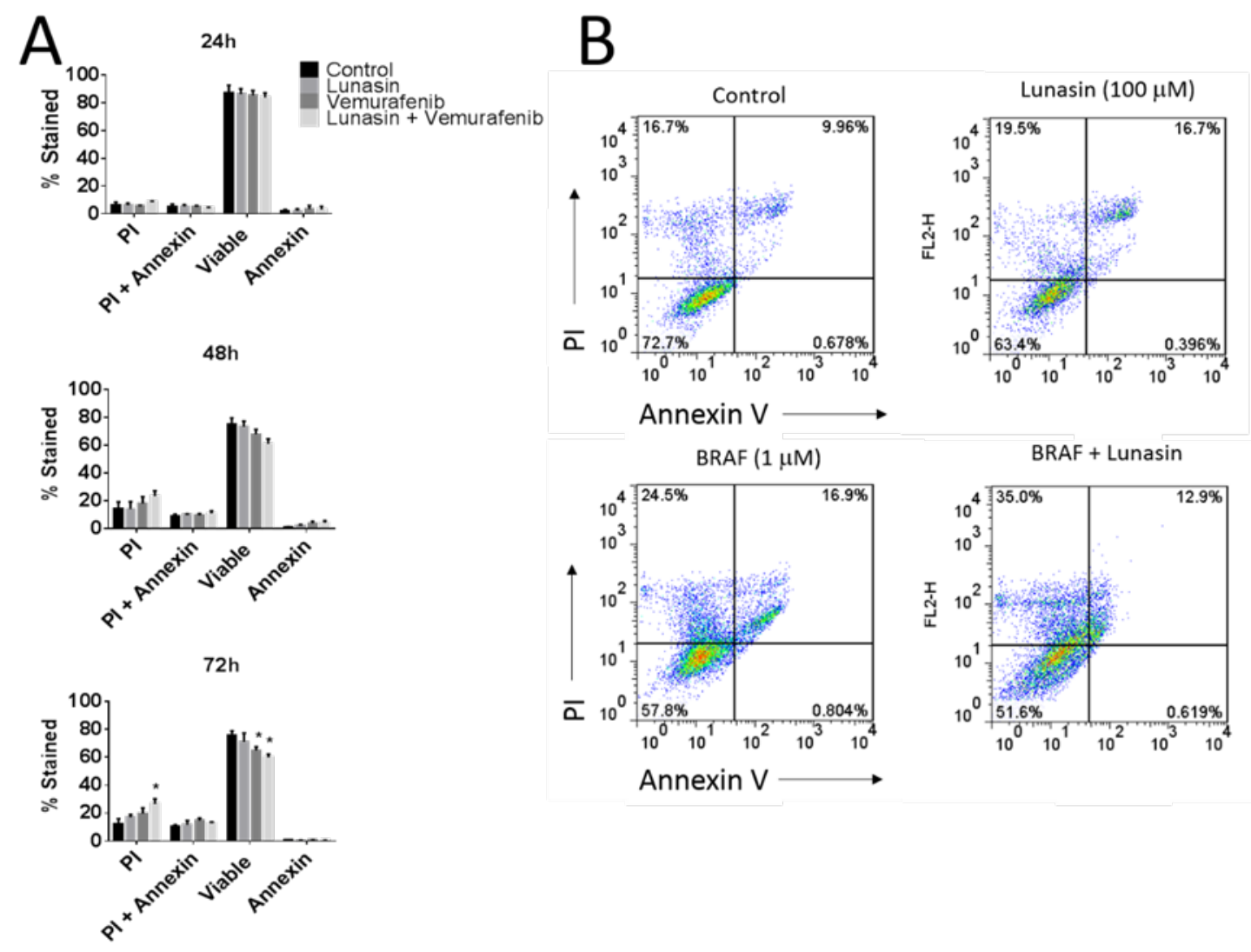

Figure 22: Lunasin in combination with vemurafenib kills A375 melanoma cells. Annexin V binding assays were performed on A375 melanoma cells treated for 24, 48, and 72 h (A). A significant difference was observed in cell viability after $72 \mathrm{~h}$ in vemurafenib and combination treatment groups compared to control $(\mathrm{p}<0.05)$. PI-stained cells were significantly increased in combination treatment when compared to control samples $(\mathrm{p}<0.05)$. Data were obtained from three independent experiments and are represented as mean percent \pm s.d. Representative dot plots are shown for vehicle, Lunasin, vemurafenib, and 
combination treatments at the $72 \mathrm{~h}$ time point (B). Statistical analysis was performed using the student's ttest. Groups were considered statistically significant when $\mathrm{p}<0.05$.

\subsection{DISCUSSION}

Consumption of large amounts of soy-derived foods is associated with a lower risk of a number of chronic diseases including cancer [180-182]. The anticancer effects of soy components have been attributed to secondary metabolites such as isoflavones and specific protein fractions [183, 184]; however, no epidemiological evidence directly correlating soy consumption with decreased melanomagenesis has come to light. Lunasin, a peptide present in crude soy protein, has been proposed to be an important chemoprevention agent in soy [9]. Lunasin is a 43-44-amino acid polypeptide [16, 18] that is encoded within the soybean GM2S-1 gene. The 22-amino acid N-terminal sequence (with no known function) of Lunasin is followed by a putative helix domain proposed to target Lunasin to chromatin, and the C-terminal end that includes a RGD cell adhesion motif followed by a poly-aspartic acid tail [15, 16]. Lunasin’s potential chemopreventive activity has been established by studies which show that Lunasin prevents cellular transformation by chemical carcinogens and viral oncogenes [9]. Recent studies have shown that Lunasin can inhibit the in vitro and in vivo growth of breast [34, 185], leukemia [186], colon [35, 187], and lung cancers [10]. These findings of this dissertation reveal that Lunasin has potential therapeutic effects against melanoma in both non-adherent in vitro assays and in vivo xenograft studies.

The ALDH ${ }^{\text {high }}$ melanoma cancer cell subpopulation has been reported to harbor the tumorinitiating and metastatic cells and is enriched in several of the self-renewal genes including NANOG [188, 189]. A recent study has shown that siRNA-mediated knockdown of ALDH in melanoma cells inhibited in vivo tumor development and metastatic properties [106]. Mechanistically, the ALDH ${ }^{\text {high }}$ melanoma cells have been shown to possess higher tumorigenic, invasive, and self-renewal capacities than ALDH ${ }^{\text {low }}$ cells and thus, can serve as a potential therapeutic target [103, 111, 188]. These studies implicate high ALDH activity as a relevant biomarker for identifying melanoma CICs, and the significant inhibition of ALDH activity that was observed with Lunasin phenocopies the antimelanoma/anti-CIC effects observed in cells silenced for ALDH. Thus, using Lunasin to reduce this aggressive populations of cells may serve as an invaluable tool in melanomas which display cells with CIC-like abilities. Using surrogate assays for CIC 
identification, it was demonstrated that sorted cell populations based on the ALDH biomarker were sensitive to Lunasin treatment in non-adherent melanosphere formation assays as well as colony formation in soft agar. As presented in these data, Lunasin functionally blocked the self-renewal capacity of isolated melanoma CICs. The activity of Lunasin both in vitro and in vivo on melanoma CICs suggests the intriguing possibility that Lunasin can target these quiescent and drug-resistant cells and is consistent with a recently published study on colon cancer [164]. Using the CIC surface markers CD133 and CD44, the authors showed that soy bioactives in combination with the antidiabetic drug, Metformin, reduced populations of cells capable of self-renewal by modulating the PTEN/PI3K/FASN axis. Taken in combination with results gathered in this dissertation, these data represent a novel idea that Lunasin and other soy derivatives may alleviate patient relapse by decreasing cancer stem cell populations.

An important and most intriguing aspect of this study is that the potential anticancer effects of Lunasin were enduring in vivo. Despite somewhat modest effects in vitro, it was observed that Lunasin had a highly significant effect on tumor growth when cells were transplanted into immunodeficient mice. Lunasin-treated mice had a significantly reduced tumor burden in both parental (46\%) and ALDH ${ }^{\text {high }}$ (73\%) A375 cells when compared to their vehicle-treated counterparts. In fact, Lunasin has been described to have immunomodulatory functions $[13,42]$ adding another feature to this multifaceted peptide. In these studies, Lunasin was shown to enhance activation of innate immunity. Lunasin-treated dendritic cells expressed higher levels of cytokines and chemokines, and induced expansion of CD4 ${ }^{+} \mathrm{T}$ cells [42]. Additionally, Lunasin-treated mice had improved responses when compared to control mice in models which were challenged with OVA-expressing influenza as well as lymphoma [42]. Specific to immunotherapy, Lunasin was shown to synergistically enhance NK cell mediated cytotoxicity when used in combination with IL-2 or IL-12 in a lymphoma model [13]. These studies open the possibility that mouse models with intact innate immunity may provide a substantial boost to the anticancer activity of the Lunasin peptide.

While the study was too small to measure a significant difference between in vivo tumorigenicity between $A L D H^{\text {high }}$ and $A L D H^{\text {low }}$ A375 cells, limiting dilutions assays did provide the intriguing possibility that the number of cells in the ALDH ${ }^{\text {high }}$ compartment may be dependent upon the number of tumor cells within the tumor microenvironment (TME). Data from these serial dilution assays would suggest a 
differential ability to proliferate and form palpable tumors in ALDH ${ }^{\text {low }}$ and ALDH ${ }^{\text {high }}$ A375 cells in a dilution-dependent manner. Additionally, samples from tumors initiated by the lowest dilution of cells demonstrated that $\mathrm{ALDH}^{\text {high }}$ cells had a higher population of cells remaining in the ALDH ${ }^{\text {high }}$ compartment after tumor formation when compared to samples derived from ALDH ${ }^{\text {low }}$ cells. It is well known that the TME can regulate the stem cell niche through cell-cell contact, secretion of proteins, and hypoxia [190192]. Though these data may be a result of the abundance of tumor cells (or lack thereof), it might also indicate that A375 cells display high plasticity, and CICs derived from the ALDH ${ }^{\text {high }}$ compartment may revert to a non-stem cell compartment and vice versa. Indeed, melanoma has been described as a highly plastic malignancy [193]. While ALDH ${ }^{\text {low }}$ cells may display a high degree of tumorigenicity in the in vivo models used in this study, the authors did not study long-term propagation and self-renewal capacity in vivo, a central feature of stem cells, of either $\mathrm{ALDH}^{\text {high }}$ or $\mathrm{ALDH}^{\text {low }}$ cells. Therefore, any conclusive evidence as to how these isolated CICs are functioning in vivo in comparison to their non-CIC counterparts will need to be explored further. Until the caveats limiting the CIC hypothesis are further addressed (i.e. improved experimental systems or a defined molecular phenotype for CIC identification), it is likely that the abundant support for the CIC theory will be met with equally abundant skepticism.

With regard to potential mechanisms of action, Lunasin contains a RGD domain and has been shown to bind specific integrins that recognize this cell adhesion motif [38]. Integrins are heterodimeric cell surface proteins that play critical roles in adhesion to the extracellular matrix, transmitting extracellular signals that affect cell migration and the regulation of signaling pathways involved in cell survival and proliferation. Recent studies [10, 12, 36, 194] strongly suggest that Lunasin bound to integrins containing combinations of the $\alpha_{5}, \alpha_{v}, \beta_{1}$, and $\beta_{3}$ subunits and modulated the ILK and FAK signaling pathways. Additionally, it is becoming clear that there is a strong linkage of integrin-matrix interactions to cancer cell initiation and progression (reviewed in [64]), including the maintenance and survival of CICs through integrin-FAK signaling [reviewed in [195]]. Interestingly, the current data indicate that sorted fractions of $\mathrm{ALDH}^{\text {high }}$ melanoma cells are more sensitive to Lunasin than the unsorted cell fractions. One possible explanation for this differential sensitivity is that when compared to the bulk of tumor cells, the ALDH ${ }^{\text {high }}$ subpopulation of melanoma cells exhibit altered integrin expression profiles. It is also possible that the $\mathrm{ALDH}^{\text {high }}$ melanoma CICs rely more heavily and specifically on 'outside-in’ signal transduction 
mechanisms mediated via integrin networks compared to $\mathrm{ALDH}^{\mathrm{low}}$ cells. Such differential integrin signaling in CICs could confer an increased sensitivity to Lunasin's anticancer activity. In fact, it has been reported that metastatic melanomas, compared to primary melanomas, favor the expression of particular integrins, including integrin $\alpha_{v} \beta_{3}$ [61], a known Lunasin target [10]. Differential expression of integrins in CICs is not only restricted to melanoma but have been reported in CICs from other cancers including prostate [196, 197], breast [198], and neuroglia cancers [172]. Given the strong interaction between Lunasin and integrins $[10,12,38]$, it is tempting to speculate that Lunasin specifically targets CICs by modulating integrin signaling circuits that are differentially expressed in melanoma CICs. Although the mode of action of Lunasin's anti-CIC activity remains to be clearly defined, future studies in the Davis lab will focus on identifying the specific integrin-mediated signaling modules required for Lunasin sensitivity against melanoma CICs.

MITF, commonly referred to as a “master controller” gene for melanocyte development strictly regulates melanocyte proliferation and differentiation [199]. Recent studies have identified the existence of slow-cycling, low MITF-expressing CICs in melanoma cell populations with intrinsic chemoresistant and tumorigenic phenotypes [200]. Additionally, this subpopulation of melanoma cells expressed high levels of the stem cell-associated markers Oct-4 and Nanog [200]. One of the most significant findings from this study is that treatment of melanoma $\mathrm{ALDH}^{\text {high }} \mathrm{CICs}$ with Lunasin induced a more differentiated phenotype by increasing the expression of MITF as well as the expression of the downstream melanocyte differentiation marker, Tyrosinase, an enzyme directly involved in melanin synthesis. Concomitant with the Lunasin-induced phenotypic shift, a significant reduction in the expression of NANOG, a transcription factor implicated in migration, invasion, self-renewal, and dedifferentiation of melanoma cells [201-203] was observed in both A375 and SKMEL-28 cells. This represents a novel activity for Lunasin that has not been reported in any cancer model to date.

The encouraging functional effects that were observed in melanoma CICs lead to the investigation of whether or not Lunasin could be used in conjunction with a clinically relevant therapeutic for the treatment of malignant melanoma. Lunasin in combination with vemurafenib, a selective B-Raf inhibitor, was used to demonstrate the potential of Lunasin as an adjuvant therapeutic. When proliferation and colony formation in soft agar were assessed, DI values indicate that Lunasin and vemurafenib did not 
interact synergistically, but did have an additive effect; the highest DI values were observed using combinations using $100 \mu \mathrm{M}$ Lunasin. At $100 \mu \mathrm{M}$, Lunasin increased the efficacy of vemurafenib in A375 cells with acquired vemurafenib-resistance to treatment in both adherent (proliferation assays) and nonadherent formats (soft agar). Multicellular generation of oncospheres was used to determine the growth characteristics when parental and resistant A375 cells were treated with combinations of Lunasin and vemurafenib. In both models, combination treatment with Lunasin and vemurafenib significantly reduced the total sphere area when compared to vemurafenib treatment alone suggesting that Lunasin enhanced the antiproliferative effects of vemurafenib. These additive effects may be driven by Lunasin's interaction with integrins and the suppression of activating phosphorylations of downstream signal transducers (i.e. FAK). In fact, research has shown that resistance to vemurafenib may be caused by elevated $\beta_{1}$-FAK signaling [204]. ERK signaling, which is typically activated downstream of integrin-mediated adhesion, is found to be constitutively activated in B-Raf mutated melanomas [205]; consequently, selective targeting of ERK or its downstream effectors may provide some therapeutic potential in B-Raf mutated melanomas. Combinations of B-Raf and MEK/ERK inhibitors continues to be a field of great interest to researchers trying to overcome chemoresistant melanomas [206]. Given the prominent role of integrins in CIC maintenance and chemoresistance [207], combining MAPK inhibitors with integrin-targeted therapies could potentially offer a novel strategy for reducing tumor burden while also targeting CICs.

Taken together, results from the present study and previously published data support the model (Figure 23) depicting the potential therapeutic benefits of Lunasin in melanoma. Effectively reducing pools of CICs by driving a movement of cells out of the cancer stem cell-like compartment (i.e. ALDH ${ }^{\text {high }}$ ) and into a more differentiated phenotype (i.e. $\mathrm{ALDH}^{\text {low }}$ ), Lunasin may alleviate patient relapse by diminishing pools of cells with the intrinsic abilities generally conserved in hematopoietic stem cells. By blocking selfrenewal and subsequent expansion of the CIC compartment, Lunasin may ultimately prove to be an indispensable tool in combating populations of cells with high invasive potential and chemoresistant characteristics. 


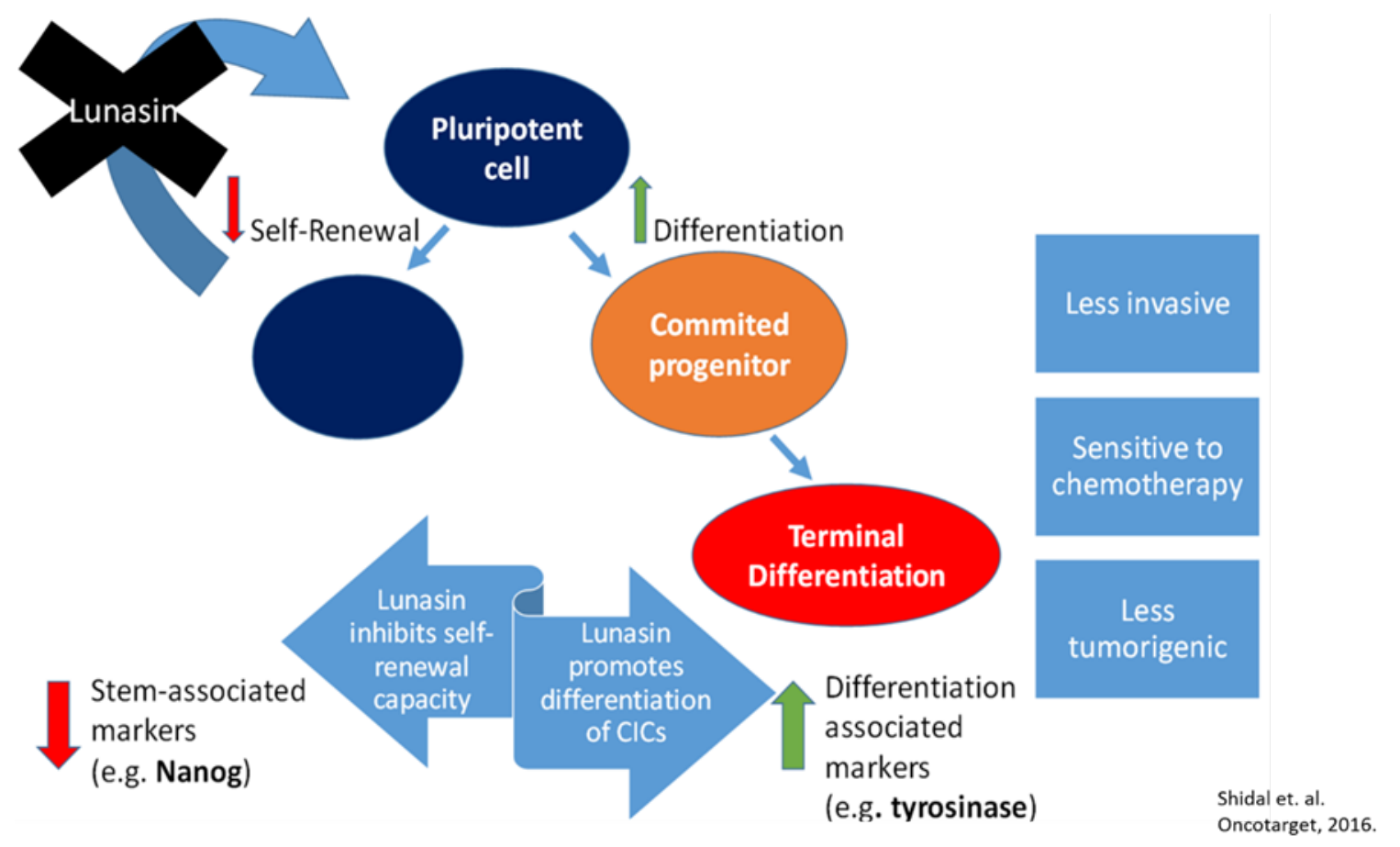

Figure 23: Proposed mechanism for Lunasin's activity in melanoma CICs. This diagram depicts the observed effects and possible therapeutic advantage of Lunasin treatment in cases of malignant melanoma. Lunasin decreased the stem-like properties of ALDH ${ }^{\text {high }}$ CICs isolated from A375 and SKMEL-28 cell lines while concurrently decreasing the stem-associated marker NANOG and inducing expression of melanocyte differentiation markers MITF and Tyrosinase. By effectively reducing this stem cell-like compartment, Lunasin may alleviate patient relapse caused by the subpopulation of cells with intrinsic metastatic potential and chemoresistance. 


\section{CHAPTER 4: LUNASIN SUPPRESSES THE METASTATIC CAPACITY OF MELANOMA}

\section{INITIATING CELLS BY INHIBITING INTEGRIN SIGNAL TRANSDUCTION}

\subsection{INTRODUCTION}

Melanoma is a notoriously aggressive form of skin cancer that represents approximately $80 \%$ of all skin cancer related deaths, despite accounting for only 5\% of diagnosed cases [208, 209]. New classes of drugs (i.e. small molecule inhibitors) combating malignant melanomas have yielded mixed results [210212]. Although many patients achieve an initial tumor regression, these agents quickly become ineffective, and additionally, may promote the spread of a highly aggressive and chemoresistant population of cells [213-215]. Studies utilizing immunotherapy (extensively reviewed in [216]) to treat malignant melanomas have been found to be an effective treatment option. However, only a relatively small subset of patients achieve a sustained complete response [217-219]. More recently, immunotherapies with substantially improved objective responses in melanoma patients have proven the clinical utility of immunotherapy [138, 220-222]. Nevertheless, adverse safety profiles, chemoresistance, and immune evasion continue to prove problematic in many of these newly approved immunotherapies [223-225]. Thus, providing patients with additional novel adjuvant therapies to reduce or even prevent metastatic spread will continue to be needed for the development for effective treatment strategies.

The process of invasion and metastasis is perhaps the most studied hallmark of cancer due to the high mortality rates caused by the metastatic dissemination of tumor cells from the primary tumor into distant organs. Malignant melanomas frequently metastasize to the brain, lymph nodes, gastrointestinal tract, liver, and most commonly the lungs [226]. Primary tumor formation and subsequent metastatic outgrowth is maintained by a subset of cells with innate stem cell-like abilities that enable them to invade and colonize surrounding tissues, while preserving a population of highly proliferative bulk tumor cells [66, 93]. The heterogeneous nature of melanomas make an intriguing model to study metastatic dissemination as they have been reported, among many classes of solid tumors, to harbor CIC populations identified by several biomarkers including ALDH [103, 106], CD20 [93], CD133 [94], CD271 [95], and ABCB5 [66]. 
Lunasin is a peptide isolated from soy that has been shown to have chemopreventive and chemotherapeutic activity $[9,10,26,27,32,35,186,227,228]$. Lunasin has three domains implicated in its anticancer activity; a RGD motif, a helical domain with a sequence conserved in chromatin binding proteins, and a poly-aspartic acid tail (Figure 24) [229]. Chapter 3 of this dissertation reported that Lunasin significantly reduced a melanoma stem cell population expressing elevated levels of ALDH [228]. Additionally, it was shown that in vivo tumor growth initiated by this putative CIC population was significantly impaired in mice treated with Lunasin [228].

\title{
SKWQHQQDSCRKQLQGVNLTPCEKHIMEKIQQGRGDDDDDDDDDN
}

\author{
Helical Region: Chromatin Binding* \\ RGD Motif: Internalization \\ Poly D tail: Histone binding ( $\mathrm{H} 3$ and $\mathrm{H} 4)$ \\ Shidal et. al. \\ Oncotarget, 2017.
}

Figure 24: Full amino acid sequence of the Lunasin peptide. Lunasin is a 44 amino acid peptide with 3 functional domains attributed with its anticancer activity: 1) a helical regional conserved in chromatinbinding proteins (blue), 2) a RGD motif recognized by integrins (red), and 3) a poly-D tail involved in histone tail binding (green).

Previously, Lunasin was shown to inhibit metastasis of malignant colon cancer cells and additionally, potentiated the antimetastatic effects of oxaliplatin [36]; however, studies linking Lunasin to suppressed metastatic dissemination are largely lacking. With the encouraging effects of Lunasin on breast and melanoma CICs [228, 230], it is plausible to speculate that by reducing expansion of the CIC compartment, Lunasin would ultimately decrease the ability of tumor cells to invade, survive, and colonize distant tissues. Mechanistic studies to date support that Lunasin's anticancer activity may be due to effects on histone acetylation and integrin signaling.

Preliminary studies of Lunasin suggested that a primary anticancer mechanism was derived from its activity as a HAT inhibitor [9]. Both HAT inhibitors and their inverse, histone deacetylase (HDAC) 
inhibitors, have been shown to have potential clinical utility in malignant melanoma [231, 232]; however, some epigenetic modulating agents may also contribute to undesirable effects. For example, it was recently published the HDAC inhibitor, valproic acid, caused breast cancer cells to dedifferentiate toward a chemoresistant stem-like state [233]. With regard to Lunasin, it was indeed found that histone acetylation patterns are altered in melanoma models; however, it is an open question as to whether or not it is the driving mechanism in Lunasin's chemotherapeutic activity. Equally, it is proposed that although HAT inhibition may cause many anticancer effects in Lunasin treated cancers, inhibition of integrin signaling stimulates the effects seen in melanoma as well as NSCLC [10]. The intertwining mechanisms between histone acetylation and integrin signal transduction remains unclear. One major question that remains to be answered is whether integrin signaling can modulate epigenetic histone modifications or vice versa?

Two key signaling pathways involved in the metastatic cascade are the integrin-FAK axis [195] and the downstream PI3K/AKT pathway [234]. FAK is a critical mediator of cell proliferation, differentiation, angiogenesis, and invasion as it promotes cytoskeletal remodeling through interactions with several proteins including Src kinases [235]. The PI3K/AKT pathway is also found to be aberrantly regulated in a variety of cancers including melanoma [236]. Although generally thought of as a central protein involved in cell survival and cell cycling, AKT has been shown to bind and regulate FAK phosphorylation suggesting an important role in metastatic adhesion [237]. Dual targeting of these dysregulated pathways by disrupting upstream (integrin) signaling remains a promising therapeutic approach despite the fact that there are few clinical applications using this approach. Pharmacologic targeting of integrins is currently undergoing clinical trials for the treatment of malignant melanomas [68]. Due to the central role of integrins in several oncogenic signaling pathways [64], blockade of integrin signal transduction seems a likely candidate for future drug development. While the potential clinical benefit of integrin antagonists seems hopeful, the future of this class of drug will likely depend upon the development of novel first line anticancer drugs as integrin antagonists are generally utilized in combination with more traditional chemotherapeutics as antiangiogenic agents [238-241].

The present study significantly extends upon previous work by demonstrating that Lunasin inhibits metastasis-associated activities in melanoma CICs both in vitro and in vivo. Additionally, it is proposed that Lunasin is a multifaceted peptide with a complementary array of mechanisms which provides 
the potential for a significant therapeutic benefit as an adjuvant therapy against malignant melanomas compared to single-agent treatment strategies. By altering histone acetylation patterns as well as inhibiting integrin signaling, Lunasin exerts a significant anticancer effect in melanoma models both in vitro and in vivo.

\subsection{MATERIALS AND METHODS}

\section{Purification of Lunasin from defatted soy and synthesis of mutated peptides}

Lunasin was isolated from defatted soy flour as described in Section 2.1 [16]. Mutated peptides were synthesized by China Peptides (China) with a purity > 95\% as assessed by HPLC/MS. Full sequences are provided (Figure 25) along with validation that these sequences were recognized by the anti-Lunasin rabbit polyclonal antibody (Figure 26) used in immunoblot and immunofluorescent assays. Peptides were dissolved in $50 \mathrm{mM}$ sodium phosphate buffer $\mathrm{pH}=7.4$ (PB), and dialyzed overnight to remove any contaminating salts. Protein concentrations from the resulting peptide solutions were determined using a bicinchoninic acid (BCA) assay (Pierce). Peptide solutions were filter sterilized by passing through a 0.22 $\mu \mathrm{m}$ filter (Millipore), aliquoted, and stored at $-20^{\circ} \mathrm{C}$ until use.

\begin{tabular}{|c|c|c|}
\hline Peptide Name (Abbreviated) & Full Amino Acid Sequence & \\
\hline KBP (Kentucky BioProcessing) & SKWQHQQDSCRKQLQGVNLTPCEKHIMEKIQGRGDDDDDDDDDN & \\
\hline NAT (Native) & SKWQHQQDSCRKQLQGVNLTPCEKHIMEKIQGRGDDDDDDDDD & \\
\hline RAD (RGD-mutated) & SKWQHQQDSCRKQLQGVNLTPCEKHIMEKIQGRADDDDDDDDD & \\
\hline S.T. (Scrambled Tail) & SKWQHQQDSCRKQLQGVNLTPCEKHIMEKIQGRGDAGGKVGVA & $\begin{array}{l}\text { Shidal et. al. } \\
\text { Oncotarget, } 2017 .\end{array}$ \\
\hline
\end{tabular}

Figure 25: Full sequences of synthesized peptides. Peptides based on Lunasin’s initial 43 amino acid sequence were synthesized by China Peptides to represent altered functional domains. Mutated amino acid sequences for each peptide are underlined in red. KBP-Lunasin was used in all experimental conditions, and varies from the native Lunasin sequence by a single asparagine residue on the C-terminal end.

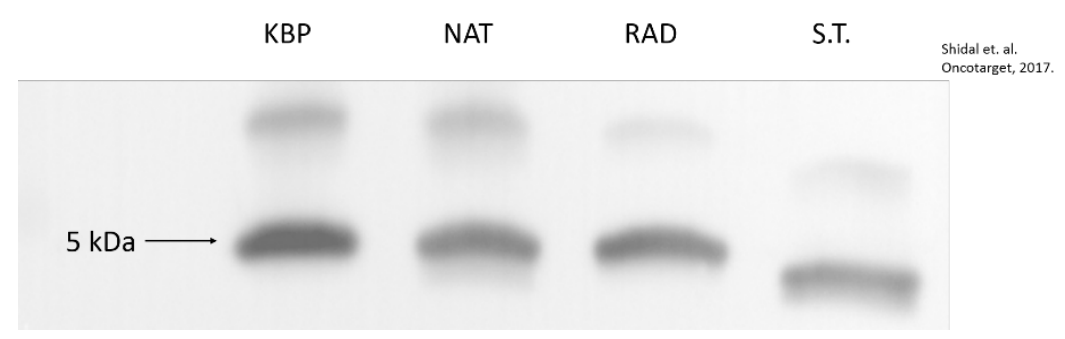

Figure 26: Validation of Lunasin antibody recognizing mutated peptides. $200 \mathrm{ng}$ of total peptide were electrophoresed in 15\% polyacrylamide gels, transferred to a PVDF membrane, and probed for Lunasin 
using a rabbit polyclonal antibody. This confirmed that the antibody used in these studies will indeed recognize the mutated peptide sequences. Lunasin is represented by the $5 \mathrm{kDa}$ band; a slight degree of oligomerization can be seen as represented by the fainter band above the $5 \mathrm{kDa}$ Lunasin band.

\section{Cell culture and reagents}

All cell cultures and reagents utilized in Chapter 4 were described in Section 2.2.

\section{Genome-wide microarray analysis}

All RNA extractions, cDNA generation, and hybridization protocols were followed as outlined in Section 2.16. RNA integrity values as assessed by the Bioanalyzer are shown in Figure 27.

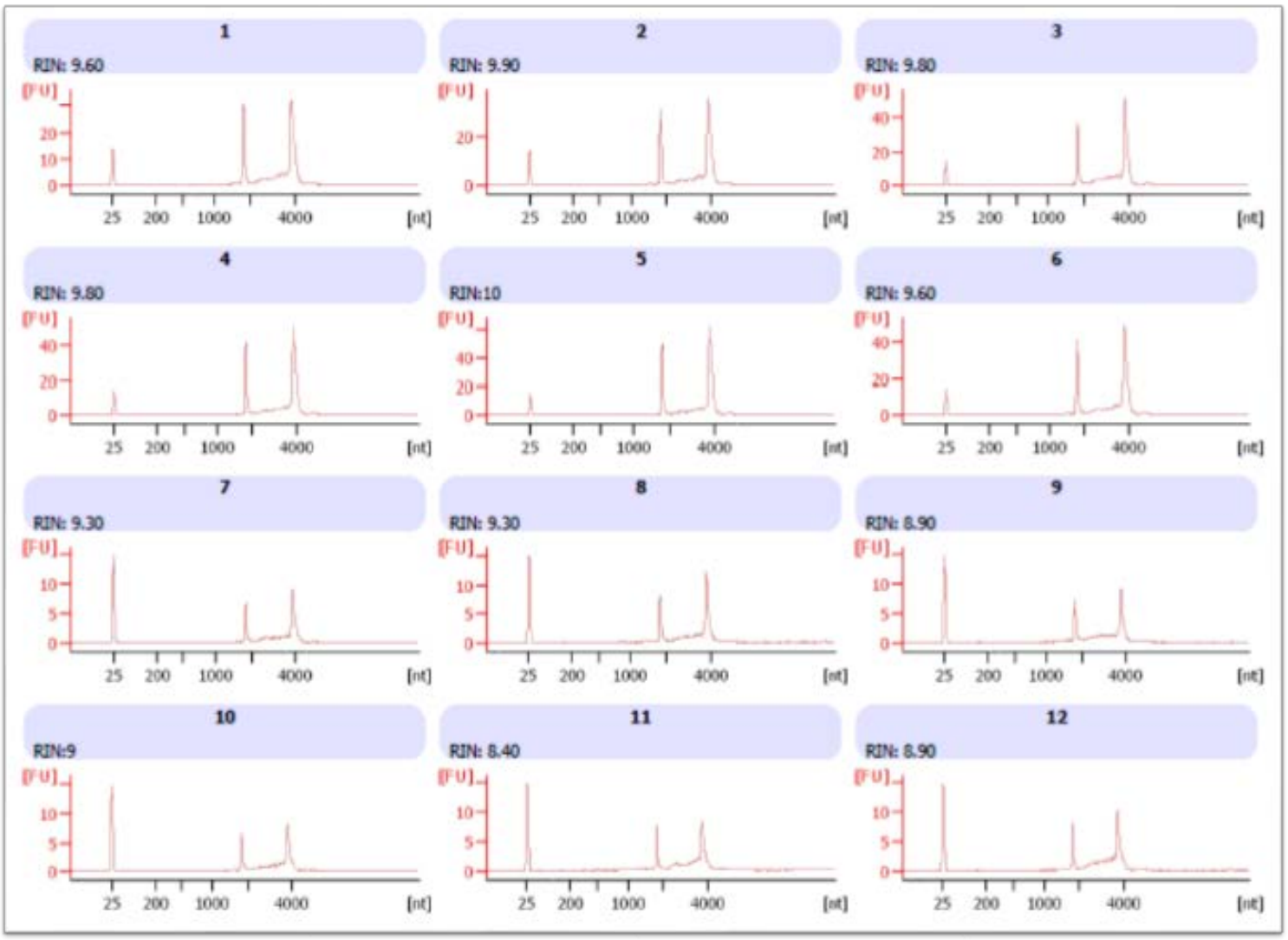

Figure 27: RNA integrity values assessed on an Agilent Bioanalyzer. Isolated RNA from parental A375

cells treated with vehicle (1-3) or Lunasin (4-6) were assessed for RNA degradation and sample integrity before generation of the cDNA template for microarray analysis. A375 $\mathrm{ALDH}^{\text {high }}$ cells were also treated with either vehicle (7-9) or Lunasin (10-12), and subsequently assessed on the Bioanalyzer. RNA integrity values were confirmed to be greater than 8 which indicates minimal samples degradation. 


\section{Immunofluorescence}

Immunofluorescent microscopy was used for colocalization analysis and Lunasin uptake experiments as described in Section 2.17.

\section{Proximity ligation assay (PLA)}

PLA assays were performed as described in Section 2.18.

\section{Oncosphere formation assay}

Generation of melanoma oncospheres was performed as outlines in Section 2.15.

\section{Flow cytometry}

Flow cytometry experiments to assess cell cycle and apoptosis have been detailed in Sections 2.6 and 2.7, respectively.

\section{Transwell invasion assay}

In vitro invasion assays were performed on $\mathrm{ALDH}^{\text {high }}$ melanoma cells as described in Section 2.19.

\section{Murine model of experimental metastasis}

In vivo metastasis models were utilized to investigate the antimetastatic properties of Lunasin as outlined in Section 2.20.

\section{Histology}

Tissues resected from primary melanoma lesions were prepared, sectioned, and stained as described in Section 2.21.

\section{Histone Extraction and Immunoblot Analysis}

Cultured cells were treated with PB or Lunasin $(100 \mu \mathrm{M})$ for $24 \mathrm{~h}$. Acid extraction of histones was performed as described [242]. Briefly, cells were washed in PBS and harvested into $15 \mathrm{~mL}$ conical tubes. Cells were pelleted by spinning at $300 \mathrm{xg}$ for $10 \mathrm{~min}$ and the resulting cell pellet was resuspended in an appropriate amount of hypotonic lysis buffer (10 mM Tris-Cl pH 8.0, $1 \mathrm{mM} \mathrm{KCl}, 1.5 \mathrm{mM} \mathrm{MgCl}_{2}$ and 1 $\mathrm{mM}$ DTT). Cell pellets were incubated at $37^{\circ} \mathrm{C}$ for $30 \mathrm{~min}$ with agitation to promote cell swelling and lysis. Lysates were pelleted by centrifugation at $10,000 \mathrm{xg}$ for $10 \mathrm{~min}$ at $4^{\circ} \mathrm{C}$ on a tabletop centrifuge (Eppendorf). The supernatant was discarded and the remaining nuclei were suspended in $0.4 \mathrm{~N} \mathrm{H}_{2} \mathrm{SO}_{4}$ and allowed to sit overnight at $4^{\circ} \mathrm{C}$ with constant agitation. Samples were centrifuged at $16,000 \mathrm{xg}$ for $10 \mathrm{~min}$ to remove nuclear debris and the resulting supernatant containing histones was transferred to a fresh $1.5 \mathrm{~mL}$ 
tube. A volume of $132 \mu \mathrm{L}$ of $100 \%$ trichloroacetic acid (TCA) was added to each sample to a final concentration of $33 \%$ TCA v/v. Histones were precipitated in TCA overnight at $4^{\circ} \mathrm{C}$. The supernatant was removed and the histones were pelleted by centrifugation at $16,000 \mathrm{xg}$ for $10 \mathrm{~min}$. The pellet was washed three times with ice-cold acetone to remove any remaining acid with spins at 16,000 xg for 10 min between each wash. After the final wash, the supernatant was removed and the pellet was allowed to air-dry for 30 min at RT. The dried pellet was dissolved in $100-200 \mu \mathrm{L}$ of ultrapure water and diluted to a concentration of $1 \mathrm{mg} / \mathrm{mL}$ as assessed by BCA method. Purified histones $(10 \mu \mathrm{g})$ were prepared, loaded, and electrophoresed in 15\% gels (Lonza) at $100 \mathrm{~V}$ for 120 min. Transfer to PVDF membranes and antibody incubations were performed as described in Section 2.11.

\section{Statistical Analysis}

Statistical analysis of data obtained from in vitro and in vivo experiments in this Chapter were analyzed for statistical significant as described in Section 2.23.

\subsection{RESULTS}

\section{Genome-wide microarray analysis reveals Lunasin-targeted genes and identifies a unique gene signature in ALDH ${ }^{\text {high }}$ melanoma cells compared to parental cells}

The initial focus in this Chapter was to validate that $\mathrm{ALDH}^{\text {high }}$ melanoma cells harbor the CIC population in the A375 cell line. Additionally, gene expression profiling was utilized as a tool to expose potential mechanisms for the selective effects seen when $\mathrm{ALDH}^{\text {high }}$ cells were treated with Lunasin. The initial datasets compared parental A375 cells in vehicle and Lunasin-treated samples (Table 1). While only a modest effect (fold-change is shown in parentheses) on gene expression was observed, some genes of interest included MAP2K7 (-1.34), MAPK11 (-1.31), RAR $\alpha$ (-1.29), WNT3A (1.28), WNT5A (-1.28), RARY (-1.27), and FOXP1 (1.52). MAP2K7 and MAPK11 are components of the MAPK signaling pathway which is commonly mutated in cancers [243], thus, reducing expression of these genes may reduce oncogenic signaling through MAPK-associated proteins. Retinoic acid (RA) and its receptors (RARs) are centrally involved in stem cell differentiation $[161,244]$ and have been reported to induce cell cycle arrest and apoptosis in melanomas [245-247]. While an exact mechanism for Lunasin's induction of melanocyteassociated differentiation markers as well as the phenotype switch out of the CIC compartment has yet to 
be elucidated, the fact that two RARs were identified in the microarray analysis suggests a potential link considering that ALDH metabolizes vitamin A into RA. To complicate the potential connection between Lunasin and RARs, it has been reported that co-repressors and co-activators of RARs have intrinsic HAT and HDAC activity, respectively [248]. Yet, there also exists a mechanism by which RARs are interconnected to cellular adhesion molecules [249, 250] and more specifically integrins [251]. Given the reports that Lunasin can alter histone acetylation patterns [142] as well as antagonize integrin signaling [10], the mechanisms for this effect remain unclear. Wnt/ $\beta$-catenin signaling is a relatively controversial therapeutic target in cancer; several models support the inhibition of the pathway in order to induce a therapeutic response [252, 253], while other models support activation of Wnt/ $\beta$-catenin [254, 255]. Others argue that the response may be context dependent [256]. Also of interest, it was found that WNT5A antagonized the proliferation induced by Wnt/ $\beta$-catenin activation [257]. FOXP1 is a member of the FOX transcription factor family, and has been shown to be a therapeutic target in tumors in which it is overexpressed [258]. In contrast, low levels of FOXP1 expression in neuroblastoma correlates with a poor prognosis, and re-expression of the transcription factor significantly reduced tumor cell proliferation and diminished tumorigenicity [259]. While these genes have been linked to a functional therapeutic response in some cancer cell types, further pathway analysis is necessary to reveal novel mechanisms suggested by this initial screen.

Next, A375 ALDH ${ }^{\text {high }}$ cells treated with vehicle or Lunasin (Table 2) were compared in order to discriminate any specific genes targeted in this cell population as opposed to the parental A375 cell line. Several genes in which Lunasin had a modest effect were identified; many have been found to significantly contribute to melanoma progression and metastasis. Genes of interest identified in this study were FOXP1 (-1.46), AKT1 (-1.31), KAT2B (-1.30), ERBB2 (-1.28), TGFB3 (-1.25), FOS (1.31), TP73 (1.31), SMAD5 (1.35), IGF1R (1.38), RAC1 (1.43). In parental cells, FOXP1 was up-regulated while in CICs treated with Lunasin a significant down-regulation of the gene. AKT represents the major signaling protein of the PI3K/AKT pathway and has been discussed previously. A down-regulation in AKT expression would presumably confer an antisurvival signal, which may help explain why A375R cells were sensitized to vemurafenib in combination treatments (discussed in Chapter 3, page 48). Given its involvement in integrin signal transduction and regulation of histone acetylation machinery, these changes in expression of 
AKT signaling components were somewhat expected. KAT2B encodes for the PCAF protein, and directly regulates transcription as it has HAT activity. Again, these results are not surprising as Lunasin has been proposed to alter histone acetylation patterns; however, this is the first report that Lunasin may directly change gene expression of HATs. ERBB2/ERBB3 heterodimers (and its activator NRG1 [-1.26]) in melanoma has been shown to modulate AKT activation and promote cell growth, survival, and metastasis [260, 261]. The TGF- $\beta /$ Smad pathway regulates the progression and metastasis of melanoma [262]. The fact that SMAD5 is up-regulated while TGFB3 is down-regulated may suggest a mechanism for Smadindependent TGF- $\beta$ responses.

Finally, gene expression in untreated cells derived from parental A375 cells and ALDH ${ }^{\text {high }}$ A375 cells was compared in order to identify a unique gene set that was expressed in $\mathrm{ALDH}^{\text {high }}$ cells, but not in the parental line. Several genes associated with invasion and epithelial to mesenchymal transition (EMT) were upregulated in $\mathrm{ALDH}^{\text {high }}$ cells compared to parental cells (Table 3). Several genes of interest were identified including MMP13 (-1.82), BMP4 (1.27), SNAI1 (1.28), TGFB2 (1.31), WNT5A (1.33), SKI (1.33), SMAD6 (1.34), BCL2L11 (1.37), ETS1 (1.37), WNT11 (1.37), TLN2 (1.37), BCL2 (1.37), SMAD7 (1.37), MMP1 (1.39), EGFR (1.39), FN1 (1.44), JUN (1.46), JAG1 (1.59), SNAI2 (1.60), FOS (1.66), FOSB (1.80), and BMP2 (1.86). Several critical mediators of the TGF- $\beta$, BMP, and $\beta$-catenin signaling pathways were identified by analysis of the microarray dataset. These pathways have been implicated to regulate key processes involved in melanoma development and progression [263-265] indicating that the increased expression seen in $\mathrm{ALDH}^{\text {high }}$ cells may confer some selective advantage when invading and proliferating in distant tissue. FN1, the gene encoding fibronectin, was upregulated in ALDH ${ }^{\text {high }}$ cells when compared to parental cells, and is implicated in melanoma cell invasion [266]. Additionally, SNAI1 and SNAI2, regulators of EMT [267], are both upregulated in $\mathrm{ALDH}^{\text {high }}$ cells compared to parental cells. Interestingly, MMP-1 and MMP-13 are inversely affected. While MMP-1 has been implicated in melanoma invasion [268], MMP-13 has also been linked to metastasis [269] and may also mediate cell cycling [270]. Finally, the AP-1 transcription factor components, JUN and FOS (and FOSB) were upregulated in ALDH ${ }^{\text {high }}$ cells compared to the parental line. Despite their well-known connection to MAPK signaling [271], these proto-oncogenes have several functions in melanomas including metastatic dissemination and chemoresistance [272-274]. These data would indicate that ALDH ${ }^{\text {high }}$ cells express 
genes associated with melanoma progression through EMT, invasion, and proliferation which supports the function of ALDH as a biomarker for CICs in melanoma.

Principle component analysis (PCA) (Figure 28A) shows the disparity between gene signatures of parental A375 cells and ALDH-sorted populations. Additionally, Lunasin-treated ALDH ${ }^{\text {high }}$ cells appeared to deviate from vehicle-treated cells more so than when their parental counterparts were treated with Lunasin, despite having a similar trend. Sources of error were scored using mean F-ratio to assess the authenticity of the microarray analysis (Figure 28B). The greatest difference between groups came from the cell type, meaning the highest variance was between parental cells and ALDH-sorted populations. This demonstrates that $\mathrm{ALDH}{ }^{\text {high }}$ cells displayed a significantly altered gene signature from the parental A375 populations; this may potentially confirm the results discussed previously describing the upregulation of several genes associated with EMT, invasion, and stemness in $\mathrm{ALDH}^{\text {high }}$ cells when compared to parental populations. Treatment with Lunasin accounted for the second highest source of variation, followed by replicates and human error, respectively.

Table 1: Microarray dataset (threshold $=1.25, \mathrm{p}<0.05$ ) for parental A375

List Report

\begin{tabular}{|c|c|c|c|c|c|c|}
\hline $\begin{array}{l}\text { Network Object } \\
\text { Name }\end{array}$ & Gene Symbol & Gene Name & Object Type & Description & Signal & $\overline{p \text {-value }}$ \\
\hline Phospholamban & PLN & phospholamban & \begin{tabular}{|l} 
Generic binding \\
protein
\end{tabular} & Cardiac phospholamban & -1.44444 & 0.0206268 \\
\hline NF-AT & NFATC4 & nuclear factor of activated T-cells 4 & $\begin{array}{l}\text { Transcription } \\
\text { factor }\end{array}$ & & -1.42274 & 0.00795497 \\
\hline NF-AT3(NFATC4) & NFATC4 & nuclear factor of activated T-cells 4 & $\begin{array}{l}\text { Transcription } \\
\text { factor }\end{array}$ & $\begin{array}{l}\text { Nuclear factor of activated T-cells, } \\
\text { cytoplasmic } 4\end{array}$ & -1.42274 & 0.00795497 \\
\hline Arrestin 3 & ARR3 & arrestin 3 retinal (X-arrestin) & $\begin{array}{l}\text { Generic binding } \\
\text { protein }\end{array}$ & Arrestin-C & -1.40384 & 0.000620583 \\
\hline Desmin & DES & desmin & $\begin{array}{l}\text { Generic binding } \\
\text { protein }\end{array}$ & Desmin & -1.39849 & 0.00816461 \\
\hline GRAP2 & GRAP2 & GRB2-related adaptor protein 2 & $\begin{array}{l}\text { Generic binding } \\
\text { protein }\end{array}$ & GRB2-related adapter protein 2 & -1.39079 & 0.0330518 \\
\hline SIA7E & ST6GALNAC5 & $\begin{array}{l}\text { ST6 N-acetylgalactosaminide alpha-2,6- } \\
\text { sialyltransferase } 5\end{array}$ & Generic enzyme & $\begin{array}{l}\text { Alpha-N-acetylgalactosaminide } \\
\text { alpha-2,6-sialyltransferase 5 }\end{array}$ & -1.38735 & 0.00809087 \\
\hline Calpain 10 & CAPN10 & calpain 10 & Generic protease & Calpain-10 & -1.38007 & 0.0309494 \\
\hline G3ST3 & GAL3ST3 & galactose-3-O-sulfotransferase 3 & Generic enzyme & Galactose-3-O-sulfotransferase 3 & -1.35473 & 0.00908722 \\
\hline Epiregulin & EREG & epiregulin & Protein & Proepiregulin & -1.35302 & 0.0101828 \\
\hline MKK7 (MAP2K7) & MAP2K7 & mitogen-activated protein kinase kinase 7 & Protein kinase & \begin{tabular}{|l|} 
Dual specificity mitogen-activated \\
protein kinase kinase 7
\end{tabular} & -1.33896 & 0.00316078 \\
\hline \begin{tabular}{|l} 
ABO system \\
transferase
\end{tabular} & $\mathrm{ABO}$ & $\begin{array}{l}\text { ABO blood group (transferase A, alpha 1-3-N- } \\
\text { acetylgalactosaminyltransferase; transferase B, } \\
\text { alpha 1-3galactosyltransferase) }\end{array}$ & Generic enzyme & $\begin{array}{l}\text { Histo-blood group } \mathrm{ABO} \text { system } \\
\text { transferase }\end{array}$ & -1.33629 & 0.0348191 \\
\hline CalDAG-GEFII & RASGRP1 & RAS guanyl releasing protein 1 & $\begin{array}{l}\text { Regulators (GDI, } \\
\text { GAP, GEF) }\end{array}$ & RAS guanyl-releasing protein 1 & -1.3217 & 0.0466738 \\
\hline
\end{tabular}




\begin{tabular}{|c|c|c|c|c|c|c|}
\hline $\mathrm{ACACB}$ & ACACB & acetyl-CoA carboxylase beta & Protein & Acetyl-CoA carboxylase 2 & -1.31886 & 0.0146277 \\
\hline ACE1 & ACE & angiotensin I converting enzyme & Generic protease & Angiotensin-converting enzyme & -1.31409 & 0.0139762 \\
\hline p38 MAPK & MAPK11 & mitogen-activated protein kinase 11 & Protein kinase & & -1.30969 & 0.0162317 \\
\hline p38beta (MAPK11) & MAPK11 & mitogen-activated protein kinase 11 & Protein kinase & $\begin{array}{l}\text { Mitogen-activated protein kinase } \\
\underline{11}\end{array}$ & -1.30969 & 0.0162317 \\
\hline BAIAP2 & BAIAP2 & BAl1 associated protein 2 & $\begin{array}{l}\text { Generic binding } \\
\text { protein }\end{array}$ & \begin{tabular}{|l} 
Brain-specific angiogenesis \\
inhibitor 1-associated protein 2 \\
\end{tabular} & -1.30952 & 0.00163325 \\
\hline $\begin{array}{l}\text { Galpha(s)-specific } \\
\text { amine } \\
\text { GPCRs }\end{array}$ & $\underline{\mathrm{HRH} 2}$ & histamine receptor $\mathrm{H} 2$ & Generic receptor & & -1.29861 & 0.0393267 \\
\hline Tissue kallikreins & $\underline{\text { KLK10 }}$ & kallikrein related peptidase 10 & Generic protease & & -1.29669 & 0.0358496 \\
\hline RARalpha & RARA & retinoic acid receptor alpha & $\begin{array}{l}\text { Transcription } \\
\text { factor }\end{array}$ & Retinoic acid receptor alpha & -1.28836 & 0.00247536 \\
\hline WNT & WNT3A & Wnt family member $3 \mathrm{~A}$ & Receptor ligand & & -1.28404 & 0.0302277 \\
\hline WNT3A & WNT3A & Wnt family member $3 \mathrm{~A}$ & Receptor ligand & Protein Wnt-3a & -1.28404 & 0.0302277 \\
\hline \begin{tabular}{|l|} 
L-type $\quad \mathrm{Ca}(\mathrm{II})$ \\
channel, alpha 1C \\
subunit \\
\end{tabular} & CACNA1C & calcium voltage-gated channel subunit alpha1 C & $\begin{array}{l}\text { Voltage-gated ion } \\
\text { channel }\end{array}$ & $\begin{array}{l}\text { Voltage-dependent I-type calcium } \\
\text { channel subunit alpha-1C }\end{array}$ & -1.27809 & 0.0123255 \\
\hline WNT & WNT5A & Wnt family member $5 \mathrm{~A}$ & Receptor ligand & & -1.2726 & 0.00115524 \\
\hline WNT5A & WNT5A & Wnt family member $5 \mathrm{~A}$ & Receptor ligand & Protein Wnt-5a & -1.2726 & 0.00115524 \\
\hline RARgamma & RARG & retinoic acid receptor gamma & Transcription factor & Retinoic acid receptor gamma & -1.2701 & 0.00193338 \\
\hline HXK4 & GCK & glucokinase & Generic kinase & Glucokinase & -1.26848 & 0.00158031 \\
\hline Tissue kallikreins & KLK12 & kallikrein related peptidase 12 & Generic protease & & -1.26669 & 0.0488501 \\
\hline HGF & HGF & hepatocyte growth factor & Receptor ligand & Hepatocyte growth factor & -1.26587 & 0.0187103 \\
\hline NR1 & GRIN1 & glutamate ionotropic receptor NMDA type subunit 1 & $\begin{array}{l}\text { Ligand-gated ion } \\
\text { channel }\end{array}$ & $\begin{array}{l}\text { Glutamate receptor ionotropic, } \\
\text { NMDA 1 }\end{array}$ & -1.26439 & 0.0494182 \\
\hline CYP4F2 & CYP4F2 & cytochrome P450 family 4 subfamily F member 2 & Generic enzyme & $\begin{array}{l}\text { Phylloquinone omega-hydroxylase } \\
\text { CYP4F2 }\end{array}$ & -1.26402 & 0.00367679 \\
\hline c-Maf & MAF & MAF bZIP transcription factor & Transcription factor & Transcription factor Maf & -1.26355 & 0.0364182 \\
\hline IGH@ & $\underline{\mathrm{IGH}}$ & immunoglobulin heavy locus & Receptor ligand & immunoglobulin heavy locus & -1.26164 & 0.0240856 \\
\hline Synaptotagmin VII & SYT7 & synaptotagmin 7 & Protein & Synaptotagmin-7 & -1.26021 & 0.0222702 \\
\hline Sirtuin6 & SIRT6 & sirtuin 6 & Generic enzyme & $\begin{array}{l}\text { NAD-dependent protein } \\
\text { deacetylase sirtuin-6 }\end{array}$ & -1.25989 & 0.0426655 \\
\hline$\underline{\mathrm{IRF5}}$ & IRF5 & interferon regulatory factor 5 & Transcription factor & Interferon regulatory factor 5 & -1.25985 & 0.0210335 \\
\hline PLC-delta & PLCD3 & phospholipase $\mathrm{C}$ delta 3 & $\begin{array}{l}\text { Generic } \\
\text { phospholipase }\end{array}$ & & -1.25942 & 0.0122591 \\
\hline GRK6 & GRK6 & G protein-coupled receptor kinase 6 & Protein kinase & $\underline{\underline{G} \text { protein-coupled receptor kinase }}$ & -1.25853 & 0.0138678 \\
\hline GLUT2 & SLC2A2 & solute carrier family 2 member 2 & Transporter & $\begin{array}{l}\text { Solute carrier family 2, facilitated } \\
\text { glucose transporter member } 2\end{array}$ & -1.25405 & 0.0335012 \\
\hline PP2A regulatory & PPP2R5D & protein phosphatase 2 regulatory subunit B'delta & $\begin{array}{l}\text { Generic binding } \\
\text { protein }\end{array}$ & & -1.21491 & 0.0285902 \\
\hline Tissue kallikreins & KLK7 & kallikrein related peptidase 7 & Generic protease & & -1.19423 & 0.0352611 \\
\hline
\end{tabular}




\begin{tabular}{|c|c|c|c|c|c|c|}
\hline Tissue kallikreins & KLK6 & kallikrein related peptidase 6 & Generic protease & & -1.18227 & 0.0432625 \\
\hline NF-AT & NFAT5 & $\begin{array}{l}\text { nuclear factor of activated T-cells 5, tonicity- } \\
\text { responsive }\end{array}$ & Transcription factor & & -1.17732 & 0.0265163 \\
\hline Tubulin alpha & TUBA3C & tubulin alpha 3c & $\begin{array}{l}\text { Generic binding } \\
\text { protein }\end{array}$ & & -1.14922 & 0.0266541 \\
\hline Tubulin alpha & TUBA3D & tubulin alpha $3 d$ & $\begin{array}{l}\text { Generic binding } \\
\text { protein }\end{array}$ & & -1.14922 & 0.0266541 \\
\hline $\begin{array}{l}\text { Galpha(s)-specific } \\
\text { amine } \\
\text { GPCRs }\end{array}$ & HTR7 & 5-hydroxytryptamine receptor 7 & Generic receptor & & -1.11885 & 0.0112545 \\
\hline NF-AT & NFATC2 & nuclear factor of activated T-cells 2 & Transcription factor & & 1.06543 & 0.0432984 \\
\hline PLC-beta & PLCB1 & phospholipase C beta 1 & $\begin{array}{l}\text { Generic } \\
\text { phospholipase }\end{array}$ & & 1.18758 & 0.0301776 \\
\hline MUNC13-1 & UNC13A & unc-13 homolog A (C. elegans) & $\begin{array}{l}\text { Generic binding } \\
\text { protein }\end{array}$ & Protein unc-13 homolog A & 1.25565 & 0.0376234 \\
\hline PARD6 & PARD6B & par-6 family cell polarity regulator beta & $\begin{array}{l}\text { Generic binding } \\
\text { protein }\end{array}$ & & 1.25711 & 0.0376021 \\
\hline P2Y1 & P2RY1 & purinergic receptor $\mathrm{P} 2 \mathrm{Y} 1$ & GPCR & P2Y purinoceptor 1 & 1.27086 & $9.23061 \mathrm{E}-05$ \\
\hline Heme oxygenase 1 & $1 \mathrm{HMOX1}$ & heme oxygenase 1 & Generic enzyme & Heme oxygenase 1 & 1.27173 & 0.000507197 \\
\hline $\mathrm{p} 130$ & RBL2 & RB transcriptional corepressor like 2 & $\begin{array}{l}\text { Generic binding } \\
\text { protein }\end{array}$ & Retinoblastoma-like protein 2 & 1.28053 & 0.0362018 \\
\hline CACNA1D & CACNA1D & calcium voltage-gated channel subunit alpha1 D & $\begin{array}{l}\text { Voltage-gated ion } \\
\text { channel }\end{array}$ & $\begin{array}{l}\text { Voltage-dependent L-type calcium } \\
\text { channel subunit alpha-1D }\end{array}$ & 1.29206 & 0.00864385 \\
\hline PACAP & ADCYAP1 & adenylate cyclase activating polypeptide 1 & Receptor ligand & 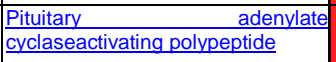 & 1.31848 & 0.0327697 \\
\hline GCL reg & GCLM & glutamate-cysteine ligase modifier subunit & Generic enzyme & \begin{tabular}{|l|l|} 
Glutamate--cysteine & ligase \\
regulatory subunit &
\end{tabular} & 1.32293 & 0.00125117 \\
\hline TLR1 & TLR1 & toll like receptor 1 & Generic receptor & Toll-like receptor 1 & 1.32839 & 0.0275434 \\
\hline Tubulin alpha & EHHADH & $\begin{array}{l}\text { enoyl-CoA, hydratase/3-hydroxyacyl CoA } \\
\text { dehydrogenase }\end{array}$ & $\begin{array}{l}\text { Generic binding } \\
\text { protein }\end{array}$ & & 1.32991 & 0.00604937 \\
\hline$\underline{\mathrm{Sec} 8}$ & EXOC4 & exocyst complex component 4 & $\begin{array}{l}\text { Generic binding } \\
\text { protein }\end{array}$ & Exocyst complex component 4 & 1.33531 & 0.033613 \\
\hline $\begin{array}{l}\text { AMPK alpha } \\
\text { subunit }\end{array}$ & PRKAA1 & $\begin{array}{l}\text { protein kinase AMP-activated catalytic subunit } \\
\text { alpha } 1\end{array}$ & Protein kinase & & 1.36607 & 0.00164903 \\
\hline PLC-beta & PLCB4 & phospholipase C beta 4 & $\begin{array}{l}\text { Generic } \\
\text { phospholipase }\end{array}$ & & 1.37036 & 0.00733205 \\
\hline$\underline{\text { Carboxypeptidase }}$ & CPM & carboxypeptidase M & Generic protease & Carboxypeptidase M & 1.37297 & 0.0184119 \\
\hline LAMP2 & LAMP2 & lysosomal associated membrane protein 2 & $\begin{array}{l}\text { Generic binding } \\
\text { protein }\end{array}$ & $\begin{array}{l}\text { Lysosome-associated membrane } \\
\text { glycoprotein } 2\end{array}$ & 1.38197 & 0.0109799 \\
\hline EGF & EGF & epidermal growth factor & Receptor ligand & Pro-epidermal growth factor & 1.38549 & 0.0313874 \\
\hline PP2A regulatory & PPP2R2B & protein phosphatase 2 regulatory subunit Bbeta & $\begin{array}{l}\text { Generic binding } \\
\text { protein }\end{array}$ & & 1.39363 & 0.00776675 \\
\hline RECK & RECK & $\begin{array}{l}\text { reversion inducing cysteine rich protein with kazal } \\
\text { motifs }\end{array}$ & $\begin{array}{l}\text { Generic binding } \\
\text { protein }\end{array}$ & $\begin{array}{l}\text { Reversion-inducing cysteine-rich } \\
\text { protein with Kazal motifs }\end{array}$ & 1.40929 & 0.00514642 \\
\hline 70Z-PEP & PTPN22 & protein tyrosine phosphatase, non-receptor type 22 & $\begin{array}{l}\text { Protein } \\
\text { phosphatase }\end{array}$ & $\begin{array}{l}\text { Tyrosine-protein phosphatase } \\
\text { nonreceptor type 22 }\end{array}$ & 1.47127 & 0.00577936 \\
\hline FOXP1 & FOXP1 & forkhead box P1 & Transcription factor & Forkhead box protein P1 & 1.52131 & 0.00252521 \\
\hline
\end{tabular}


Table 2: Microarray dataset (threshold $=1.25, \mathrm{p}<0.05$ ) for ALDH-high A375 cells

List Report

\begin{tabular}{|c|c|c|c|c|c|c|}
\hline $\begin{array}{l}\text { Network Object } \\
\text { Name }\end{array}$ & $\begin{array}{c}\text { Gene } \\
\text { Symbol }\end{array}$ & Gene Name & Object Type & Description & Signal & p-value \\
\hline Protein kinase G & PRKG1 & protein kinase, cGMP-dependent, type I & Protein kinase & & -1.5701 & 0.00337114 \\
\hline FOXP1 & FOXP1 & forkhead box P1 & Transcription factor & Forkhead box protein P1 & -1.46271 & 0.0125002 \\
\hline KCRU & CKMT1A & creatine kinase, mitochondrial $1 \mathrm{~A}$ & Generic kinase & Creatine kinase U-type, mitochondrial & -1.45383 & 0.00150056 \\
\hline KCRU & CKMT1B & creatine kinase, mitochondrial 1B & Generic kinase & Creatine kinase U-type, mitochondrial & -1.45383 & 0.00150056 \\
\hline PP2A regulatory & PTPA & $\begin{array}{l}\text { protein phosphatase } 2 \text { phosphatase } \\
\text { activator }\end{array}$ & $\begin{array}{l}\text { Generic binding } \\
\text { protein }\end{array}$ & & -1.42442 & 0.00947514 \\
\hline CARD8 & CARD8 & $\begin{array}{l}\text { caspase recruitment domain family } \\
\text { member } 8\end{array}$ & $\begin{array}{l}\text { Generic binding } \\
\text { protein }\end{array}$ & $\begin{array}{l}\text { Caspase recruitment domain-containing } \\
\text { protein } 8\end{array}$ & -1.40269 & 0.00466734 \\
\hline Bim & BCL2L11 & BCL2 like 11 & $\begin{array}{l}\text { Generic binding } \\
\text { protein }\end{array}$ & Bcl-2-like protein 11 & -1.3764 & 0.0226245 \\
\hline MSP & MST1 & macrophage stimulating 1 & Receptor ligand & Hepatocyte growth factorlike protein & -1.3685 & 0.0243488 \\
\hline Schwannomin (NF2) & $\mathrm{NF2}$ & neurofibromin 2 (merlin) & $\begin{array}{l}\text { Generic binding } \\
\text { protein }\end{array}$ & Merlin & -1.36212 & 0.0331648 \\
\hline MEK6(MAP2K6) & MAP2K6 & $\begin{array}{l}\text { mitogen-activated protein kinase kinase } \\
6\end{array}$ & Protein kinase & $\begin{array}{l}\text { Dual specificity mitogenactivated protein } \\
\text { kinase kinase } 6\end{array}$ & -1.34109 & 0.0465563 \\
\hline CAMP-GEFII & RAPGEF4 & $\begin{array}{l}\text { Rap guanine nucleotide exchange factor } \\
4\end{array}$ & $\begin{array}{l}\text { Regulators (GDI, } \\
\text { GAP, GEF) }\end{array}$ & Rap guanine nucleotide exchange factor 4 & -1.33651 & 0.0162899 \\
\hline CNTN1 (F3) & CNTN1 & contactin 1 & $\begin{array}{l}\text { Generic binding } \\
\text { protein }\end{array}$ & Contactin-1 & -1.3314 & 0.0458024 \\
\hline Intersectin & ITSN1 & intersectin 1 & $\begin{array}{l}\text { Regulators (GDI, } \\
\text { GAP, GEF) }\end{array}$ & Intersectin-1 & -1.32506 & 0.000236297 \\
\hline NALP2 & NLRP2 & NLR family pyrin domain containing 2 & $\begin{array}{l}\text { Generic binding } \\
\text { protein }\end{array}$ & $\begin{array}{l}\text { NACHT, LRR and PYD } \\
\text { domains-containing protein } 2 \\
\end{array}$ & -1.3211 & 0.00221173 \\
\hline GP-IB alpha & GP1BA & glycoprotein Ib platelet alpha subunit & GPCR & Platelet glycoprotein Ib alpha chain & -1.31542 & 0.0457474 \\
\hline GAB2 & GAB2 & GRB2 associated binding protein 2 & $\begin{array}{l}\text { Generic binding } \\
\text { protein }\end{array}$ & GRB2-associated-binding protein 2 & -1.31488 & 0.0380525 \\
\hline CD70(TNFSF7) & CD70 & CD70 molecule & Receptor ligand & CD70 antigen & -1.30677 & 0.0111134 \\
\hline AKT(PKB) & AKT1 & AKT serine/threonine kinase 1 & Protein kinase & & -1.30416 & 0.000226758 \\
\hline AKT1 & AKT1 & AKT serine/threonine kinase 1 & Protein kinase & BAC-alpha serine/threonineprotein kinase & -1.30416 & 0.000226758 \\
\hline HIVEP2 & HIVEP2 & $\begin{array}{l}\text { human immunodeficiency virus type I } \\
\text { enhancer binding protein } 2\end{array}$ & Transcription factor & $\begin{array}{l}\text { Transcription factor } \\
\text { HIVEP2 }\end{array}$ & -1.29905 & 0.00355775 \\
\hline Ephrin-A receptors & EPHA3 & EPH receptor $A 3$ & Generic receptor & & -1.29764 & 0.000542762 \\
\hline PCAF & KAT2B & lysine acetyltransferase 2B & Generic enzyme & $\begin{array}{l}\text { Histone acetyltransferase } \\
\text { KAT2B }\end{array}$ & -1.29653 & 0.00198854 \\
\hline $\begin{array}{l}\text { PPARGC1 (PGC1- } \\
\text { alpha) }\end{array}$ & PPARGC1A & PPARG coactivator 1 alpha & $\begin{array}{l}\text { Generic binding } \\
\text { protein }\end{array}$ & $\begin{array}{l}\text { Peroxisome proliferatoractivated receptor } \\
\text { gamma coactivator 1-alpha }\end{array}$ & -1.29602 & 0.0191075 \\
\hline B-chimaerin & $\mathrm{CHN} 2$ & chimerin 2 & $\begin{array}{l}\text { Regulators (GDI, } \\
\text { GAP, GEF) }\end{array}$ & Beta-chimaerin & -1.29129 & 0.0233722 \\
\hline ELF5 & ELF5 & E74 like ETS transcription factor 5 & Transcription factor & ETS-related transcription factor Elf-5 & -1.29026 & 0.0487005 \\
\hline Ephrin-B receptor 1 & EPHB1 & EPH receptor $\mathrm{B} 1$ & $\begin{array}{l}\text { Receptor with } \\
\text { enzyme activity }\end{array}$ & Ephrin type-B receptor 1 & -1.28997 & 0.0450225 \\
\hline Ephrin-B receptors & EPHB1 & EPH receptor B1 & Generic receptor & & -1.28997 & 0.0450225 \\
\hline
\end{tabular}




\begin{tabular}{|c|c|c|c|c|c|c|}
\hline PP2A regulatory & PPP2R5D & $\begin{array}{l}\text { protein phosphatase } 2 \text { regulatory } \\
\text { subunit B'delta }\end{array}$ & $\begin{array}{l}\text { Generic binding } \\
\text { protein }\end{array}$ & & -1.28952 & 0.00831128 \\
\hline MSK1 & RPS6KA5 & ribosomal protein S6 kinase A5 & Protein kinase & Ribosomal protein S6 kinase alpha-5 & -1.28643 & 0.0290961 \\
\hline $\begin{array}{l}\text { MSK1/2 } \\
\text { (RPS6KA5/4) } \\
\end{array}$ & RPS6KA5 & ribosomal protein S6 kinase A5 & Protein kinase & & -1.28643 & 0.0290961 \\
\hline MNK1 & MKNK1 & $\begin{array}{l}\text { MAP kinase interacting serine/threonine } \\
\text { kinase } 1\end{array}$ & Protein kinase & $\begin{array}{l}\text { MAP kinase-interacting serine/threonine- } \\
\text { protein kinase } 1\end{array}$ & -1.28634 & 0.00102042 \\
\hline ErbB2 & ERBB2 & erb-b2 receptor tyrosine kinase 2 & \begin{tabular}{|l|} 
Receptor with \\
enzyme activity
\end{tabular} & Receptor tyrosine-protein kinase erbB-2 & -1.28262 & 0.0183775 \\
\hline IGHG1 & IGHG1 & $\begin{array}{l}\text { immunoglobulin heavy constant gamme } \\
1 \text { (G1m marker) }\end{array}$ & a Receptor ligand & Ig gamma-1 chain $\mathrm{C}$ region & -1.27369 & 0.00748698 \\
\hline elF4A & ElF4A1 & $\begin{array}{l}\text { eukaryotic translation initiation factor } \\
\text { 4A1 }\end{array}$ & Generic enzyme & & -1.27351 & 0.0120587 \\
\hline CARD7 & NLRP1 & NLR family pyrin domain containing 1 & $\begin{array}{l}\text { Generic binding } \\
\text { protein }\end{array}$ & $\begin{array}{l}\text { NACHT, LRR and PYD } \\
\text { domains-containing protein } 1\end{array}$ & -1.27181 & 0.0355684 \\
\hline DR5(TNFRSF10B) & TNFRSF10B & $\begin{array}{l}\text { tumor necrosis factor receptor } \\
\text { superfamily member } 10 \mathrm{~b}\end{array}$ & $\begin{array}{l}\text { Receptor with } \\
\text { enzyme activity }\end{array}$ & $\begin{array}{l}\text { Tumor necrosis factor } \\
\text { receptor superfamily member } 10 \mathrm{~B}\end{array}$ & -1.26909 & 0.000643637 \\
\hline ADAM17 & ADAM17 & ADAM metallopeptidase domain 17 & Metalloprotease & $\begin{array}{l}\text { Disintegrin and } \quad \text { metalloproteinase } \\
\text { domaincontaining protein } 17\end{array}$ & -1.26776 & 0.0033431 \\
\hline CD36 & CD36 & CD36 molecule & Generic receptor & Platelet glycoprotein 4 & -1.26623 & 0.018395 \\
\hline IL4RA & IL4R & interleukin 4 receptor & Generic receptor & Interleukin-4 receptor subunit alpha & -1.26512 & 0.0191704 \\
\hline NKG2A & KLRC1 & killer cell lectin like receptor C1 & Generic receptor & $\begin{array}{l}\text { NKG2-A/NKG2-B type II integral membrane } \\
\text { protein }\end{array}$ & -1.26289 & 0.0334868 \\
\hline GRB10 & GRB10 & growth factor receptor bound protein 10 & $\begin{array}{l}\text { Generic binding } \\
\text { protein }\end{array}$ & Growth factor receptorbound protein 10 & -1.26127 & 0.0157259 \\
\hline FKHR & FOXO1 & forkhead box $\mathrm{O} 1$ & Transcription factor & Forkhead box protein $\mathrm{O} 1$ & -1.25939 & 0.00206426 \\
\hline Neurotractin & NEGR1 & neuronal growth regulator 1 & $\begin{array}{l}\text { Generic binding } \\
\text { protein }\end{array}$ & Neuronal growth regulator 1 & -1.25895 & 0.00424239 \\
\hline Neuregulin 1 & NRG1 & neuregulin 1 & Receptor ligand & Pro-neuregulin-1, membrane-bound isoform & -1.25677 & 0.0236608 \\
\hline CLIP3 & CLIP3 & $\begin{array}{l}\text { CAP-Gly domain containing linker } \\
\text { protein } 3\end{array}$ & Protein & CAP-Gly domain-containing linker protein 3 & -1.25409 & 0.00303439 \\
\hline HGF & $\mathrm{HGF}$ & hepatocyte growth factor & Receptor ligand & Hepatocyte growth factor & -1.25234 & 0.0229854 \\
\hline TGF-beta & TGFB3 & transforming growth factor beta 3 & Receptor ligand & & -1.25052 & 0.00532903 \\
\hline Ephrin-A receptors & EPHA4 & EPH receptor $\mathrm{A} 4$ & Generic receptor & & -1.2152 & 0.0120193 \\
\hline Adenylate cyclase & ADCY7 & adenylate cyclase 7 & Generic enzyme & & -1.192 & 0.0181893 \\
\hline elF4G1/3 & EIF4G1 & $\begin{array}{l}\text { eukaryotic translation initiation factor } 4 \\
\text { gamma } 1\end{array}$ & $\begin{array}{l}\text { Generic binding } \\
\text { protein }\end{array}$ & & -1.11566 & 0.0103837 \\
\hline $\mathrm{AKT}(\mathrm{PKB})$ & AKT2 & AKT serine/threonine kinase 2 & Protein kinase & & -1.10513 & 0.00858131 \\
\hline MHC class I & HLA-E & $\begin{array}{l}\text { major histocompatibility complex, class } \\
\text { I, E }\end{array}$ & Generic receptor & & -1.10479 & 0.0367323 \\
\hline HSP90 & HSP90AB1 & $\begin{array}{l}\text { heat shock protein 90kDa alpha family } \\
\text { class B member } 1\end{array}$ & $\begin{array}{l}\text { Generic binding } \\
\text { protein }\end{array}$ & & -1.02524 & 0.0469378 \\
\hline $\mathrm{AKT}(\mathrm{PKB})$ & AKT3 & AKT serine/threonine kinase 3 & Protein kinase & & 1.08838 & 0.0379968 \\
\hline $14-3-3$ & YWHAQ & $\begin{array}{l}\text { tyrosine 3-monooxygenase/tryptophan } \\
5 \text { monooxygenase activation protein } \\
\text { theta }\end{array}$ & $\begin{array}{l}\text { Generic binding } \\
\text { protein }\end{array}$ & & 1.09529 & 0.000338352 \\
\hline $14-3-3$ & YWHAE & $\begin{array}{l}\text { tyrosine 3-monooxygenase/tryptophan } \\
\text { 5monooxygenase activation protein } \\
\text { epsilon }\end{array}$ & $\begin{array}{l}\text { Generic binding } \\
\text { protein }\end{array}$ & & 1.1424 & 0.005047 \\
\hline
\end{tabular}




\begin{tabular}{|c|c|c|c|c|c|c|}
\hline$\underline{14-3-3}$ & YWHAG & $\begin{array}{l}\text { tyrosine 3-monooxygenase/tryptophan } \\
\text { 5monooxygenase activation protein } \\
\text { gamma }\end{array}$ & $\begin{array}{l}\text { Generic binding } \\
\text { protein }\end{array}$ & & 1.14443 & 0.0106333 \\
\hline$\underline{M R L C}$ & MYL12A & myosin light chain 12A & $\begin{array}{l}\text { Generic binding } \\
\text { protein }\end{array}$ & & 1.14548 & 0.00470967 \\
\hline PP2A regulatory & PPP2R5E & $\begin{array}{l}\text { protein phosphatase } 2 \text { regulatory } \\
\text { subunit B'epsilon }\end{array}$ & $\begin{array}{l}\text { Generic binding } \\
\text { protein }\end{array}$ & & 1.18192 & 0.0478546 \\
\hline$\underline{\text { HSP90 }}$ & HSP90AA1 & $\begin{array}{l}\text { heat shock protein 90kDa alpha family } \\
\text { class A member } 1\end{array}$ & $\begin{array}{l}\text { Generic binding } \\
\text { protein }\end{array}$ & & 1.21348 & 0.00543915 \\
\hline Ephrin-A receptors & EPHA5 & EPH receptor A5 & Generic receptor & & 1.23325 & 0.00135816 \\
\hline MHC class I & HLA-G & $\begin{array}{l}\text { major histocompatibility complex, class } \\
\text { I, G }\end{array}$ & Generic receptor & & 1.23695 & 0.0262767 \\
\hline NGF & NGF & nerve growth factor & Receptor ligand & Beta-nerve growth factor & 1.25368 & 0.0133639 \\
\hline Adenylate cyclase & ADCY8 & adenylate cyclase 8 (brain) & Generic enzyme & & 1.25427 & 0.0112251 \\
\hline \begin{tabular}{|l|} 
Adenylate cyclase \\
type VIII
\end{tabular} & ADCY8 & adenylate cyclase 8 (brain) & Generic enzyme & Adenylate cyclase type 8 & 1.25427 & 0.0112251 \\
\hline Brca2 & BRCA2 & BRCA2, DNA repair associated & $\begin{array}{l}\text { Generic binding } \\
\text { protein }\end{array}$ & Breast cancer type 2 susceptibility protein & 1.25438 & 0.000775725 \\
\hline$\underline{A B R}$ & $\underline{A B R}$ & active BCR-related & $\begin{array}{l}\text { Regulators (GDI, } \\
\text { GAP, GEF) }\end{array}$ & $\begin{array}{l}\text { Active breakpoint cluster region-related } \\
\text { protein }\end{array}$ & 1.25461 & 0.00190559 \\
\hline$\underline{\underline{L R R K 2}}$ & LRRK2 & leucine rich repeat kinase 2 & Protein kinase & 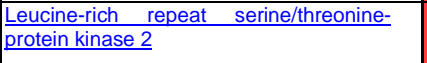 & 1.2566 & 0.00710897 \\
\hline SMAD1 & SMAD1 & SMAD family member 1 & Transcription factor & Mothers against decapentaplegic homolog 1 & 1.25784 & 0.00175723 \\
\hline RacGAP1 & RACGAP1 & Rac GTPase activating protein 1 & $\begin{array}{l}\text { Regulators (GDI, } \\
\text { GAP, GEF) }\end{array}$ & Rac GTPase-activating protein 1 & 1.26471 & 0.00486122 \\
\hline EBP50 & SLC9A3R1 & SLC9A3 regulator 1 & $\begin{array}{l}\text { Generic binding } \\
\text { protein }\end{array}$ & $\begin{array}{l}\frac{\mathrm{Na}(+) / \mathrm{H}(+) \text { exchange }}{\text { regulatory cofactor NHE- }} \\
\mathrm{RF1}\end{array}$ & 1.26562 & 0.00298857 \\
\hline E3b1(ABI-1) & $\mathrm{ABI} 1$ & abl interactor 1 & $\begin{array}{l}\text { Generic binding } \\
\text { protein }\end{array}$ & Abl interactor 1 & 1.26599 & 0.000897763 \\
\hline Cathepsin B & CTSB & cathepsin B & Generic protease & Cathepsin B & 1.26656 & 0.0253929 \\
\hline$\underline{P 2 \times 7}$ & P2RX7 & purinergic receptor P2X 7 & $\begin{array}{l}\text { Ligand-gated ion } \\
\text { channel }\end{array}$ & P2X purinoceptor 7 & 1.26689 & 0.0271523 \\
\hline CREB1 & CREB1 & $\begin{array}{l}\text { cAMP responsive element binding } \\
\text { protein } 1\end{array}$ & Transcription factor & $\begin{array}{l}\text { Cyclic AMP-responsive element-binding } \\
\text { protein } 1\end{array}$ & 1.26771 & 0.00371316 \\
\hline elF4B & EIF4B & eukaryotic translation initiation factor 4B & $\begin{array}{l}\text { Generic binding } \\
\text { protein }\end{array}$ & Eukaryotic translation initiation factor $4 \mathrm{~B}$ & 1.26771 & 0.0362407 \\
\hline p18 & CDKN2C & cyclin dependent kinase inhibitor $2 \mathrm{C}$ & $\begin{array}{l}\text { Generic binding } \\
\text { protein }\end{array}$ & Cyclin-dependent kinase 4 inhibitor $\mathrm{C}$ & 1.27536 & 0.00174692 \\
\hline OATP-A & $\underline{\text { SLCO1A2 }}$ & $\begin{array}{l}\text { solute carrier organic anion transporter } \\
\text { family member } 1 \mathrm{~A} 2\end{array}$ & Transporter & $\begin{array}{l}\text { Solute carrier organic anion } \\
\text { transporter family member } 1 \mathrm{~A} 2\end{array}$ & 1.2768 & 0.0127423 \\
\hline PP2A regulatory & PPP2R5B & $\begin{array}{l}\text { protein phosphatase } 2 \text { regulatory } \\
\text { subunit B'beta }\end{array}$ & $\begin{array}{l}\text { Generic binding } \\
\text { protein }\end{array}$ & & 1.28013 & 0.028923 \\
\hline Rictor & RICTOR & $\begin{array}{l}\text { RPTOR independent companion of } \\
\text { MTOR complex } 2\end{array}$ & $\begin{array}{l}\text { Generic binding } \\
\text { protein }\end{array}$ & Rapamycin-insensitive companion of mTOR & 1.28306 & 0.00299417 \\
\hline Perforin & PRF1 & perforin 1 & Transporter & Perforin-1 & 1.28693 & 0.0356184 \\
\hline$\underline{\text { KAP3 }}$ & KIFAP3 & kinesin associated protein 3 & $\begin{array}{l}\text { Generic binding } \\
\text { protein }\end{array}$ & Kinesin-associated protein 3 & 1.28759 & 0.00119856 \\
\hline$\underline{A L P L}$ & $\underline{A L P L}$ & alkaline phosphatase, liver/bone/kidney & Generic phosphatase & 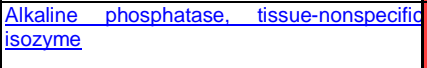 & 1.29131 & 0.0245732 \\
\hline Tob1 & TOB1 & transducer of ERBB2, 1 & $\begin{array}{l}\text { Generic binding } \\
\text { protein }\end{array}$ & Protein Tob1 & 1.29203 & 0.00351566 \\
\hline$\underline{\mathrm{CCL} 2}$ & $\underline{\mathrm{CCL} 2}$ & C-C motif chemokine ligand 2 & Receptor ligand & C-C motif chemokine 2 & 1.29588 & 0.0249862 \\
\hline
\end{tabular}




\begin{tabular}{|c|c|c|c|c|c|c|}
\hline MR-GEF & RAPGEF5 & $\begin{array}{l}\text { Rap guanine nucleotide exchange } \\
\text { factor } 5\end{array}$ & $\begin{array}{l}\text { Regulators (GDI, } \\
\text { GAP, GEF) }\end{array}$ & Rap guanine nucleotide exchange factor 5 & 1.29627 & 0.0364294 \\
\hline STK4 & STK4 & serine/threonine kinase 4 & Protein kinase & Serine/threonine-protein kinase 4 & 1.2963 & 0.0067006 \\
\hline RHAMM & HMMR & hyaluronan mediated motility receptor & Generic receptor & Hyaluronan mediated motility receptor & 1.29916 & 0.00116314 \\
\hline RhoGAP5 & ARHGAP5 & Rho GTPase activating protein 5 & $\begin{array}{l}\text { Regulators (GDI, } \\
\text { GAP, GEF) }\end{array}$ & Rho GTPase-activating protein 5 & 1.29932 & 0.00320296 \\
\hline SOD2 & $\underline{\mathrm{SOD} 2}$ & superoxide dismutase 2, mitochondrial & Generic enzyme & Superoxide dismutase [Mn], mitochondrial & 1.30008 & 0.000133145 \\
\hline PARP-1 & PARP1 & poly(ADP-ribose) polymerase 1 & Generic enzyme & Poly [ADP-ribose] polymerase 1 & 1.3017 & 0.0167984 \\
\hline MPP5 & MPP5 & membrane palmitoylated protein 5 & $\begin{array}{l}\text { Generic binding } \\
\text { protein }\end{array}$ & MAGUK p55 subfamily member 5 & 1.30188 & 0.00231735 \\
\hline APC protein & $\underline{A P C}$ & WNT signaling pathway regulator & $\begin{array}{l}\text { Generic binding } \\
\text { protein }\end{array}$ & Adenomatous polyposis coli protein & 1.30488 & 0.0062747 \\
\hline RAP-1A & RAP1A & $\begin{array}{l}\text { RAP1A, member of RAS oncogene } \\
\text { family }\end{array}$ & RAS - superfamily & Ras-related protein Rap-1A & 1.30488 & 0.0416244 \\
\hline PSAT & PSAT1 & phosphoserine aminotransferase 1 & Generic enzyme & Phosphoserine aminotransferase & 1.30787 & 0.000502575 \\
\hline c-Fos & FOS & $\begin{array}{l}\text { Fos proto-oncogene, AP-1 transcription } \\
\text { factor subunit }\end{array}$ & Transcription factor & Proto-oncogene c-Fos & 1.30873 & 0.000144963 \\
\hline p73 & TP73 & tumor protein p73 & Transcription factor & Tumor protein p73 & 1.3132 & 0.0179451 \\
\hline $14-3-3$ & YWHAZ & $\begin{array}{l}\text { tyrosine 3-monooxygenase/tryptophan } \\
\text { 5monooxygenase activation protein } \\
\text { zeta }\end{array}$ & $\begin{array}{l}\text { Generic binding } \\
\text { protein }\end{array}$ & & 1.31677 & 0.0236916 \\
\hline 14-3-3 zeta/delta & YWHAZ & $\begin{array}{l}\text { tyrosine 3-monooxygenase/tryptophan } \\
\text { 5monooxygenase activation protein } \\
\text { zeta }\end{array}$ & $\begin{array}{l}\text { Generic binding } \\
\text { protein }\end{array}$ & 14-3-3 protein zeta/delta & 1.31677 & 0.0236916 \\
\hline mGluR1 & GRM1 & glutamate metabotropic receptor 1 & GPCR & Metabotropic glutamate receptor 1 & 1.31864 & 0.0051418 \\
\hline MHC class I & HLA-F & $\begin{array}{l}\text { major histocompatibility complex, class } \\
\text { I, F }\end{array}$ & Generic receptor & & 1.31998 & 0.00676518 \\
\hline $\mid \underline{\mid L-1 R I}$ & IL1R1 & interleukin 1 receptor type 1 & Generic receptor & Interleukin-1 receptor type 1 & 1.3234 & 0.00954023 \\
\hline Syndecan-2 & SDC2 & syndecan 2 & Generic receptor & Syndecan-2 & 1.32432 & 0.000543997 \\
\hline IRF1 & IRF1 & interferon regulatory factor 1 & Transcription factor & $\begin{array}{l}\text { Interferon regulatory factor } \\
\underline{1}\end{array}$ & 1.32567 & 0.0148805 \\
\hline elF4G1/3 & EIF4G3 & $\begin{array}{l}\text { eukaryotic translation initiation factor } 4 \\
\text { gamma } 3\end{array}$ & $\begin{array}{l}\text { Generic binding } \\
\text { protein }\end{array}$ & & 1.32688 & 0.0240793 \\
\hline ATF-1 & ATF1 & activating transcription factor 1 & Transcription factor & $\begin{array}{l}\text { Cyclic AMP-dependent transcription factor } \\
\text { ATF-1 }\end{array}$ & 1.33141 & 0.00862807 \\
\hline PP2A regulatory & PPP2R3A & $\begin{array}{l}\text { protein phosphatase } 2 \text { regulatory } \\
\text { subunit B"alpha }\end{array}$ & $\begin{array}{l}\text { Generic binding } \\
\text { protein }\end{array}$ & & 1.3348 & 0.00213492 \\
\hline Caspase-2 & CASP2 & caspase 2 & Generic protease & Caspase-2 & 1.34305 & 0.00221027 \\
\hline SMAD5 & SMAD5 & SMAD family member 5 & Transcription factor & Mothers against decapentaplegic homolog 5 & 1.34693 & 0.012205 \\
\hline RASSF5 & RASSF5 & $\begin{array}{l}\text { Ras association domain family member } \\
5\end{array}$ & $\begin{array}{l}\text { Generic binding } \\
\text { protein }\end{array}$ & Ras association domaincontaining protein 5 & 1.3648 & 0.00616737 \\
\hline Nucleophosmin & NPM1 & $\begin{array}{l}\text { nucleophosmin (nucleolar } \\
\text { phosphoprotein B23, numatrin) }\end{array}$ & $\begin{array}{l}\text { Generic binding } \\
\text { protein }\end{array}$ & Nucleophosmin & 1.36901 & 0.00132591 \\
\hline Endoplasmin & HSP90B1 & $\begin{array}{l}\text { heat shock protein } 90 \mathrm{kDa} \text { beta family } \\
\text { member } 1\end{array}$ & $\begin{array}{l}\text { Generic binding } \\
\text { protein }\end{array}$ & Endoplasmin & 1.37222 & 0.0376878 \\
\hline HSP90 & HSP90B1 & $\begin{array}{l}\text { heat shock protein } 90 \mathrm{kDa} \text { beta family } \\
\text { member } 1\end{array}$ & $\begin{array}{l}\text { Generic binding } \\
\text { protein }\end{array}$ & & 1.37222 & 0.0376878 \\
\hline RHEB2 & RHEB & Ras homolog enriched in brain & RAS - superfamily & GTP-binding protein Rheb & 1.37269 & 0.00391466 \\
\hline
\end{tabular}




\begin{tabular}{|c|c|c|c|c|c|c|}
\hline MHC class I & $\mathrm{B} 2 \mathrm{M}$ & beta-2-microglobulin & Generic receptor & & 1.37655 & 0.00262384 \\
\hline BMPR1A & BMPR1A & $\begin{array}{l}\text { bone morphogenetic protein receptor } \\
\text { type } 1 \mathrm{~A}\end{array}$ & $\begin{array}{l}\text { Receptor with } \\
\text { enzyme activity }\end{array}$ & Bone morphogenetic protein receptor type-1A & 1.37717 & 0.00542215 \\
\hline FAP-1 & PTPN13 & $\begin{array}{l}\text { protein tyrosine phosphatase, non- } \\
\text { receptor type } 13\end{array}$ & $\begin{array}{l}\text { Generic } \\
\text { phosphatase }\end{array}$ & $\begin{array}{l}\text { Tyrosine-protein phosphatase non-receptor } \\
\text { type 13 }\end{array}$ & 1.37852 & 0.0181538 \\
\hline IGF-1 receptor & IGF1R & insulin like growth factor 1 receptor & $\begin{array}{l}\text { Receptor with } \\
\text { enzyme activity }\end{array}$ & Insulin-like growth factor 1 receptor & 1.38488 & 0.00124826 \\
\hline Dynorphin A(1-13) & PDYN & prodynorphin & Receptor ligand & Dynorphin-A(1-13) & 1.38832 & 0.00114984 \\
\hline Leu-enkephalin & PDYN & prodynorphin & Receptor ligand & Leu-enkephalin & 1.38832 & 0.00114984 \\
\hline Proenkephalin-B & PDYN & prodynorphin & Receptor ligand & Proenkephalin-B & 1.38832 & 0.00114984 \\
\hline Caspase-8 & CASP8 & caspase 8 & Generic protease & Caspase-8 & 1.39804 & 0.0119021 \\
\hline ESR2 & ESR2 & estrogen receptor 2 & Transcription factor & Estrogen receptor beta & 1.40974 & 0.0236654 \\
\hline LAMP2 & LAMP2 & $\begin{array}{l}\text { lysosomal associated membrane } \\
\text { protein } 2\end{array}$ & $\begin{array}{l}\text { Generic binding } \\
\text { protein }\end{array}$ & $\begin{array}{l}\text { Lysosome-associated membrane } \\
\text { glycoprotein } 2\end{array}$ & 1.41288 & 0.000310979 \\
\hline Rac1 & RAC1 & \begin{tabular}{|l} 
ras-related C3 botulinum toxin \\
substrate 1 (rho family, small GTP \\
binding protein Rac1)
\end{tabular} & RAS - superfamily & Ras-related C3 botulinum toxin substrate 1 & 1.43303 & 0.00759662 \\
\hline MRLC & MYL12B & myosin light chain 12B & $\begin{array}{l}\text { Generic binding } \\
\text { protein }\end{array}$ & & 1.50417 & 0.000444727 \\
\hline Adenylate cyclase & $A D C Y 1$ & adenylate cyclase 1 (brain) & Generic enzyme & & 1.52523 & $2.81187 \mathrm{E}-06$ \\
\hline $\begin{array}{l}\text { Adenylate cyclase } \\
\text { type I }\end{array}$ & $A D C Y 1$ & adenylate cyclase 1 (brain) & Generic enzyme & Adenylate cyclase type 1 & 1.52523 & $2.81187 \mathrm{E}-06$ \\
\hline KIR2DL1 & KIR2DL1 & $\begin{array}{l}\text { killer cell immunoglobulin like receptor, } \\
\text { two Ig domains and long cytoplasmic } \\
\text { tail } 1\end{array}$ & Generic receptor & Killer cell immunoglobulinlike receptor 2DL1 & 1.84246 & 0.022848 \\
\hline KIR2DL2 & KIR2DL2 & \begin{tabular}{|l|} 
killer cell immunoglobulin like receptor, \\
two Ig domains and long cytoplasmic \\
tail 2
\end{tabular} & Generic receptor & Killer cell immunoglobulinlike receptor 2DL2 & 1.84246 & 0.022848 \\
\hline KIR2DL3 & KIR2DL3 & $\begin{array}{l}\text { killer cell immunoglobulin like receptor, } \\
\text { two Ig domains and long cytoplasmic } \\
\text { tail } 3\end{array}$ & Generic receptor & Killer cell immunoglobulinlike receptor 2DL3 & 1.84246 & 0.022848 \\
\hline KIR2DL4 & KIR2DL4 & $\begin{array}{l}\text { killer cell immunoglobulin like receptor, } \\
\text { two Ig domains and long cytoplasmic } \\
\text { tail } 4\end{array}$ & Generic receptor & Killer cell immunoglobulinlike receptor 2DL4 & 1.84246 & 0.022848 \\
\hline$\underline{\text { KIR2DL5 }}$ & KIR2DL5A & \begin{tabular}{|l|} 
killer cell immunoglobulin like receptor, \\
two Ig domains and long cytoplasmic \\
tail 5A
\end{tabular} & Generic receptor & Killer cell immunoglobulinlike receptor 2DL5A & 1.84246 & 0.022848 \\
\hline
\end{tabular}

Table 3: Parental versus ALDH-high A375 cells (Untreated)

List Report

\begin{tabular}{|c|c|c|c|c|c|c|}
\hline $\begin{array}{c}\text { Network Object } \\
\text { Name }\end{array}$ & $\begin{array}{l}\text { Gene } \\
\text { Symbol }\end{array}$ & Gene Name & Object Type & Description & Signal & p-value \\
\hline$\underline{\mathrm{CCL} 2}$ & $\mathrm{CCL} 2$ & C-C motif chemokine ligand 2 & Receptor ligand & C-C motif chemokine 2 & -2.36328 & 1.66572E-05 \\
\hline $\mathrm{p} 57$ & CDKN1C & cyclin dependent kinase inhibitor $1 \mathrm{C}$ & $\begin{array}{l}\text { Generic binding } \\
\text { protein }\end{array}$ & Cyclin-dependent kinase inhibitor $1 \mathrm{C}$ & -2.35549 & 7.53913E-07 \\
\hline MHC class II & HLA-DOA & $\begin{array}{l}\text { major histocompatibility complex, class } \\
\text { II, DO alpha }\end{array}$ & Generic receptor & & -1.88445 & 1.96402E-05 \\
\hline MMP-13 & MMP13 & matrix metallopeptidase 13 & Metalloprotease & Collagenase 3 & -1.81956 & 0.00133048 \\
\hline MEF2C & MEF2C & myocyte enhancer factor $2 \mathrm{C}$ & Transcription factor & Myocyte-specific enhancer factor $2 \mathrm{C}$ & -1.72111 & 0.000499586 \\
\hline TRAF1 & TRAF1 & TNF receptor associated factor 1 & $\begin{array}{l}\text { Generic binding } \\
\text { protein }\end{array}$ & TNF receptor-associated factor 1 & -1.56675 & 0.000152341 \\
\hline
\end{tabular}




\begin{tabular}{|c|c|c|c|c|c|c|}
\hline MEK6(MAP2K6) & MAP2K6 & $\begin{array}{l}\text { mitogen-activated protein kinase kinase } \\
6\end{array}$ & Protein kinase & 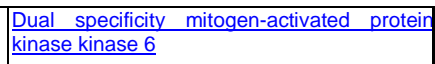 & -1.5054 & 3.59244E-05 \\
\hline elF4A & EIF4A2 & $\begin{array}{l}\text { eukaryotic translation initiation factor } \\
4 \mathrm{~A} 2\end{array}$ & Generic enzyme & & -1.46238 & 0.000581214 \\
\hline MHC class II & HLA-DOB & $\begin{array}{l}\text { major histocompatibility complex, class } \\
\text { II, DO beta }\end{array}$ & Generic receptor & & -1.43366 & 0.0276582 \\
\hline Osteopontin & SPP1 & secreted phosphoprotein 1 & Receptor ligand & Osteopontin & -1.37772 & $1.37342 \mathrm{E}-05$ \\
\hline GAB1 & GAB1 & GRB2 associated binding protein 1 & $\begin{array}{l}\text { Generic binding } \\
\text { protein }\end{array}$ & GRB2-associated-binding protein 1 & -1.36772 & 0.0477614 \\
\hline Histone $\mathrm{H} 4$ & HIST1H4A & histone cluster $1, \mathrm{H} 4 \mathrm{a}$ & $\begin{array}{l}\text { Generic binding } \\
\text { protein }\end{array}$ & Histone $\mathrm{H} 4$ & -1.3674 & 0.000812007 \\
\hline Histone $\mathrm{H} 4$ & HIST1H4B & histone cluster $1, \mathrm{H} 4 \mathrm{~b}$ & $\begin{array}{l}\text { Generic binding } \\
\text { protein }\end{array}$ & Histone $\mathrm{H} 4$ & -1.3674 & 0.000812007 \\
\hline Histone $\mathrm{H} 4$ & HIST1H4C & histone cluster $1, \mathrm{H} 4 \mathrm{c}$ & $\begin{array}{l}\text { Generic binding } \\
\text { protein }\end{array}$ & Histone $\mathrm{H} 4$ & -1.3674 & 0.000812007 \\
\hline Histone $\mathrm{H} 4$ & HIST1H4D & histone cluster 1, H4d & $\begin{array}{l}\text { Generic binding } \\
\text { protein }\end{array}$ & Histone $\mathrm{H} 4$ & -1.3674 & 0.000812007 \\
\hline Histone $\mathrm{H} 4$ & HIST1H4E & histone cluster $1, \mathrm{H} 4 \mathrm{e}$ & $\begin{array}{l}\text { Generic binding } \\
\text { protein }\end{array}$ & Histone $\mathrm{H} 4$ & -1.3674 & 0.000812007 \\
\hline Histone $\mathrm{H} 4$ & HIST1H4F & histone cluster $1, \mathrm{H} 4 \mathrm{f}$ & $\begin{array}{l}\text { Generic binding } \\
\text { protein }\end{array}$ & Histone $\mathrm{H} 4$ & -1.3674 & 0.000812007 \\
\hline Histone $\mathrm{H} 4$ & HIST1H4H & histone cluster $1, \mathrm{H} 4 \mathrm{~h}$ & $\begin{array}{l}\text { Generic binding } \\
\text { protein }\end{array}$ & Histone $\mathrm{H} 4$ & -1.3674 & 0.000812007 \\
\hline Histone $\mathrm{H} 4$ & HIST1H4I & histone cluster $1, \mathrm{H} 4 \mathrm{i}$ & $\begin{array}{l}\text { Generic binding } \\
\text { protein }\end{array}$ & Histone $\mathrm{H} 4$ & -1.3674 & 0.000812007 \\
\hline Histone $\mathrm{H} 4$ & HIST1H4J & histone cluster $1, \mathrm{H} 4 \mathrm{j}$ & $\begin{array}{l}\text { Generic binding } \\
\text { protein }\end{array}$ & Histone $\mathrm{H} 4$ & -1.3674 & 0.000812007 \\
\hline Histone $\mathrm{H} 4$ & HIST1H4K & histone cluster $1, \mathrm{H} 4 \mathrm{k}$ & $\begin{array}{l}\text { Generic binding } \\
\text { protein }\end{array}$ & Histone $\mathrm{H} 4$ & -1.3674 & 0.000812007 \\
\hline Histone $\mathrm{H} 4$ & HIST1H4L & histone cluster $1, \mathrm{H} 4 \mathrm{I}$ & $\begin{array}{l}\text { Generic binding } \\
\text { protein }\end{array}$ & Histone $\mathrm{H} 4$ & -1.3674 & 0.000812007 \\
\hline Histone $\mathrm{H} 4$ & HIST2H4A & histone cluster $2, \mathrm{H} 4 \mathrm{a}$ & $\begin{array}{l}\text { Generic binding } \\
\text { protein }\end{array}$ & Histone $\mathrm{H} 4$ & -1.3674 & 0.000812007 \\
\hline Histone $\mathrm{H} 4$ & HIST2H4B & histone cluster 2, $\mathrm{H} 4 \mathrm{~b}$ & $\begin{array}{l}\text { Generic binding } \\
\text { protein }\end{array}$ & Histone $\mathrm{H} 4$ & -1.3674 & 0.000812007 \\
\hline Histone $\mathrm{H} 4$ & HIST4H4 & histone cluster $4, \mathrm{H} 4$ & $\begin{array}{l}\text { Generic binding } \\
\text { protein }\end{array}$ & Histone $\mathrm{H} 4$ & -1.3674 & 0.000812007 \\
\hline$\frac{\text { CD40(TNFRSF5 }}{2}$ & CD40 & CD40 molecule & Generic receptor & $\begin{array}{l}\text { Tumor necrosis factor receptor superfamily } \\
\text { member } 5\end{array}$ & -1.36382 & 0.0110669 \\
\hline PP2A regulatory & PPP2R3A & $\begin{array}{l}\text { protein phosphatase } 2 \text { regulatory } \\
\text { subunit B"alpha }\end{array}$ & $\begin{array}{l}\text { Generic binding } \\
\text { protein }\end{array}$ & & -1.36311 & 0.00139958 \\
\hline PLP1 & PLP1 & proteolipid protein 1 & $\begin{array}{l}\text { Generic binding } \\
\text { protein }\end{array}$ & Myelin proteolipid protein & -1.35525 & 0.0103633 \\
\hline MHC class II & HLA-DMB & $\begin{array}{l}\text { major histocompatibility complex, class } \\
\text { II, DM beta }\end{array}$ & Generic receptor & & -1.35184 & 3.44602E-05 \\
\hline $\begin{array}{l}\text { von Willebrand } \\
\underline{\text { factor }}\end{array}$ & VWF & von Willebrand factor & Receptor ligand & von Willebrand factor & -1.3206 & 0.0210621 \\
\hline Fc gamma RII alpha & FCGR2A & Fc fragment of IgG receptor Ila & Generic receptor & $\begin{array}{l}\text { Low affinity immunoglobulin gamma Fc } \\
\text { region receptor II-a }\end{array}$ & -1.31836 & 0.00296042 \\
\hline VDR & VDR & $\begin{array}{l}\text { vitamin D (1,25- dihydroxyvitamin D3) } \\
\text { receptor }\end{array}$ & Transcription factor & Vitamin D3 receptor & -1.31617 & 0.00300324 \\
\hline c-Maf & MAF & MAF bZIP transcription factor & Transcription factor & Transcription factor Maf & -1.30398 & 0.021578 \\
\hline Frizzled & FZD4 & frizzled class receptor 4 & GPCR & & -1.30301 & 0.0233367 \\
\hline COL1A1 & COL1A1 & collagen type I alpha 1 & $\begin{array}{l}\text { Generic binding } \\
\text { protein }\end{array}$ & Collagen alpha-1(I) chain & -1.29164 & 0.0279799 \\
\hline
\end{tabular}




\begin{tabular}{|c|c|c|c|c|c|c|}
\hline Adenylate cyclase & $A D C Y 6$ & adenylate cyclase 6 & Generic enzyme & & -1.28938 & 0.00835718 \\
\hline PDGF receptor & PDGFRB & $\begin{array}{l}\text { platelet derived growth factor receptor } \\
\text { beta }\end{array}$ & $\begin{array}{l}\text { Receptor with } \\
\text { enzyme activity }\end{array}$ & & -1.28614 & 0.00403004 \\
\hline PDGF-R-beta & PDGFRB & $\begin{array}{l}\text { platelet derived growth factor receptor } \\
\text { beta }\end{array}$ & \begin{tabular}{|l|} 
Receptor with \\
enzyme activity
\end{tabular} & Platelet-derived growth factor receptor beta & -1.28614 & 0.00403004 \\
\hline Follistatin & FST & follistatin & $\begin{array}{l}\text { Generic binding } \\
\text { protein }\end{array}$ & Follistatin & -1.2848 & 0.000024051 \\
\hline PP2A structural & PPP2R1B & $\begin{array}{l}\text { protein phosphatase } 2 \text { scaffold subunit } \\
\text { Abeta }\end{array}$ & $\begin{array}{l}\text { Generic binding } \\
\text { protein }\end{array}$ & & -1.28221 & 0.0177006 \\
\hline CDK6 & $\underline{\mathrm{CDK} 6}$ & cyclin dependent kinase 6 & Protein kinase & Cyclin-dependent kinase 6 & -1.27706 & 0.00107739 \\
\hline MLCK & MYLK & myosin light chain kinase & Protein kinase & & -1.2671 & 0.00395734 \\
\hline MYLK1 & MYLK & myosin light chain kinase & Protein kinase & Myosin light chain kinase, smooth muscle & -1.2671 & 0.00395734 \\
\hline TAB1 & TAB1 & $\begin{array}{l}\text { TGF-beta activated kinase 1/MAP3K7 } \\
\text { binding protein } 1\end{array}$ & $\begin{array}{l}\text { Generic binding } \\
\text { protein }\end{array}$ & $\begin{array}{l}\text { TGF-beta-activated kinase } 1 \text { and } \\
\text { MAP3K7binding protein } 1\end{array}$ & -1.2654 & 0.00263249 \\
\hline p38 MAPK & MAPK11 & mitogen-activated protein kinase 11 & Protein kinase & & -1.25439 & 0.0342748 \\
\hline$\frac{\text { p38beta }}{\text { (MAPK11) }}$ & MAPK11 & mitogen-activated protein kinase 11 & Protein kinase & Mitogen-activated protein kinase 11 & -1.25439 & 0.0342748 \\
\hline NGF & NGF & nerve growth factor & Receptor ligand & Beta-nerve growth factor & -1.25013 & 0.0141866 \\
\hline MHC class II & HLA-DPB1 & $\begin{array}{l}\text { major histocompatibility complex, class } \\
\text { II, DP beta } 1\end{array}$ & Generic receptor & & -1.24615 & 0.0241933 \\
\hline IP3 receptor & ITPR2 & $\begin{array}{l}\text { inositol 1,4,5-trisphosphate receptor } \\
\text { type } 2\end{array}$ & $\begin{array}{l}\text { Ligand-gated ion } \\
\text { channel }\end{array}$ & & -1.24373 & 0.0308373 \\
\hline MHC class II & HLA-DMA & $\begin{array}{l}\text { major histocompatibility complex, class } \\
\text { II, DM alpha }\end{array}$ & Generic receptor & & -1.23692 & 0.00037169 \\
\hline PKC & PRKCZ & protein kinase C zeta & Protein kinase & & -1.22047 & 0.0013793 \\
\hline MHC class II & HLA-DRA & $\begin{array}{l}\text { major histocompatibility complex, class } \\
\text { II, DR alpha }\end{array}$ & Generic receptor & & -1.214 & 0.0283084 \\
\hline MHC class II & HLA-DQA1 & $\begin{array}{l}\text { major histocompatibility complex, class } \\
\text { II, DQ alpha } 1\end{array}$ & Generic receptor & & -1.21032 & 0.00112998 \\
\hline Adenylate cyclase & ADCY1 & adenylate cyclase 1 (brain) & Generic enzyme & & -1.18377 & 0.00169305 \\
\hline PP2A regulatory & PPP2R5C & $\begin{array}{l}\text { protein phosphatase } 2 \text { regulatory } \\
\text { subunit B'gamma }\end{array}$ & $\begin{array}{l}\text { Generic binding } \\
\text { protein }\end{array}$ & & -1.17906 & 0.0275376 \\
\hline Histone $\mathrm{H} 2$ & HIST1H2AC & histone cluster 1, H2ac & $\begin{array}{l}\text { Generic binding } \\
\text { protein }\end{array}$ & & -1.17575 & 0.033901 \\
\hline p38 MAPK & MAPK12 & mitogen-activated protein kinase 12 & Protein kinase & & -1.17095 & 0.00706191 \\
\hline MHC class II & HLA-DPA1 & $\begin{array}{l}\text { major histocompatibility complex, class } \\
\text { II, DP alpha } 1\end{array}$ & Generic receptor & & -1.16399 & 0.027006 \\
\hline PP2A regulatory & PPP2R3B & $\begin{array}{l}\text { protein phosphatase } 2 \text { regulatory } \\
\text { subunit B"beta }\end{array}$ & $\begin{array}{l}\text { Generic binding } \\
\text { protein }\end{array}$ & & -1.15891 & 0.0157553 \\
\hline Histone $\mathrm{H} 2$ & HIST1H2BH & histone cluster $1, \mathrm{H} 2 \mathrm{bh}$ & $\begin{array}{l}\text { Generic binding } \\
\text { protein }\end{array}$ & & -1.14047 & 0.0249971 \\
\hline SOS & $\underline{\mathrm{SOS} 1}$ & $\begin{array}{l}\text { SOS Ras/Rac guanine nucleotide } \\
\text { exchange factor } 1\end{array}$ & $\begin{array}{l}\text { Regulators (GDI, } \\
\text { GAP, GEF) }\end{array}$ & & -1.10822 & 0.0208185 \\
\hline p90Rsk & RPS6KA1 & ribosomal protein S6 kinase A1 & Protein kinase & & -1.09743 & 0.0387703 \\
\hline WNT & WNT2 & Wnt family member 2 & Receptor ligand & & -1.09671 & 0.0484961 \\
\hline Histone $\mathrm{H} 2$ & $\mathrm{HIST} 2 \mathrm{H} 2 \mathrm{AC}$ & histone cluster 2, H2ac & $\begin{array}{l}\text { Generic binding } \\
\text { protein }\end{array}$ & & -1.09121 & 0.0183897 \\
\hline
\end{tabular}




\begin{tabular}{|c|c|c|c|c|c|c|}
\hline MHC class II & HLA-DRB3 & $\begin{array}{l}\text { major histocompatibility complex, class } \\
\text { II, DR beta } 3\end{array}$ & Generic receptor & & -1.08555 & 0.0133047 \\
\hline MHC class II & HLA-DRB4 & $\begin{array}{l}\text { major histocompatibility complex, class } \\
\text { II, DR beta } 4\end{array}$ & Generic receptor & & -1.08555 & 0.0133047 \\
\hline MHC class II & HLA-DRB5 & $\begin{array}{l}\text { major histocompatibility complex, class } \\
\text { II, DR beta } 5\end{array}$ & Generic receptor & & -1.08555 & 0.0133047 \\
\hline $\begin{array}{l}\text { G-protein alpha-i } \\
\text { family }\end{array}$ & GNAI2 & G protein subunit alpha i2 & G-alpha & & -1.07362 & 0.00354277 \\
\hline Collagen IV & COL4A4 & collagen type IV alpha 4 chain & $\begin{array}{l}\text { Generic binding } \\
\text { protein }\end{array}$ & & -1.05384 & 0.0498416 \\
\hline IP3 receptor & ITPR3 & $\begin{array}{l}\text { inositol 1,4,5-trisphosphate receptor } \\
\text { type } 3\end{array}$ & $\begin{array}{l}\text { Ligand-gated ion } \\
\text { channel }\end{array}$ & & 1.1381 & 0.0477303 \\
\hline Collagen IV & COL4A2 & collagen type IV alpha 2 & $\begin{array}{l}\text { Generic binding } \\
\text { protein }\end{array}$ & & 1.17528 & $\begin{array}{r}5.54546 \mathrm{E}- \\
05\end{array}$ \\
\hline elF4A & EIF4A1 & $\begin{array}{l}\text { eukaryotic translation initiation factor } \\
\text { 4A1 }\end{array}$ & Generic enzyme & & 1.18902 & 0.0112779 \\
\hline$\underline{P K C}$ & PRKCA & protein kinase $\mathrm{C}$ alpha & Protein kinase & & 1.19457 & 0.00355992 \\
\hline Histone $\mathrm{H} 2$ & HIST1H2BD & histone cluster 1, H2bd & $\begin{array}{l}\text { Generic binding } \\
\text { protein }\end{array}$ & & 1.22971 & 0.00741417 \\
\hline$\underline{P K C}$ & PRKD3 & protein kinase D3 & Protein kinase & & 1.25218 & 0.0170282 \\
\hline EDNRA & EDNRA & endothelin receptor type $A$ & GPCR & Endothelin-1 receptor & 1.25971 & 0.0455197 \\
\hline AP-1 & FOSL1 & $\begin{array}{l}\text { FOS like 1, AP-1 transcription factor } \\
\text { subunit }\end{array}$ & Transcription factor & & 1.26072 & 0.00083762 \\
\hline Fra-1 & FOSL1 & $\begin{array}{l}\text { FOS like 1, AP-1 transcription factor } \\
\text { subunit }\end{array}$ & Transcription factor & Fos-related antigen 1 & 1.26072 & 0.00083762 \\
\hline$\underline{\text { KLF5 }}$ & $\underline{\text { KLF5 }}$ & Kruppel like factor 5 & Transcription factor & Krueppel-like factor 5 & 1.26959 & 0.00193235 \\
\hline Histone $\mathrm{H} 3$ & $\mathrm{H} 3 \mathrm{~F} 3 \mathrm{~A}$ & $\mathrm{H} 3$ histone, family $3 \mathrm{~A}$ & $\begin{array}{l}\text { Generic binding } \\
\text { protein }\end{array}$ & & 1.27027 & 0.0349977 \\
\hline Histone $\mathrm{H} 3$ & H3F3B & H3 histone, family 3B (H3.3B) & $\begin{array}{l}\text { Generic binding } \\
\text { protein }\end{array}$ & & 1.27027 & 0.0349977 \\
\hline BMP4 & BMP4 & bone morphogenetic protein 4 & Receptor ligand & Bone morphogenetic protein 4 & 1.27237 & 0.0042337 \\
\hline $\begin{array}{l}\text { G-protein alpha-i } \\
\text { family }\end{array}$ & GNAI1 & G protein subunit alpha i1 & G-alpha & & 1.27252 & $\begin{array}{r}8.97476 \mathrm{E}- \\
05\end{array}$ \\
\hline G-protein alphai1 & GNAI1 & G protein subunit alpha i1 & G-alpha & $\begin{array}{l}\text { Guanine nucleotide-binding protein G(i) } \\
\text { subunit alpha-1 }\end{array}$ & 1.27252 & $\begin{array}{r}8.97476 E- \\
05\end{array}$ \\
\hline$\underline{G C R}$ & NR3C1 & $\begin{array}{l}\text { nuclear receptor subfamily } 3 \text { group C } \\
\text { member } 1\end{array}$ & Transcription factor & Glucocorticoid receptor & 1.27334 & $\begin{array}{r}1.09912 E- \\
05\end{array}$ \\
\hline GATA-1 & GATA1 & GATA binding protein 1 & Transcription factor & Erythroid transcription factor & 1.27414 & 0.0193385 \\
\hline$\underline{\mathrm{SOS}}$ & $\underline{\mathrm{SOS} 2}$ & $\begin{array}{l}\text { SOS Ras/Rho guanine nucleotide } \\
\text { exchange factor } 2\end{array}$ & $\begin{array}{l}\text { Regulators (GDI, } \\
\text { GAP, GEF) }\end{array}$ & & 1.27712 & 0.00811183 \\
\hline SNAIL1 & SNAI1 & snail family transcriptional repressor 1 & Transcription factor & Zinc finger protein SNAI1 & 1.27758 & 0.00712077 \\
\hline$\underline{\underline{L D L R}}$ & $\underline{L D L R}$ & low density lipoprotein receptor & Generic receptor & Low-density lipoprotein receptor & 1.27923 & 0.00008782 \\
\hline C/EBPbeta & CEBPB & CCAAT/enhancer binding protein beta & Transcription factor & CCAAT/enhancer-binding protein beta & 1.27983 & 0.00025230 \\
\hline TRAF2 & TRAF2 & TNF receptor associated factor 2 & $\begin{array}{l}\text { Generic binding } \\
\text { protein }\end{array}$ & TNF receptor-associated factor 2 & 1.28784 & 0.0323403 \\
\hline$\underline{\text { HSP70 }}$ & HSPA8 & $\begin{array}{l}\text { heat shock protein family A (Hsp70) } \\
\text { member } 8\end{array}$ & $\begin{array}{l}\text { Generic binding } \\
\text { protein }\end{array}$ & & 1.29043 & $\begin{array}{r}0.00070906 \\
8\end{array}$ \\
\hline Histone $\mathrm{H} 2$ & HIST1H2BC & histone cluster $1, \mathrm{H} 2 \mathrm{bc}$ & $\begin{array}{l}\text { Generic binding } \\
\text { protein }\end{array}$ & & 1.29919 & 0.0160555 \\
\hline
\end{tabular}




\begin{tabular}{|c|c|c|c|c|c|c|}
\hline Histone $\mathrm{H} 2$ & HIST1H2BE & histone cluster $1, \mathrm{H} 2 \mathrm{be}$ & $\begin{array}{l}\text { Generic binding } \\
\text { protein }\end{array}$ & & 1.29919 & 0.0160555 \\
\hline Histone $\mathrm{H} 2$ & HIST1H2BF & histone cluster $1, \mathrm{H} 2 \mathrm{bf}$ & $\begin{array}{l}\text { Generic binding } \\
\text { protein }\end{array}$ & & 1.29919 & 0.0160555 \\
\hline Histone $\mathrm{H} 2$ & HIST1H2BG & histone cluster $1, \mathrm{H} 2 \mathrm{bg}$ & $\begin{array}{l}\text { Generic binding } \\
\text { protein }\end{array}$ & & 1.29919 & 0.0160555 \\
\hline Histone $\mathrm{H} 2$ & HIST1H2BI & histone cluster 1, H2bi & $\begin{array}{l}\text { Generic binding } \\
\text { protein }\end{array}$ & & 1.29919 & 0.0160555 \\
\hline$\underline{\mathrm{SOX9}}$ & $\underline{\mathrm{SOX9}}$ & SRY-box 9 & Transcription factor & Transcription factor SOX-9 & 1.30548 & 0.042592 \\
\hline Cytochrome c & CYCS & cytochrome c, somatic & Generic enzyme & Cytochrome c & 1.30676 & 0.0160318 \\
\hline VEGF-A & VEGFA & vascular endothelial growth factor $\mathrm{A}$ & Receptor ligand & Vascular endothelial growth factor A & 1.3092 & 0.00443429 \\
\hline TGF-beta & TGFB2 & transforming growth factor beta 2 & Receptor ligand & & 1.31177 & 0.0495434 \\
\hline TGF-beta 2 & TGFB2 & transforming growth factor beta 2 & Receptor ligand & Transforming growth factor beta- 2 & 1.31177 & 0.0495434 \\
\hline IP3 receptor & ITPR1 & $\begin{array}{l}\text { inositol 1,4,5-trisphosphate receptor } \\
\text { type } 1\end{array}$ & $\begin{array}{l}\text { Ligand-gated ion } \\
\text { channel }\end{array}$ & & 1.31212 & 0.0031542 \\
\hline PDGF-A & PDGFA & platelet derived growth factor subunit A & Receptor ligand & Platelet-derived growth factor subunit A & 1.31216 & 0.00039450 \\
\hline Alpha-actinin & ACTN2 & actinin alpha 2 & $\begin{array}{l}\text { Generic binding } \\
\text { protein }\end{array}$ & & 1.31256 & 0.00387745 \\
\hline Cyclin A & CCNA1 & cyclin A1 & $\begin{array}{l}\text { Generic binding } \\
\text { protein }\end{array}$ & & 1.3241 & $\begin{array}{r}0.00093803 \\
5\end{array}$ \\
\hline WNT & WNT5A & Wnt family member $5 \mathrm{~A}$ & Receptor ligand & & 1.32631 & $\begin{array}{r}8.78136 \mathrm{E}- \\
06\end{array}$ \\
\hline$\underline{\text { Ski }}$ & $\underline{\mathrm{SKI}}$ & SKI proto-oncogene & $\begin{array}{l}\text { Generic binding } \\
\text { protein }\end{array}$ & Ski oncogene & 1.33162 & 0.0187077 \\
\hline PTHrP & PTHLH & parathyroid hormone-like hormone & Receptor ligand & Parathyroid hormone-related protein & 1.33186 & 0.00043387 \\
\hline p90Rsk & RPS6KA2 & ribosomal protein S6 kinase A2 & Protein kinase & & 1.33239 & 0.00884093 \\
\hline FSRP & FSTL3 & follistatin like 3 & $\begin{array}{l}\text { Generic binding } \\
\text { protein }\end{array}$ & Follistatin-related protein 3 & 1.3342 & $\begin{array}{r}0.00020716 \\
7\end{array}$ \\
\hline SMAD6 & SMAD6 & SMAD family member 6 & Transcription factor & Mothers against decapentaplegic homolog 6 & 1.3376 & 0.00518022 \\
\hline Bim & BCL2L11 & BCL2 like 11 & $\begin{array}{l}\text { Generic binding } \\
\text { protein }\end{array}$ & Bcl-2-like protein 11 & 1.3653 & 0.0252576 \\
\hline$\underline{A P-1}$ & FOSL2 & $\begin{array}{l}\text { FOS like 2, AP-1 transcription factor } \\
\text { subunit }\end{array}$ & Transcription factor & & 1.36594 & 0.01046 \\
\hline ETS1 & ETS1 & $\begin{array}{l}\text { ETS proto-oncogene 1, transcription } \\
\text { factor }\end{array}$ & Transcription factor & Protein C-ets-1 & 1.36672 & 0.00053754 \\
\hline WNT & WNT11 & Wnt family member 11 & Receptor ligand & & 1.37035 & 0.0215301 \\
\hline Talin & $\underline{T L N 2}$ & talin 2 & $\begin{array}{l}\text { Generic binding } \\
\text { protein }\end{array}$ & & 1.37124 & 0.00143352 \\
\hline $\mathrm{Bcl}-2$ & BCL2 & BCL2, apoptosis regulator & $\begin{array}{l}\text { Generic binding } \\
\text { protein }\end{array}$ & Apoptosis regulator $\mathrm{Bcl}-2$ & 1.37145 & 0.00660047 \\
\hline SMAD7 & SMAD7 & SMAD family member 7 & Transcription factor & Mothers against decapentaplegic homolog 7 & 1.3735 & 0.0013868 \\
\hline EGR1 & EGR1 & early growth response 1 & Transcription factor & Early growth response protein 1 & 1.38222 & 0.000708757 \\
\hline IL4RA & $\underline{\mathrm{IL}} 4 \mathrm{R}$ & interleukin 4 receptor & Generic receptor & Interleukin-4 receptor subunit alpha & 1.3835 & 0.00375447 \\
\hline MMP-1 & MMP1 & matrix metallopeptidase 1 & Metalloprotease & Interstitial collagenase & 1.38518 & 0.000936588 \\
\hline
\end{tabular}




\begin{tabular}{|c|c|c|c|c|c|c|}
\hline EGFR & EGFR & epidermal growth factor receptor & $\begin{array}{l}\text { Receptor with } \\
\text { enzyme activity }\end{array}$ & Epidermal growth factor receptor & 1.39085 & 0.0112142 \\
\hline elF4E & EIF4E & eukaryotic translation initiation factor $4 \mathrm{E}$ & $\begin{array}{l}\text { Generic binding } \\
\text { protein }\end{array}$ & Eukaryotic translation initiation factor $4 \mathrm{E}$ & 1.40812 & 0.0168678 \\
\hline$\underline{\text { SCUBE3 }}$ & SCUBE3 & $\begin{array}{l}\text { signal peptide, CUB domain and EGF } \\
\text { like domain containing } 3\end{array}$ & $\begin{array}{l}\text { Generic binding } \\
\text { protein }\end{array}$ & $\begin{array}{l}\text { Signal peptide, CUB and EGF-like } \\
\text { domaincontaining protein } 3 \\
\end{array}$ & 1.42369 & 0.000614548 \\
\hline TIMP1 & TIMP1 & TIMP metallopeptidase inhibitor 1 & $\begin{array}{l}\text { Generic binding } \\
\text { protein }\end{array}$ & Metalloproteinase inhibitor 1 & 1.42794 & 1.17491E-06 \\
\hline Fibronectin & FN1 & fibronectin 1 & Receptor ligand & Fibronectin & 1.44107 & 0.000135032 \\
\hline $\mathrm{AP}-1$ & JUN & $\begin{array}{l}\text { Jun proto-oncogene, AP-1 transcription } \\
\text { factor subunit }\end{array}$ & Transcription factor & & 1.46266 & 3.33637E-05 \\
\hline C-Jun & JUN & $\begin{array}{l}\text { Jun proto-oncogene, AP-1 transcription } \\
\text { factor subunit }\end{array}$ & Transcription factor & Transcription factor AP-1 & 1.46266 & $3.33637 \mathrm{E}-05$ \\
\hline c-Jun/c-Fos & JUN & $\begin{array}{l}\text { Jun proto-oncogene, AP-1 transcription } \\
\text { factor subunit }\end{array}$ & Transcription factor & & 1.46266 & 3.33637E-05 \\
\hline Heme oxygenase 1 & $\underline{\mathrm{HMOX} 1}$ & heme oxygenase 1 & Generic enzyme & Heme oxygenase 1 & 1.46526 & 1.99778E-05 \\
\hline$\underline{T R I O}$ & TRIO & $\begin{array}{l}\text { trio Rho guanine nucleotide exchange } \\
\text { factor }\end{array}$ & $\begin{array}{l}\text { Regulators (GDI, } \\
\text { GAP, GEF) }\end{array}$ & Triple functional domain protein & 1.48572 & $2.28255 \mathrm{E}-05$ \\
\hline CYP24A1 & CYP24A1 & $\begin{array}{l}\text { cytochrome P450 family } 24 \text { subfamily A } \\
\text { member } 1\end{array}$ & Generic enzyme & $\begin{array}{l}\text { 1,25-dihydroxyvitamin } \mathrm{D}(3) \text { 24-hydroxylase, } \\
\text { mitochondrial }\end{array}$ & 1.51113 & 0.0187962 \\
\hline MAP2K5 (MEK5) & MAP2K5 & $\begin{array}{l}\text { mitogen-activated protein kinase kinase } \\
5\end{array}$ & Protein kinase & \begin{tabular}{|l} 
Dual $\quad$ specificity \\
kinase kinase 5
\end{tabular} & 1.51502 & 0.00417811 \\
\hline Collagen IV & COL4A1 & collagen type IV alpha 1 chain & $\begin{array}{l}\text { Generic binding } \\
\text { protein }\end{array}$ & & 1.51599 & 0.000878077 \\
\hline FKHR & FOXO1 & forkhead box 01 & Transcription factor & Forkhead box protein $\mathrm{O} 1$ & 1.54368 & $2.99464 \mathrm{E}-05$ \\
\hline SHP-2 & PTPN11 & $\begin{array}{l}\text { protein tyrosine phosphatase, non- } \\
\text { receptor type } 11\end{array}$ & Protein phosphatase & $\frac{\text { Tyrosine-protein phosphatase non-receptor }}{\text { type } 11}$ & 1.55187 & 0.02919 \\
\hline Histone $\mathrm{H} 2$ & HIST1H2AG & histone cluster $1, \mathrm{H} 2 \mathrm{ag}$ & $\begin{array}{l}\text { Generic binding } \\
\text { protein }\end{array}$ & & 1.58172 & 0.00195219 \\
\hline Histone $\mathrm{H} 2$ & HIST1H2AI & histone cluster 1, H2ai & $\begin{array}{l}\text { Generic binding } \\
\text { protein }\end{array}$ & & 1.58172 & 0.00195219 \\
\hline Histone $\mathrm{H} 2$ & HIST1H2AK & histone cluster $1, \mathrm{H} 2 \mathrm{ak}$ & $\begin{array}{l}\text { Generic binding } \\
\text { protein }\end{array}$ & & 1.58172 & 0.00195219 \\
\hline Histone $\mathrm{H} 2$ & HIST1H2AL & histone cluster 1, H2al & $\begin{array}{l}\text { Generic binding } \\
\text { protein }\end{array}$ & & 1.58172 & 0.00195219 \\
\hline Histone $\mathrm{H} 2$ & HIST1H2AM & histone cluster 1, H2am & $\begin{array}{l}\text { Generic binding } \\
\text { protein }\end{array}$ & & 1.58172 & 0.00195219 \\
\hline Jagged1 & JAG1 & jagged 1 & Receptor ligand & Protein jagged-1 & 1.58718 & $1.62228 \mathrm{E}-06$ \\
\hline SLUG & SNAI2 & snail family transcriptional repressor 2 & Transcription factor & Zinc finger protein SNAI2 & 1.59851 & $3.98516 \mathrm{E}-05$ \\
\hline PAl1 & SERPINE1 & serpin family E member 1 & Receptor ligand & Plasminogen activator inhibitor 1 & 1.60385 & 5.49105E-05 \\
\hline Neurofibromin & NF1 & neurofibromin 1 & $\begin{array}{l}\text { Regulators (GDI, } \\
\text { GAP, GEF) }\end{array}$ & Neurofibromin & 1.65278 & 0.0100313 \\
\hline AP-1 & FOS & $\begin{array}{l}\text { Fos proto-oncogene, AP-1 transcription } \\
\text { factor subunit }\end{array}$ & Transcription factor & & 1.6562 & 0.00330321 \\
\hline c-Fos & FOS & $\begin{array}{l}\text { Fos proto-oncogene, AP-1 transcription } \\
\text { factor subunit }\end{array}$ & Transcription factor & Proto-oncogene c-Fos & 1.6562 & 0.00330321 \\
\hline c-Jun/c-Fos & FOS & $\begin{array}{l}\text { Fos proto-oncogene, AP-1 transcription } \\
\text { factor subunit }\end{array}$ & Transcription factor & & 1.6562 & 0.00330321 \\
\hline ID2 & ID2 & inhibitor of DNA binding 2, HLH protein & Transcription factor & DNA-binding protein inhibitor ID-2 & 1.70344 & $1.43712 \mathrm{E}-05$ \\
\hline Amphiregulin & AREG & amphiregulin & Receptor ligand & Amphiregulin & 1.71147 & 3.82709E-07 \\
\hline
\end{tabular}




\begin{tabular}{|c|c|c|c|c|c|c|}
\hline HSP70 & HSPA7 & $\begin{array}{l}\text { heat shock protein family A (Hsp70) } \\
\text { member } 7\end{array}$ & $\begin{array}{l}\text { Generic binding } \\
\text { protein }\end{array}$ & & 1.74553 & 0.00216841 \\
\hline$\underline{\mathrm{HSP} 70}$ & HSPA6 & $\begin{array}{l}\text { heat shock protein family A (Hsp70) } \\
\text { member } 6\end{array}$ & $\begin{array}{l}\text { Generic binding } \\
\text { protein }\end{array}$ & & 1.78839 & 0.00171406 \\
\hline $\mathrm{AP}-1$ & FOSB & $\begin{array}{l}\text { FosB proto-oncogene, AP-1 } \\
\text { transcription factor subunit }\end{array}$ & Transcription factor & & 1.80026 & 0.000011886 \\
\hline FosB & FOSB & $\begin{array}{l}\text { FosB proto-oncogene, AP-1 } \\
\text { transcription factor subunit }\end{array}$ & Transcription factor & Protein fosB & 1.80026 & 0.000011886 \\
\hline EGR2 (Krox20) & EGR2 & early growth response 2 & Transcription factor & E3 SUMO-protein ligase EGR2 & 1.85416 & $7.39307 \mathrm{E}-05$ \\
\hline BMP2 & BMP2 & bone morphogenetic protein 2 & Receptor ligand & Bone morphogenetic protein 2 & 1.85652 & 4.92344E-05 \\
\hline COX-2 (PTGS2) & PTGS2 & prostaglandin-endoperoxide synthase 2 & Generic enzyme & Prostaglandin $\mathrm{G} / \mathrm{H}$ synthase 2 & 2.59037 & $7.57152 \mathrm{E}-07$ \\
\hline
\end{tabular}
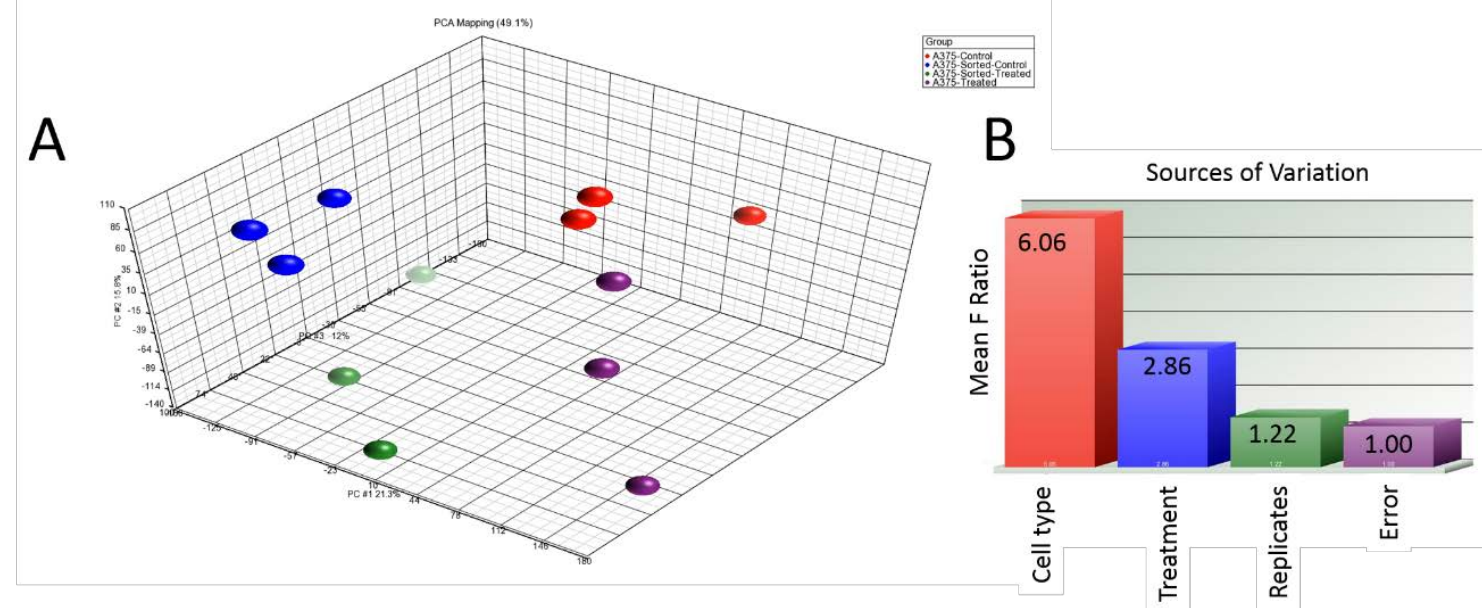

Figure 28: Principle component analysis and sources of variation resulting from genome-wide microarray analysis. Parental A375 cells (red) were compared to ALDH ${ }^{\text {high }}$ A375 cells (blue). The response to Lunasin treatment in A375 (purple) and A375 ALDH $^{\text {high }}$ cells (green) was also compared (A). The largest source of variation between the experimental groups was cell type (parental vs ALDH) followed by treatment (vehicle vs Lunasin). Technical replicates and human error accounted for comparatively little variation with F-ratios of 1.22 and 1.00, respectively (B).

\section{Lunasin uptake correlates with expression of $\alpha_{v}$ integrin subunits}

Lunasin internalization is thought to be dependent upon endocytic mechanisms involving integrins [38]. A375 cells, which overexpress the integrin $\alpha_{\mathrm{V}} \beta_{3}$, were treated with vehicle or $100 \mu \mathrm{M}$ Lunasin, and analyzed for colocalization of integrin subunits and Lunasin at several time points ranging from 4 to $24 \mathrm{~h}$. It was observed that Lunasin is abundantly internalized in A375 cells, and present both in the cytoplasm 
and the nucleus. Interestingly, cell morphology was slightly altered at later time points in Lunasin-treated cells; a decrease in cell size as well as localization of integrins around the nucleus was observed in treated cells when compared to cells in control wells (Figure 29).

\section{B16-F10 CIC populations were reduced with Lunasin treatment}

Previously, it was shown Lunasin reduced ALDH-expressing populations of cells in A375 and SK-MEL-28 melanoma cell lines (Chapter 3, Figure 11) concomitant with a decreased ability of these cells to form oncospheres (Chapter 3, Figure 12) when plated in anchorage-independent culture conditions in serum-free media [228]. To determine if this is the case with a murine model of melanoma, these experiments were repeated using the aggressive mouse-derived melanoma line B16-F10 (Figure 30). Treatment with $100 \mu \mathrm{M}$ Lunasin reduced oncosphere formation by $29 \%(p=0.005)$. Representative images taken at 7 days post-treatment show the inhibitory effect of Lunasin on oncosphere formation (Figure 30A). Additionally, a decrease in the $\mathrm{ALDH}^{\text {high }}$ population when cells were treated with $100 \mu \mathrm{M}$ Lunasin for $24 \mathrm{~h}$ was observed. Treatment reduced the mean percentage of ALDH-positive B16-F10 cells from $8 \%$ in the control samples to $1.9 \%$ in the Lunasin-treated samples $(\mathrm{p}=0.029)$. The 4 -fold decrease in $\mathrm{ALDH}^{\text {high }}$ cells is depicted in a representative series of flow cytometry dot-plots (Figure 30C) showing DEAB, Control, and Lunasin-treated samples. Three populations with varying degrees of ALDH activity exist within parental B16-F10 cells (Figure 30C); an ALDH-negative population represented at the left of each dot-plot, an ALDH ${ }^{\text {low }}$ population that displays a baseline expression of ALDH activity (i.e. these cells are ALDH-positive, but do not significantly shift in fluorescence intensity when exposed to ALDEFLUOR reagent in the absence of DEAB) represented by the population of cells clustered at a slightly higher intensity than the ALDH-negative population, and an ALDH ${ }^{\text {high }}$ population (at least a one-log shift in fluorescence intensity over DEAB controls) represented by the cells in the gated compartment on the right of the dot-plot. 

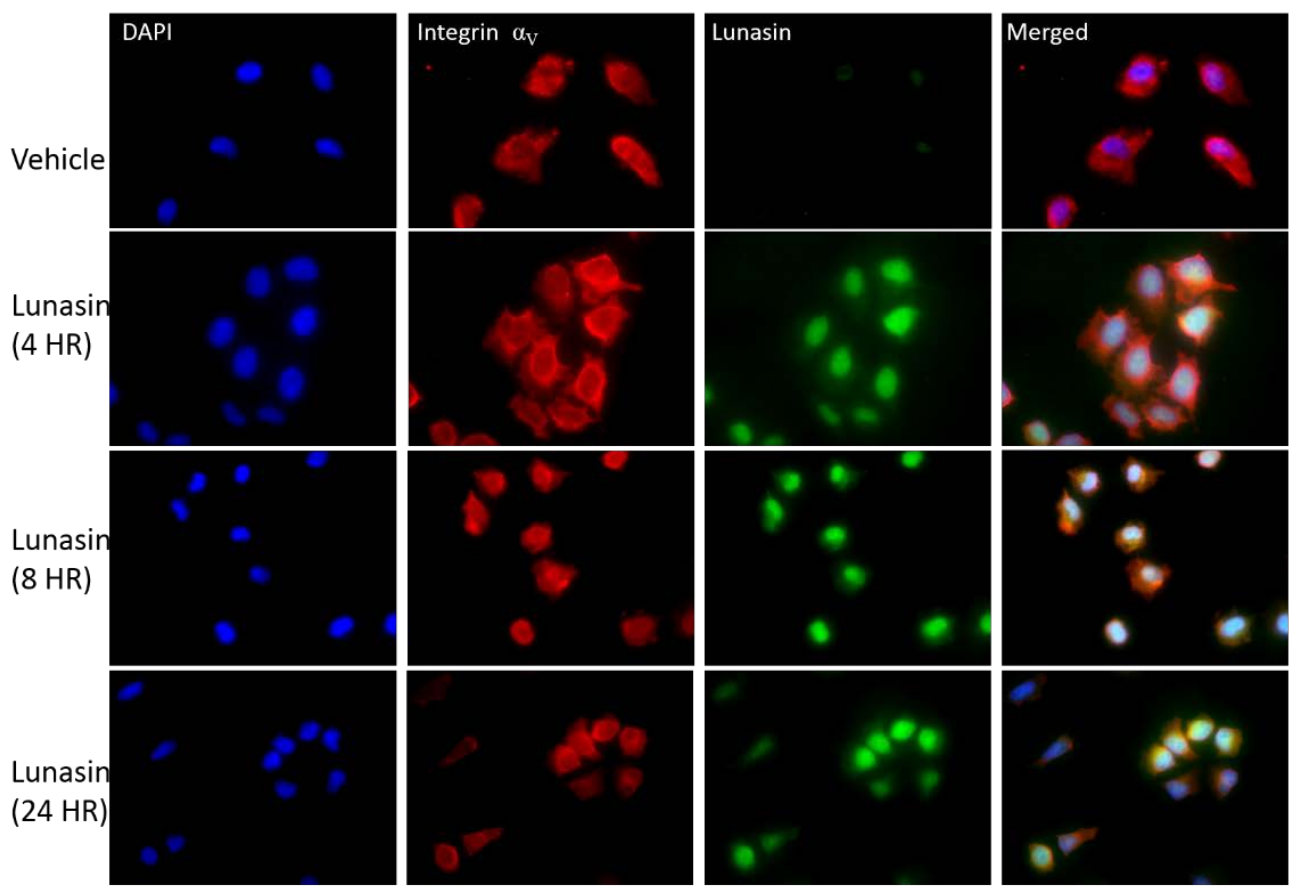

Shidal et. al. Oncotarget, 2017

Figure 29: Lunasin is readily internalized in A375 melanoma cells. A375 cells treated with Lunasin for up to $24 \mathrm{~h}$ internalized Lunasin, which was found to colocalize with integrin $\alpha_{\mathrm{v}}$ subunits. Additionally, nuclear localization of Lunasin was observed after $4 \mathrm{~h}$, and Lunasin persisted in cells up to $24 \mathrm{~h}$ posttreatment. Florescence intensity of clustered integrin subunits was higher around the nucleus in Lunasintreated cells when compared to vehicle-treated cells where integrin $\alpha_{\mathrm{V}}$ subunits appeared on the periphery of A375 cells. These results demonstrate that Lunasin was readily internalized in A375 cells, and may support a mechanism in which Lunasin is internalized with integrin $\alpha_{V}$ subunits. Representative images from three independent experiments were used, and were taken at 40x magnification. $(\mathrm{Blue}=$ dapi, green $=$ Lunasin, red $=$ integrin $\alpha_{\mathrm{V}}$ ) 
A
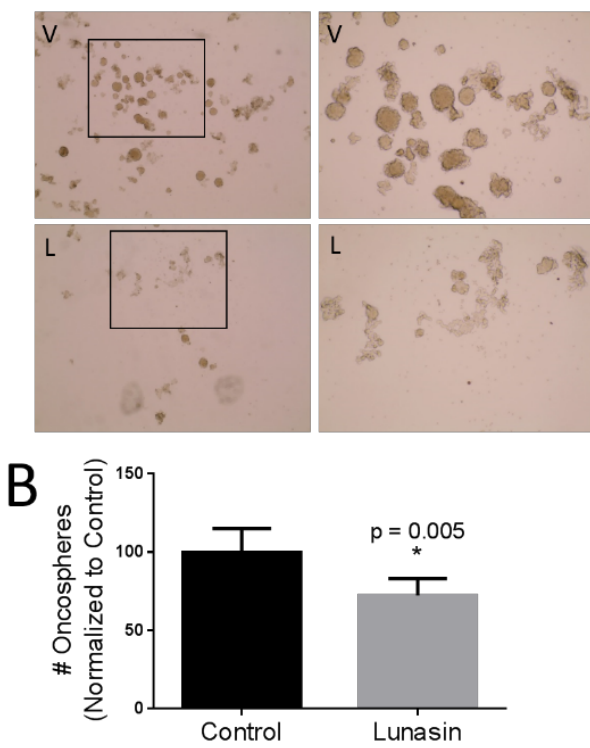

C

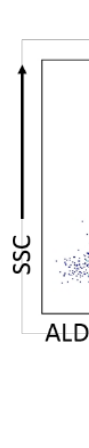

D

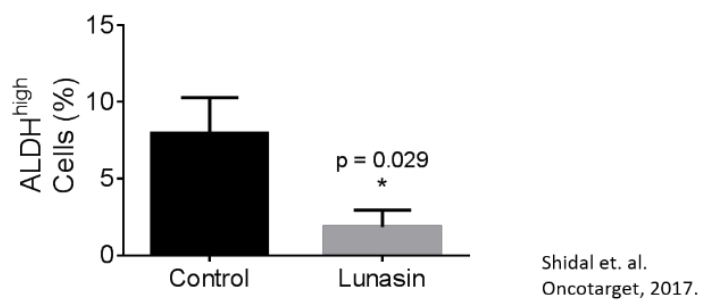

Figure 30: Lunasin disrupted oncosphere formation and reduces ALDH ${ }^{\text {high }}$ populations. B16-F10

ALDH ${ }^{\text {high }}$ cells were plated in low adherent culture in stem cell media and allowed to form floating oncospheres. When media was amended with $100 \mu \mathrm{M}$ Lunasin, a significant decrease in oncosphere formation compared to control samples was observed (A, B). V = vehicle, $L=$ Lunasin. ALDH activity was measured as described in Section 2.5. When B16-F10 cells were treated with Lunasin, a significant reduction in cells displaying the $\mathrm{ALDH}^{\text {high }}$ phenotype was observed (C,D). Figures represent data obtained from three independent experiments and are shown as mean \pm s.d. Statistical significance $(\mathrm{p}<0.05)$ was determined by student’s t-test and denoted by an asterisk $(*)$.

\section{Lunasin inhibits invasion of ALDH ${ }^{\text {high }}$ melanoma stem cells in vitro}

A375 and B16-F10 cells were sorted to isolate populations with elevated ALDH activity. These cells were pretreated with $100 \mu \mathrm{M}$ Lunasin for $24 \mathrm{~h}$, and subsequently replated in the upper chamber of transwell inserts containing serum-free DMEM/F12 media amended with PB or Lunasin. After adding media containing 10\% FBS to the lower chamber, plates were incubated for $24 \mathrm{~h}$, and the cells invading through the Matrigel basement membrane were counted. Invasion of A375 and B16-F10 ALDH ${ }^{\text {high }}$ was significantly inhibited in Lunasin-treated wells compared to vehicle-treated wells resulting in a $57 \%$ (p = $0.02)$ and $60 \%(p=0.04)$ decrease in invading cells, respectively (Figure 31A). Representative images 
showing the Toluidine-stained invading cells from the bottom of the inserts illustrate the antimetastatic effects of Lunasin in vitro (Figure 31B).

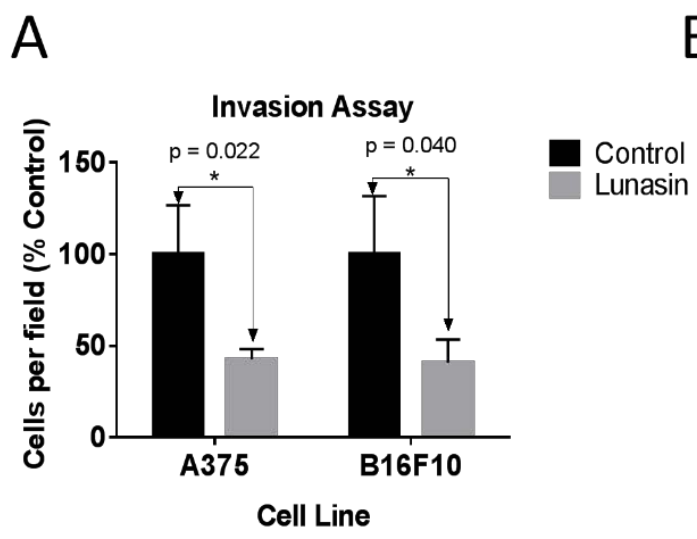

Shidal et. al.

Oncotarget, 2017.
B

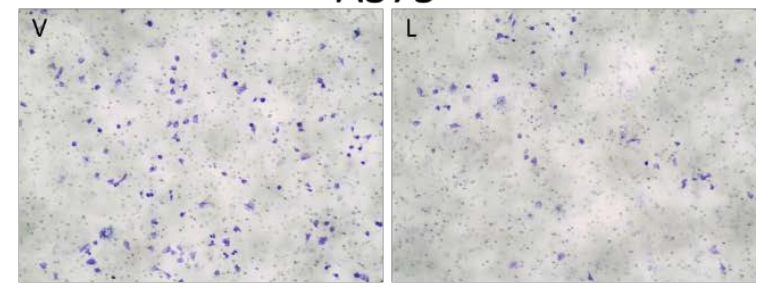

B16F10

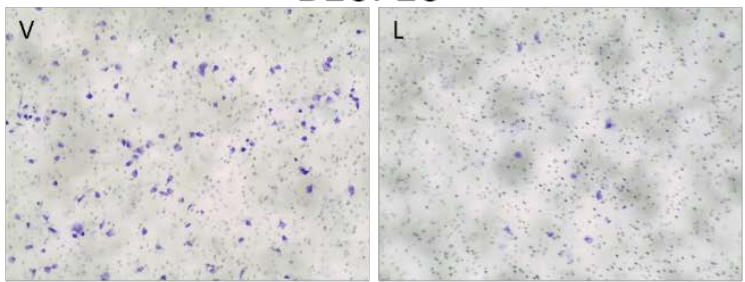

Figure 31: CIC invasion was suppressed in Lunasin-treated cells. In vitro invasion assays demonstrate that Lunasin-treated A375 and B16-F10 ALDH ${ }^{\text {high }}$ cells had less invasive capacity than cells treated with vehicle (A). A375 and B16-F10 ALDH ${ }^{\text {high }}$ cells were plated in the upper compartment of a Boyden chamber, and allowed to migrate through a Matrigel-coated insert ( $8 \mu \mathrm{m}$ pore size) toward a chemoattractant as described in Section 2.19. Invading cells were stained with toluidine blue and representative images are shown at 20x magnification (B). Five fields from each insert were counted and the mean number of stained cells per field in Lunasin-treated wells was normalized to the mean number of invading cells in vehicle-treated wells. The normalized values were expressed as percent (\%) control. Data from three independent experiments are shown as mean \pm s.d. Statistical significance was determined by student's t-test and is denoted by an asterisks.

\section{Lunasin abrogates pulmonary metastasis in vivo}

To test whether Lunasin's antimetastatic effects would persist in vivo, a syngeneic mouse model using the B16-F10 cell line was employed. This system was shown to represent an excellent model to test Lunasin’s efficacy in inhibiting tumor growth in xenograft experiments [275]. When 2.5x10 B16-F10 cells were intravenously injected into C57Bl/6 mice, pulmonary seeding and subsequent tumor establishment occurred within 18 days. Throughout the experiment, mice were dosed daily with vehicle or 
Lunasin (30 mg/ kg) by i.p. injection. Upon experimental endpoint, it was observed that Lunasin-treated mice had significantly reduced metastatic outgrowths when compared to control mice (Figure 32). Mice in the control group averaged 45 ( \pm 22 ) observable pulmonary lesions compared to only $9.5( \pm 8)$ in Lunasintreated mice (Figure 32A). These results were consistent with data obtained when observable microscopic lesions from randomized lung sections of control and Lunasin-treated mice were counted and measured (Figure 32B). Representative images of lungs resected from metastasis-bearing mice in control (Figure 32C) and Lunasin (Figure 32D) treatment groups are shown. In addition, macrometastases were present in the lungs of all control mice $(n=10)$; however, lungs from 2 mice in the Lunasin group $(n=10)$ had no observable macrometastases.

Hematoxylin and eosin (H\&E) stained lung sections also showed an observable difference in the average area of micrometastases between treatment groups. Control mice had an average lesion area of $31.6 \mathrm{~mm}^{2}$ compared to $10.3 \mathrm{~mm}^{2}$ in the Lunasin group (Figure 32B). Micrometastases formed in the lungs of vehicle treated mice (Figure 32E) were larger and more abundant than in mice treated with Lunasin (Figure 32F). Cellular morphology was similar between lesions derived from both control and Lunasintreated mice. A subsequent graphic (Figure 33) which includes all pulmonary tissues resected from all mice in each treatment group $(n=20)$ is also provided. The total number of observable macrometastases found on each set of lungs is provided in the bottom left corner of each image (Figure 33).

The decreased size and number of micrometastases present in Lunasin-treated animals led to the investigation of whether Lunasin has a significant effect on cell cycling in melanoma cell lines. Although Lunasin has been shown to have an antiproliferative effect in NSCLC, no significant effect on cell cycle or cell viability (despite a modest increase in the $\mathrm{G}_{1}$ population) was observed when A375 or B16-F10 cell were treated with $100 \mu \mathrm{M}$ Lunasin (Figure 34A-B). Vemurafenib was used as a positive control and significantly reduced the number of cells in S-phase leading to an accumulation of cells in $\mathrm{G}_{1}$ (Figure 34C). 


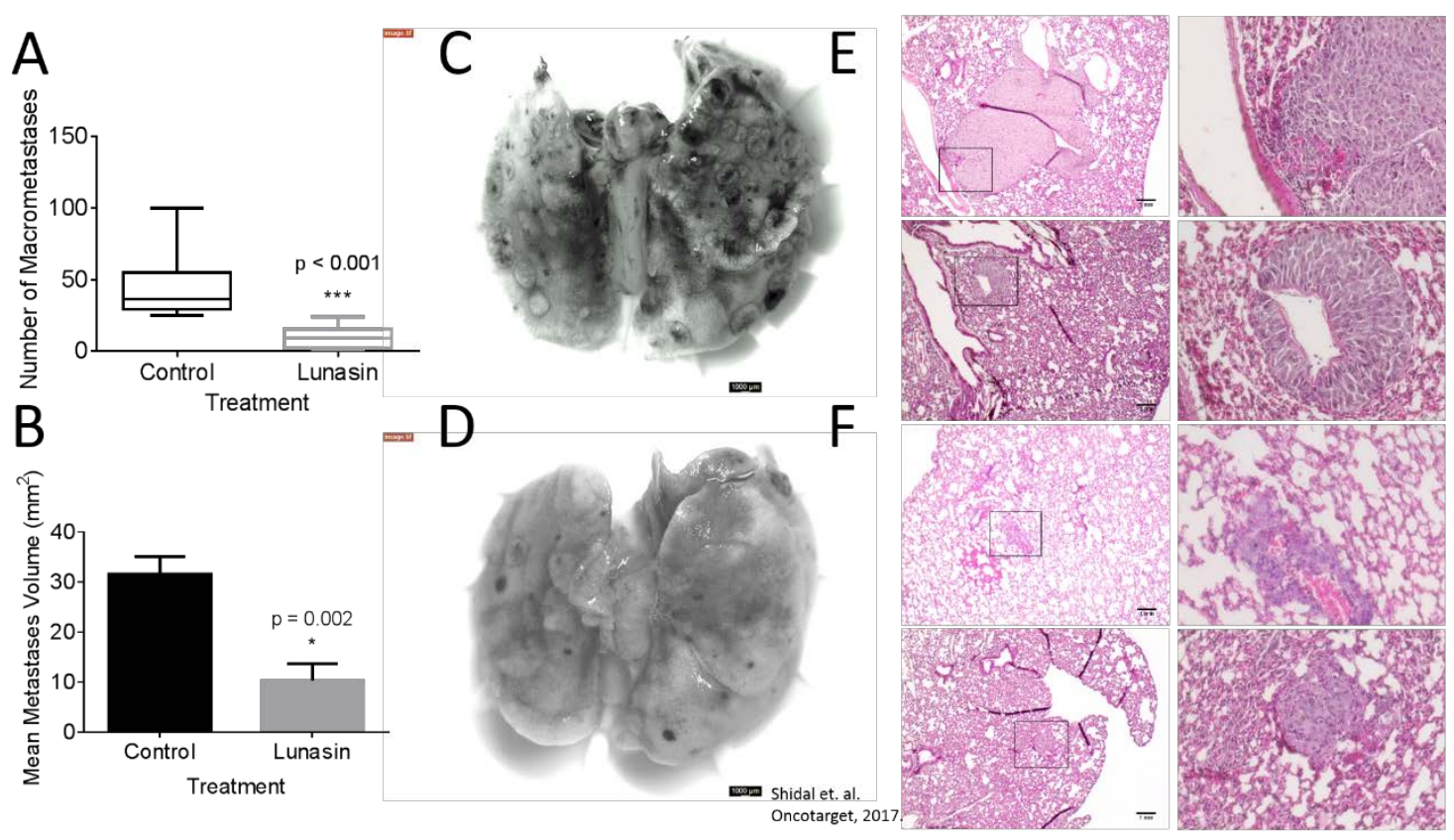

Figure 32: Lunasin reduced pulmonary metastases in vivo. B16-F10 melanoma cells were injected i.v. into female C57BL/6 mice. Lunasin-treated mice had less incidence of macrometastases (A) as well as significantly reduced average lesion area (B) as measured using ImageJ software. Representative images of pulmonary tissues resected from control (C) and Lunasin (D) treated mice are shown. H\&E stained sections demonstrate the significant difference between average lesion area in vehicle (E) and Lunasin (F) treated mice. Stained sections were imaged at 10x (left) and 40x (right), scale bar $=1 \mathrm{~mm}$. Graphs represent data plotted as mean \pm s.e.m. Means were determined to be statistically significant by student's ttest and significance is denoted by an asterisk.

\section{Lunasin antagonizes integrin signaling through FAK/AKT/ERK and inhibits histone acetylation}

It was next investigated whether the effects of Lunasin on human and murine melanoma cells is related to the known effects of Lunasin on integrin signaling. Immunoblot analysis showed that A375 and B16-F10 melanoma lines treated with Lunasin for $24 \mathrm{~h}$ had decreased phosphorylation patterns of FAK, AKT, and ERK. When compared to ALDH ${ }^{\text {low }}$ cells, A375 ALDH ${ }^{\text {high }}$ cells exhibited decreased AKT and ERK phosphorylation in Lunasin-treated cells (Figure 35A); both ALDH ${ }^{\text {low }}$ and ALDH ${ }^{\text {high }}$ showed decreased FAK phosphorylation when treated with $100 \mu \mathrm{M}$ Lunasin. Integrin $\beta_{1}$ engagement has been shown to activate auto-phosphorylation of FAK at Y397 [276, 277], thus, binding of Lunasin to the $\alpha$ - 
subunit (via Lunasin's RGD motif) and the subsequent inhibition of $\beta_{1}$ engagement with downstream signal transducers may cause the observed decreased in phosphorylation patterns. Because $\beta_{1}$ subunits dimerize with a plethora of $\alpha$ subunits (reviewed in [278]), the baseline phosphorylation may be due to the expression of various integrin heterodimers (e.g. $\left.\alpha_{1} \beta_{1}\right)$ in melanoma cells. Similarly, the $\beta_{1}$ integrin subunit has been shown to phosphorylate AKT at S473 [279], suggesting a analogous mechanism to FAK activation.

In order to validate the effects of Lunasin on integrin signaling in CICs, PLA assays were used to investigate the interactions between integrin $\beta$ subunits and the intracellular signal transducers ILK and pFAK (Y397). Firstly, it was observed that Lunasin interacts with the integrin $\alpha_{v}$ subunit of A375 ALDH ${ }^{\text {high }}$ cells (Figure 35B). This interaction suppressed downstream interactions between $\beta_{1}$ and $\beta_{3}$ integrin subunits with ILK and pFAK by approximately 40- 50\% (Figure 35B and 35C). These results are consistent with those seen in NSCLC models [10], and further confirm that the effects of Lunasin on melanoma CICs are, in part, due to altered integrin signaling pathways.

Immunoblot analysis for several phosphorylation sites corresponding to activation of FAK and AKT were conducted on A375 and B16-F10 ALDH ${ }^{\text {high }}$ cells. Phosphorylation of FAK at tyrosine residues Y397 and Y925 was inhibited when ALDH ${ }^{\text {high }}$ cells were treated with Lunasin for $24 \mathrm{~h}$ (Figure 36A). It was also observed that PI3K/AKT signaling was reduced in Lunasin-treated cells. Lunasin treatment decreased phosphorylation of AKT at S473 and T308 as well as phosphorylated ERK1/2 at T202/Y204 (Figure 36B).

Because Lunasin has been reported to have activity as a HAT inhibitor, it was also investigated if any histone acetylation marks may have been changed in Lunasin-treated cells. Histones were isolated by acid extraction, and acetylation marks in $\mathrm{H} 3$ and $\mathrm{H} 4$ histone were assessed by immunoblot analysis. It was previously reported that several acetylation marks were altered when NSCLC cells were incubated with Lunasin [10]. Interestingly, an observable change in a different set of acetylation marks in melanoma cells treated with Lunasin. Lunasin treatment reduced histone acetylation at H3K9 and H4K12, while no difference was seen in acetylation of H4K8 and H3K14 (Figure 37). The present data suggest that Lunasin modulates histone acetylation in melanoma cells resulting in decreased acetylation marks, which may lend 
itself to the anticancer effects of Lunasin. These results are consistent with previously published reports supporting a mechanism in which Lunasin disrupts histone acetylation at $\mathrm{H} 3$ and $\mathrm{H} 4$ histone tails $[9,10]$.
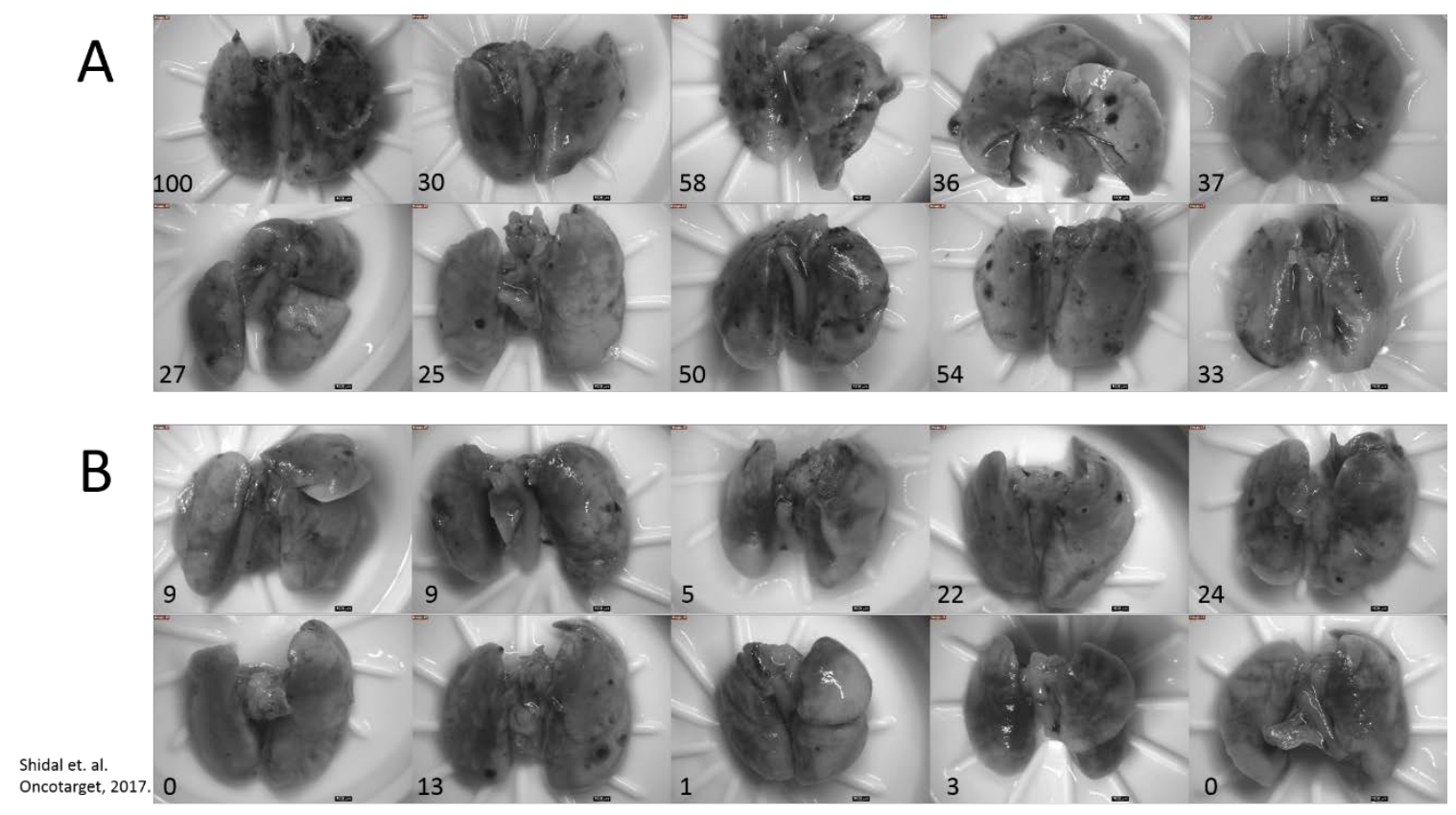

Figure 33: Lungs resected from experimental metastasis in vivo model. Lungs were resected from mice receiving vehicle (A) or Lunasin (B) treatment after implantation of B16-F10 cells. Lunasin-treated mice displayed significantly less tumor burden in pulmonary tissues when compared to vehicle-treated mice. The number of macrometastatic lesions observed for each set of lungs is shown in the bottom left of each image.

Interestingly, $\mathrm{ALDH}^{\text {high }}$ and $\mathrm{ALDH}{ }^{\text {low }} \mathrm{A} 375$ cells had somewhat contrasting integrin expression profiles; ALDH ${ }^{\text {high }}$ cells expressed integrin subunits $\alpha_{\mathrm{V}}$ and $\beta_{3}$ more abundantly than ALDH ${ }^{\text {low }}$ cells when grown in anchorage independent culture, while $\mathrm{ALDH}^{\text {low }}$ cells seemed to express higher levels of $\alpha_{5}$ and $\beta_{1}$ integrin subunits (Figure 38). These data may suggest a mechanism for the increased disruption of integrin-associated signaling in cells derived from ALDH ${ }^{\text {high }}$ CICs when compared to cells from the nonCIC compartment (i.e. ALDH ${ }^{\text {low }}$ ).

\section{The RGD-domain is essential for Lunasin uptake and disrupting oncosphere formation}

Immunoblot analyses implicated suppression of integrin signaling and effects on histone acetylation as being important for Lunasin action. To investigate whether these mechanisms are required 
for Lunasin activity, peptides were synthesized in which the RGD domain or poly-D tail were mutated in order to disrupt Lunasin’s interaction between integrins or histones, respectively. The generation of oncospheres was utilized as a surrogate assay to identify the effect of Lunasin on CIC clonogenicity. No difference in the ability of A375 ALDH ${ }^{\text {high }}$ cells to form oncospheres between vehicle-treated cells and cells treated with RAD-mutated peptide was observed. Conversely, cells treated with native Lunasin $(\mathrm{p}<0.001)$ and the scrambled tail peptide $(\mathrm{p}=0.0013)$ had a significantly reduced ability to form oncospheres in anchorage-independent culture (Figure 39). These data suggest that the RGD domain, which interacts with integrins, is necessary for preventing sphere formation by CICs.

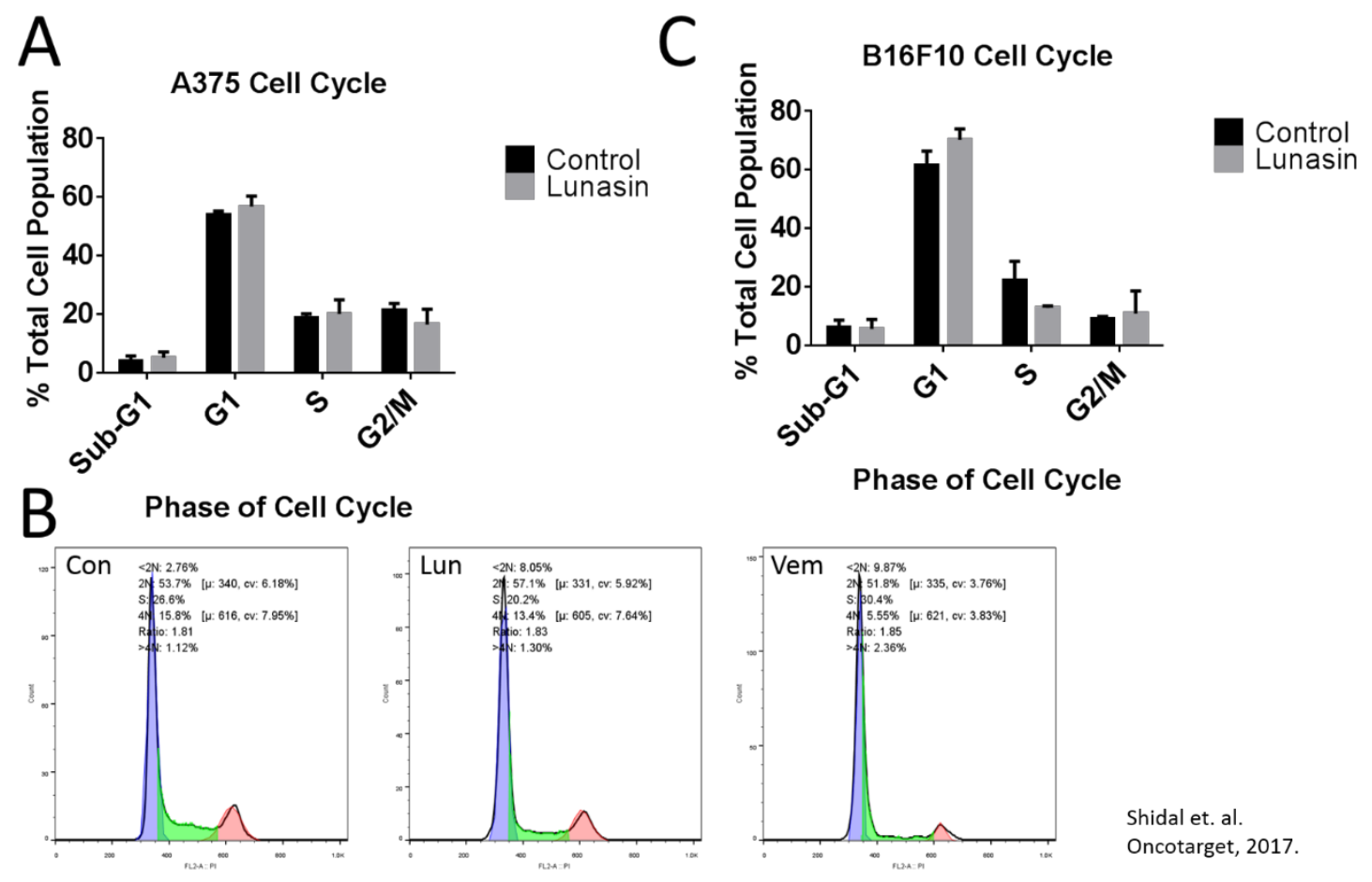

Figure 34: Cell cycle was not significantly affected by Lunasin. A375 (A) and B16-F10 (B) ALDH ${ }^{\text {high }}$ cells were treated with $100 \mu \mathrm{M}$ Lunasin, and stained with PI for analysis of cell cycle. No significant difference in populations in G1, S-phase, or G2/M was observed with Lunasin treatment compared to control in either cell line. A representative image shows the cell cycle curve for control, Lunasin, and vemurafenib (positive control) as analyzed using FlowJo cell cycle analysis software. Data were obtained from three independent experiments and shown as mean \pm s.d. Statistical significance was determined by student’s t-test $(\mathrm{p}<0.05)$, and significant values are denoted by an asterisk $(*)$. 
An endocytic mechanism by which Lunasin is internalized has been reported in human macrophages [38]. Since the RGD domain appears to be necessary for Lunasin’s disruption of oncosphere formation, it was next asked whether or not the RGD domain was essential for Lunasin's internalization. A375 cells, which express the RGD-recognizing integrin subunits $\alpha_{\mathrm{V}}$ and $\alpha_{5}$, were treated with $100 \mu \mathrm{M}$ native Lunasin (Figure 40A) or RAD-Lunasin (Figure 40B) for 5, 10, 30, and $60 \mathrm{~min}$. Cells were fixed and probed for Lunasin using a rabbit polyclonal antibody which was confirmed to recognize the mutated peptide sequence. Although Lunasin was detected intracellularly in cells treated with both native and RAD-mutated peptides, fluorescent intensity was much higher in cells treated with native Lunasin compared to RAD-Lunasin. Interestingly, RAD-Lunasin never localized in the nucleus, while the native peptide was observed in the nucleus after 10-30 m. These data support the notion that Lunasin's internalization is integrin-dependent, and may explain why the RGD domain is an integral part of Lunasin's anticancer activity.

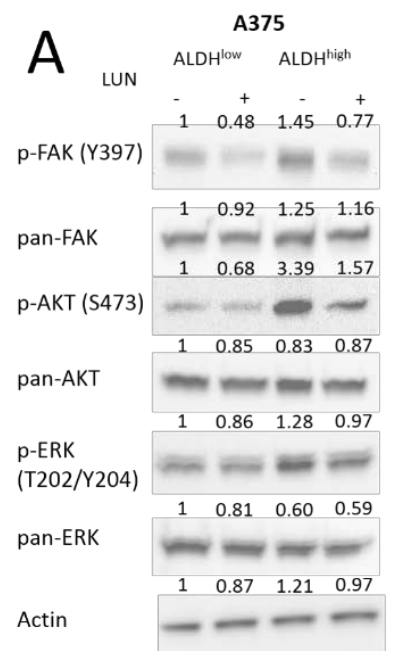

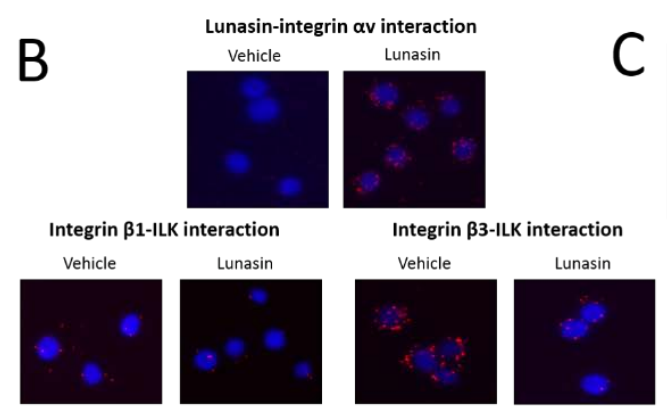

Integrin $\beta 1$-pFAK interaction

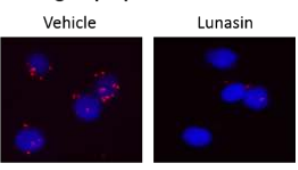

Integrin $\beta 3$-pFAK interaction
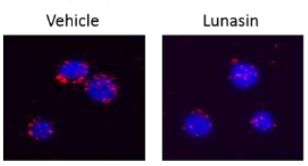

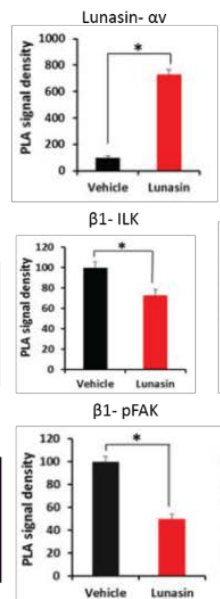

Adapted from Shidal et. al. Oncotarget, 2017.

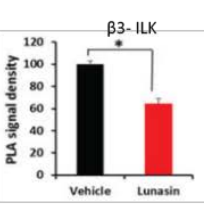
B3- PFAK

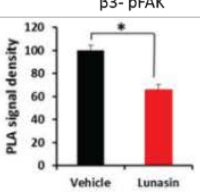

Figure 35: Lunasin suppressed integrin signal transduction. $A L D H^{\text {high }}$ and $A L D H^{\text {low }}$ cells derived from the A375 melanoma cell line were treated with $100 \mu \mathrm{M}$ Lunasin in low adherent culture for $24 \mathrm{~h}$, and the resulting lysates were probed for integrin-associated signaling proteins (A). Reductions in phosphorylation patterns of FAK, AKT, and ERK in ALDH ${ }^{\text {high }}$ cells were observed in Lunasin-treated ALDH ${ }^{\text {high }}$ cells, while only a modest effect was observed on FAK phosphorylation in $\mathrm{ALDH}^{\text {low }}$ cells (A). Actin was used as a reference protein. Relative protein expression (normalized to control) is shown above corresponding bands. Additionally, PLA assays were utilized to validate that Lunasin was targeting integrin signal 
transduction (B). A significant decrease ( $40-50 \%)$ in fluorescence signals per cell were observed when interactions between integrins and ILK/pFAK were detected in vehicle and Lunasin-treated cells (C).

These results suggest Lunasin decreased the interactions between integrin $\beta$ subunits and the intracellular kinases FAK and ILK.

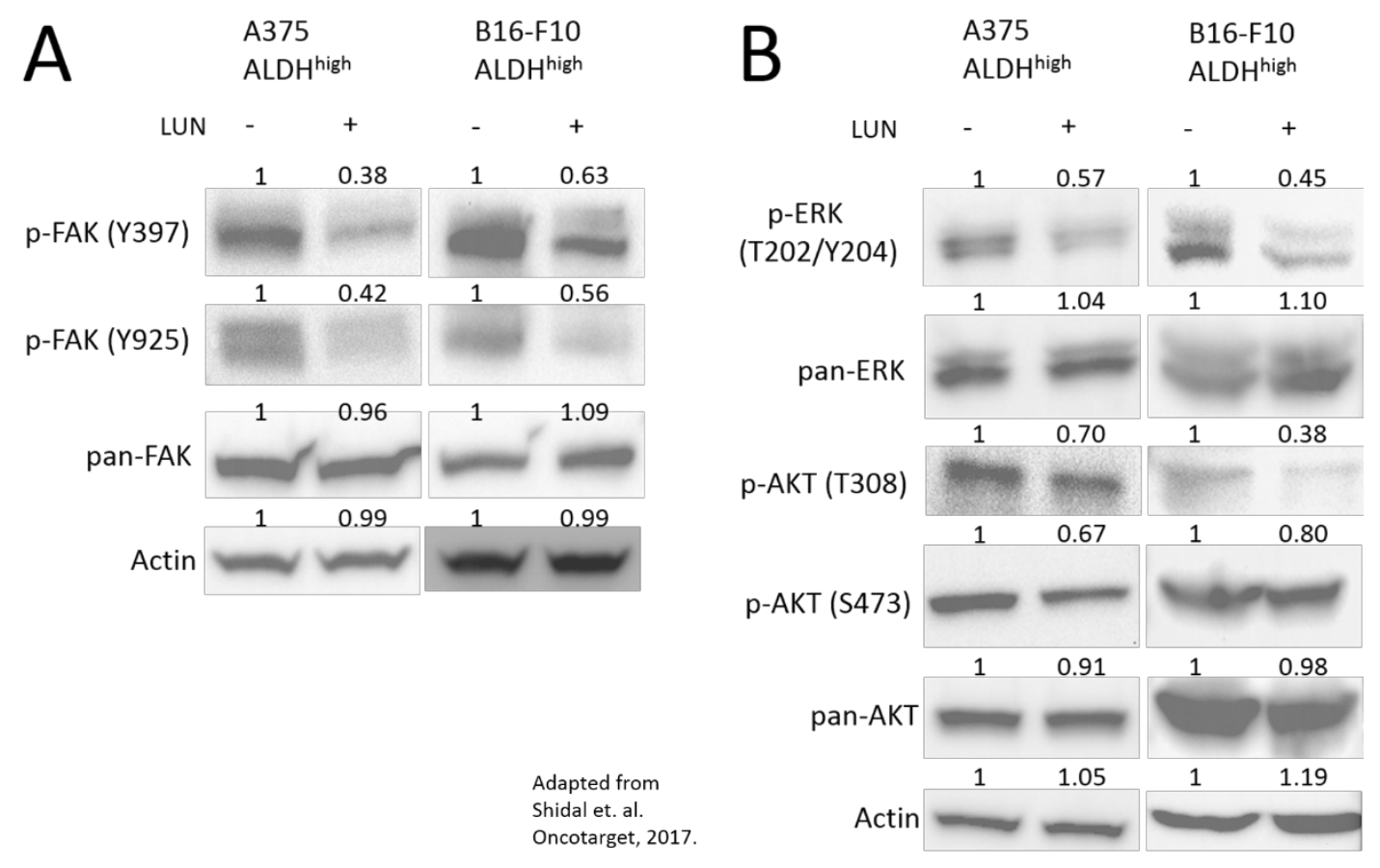

Figure 36: Lunasin inhibited phosphorylation of FAK, AKT, and ERK. ALDH ${ }^{\text {high }}$ cells derived from human A375 and murine B16-F10 melanomas were treated with Lunasin for $24 \mathrm{~h}$, and the resulting cell lysates were subjected to SDS-PAGE and probed for integrin-associated signaling pathways. Lunasin inhibited activating phosphorylations of FAK (A), AKT (B), and ERK (B) at several amino acid residues. Immunoblot analysis of integrin-associated pathways were performed in two independent experiments. Densitometry analysis was performed, normalized to control, and is denoted above each representative band. 


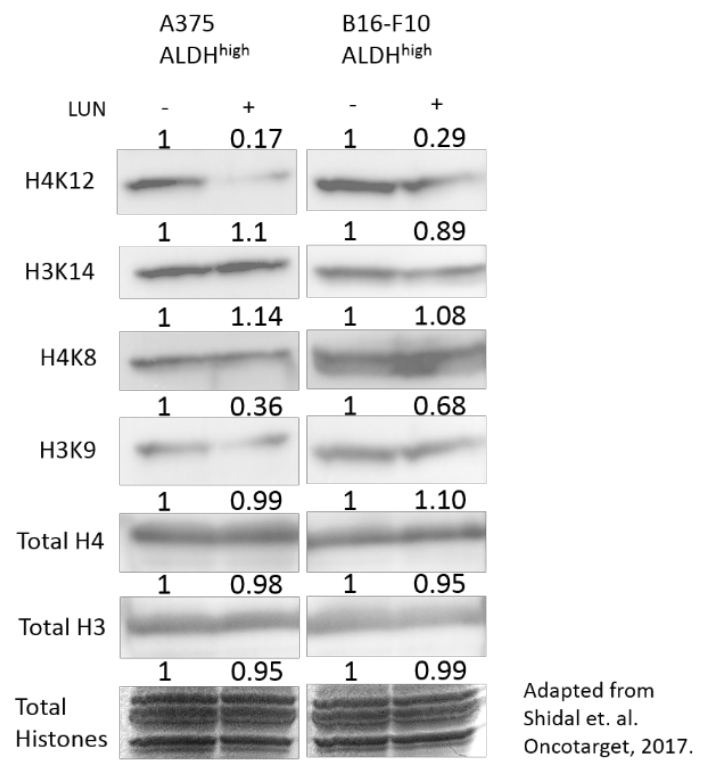

Figure 37: Lunasin modulates histone acetylation. It was observed that Lunasin treatment caused a decrease in histone acetylation at H3K9 and H4K12, which suggests epigenetic modification may play a role in Lunasin's effects on melanoma CICs. Histone acetylation was assessed by immunoblot and relative protein expression (shown above corresponding bands) was taken from analysis of two independent experiments.

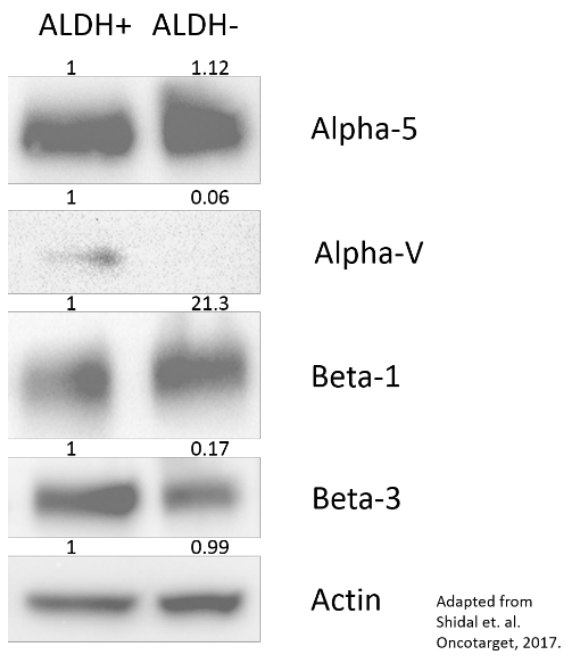

Figure 38: Differential expression of integrin subunits by melanoma CICs. A375 ALDH ${ }^{\text {low }}$ and $\mathrm{ALDH}^{\text {high }}$ cells were isolated by FACS, and lysates were subjected to SDS-PAGE. Integrin expression profiles show that ALDH ${ }^{\text {high }}$ cells express higher levels of $\alpha_{\mathrm{V}}$ and $\beta_{3}$ subunits when compared to $\mathrm{ALDH}^{\text {low }}$ 
cells. ALDH ${ }^{\text {low }}$ cells showed higher abundance of integrin $\alpha_{5}$ and $\beta_{1}$ subunits when compared to samples from ALDH ${ }^{\text {high }}$ cells.
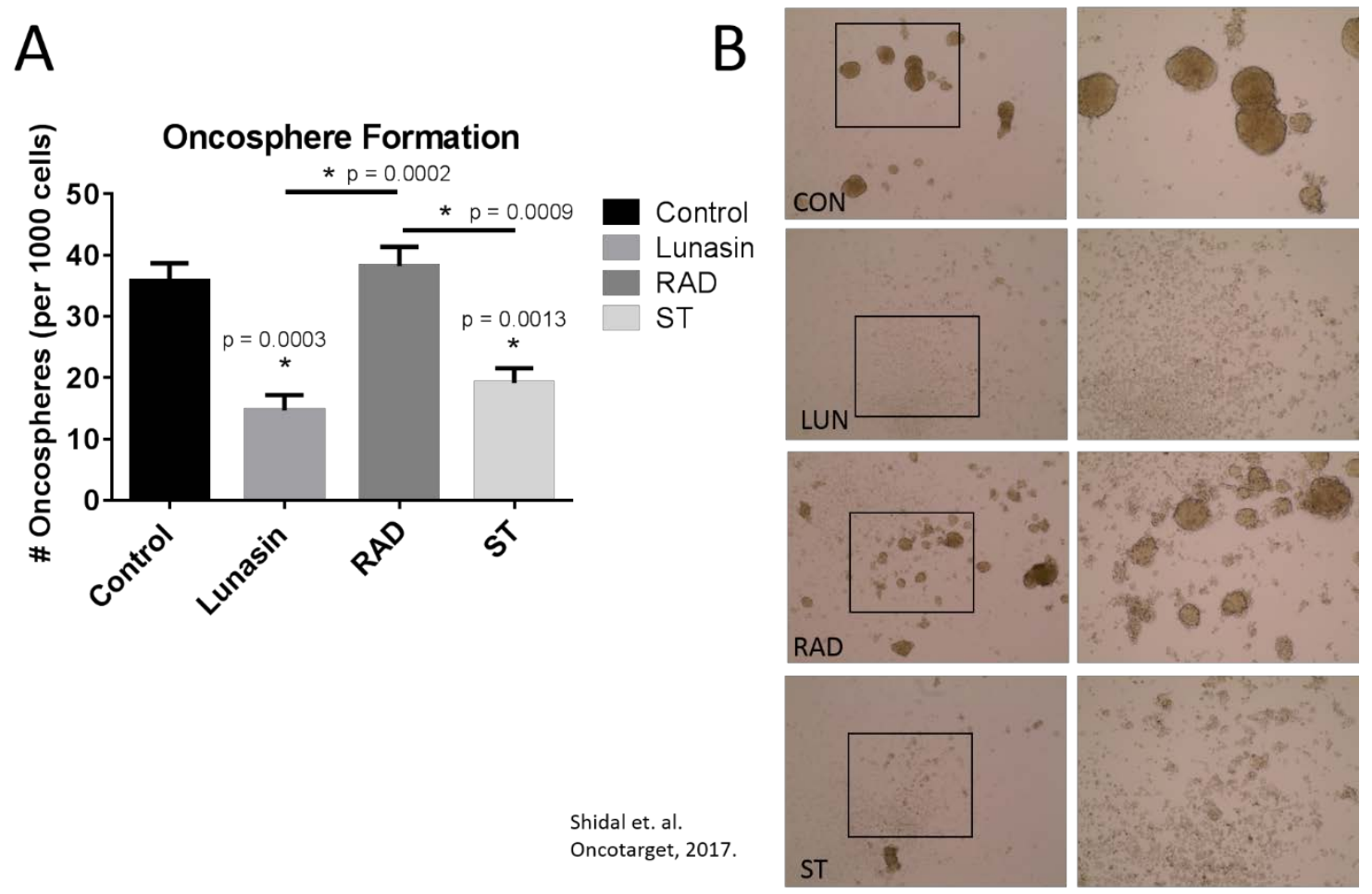

Figure 39: Lunasin's RGD motif is essential for disrupting oncosphere formation. Mutated peptides based on Lunasin's activity domains were synthesized and used to treat A375 ALDH ${ }^{\text {high }}$ cells in low adherent culture. Vehicle-treated cells readily formed oncospheres, but native Lunasin disrupted oncosphere formation (A). When the RGD sequence was mutated to RAD, Lunasin lost its ability to inhibit oncosphere formation, while a peptide containing a scrambled tail retained the ability to inhibit oncosphere generation (A). Representative images taken at 10x (left) and 20x (right) demonstrate the ability of the peptide to inhibit oncosphere formation (B). Averages from three independent experiments were plotted at mean \pm s.d. Statistical significance was determined by student's t-test and denoted by an asterisk. 

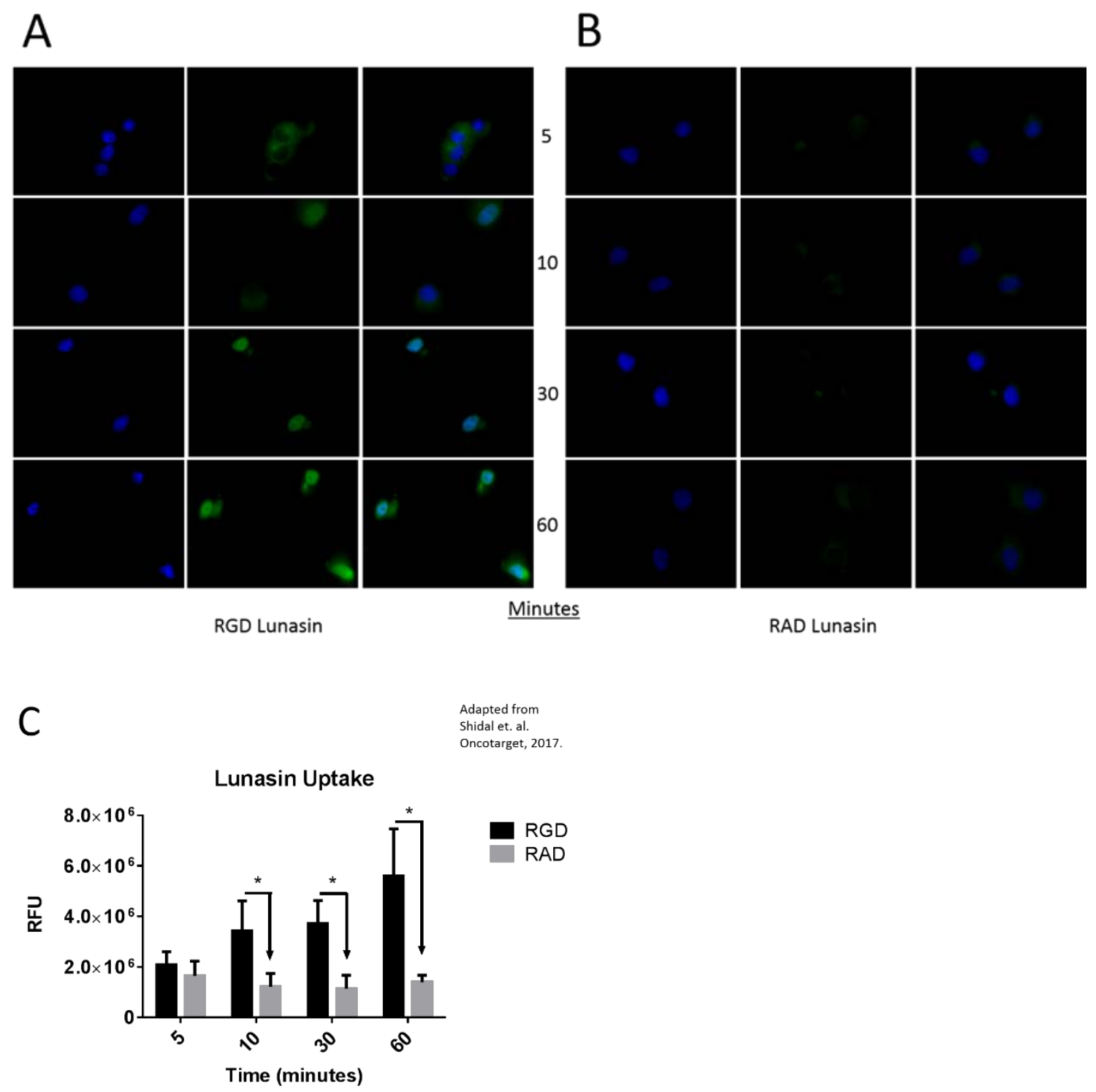

Figure 40: Lunasin uptake is an integrin-dependent process. RGD (A) and RAD (B) Lunasin peptides were incubated with A375 cells for various time points up to $1 \mathrm{~h}$. While some RAD-Lunasin was detected, cells treated with RGD-Lunasin (native) showed significantly more abundant intracellular Lunasin as illustrated by a significantly increased fluorescent signal (C). Additionally, it was observed that native Lunasin with an intact RGD motif was localized in the nucleus of A375 cells after just 10 min, while RADLunasin was only detected in the cytoplasm at up to $1 \mathrm{~h}$ after treatment. Images represent data obtained from two independent experiments, and is plotted as average fluorescence per cell \pm s.d. Statistical 
significance was determined by student’s t-test $(\mathrm{p}<0.05)$. An asterisk $(*)$ denotes significance between RGD and RAD peptides at the respective time points.

\subsection{DISCUSSION}

The findings that Lunasin reduced metastatic dissemination in vivo and invasion through Matrigel in vitro, support the unique hypothesis that RGD peptides may help alleviate patient relapse in malignant melanomas. Chapter 4 shows that mechanisms previously described for Lunasin's anticancer effects persist in melanoma models, and perhaps most importantly, are exacerbated in isolated CIC populations. Uptake and internalization of Lunasin in A375 cells was shown to be integrin-dependent and correlated with the expression of the integrin $\alpha_{\mathrm{V}}$ subunit. Colocalization of Lunasin with integrin subunits was observed at several time points varying from $4 \mathrm{~h}$ to $24 \mathrm{~h}$, and localization of Lunasin in both the cytoplasm and nucleus was observed for all time points. These data are in agreement with previously reported studies on Lunasin's interaction and uptake with specific integrin subunits [12, 38]. Interestingly, a morphological difference between A375 cells treated with Lunasin and vehicle was observed. Intracellular localization of integrin $\alpha_{V}$ in Lunasin-treated cells was observed, while integrin $\alpha_{V}$ was found only on the periphery of vehicle-treated cells. These data indicate that Lunasin was readily internalized in A375 cells, and support the previously described endocytic mechanism reported in human macrophages [38].

The Davis lab has previously published results using human melanoma cell lines showing that Lunasin efficiently reduced pools of CICs based on the ALDH biomarker, and resulted in disrupted oncosphere formation when ALDH ${ }^{\text {high }}$ cells were plated in stem cell media in anchorage-independent culture conditions [228] (described in Chapter 3, page 43). Additionally, it was found that Lunasin induced expression of melanocyte-associated differentiation markers MITF and Tyrosinase (described in Chapter 3, page 46). Low-MITF expressing populations in melanomas have been described to harbor a slow cycling stem-like population with intrinsic chemoresistant and tumorigenic properties [200]. It was recently reported that MITF regulates melanoma invasion through Rac/Rho GTPases [280], which supports previous evidence showing MITF is explicitly involved in melanoma progression [281, 282]. This is a particularly interesting discovery given the regulation of Rac1 by integrins [283]. 
In the present study, a significant decrease in B16-F10 oncosphere generation was observed when cells were treated with $100 \mu \mathrm{M}$ Lunasin concomitant with a significant decrease in the ALDH-positive population of cells, which has been reported to bear the CIC fraction responsible for tumor formation and metastasis [103]. When the in vitro invasive potential of A375 and B16-F10 ALDH ${ }^{\text {high }}$ cells was measured, Lunasin-treated cells were significantly less capable of invading through the basement membrane when compared to vehicle-treated cells). These data are in agreement with Lunasin’s effect on depleting ALDH ${ }^{\text {high }}$ populations [228], which may be responsible for metastatic dissemination [103, 106, 228]. When C57Bl/6 mice were subjected to an experimental metastasis model of melanoma using B16F10 cells, Lunasin treatment significantly suppressed the ability of these cells to invade and proliferate in the lungs. Two mice in the Lunasin-treated group displayed no sign of macrometastases suggesting that Lunasin was an effective treatment for reducing or abolishing metastatic burden altogether. It was demonstrated that Lunasin inhibited subcutaneous tumor growth of murine models of melanoma and NSCLC [275]. Utilizing immunocompetent preclinical models of cancer allows researchers to explore the complex relationship between host immunity and tumor microenvironment; this especially holds true given the immunogenic nature of melanomas [136, 284]. It has been found that Lunasin has robust immune boosting effects, and may improve vaccine efficacy by promoting dendritic cell maturation [41, 42]. Furthermore, Lunasin synergistically enhanced the cytotoxic effect of NK cells when combined with cytokine therapy [13]. The exciting possibility that Lunasin not only directly affects cells by reducing integrin signaling or histone acetylation, but can also "prime" the innate immune system to repress cancer cell proliferation illustrates the extremely promising benefits of the peptide that deserve further study. As described in Chapter 3 [228], Lunasin has a selective effect on melanoma CICs compared to bulk tumor cells. It was questioned whether these selective effects would persist when integrin signal transduction was evaluated. Phosphorylations of FAK, AKT, and ERK, intracellular kinases downstream of integrins, were significantly reduced when A375 and B16-F10 cells were treated with Lunasin; A more robust effect was observed in the $\mathrm{ALDH}{ }^{\text {high }}$ cells when compared to the ALDH ${ }^{\text {low }}$ cells. These mechanisms have been described in several cancer models including breast [227], colon [36], and lung cancer [10]; however, the Davis lab is the first to report that CICs are more sensitive to Lunasin's integrin antagonism in melanoma. Given the explicit involvement of FAK and AKT in carcinogenesis, progression, and 
metastasis [195, 234], these results are promising especially taken in conjunction with the finding that Lunasin decreased CIC pools.

Lunasin sensitivity of A375 ALDH ${ }^{\text {high }}$ and $\mathrm{ALDH}^{\text {low }}$ cells correlates with differential expression of specific integrin subunits when cultured as spheres in low-adherent conditions. ALDH ${ }^{\text {high }}$ cells expressed relatively higher amounts of $\alpha_{\mathrm{V}}$ and $\beta_{3}$ integrin subunits, while ALDH ${ }^{\text {low }}$ cells expressed comparatively higher levels of $\alpha_{5}$ and $\beta_{1}$ integrin subunits. The complexities of integrin signal transduction mechanisms remain somewhat of a mystery; however, new research has revealed disparities in signaling coordinated though $\alpha_{v} \beta_{3}$ integrins and $\alpha_{5} \beta_{1}[285,286]$. In fact, expression of specific integrins in stem cell-like cancer cells has been reported in other cancer models including prostate [196] and breast [198], which may reveal a potential weakness of CICs that provides a potential therapeutic target to specifically inhibit CIC expansion.

Histone acetylation by HATs (Reviewed in [287]) results in chromatin remodeling to allow for the initiation of transcription; efficient histone acetylation is necessary for replicative machinery to initiate transcription of target genes. Thus, targeting HATs appears an attractive means to reduce cancer cell proliferation. Lunasin's activity as a HAT inhibitor has been described [20]. Histone acetylation in A375 and B16F10 ALDH ${ }^{\text {high }}$ cells was affected with Lunasin treatment; however, Lunasin induced different acetylation patterns in melanoma when compared to previously reported results in NSCLC [10]. Recently, it was shown that HAT inhibition preferentially induced apoptosis and inhibited stem-associated markers in a NSCLC model [288]. While an induction of apoptosis in melanoma was not observed, many of the results described in Chapters 3 and 4 parallel those obtained in this study, suggesting a potential link between suppression of CIC invasion and Lunasin’s epigenetic mechanisms.

The present study suggests that inhibition of integrin signaling is the primary mechanism mediating Lunasin's effects in melanoma stem cells. When the RGD domain of Lunasin was mutated, Lunasin lost its ability to disrupt oncosphere formation, a surrogate assay for stem cell identification and propagation. Mutating the poly-aspartic acid tail seemingly had no effect on oncosphere formation. This result implies that the poly aspartic acid tail is not required for inhibiting CIC clonogenicity; however, functional assays utilizing siRNA-mediated knockdown of both integrins and histone acetylation would provide a more suitable system to test this hypothesis. Though supporting evidence shows that stem cells 
can be maintained through integrin signaling [289], further research must be conducted to unequivocally determine that integrin antagonism is the sole mechanism for Lunasin's reduction of the CIC compartment, especially given that CICs may also be maintained by histone acetylation [290]. This is particularly interesting considering that when p300, a HAT whose activity is antagonized by Lunasin [33], was knocked out in embryonic stem (ES) cells, Nanog expression was markedly reduced yet, self-renewal capacity (a function measured by oncosphere formation) was not significantly affected [291]. These results corroborate findings from a previous study [228] (described in Chapter 3, page 47) showing Lunasin treatment resulted in a significant reduction in Nanog levels; however, Lunasin treatment also robustly inhibited sphere formation, suggesting oncosphere formation may be integrin-dependent and independent of histone acetylation. Crosstalk between integrin signaling and histone acetylation is relatively unexplored; though, evidence that integrin $\beta_{1}$ engagement with ECM proteins may regulate H3 acetylation patterns has been described [292]. The complex signaling circuits between extracellular cues transduced through integrins, and intracellular events leading to changes in histone acetylation patterns is slowly unraveling; however, several key pieces of the puzzle remain. Lunasin may serve as a key tool to bridge the gap between these two interesting and highly complex signaling pathways.

In summary, the present study found that Lunasin has robust antimetastatic properties in vitro and in vivo. CICs, characterized by elevated ALDH activity, showed a greater disruption in integrin signaling induced by Lunasin treatment when compared to non-CICs as assessed by downstream activating phosphorylations of FAK and AKT. In agreement with the studies described in Chapter 3, it was shown that B16-F10 cells exhibited Lunasin-dependent depletion of $\mathrm{ALDH}^{\text {high }}$ populations, and disruption of oncosphere formation. While Lunasin also altered histone acetylation patterns, Lunasin's effects in melanoma appear to be largely an integrin-dependent process. The present study extends upon the novel therapeutic approach that using Lunasin to reduce pools of CICs will ultimately lead to decreased invasion and subsequent metastatic outgrowths. By modulating integrin signaling through FAK and PI3K/AKT pathways as well as altering histone acetylation patterns, Lunasin’s complex and multifaceted anticancer activities suggest a potential therapeutic utility against malignant diseases in which recurrence due to CICs is likely. Given the results presented in this dissertation as well as those from others, a sufficient body of 
evidence has been presented to examine the clinical utility of Lunasin as an antimetastatic agent in patients with late stage cancers that are at risk of further metastatic dissemination. 


\section{CHAPTER 5: DISCUSSION AND CONCLUSIONS}

\subsection{Restatement of Specific Aims}

Specific Aim 1: Identify the mechanisms in which Lunasin targets CICs

Sub Aim A. Assess the ability of Lunasin to reduce populations expressing CIC and stemassociated markers

Sub Aim B. Characterize the effects of Lunasin on CICs through analysis of proliferative, apoptotic, and differentiation markers

Specific Aim 2: Evaluate the interaction between Lunasin and integrin subunits

Sub Aim A. Specify the explicit integrin subunits interacting with Lunasin and identify the downstream mediators of integrin signal transduction

Sub Aim B. Mutate the Lunasin peptide to discriminate the effects caused by histone acetyltransferase inhibition and integrin antagonism

Sub Aim C. Genome-wide microarray analysis to discover Lunasin associated gene targets Specific Aim 3: Investigate the antimetastatic effects of Lunasin

\subsection{Summary of Findings and Impact of the Work}

The overall aim of this dissertation was to investigate the therapeutic benefit that Lunasin may achieve in malignant melanomas, and identify the potential mechanisms driving its anticancer properties. Initially, it was demonstrated that Lunasin suppressed melanoma cell growth in 3D in vitro assays as well as in vivo. In Chapter 3, these studies were expanded to describe the selective effects of Lunasin on CICs, identified by elevated ALDH activity. It was shown that Lunasin efficiently reduced ALDH-high populations, a subset of cells that harbor the stem cell-like population, and consequently inhibited the functional characteristics and self-renewal capabilities of these cells. Mechanistically, Lunasin drastically decreased integrin signaling through FAK, AKT, and ERK while also inducing a differentiated phenotype with reduced expression of stem-associated markers. Data presented in Chapter 4, investigated the antimetastatic effects of Lunasin on melanoma CICs, and elucidated the potential mechanisms underlying 
Lunasin’s antimetastatic activity. Given the significant involvement of CICs and integrin signaling in metastatic dissemination, this work aims to explain how Lunasin may be useful clinically in patients with malignant diseases. This dissertation advances the potential utility of the novel therapeutic Lunasin which is largely unexplored and additionally, provides a compelling argument for the development of Lunasin, not only in melanoma, but malignant diseases in which CICs can produce refractory tumors.

The first aim of this work was to define the selective effects of Lunasin on CICs by assessing proliferation, apoptosis, and differentiation markers, and additionally, show that Lunasin induced a movement of cells out of the CIC compartment (defined by elevated ALDH activity) and into the non-stem compartment (i.e. ALDH ${ }^{\text {low }}$ ). The human melanoma cell lines A375 and SKMEL-28 had subpopulations of cells with both $\mathrm{ALDH}^{\text {high }}$ and ALDH ${ }^{\text {low }}$ activity. In both cell lines, Lunasin induced a shift of cells from the $\mathrm{ALDH}^{\text {high }}$ compartment to the $\mathrm{ALDH}^{\text {low }}$ compartment without decreasing cell viability or cell cycling. This phenotype switch was concomitant with an induction of melanocyte-associated differentiation markers MITF and its downstream target Tyrosinase. A significant decrease in the stem-associated transcription factor NANOG was observed when melanoma cell lines were treated with Lunasin. NANOG has been shown to control stemness and self-renewal properties of physiological stem cells as well as CICs [293]. Perhaps the most interesting discovery from these initial studies is the fact that CICs were more sensitive to Lunasin when compared to parental cells in vitro. This exacerbated effect on melanoma CICs persisted in vivo when nude mice were subcutaneously injected with parental and ALDH ${ }^{\text {high }}$ A375 cells. Lunasin's safety profile was also quite promising; no cytotoxicity was observed in mice receiving i.p. injections of Lunasin at $30 \mathrm{mg} / \mathrm{kg}$. Liver and kidney functions were not significantly impaired, nor was a significant difference in CBC counts observed between mice receiving vehicle and Lunasin-treated mice.

To follow up the studies presented in Chapter 3, Chapter 4 questioned whether Lunasin's effects on CICs were driven by the inhibition of integrin signaling; thus, the second aim of this dissertation was to describe the downstream effectors of integrin signal transduction which may be affected by Lunasin. Additionally, the work in Chapter 4 investigated the effects elicited by Lunasin on integrin antagonism and alterations in histone acetylation patterns. It was revealed that Lunasin's effects in melanoma cells was primarily integrin-driven, and integrin signal transduction through FAK, PI3K-AKT, and ERK was significantly suppressed when melanoma cells were treated with Lunasin. The final sub-aim was to utilize 
a genome-wide microarray screen in order to help reveal selective targets of Lunasin in CICs, but also to define a unique gene signatures between ALDH ${ }^{\text {high }}$ melanoma cells and parental cells. The datasets generated from the microarray analysis revealed the upregulation of EMT-associated genes in ALDH ${ }^{\text {high }}$ populations along with several genes linked to invasion and metastasis. Although Lunasin had a modest effect on both parental and ALDH ${ }^{\text {high }}$ cells treated for $72 \mathrm{~h}$, ALDH-sorted cells had nearly twice as many genes up- or down-regulated when compared to parental cells, which may indicate why isolated CIC were more sensitive to Lunasin. Furthermore, this study validated the use of ALDH as a viable biomarkers for stem-like cells in melanoma models; ALDH ${ }^{\text {high }}$ cells had increased expression of several genes associated with EMT and melanoma invasion.

Given the results presented in Chapter 3 and Chapter 4 describing the robust effects of Lunasin on depleting CIC pools and suppression of integrin signaling, it was hypothesized that Lunasin would have significant antimetastatic effects. Therefore, the final aim of this dissertation was to investigate the proposed antimetastatic effects using an experimental metastasis model. Boyden chamber assays using Matrigel coated inserts provided evidence that in vitro invasion was repressed when A375 and B16-F10 ALDH ${ }^{\text {high }}$ melanoma cells were pretreated with Lunasin. Subsequently, a syngeneic murine model of metastasis was utilized to demonstrate that Lunasin's antimetastatic effects were enduring in vivo. A significant decrease in pulmonary colonization of B16-F10 cells was observed in Lunasin-treated mice when compared to mice receiving vehicle treatment.

Completion of these studies contributed significantly to the field of Lunasin research in several ways. The Davis laboratory is the first to report on the anticancer effects of Lunasin in a melanoma model, and additionally, the first to report that CICs may be more sensitive to Lunasin's inhibition of integrin signaling. The present study also showed that functionally, the RGD domain of the Lunasin peptide is essential for Lunasin uptake as well as its disruption of oncospheres generated from isolated CICs. This dissertation provides substantial evidence supporting that Lunasin has robust antiproliferative effects in subcutaneous xenograft models of melanoma as well as considerable antimetastatic effects in a syngeneic mouse model of experimental metastasis; studies which are largely lacking in the field of Lunasin research. Moreover, this work has created a foundation upon which future studies of Lunasin can draw from in 
addition to provided concepts which could be further expanded upon. These studies support the already solid body of evidence supporting the development of the Lunasin peptide as an anticancer therapeutic.

\section{3: Strengths and Weaknesses of the Dissertation}

This dissertation has several strengths that have contributed significantly to understanding the mechanisms involved in the anticancer activities of Lunasin. Using Lunasin to treat isolated CICs based on the ALDH biomarker is a novel strategy for the treatment of malignant disease in which CICs have been described. Furthermore, the present study compared ALDH ${ }^{\text {high }}$ samples to parental samples in order to differentiate the specific signaling pathways mediating Lunasin-sensitivity. Evidence was provided which supports previous studies involving Lunasin's interactions and uptake with specific integrin subunits, as well as expands upon the idea that Lunasin drives alterations in intracellular signaling cascades involving FAK, AKT, and ERK. Not only do these studies define specific mechanisms implicated in Lunasin’s activity as a chemotherapeutic, but also support the concept that targeting CICs may provide an innovative intervention strategy for malignant diseases.

Another strength of the dissertation is the use of several preclinical in vivo murine models of cancer to demonstrate the ability of Lunasin to inhibit cancer progression in a living system. Immunocompromised mice were utilized to show that Lunasin robustly inhibits human melanoma proliferation in subcutaneous xenograft models of melanoma. An immunocompetent syngeneic mouse model was also utilized to demonstrate that Lunasin significantly suppressed metastatic dissemination to pulmonary tissues of mice injected with the highly metastatic B16-F10 cell line. Both immunocompromised and immunocompetent mouse models have distinct advantages and disadvantages. By using both types of murine models, this dissertation demonstrates that Lunasin has robust anticancer effects regardless of host immune status, or species from which the cancer cells are derived.

Although preclinical murine models can mimic human diseases, there are several distinct differences between model organisms and humans. Firstly, subcutaneous xenografts do not recapitulate the correct microenvironment from which a human tumor will arise. Although the human condition cannot be exactly recapitulated in murine models, certain cellular processes such as angiogenesis or proliferation can somewhat be observed within the tumor microenvironment; however, these model are lacking the interactions typically reserved between tumor stroma and surrounding tissues. Additionally, these studies 
cannot accurately mimic the de novo formation of tumor cells; nor do subcutaneous tumors readily progress to malignant disease, therefore, limiting subcutaneous models to essentially measuring in vivo tumor proliferation, but not progression.

Experimental metastasis models have the advantage of being quick, easy, and reproducible. Yet, injecting tumor cells intravenously does not account for the early cellular changes involved in metastatic dissemination. Because these cells are already in systemic circulation, this model avoids important processes involved in metastasis including invasion of surrounding tissues and extravasation. While melanomas commonly metastasize to the lungs, experimental metastasis models are generally confined to producing pulmonary lesions and do not allow for colonization of other common metastatic sites such as the brain, bone, or lymph nodes.

The lack of positive controls for several in vitro assays is another source of potential error. In order to determine if the assay(s) is working correctly, positive controls must be included in the analysis of apoptosis, proliferation, and invasion. For Annexin V binding assays and immunoblot analysis of apoptosis-associated proteins, a positive control (e.g. staurosporin) should have been included. Additionally, the inclusion of an agent known to inhibit proliferation of melanoma cells (e.g. vemurafenib) should have been included in the tetrazolium-based proliferation assays. Many of these controls were used in prior experiments to demonstrate that the assays were performing as expected; however, were not included in the representative experiments shown in this dissertation. The absence of such controls lowers the potential impact of such studies, and should be included in any future studies. Furthermore, many assays utilizing PB (the vehicle in which Lunasin is dissolved) as a control would benefit from the addition of an RGD tripeptide control. The simple addition of this tripeptide as a control would potentially explain if perhaps Lunasin's activity is significantly higher due to mechanisms other than those associated with its RGD domain. Several experiments in which immunoblot analysis revealed a significant impact on integrin-associated signal transduction would have benefitted from the inclusion of several concentrations of Lunasin; the addition of multiple treatment groups would demonstrate whether or not the observed effects were dose-dependent. Furthermore, several techniques could have been used to definitively demonstrate that mutated peptides were interacting with integrin subunits including knockdown of integrins and subsequent Lunasin internalization, saturation binding assays, or competition binding assays. The 
addition of such an assay would strengthen the discussion on whether or not the RGD motif is necessary to Lunasin’s activity in melanoma cells.

Perhaps the most glaring weakness of this dissertation is the use of cell lines without employing any primary melanoma cultures. Several disadvantages to using cell lines include: 1) the continual passage in culture can alter cellular phenotypes, 2) without genotyping the status of several critical genes involved in specific models of cancer (e.g. B-Raf) can be ambiguous, 3) cross-contamination and mycoplasma, and 4) they do not accurately mimic primary cultures. Although many of these problems can be avoided through simple testing procedures, purchasing from approved vendors, and using proper controls in experiments, using cell lines can be especially problematic when studying CIC populations.

While the experimental system used to identify changes in gene expression in the genome-wide microarray analysis was robust and technically sound, it is necessary to validate these results by qRT-PCR as well as determine the subsequent changes in protein levels. Conversely, the inclusion of several technical replicates, sample integrity, and stringent analysis minimized any artifacts or false discoveries resulting from the array.

It was observed that ALDH ${ }^{\text {low }}$ cells derived from A375 and SKMEL-28 cell lines tended to "dedifferentiate” into ALDH ${ }^{\text {high }}$ cells when grown in culture (described in Chapter 3). This is counter to some studies in which ALDH-sorted cells were isolated from primary melanomas; ALDH ${ }^{\text {high }}$ cells could differentiate into $\mathrm{ALDH}^{\text {low }}$ cells, but $\mathrm{ALDH}^{\text {low }}$ cells did not generate $\mathrm{ALDH}{ }^{\text {high }}$ populations. Whether this is a condition of using cells that have been propagated in culture, plasticity in $\mathrm{ALDH}^{\mathrm{low}}$ melanoma cells, or a "rebound" effect initiated by cells trying to recapitulate the balance of heterogeneous populations in parental cell lines remains unclear.

\section{4: Future Studies}

The questions answered in this work, while significant to the field of Lunasin, created several new questions that will need to be investigated to obtain a more thorough understanding of the novel mechanisms described in CICs as well as the role they play in tumorigenesis and metastasis. Listed below are several of these questions:

\section{What is the connection (if any) between integrin signaling and histone acetylation?}


While this study linked several of Lunasin's effects in melanoma to integrin signaling, a significant change in histone acetylation patterns was also observed. Without functional studies which manipulate integrin signaling and measure the resulting histone acetylation patterns (or vice versa), it is impossible to determine unequivocally that these effects are only driven by integrin signaling networks. Using peptides with mutated activity domains, it was shown that uptake and localization of Lunasin intracellularly was associated with the interaction between the RGD domain and integrins. In RADLunasin-treated samples, a minimal fluorescent signal was observed when probing for Lunasin. However, some Lunasin in the cytoplasm was observed, which may suggest an alternative mechanism for Lunasin internalization.

\section{What are the pharmacokinetic properties of Lunasin?}

Lunasin has been shown to be bioavailable in men consuming applicable amounts of soy protein; however, kinetic profiling of Lunasin in vivo has been a rather unexplored field. Obtaining metabolomics data in a relevant system is paramount to developing any therapeutic. Because this study used comparatively high concentrations of Lunasin in vitro, many questions arise to the practicality and correlation to achievable concentrations in vivo. While the authors digress that Lunasin's kinetic properties are unknown, several biologics including peptide therapeutics and monoclonal antibodies are dosed at similar ranges to the in vivo studies in this work which utilized Lunasin at a concentration of $30 \mathrm{mg} / \mathrm{kg}$. More importantly, robust anticancer effects were achieved using this dosing regimen while also observing minimal dose-limiting toxicity.

\section{What therapeutics could be used in conjunction with Lunasin to achieve a synergistic response?}

Novel, first-line therapeutics to battle cancer are essential to the development and evolution of chemotherapy; however, several institutions are focusing on combination therapies to combat diseases traditionally treated with single agents; malignant melanomas are often treated with temozolomide as the only agent of the chemotherapeutic arm. While these strategies may alleviate some primary and secondary tumor growth, they simply are not effective in the long-term treatment of recurrent malignant diseases. Combination therapy allows for several advantages over traditional single agent approaches including less dose-associated toxicity, minimizing chemoresistance, and modulation of several oncogenic pathways. 
Initial studies in the Davis laboratory have focused on utilizing molecules which affected histone acetylation in combination with Lunasin in order to induce a synergistic response in cancer cells. While little positive data were obtained from these studies, they seem to support the hypothesis that Lunasin's anticancer effects are primarily integrin-driven. Indeed, combinations of vemurafenib and Lunasin resulted in an additive/ slightly synergistic interaction. Because Lunasin does not induce apoptosis or inhibit proliferation in vitro, the authors do not foresee using the peptide as a stand-alone therapeutic; a real-world application of Lunasin as an adjuvant therapy seems much more likely.

\section{Does Lunasin target EMT-associated genes?}

It was demonstrated that Lunasin repressed the invasive phenotype of melanoma CICs; however proteins associated with EMT were not explored in this study. Since the experimental metastasis model used in this dissertation does not accurately mimic EMT and extravasation, it would be interesting to explore the modulation of EMT-associated genes that are potentially targeted by Lunasin. For example, assessing the effect of Lunasin on Notch, TGF- $\beta$, Wnt/ $\beta$-Catenin, and BMP signaling may provide a critical perspective in further describing mechanisms associated with Lunasin's antimetastatic properties.

\section{How does Lunasin modulate the expression of differentiation-associated biomarkers?}

A novel component of this study was revealing the activity of Lunasin on the induction of melanocyte-associated differentiation markers. Several proteins can regulate MITF expression including AKT yet, a major unanswered question to this dissertation is how Lunasin induced MITF. What upstream pathway(s) was associated with the observed effects on MITF protein expression? Answering these questions would unravel the mechanisms behind Lunasin’s function as a differentiation-inducing agent, and perhaps the mechanisms behind the suppression of self-renewal capacity of CICs. While it was shown that Lunasin treatment suppressed Nanog levels, it was not conclusively answered how Lunasin was inhibiting Nanog expression, and whether this effect was a result of altered integrin signaling, histone acetylation, or some other mechanism.

\section{Can Lunasin prevent UV-mediated melanomagenesis?}

As several studies have shown, Lunasin has significant chemopreventive activity in chemical and viral oncogene-induced carcinogenesis [27]. In the case of melanoma, the greatest risk factor is ultraviolet (UV) exposure. Examining the literature on Lunasin revealed that there have been no studies investigating 
whether Lunasin's chemopreventive activity would apply to a UV-induced model of carcinogenesis. The data presented in this dissertation would indicate that Lunasin has significant antimelanoma effects, yet, this work did not test human melanocytes for any functional effects stemming from Lunasin treatment. It would be interesting to see if the protective effects of Lunasin exist in melanocytes, or if the results observed in this work are due to dysregulated oncogenic signaling in melanoma cells. Although several studies in NSCLC parallel these results, it would be interesting to assess whether these effects are tissuespecific especially when considering the induction of melanocyte-specific transcription factors such as MITF.

\section{5: Final Summary and Conclusions}

The overall aim of this work was to examine the mechanisms involved in the anticancer effects of the Lunasin peptide. The work in Chapter 3 uncovered a novel function of Lunasin in that it can selectively target CICs based on the ALDH biomarker. Additionally, it was demonstrated that Lunasin depleted pools of cells displaying elevated ALDH activity, a subpopulation which has been reported to harbor the stem cell-like population occurring in several malignant diseases. These studies were extended upon by using in vivo xenograft studies to demonstrate that Lunasin has robust antiproliferative effects in preclinical melanoma models, and exhibited an excellent safety profile with no significant cytotoxicity. Work completed in Chapter 4 confirmed that CICs were more sensitive to the antagonism of integrin signaling by Lunasin; however, Lunasin treatment also resulted in alterations of histone acetylation patterns. Mechanistically, the work presented in this dissertation showed that the RGD domain is necessary for rapid uptake of Lunasin as well as for inhibiting the self-renewal capacity of CICs. Combining the concepts that Lunasin depleted pools of CICs and antagonizes integrin signaling, this study investigated the antimetastatic effects of Lunasin in vitro and in vivo. Lunasin significantly reduced invasive potential of $\mathrm{ALDH}^{\text {high }} \mathrm{CICs}$ in vitro, and suppressed colonization of the lungs by B16-F10 cells in an experimental metastasis model. Taken together, this dissertation highlights several mechanisms associated with Lunasin's effects, and examines its potential clinical utility as an adjuvant therapy to minimize patient relapse due to the presence of highly invasive and tumorigenic subpopulations of CICs. 


\section{REFERENCES}

1. Shin, A., et al., Isoflavone and Soyfood Intake and Colorectal Cancer Risk: A Case-Control Study in Korea. PloS one, 2015. 10(11): p. e0143228.

2. Zhang, G.Q., et al., Soy Intake Is Associated With Lower Endometrial Cancer Risk: A Systematic Review and Meta-Analysis of Observational Studies. Medicine, 2015. 94(50): p. e2281.

3. Wu, S.H. and Z. Liu, Soy food consumption and lung cancer risk: a meta-analysis using a common measure across studies. Nutrition and cancer, 2013. 65(5): p. 625-32.

4. Pudenz, M., K. Roth, and C. Gerhauser, Impact of soy isoflavones on the epigenome in cancer prevention. Nutrients, 2014. 6(10): p. 4218-72.

5. McCormick, D.L., et al., Chemoprevention of rat prostate carcinogenesis by soy isoflavones and by Bowman-Birk inhibitor. Nutrition and cancer, 2007. 57(2): p. 184-93.

6. Lopez-Barrios, L., J.A. Gutierrez-Uribe, and S.O. Serna-Saldivar, Bioactive peptides and hydrolysates from pulses and their potential use as functional ingredients. Journal of food science, 2014. 79(3): p. R273-83.

7. Rauth, S., J. Kichina, and A. Green, Inhibition of growth and induction of differentiation of metastatic melanoma cells in vitro by genistein: chemosensitivity is regulated by cellular p53. British journal of cancer, 1997. 75(11): p. 1559-66.

8. Park, J.H., H.J. Jeong, and B.O. Lumen, In vitro digestibility of the cancer-preventive soy peptides lunasin and BBI. Journal of agricultural and food chemistry, 2007. 55(26): p. 10703-6.

9. Galvez, A.F., et al., Chemopreventive property of a soybean peptide (lunasin) that binds to deacetylated histones and inhibits acetylation. Cancer research, 2001. 61(20): p. 7473-8.

10. Inaba, J., E.J. McConnell, and K.R. Davis, Lunasin sensitivity in non-small cell lung cancer cells is linked to suppression of integrin signaling and changes in histone acetylation. International journal of molecular sciences, 2014. 15(12): p. 23705-24.

11. Garcia-Nebot, M.J., I. Recio, and B. Hernandez-Ledesma, Antioxidant activity and protective effects of peptide lunasin against oxidative stress in intestinal Caco- 2 cells. Food and chemical toxicology : an international journal published for the British Industrial Biological Research Association, 2014. 65: p. 155-61.

12. Cam, A. and E.G. de Mejia, RGD-peptide lunasin inhibits Akt-mediated NF-kappaB activation in human macrophages through interaction with the alphaVbeta3 integrin. Molecular nutrition \& food research, 2012. 56(10): p. 1569-81.

13. Chang, H.C., et al., Soypeptide lunasin in cytokine immunotherapy for lymphoma. Cancer immunology, immunotherapy : Cll, 2014. 63(3): p. 283-95.

14. Hernandez-Ledesma, B., C.C. Hsieh, and B.O. de Lumen, Antioxidant and antiinflammatory properties of cancer preventive peptide lunasin in RAW 264.7 macrophages. Biochemical and biophysical research communications, 2009. 390(3): p. 803-8.

15. Odani, S., T. Koide, and T. Ono, Amino acid sequence of a soybean (Glycine max) seed polypeptide having a poly(L-aspartic acid) structure. The Journal of biological chemistry, 1987. 262(22): p. 10502-5.

16. Seber, L.E., et al., Scalable purification and characterization of the anticancer lunasin peptide from soybean. PLoS One, 2012. 7(4): p. e35409.

17. Serra, A., et al., Commercial processed soy-based food product contains glycated and glycoxidated lunasin proteoforms. Scientific reports, 2016. 6: p. 26106. 
18. Galvez, A.F. and B.O. de Lumen, A soybean CDNA encoding a chromatin-binding peptide inhibits mitosis of mammalian cells. Nature biotechnology, 1999. 17(5): p. 495-500.

19. Jeong, H.J., Y. Lam, and B.O. de Lumen, Barley lunasin suppresses ras-induced colony formation and inhibits core histone acetylation in mammalian cells. Journal of agricultural and food chemistry, 2002. 50(21): p. 5903-8.

20. de Lumen, B.O., Lunasin: a cancer-preventive soy peptide. Nutrition reviews, 2005. 63(1): p. 16-21.

21. Jeong, H.J., et al., The cancer preventive peptide lunasin from wheat inhibits core histone acetylation. Cancer letters, 2007. 255(1): p. 42-8.

22. Jeong, J.B., et al., Cancer-preventive peptide lunasin from Solanum nigrum L. inhibits acetylation of core histones $\mathrm{H} 3$ and $\mathrm{H} 4$ and phosphorylation of retinoblastoma protein $(R b)$. Journal of agricultural and food chemistry, 2007. 55(26): p. 10707-13.

23. Omoni, A.O. and R.E. Aluko, Soybean foods and their benefits: potential mechanisms of action. Nutrition reviews, 2005. 63(8): p. 272-83.

24. Lee, M.M., et al., Soy and isoflavone consumption in relation to prostate cancer risk in China. Cancer epidemiology, biomarkers \& prevention : a publication of the American Association for Cancer Research, cosponsored by the American Society of Preventive Oncology, 2003. 12(7): p. 665-8.

25. Messina, M.J., et al., Soy intake and cancer risk: a review of the in vitro and in vivo data. Nutrition and cancer, 1994. 21(2): p. 113-31.

26. Hernandez-Ledesma, B., C.C. Hsieh, and B.O. de Lumen, Lunasin, a novel seed peptide for cancer prevention. Peptides, 2009. 30(2): p. 426-30.

27. Lam, Y., A. Galvez, and B.O. de Lumen, Lunasin suppresses E1A-mediated transformation of mammalian cells but does not inhibit growth of immortalized and established cancer cell lines. Nutrition and cancer, 2003. 47(1): p. 88-94.

28. Hsieh, C.C., B. Hernandez-Ledesma, and B.O. de Lumen, Lunasin-aspirin combination against NIH/3T3 cells transformation induced by chemical carcinogens. Plant foods for human nutrition, 2011. 66(2): p. 107-13.

29. Avvakumov, N., et al., Conserved molecular interactions within the HBO1 acetyltransferase complexes regulate cell proliferation. Molecular and cellular biology, 2012. 32(3): p. 689-703.

30. Santer, F.R., et al., Inhibition of the acetyltransferases $p 300$ and CBP reveals a targetable function for $p 300$ in the survival and invasion pathways of prostate cancer cell lines. Molecular cancer therapeutics, 2011. 10(9): p. 1644-55.

31. Ait-Si-Ali, S., et al., CBP/p300 histone acetyl-transferase activity is important for the $\mathrm{G} 1 / \mathrm{S}$ transition. Oncogene, 2000. 19(20): p. 2430-7.

32. McConnell, E.J., et al., The soybean-derived peptide lunasin inhibits non-small cell lung cancer cell proliferation by suppressing phosphorylation of the retinoblastoma protein. Oncotarget, 2015. 6(7): p. 4649-62.

33. Hernandez-Ledesma, B., C.C. Hsieh, and B.O. de Lumen, Relationship between lunasin's sequence and its inhibitory activity of histones $\mathrm{H} 3$ and $\mathrm{H} 4$ acetylation. Molecular nutrition \& food research, 2011. 55(7): p. 989-98.

34. Hsieh, C.C., B. Hernandez-Ledesma, and B.O. de Lumen, Lunasin, a novel seed peptide, sensitizes human breast cancer MDA-MB-231 cells to aspirin-arrested cell cycle and induced apoptosis. Chemico-biological interactions, 2010. 186(2): p. 127-34.

35. Dia, V.P. and E. Gonzalez de Mejia, Lunasin induces apoptosis and modifies the expression of genes associated with extracellular matrix and cell adhesion in human metastatic colon cancer cells. Molecular nutrition \& food research, 2011. 55(4): p. 623-34. 
36. Dia, V.P. and E. Gonzalez de Mejia, Lunasin potentiates the effect of oxaliplatin preventing outgrowth of colon cancer metastasis, binds to alpha5beta1 integrin and suppresses FAK/ERK/NF-kappaB signaling. Cancer letters, 2011. 313(2): p. 167-80.

37. Dia, V.P., et al., Structural property of soybean lunasin and development of a method to quantify lunasin in plasma using an optimized immunoassay protocol. Food chemistry, 2013. 138(1): p. 334-41.

38. Cam, A., M. Sivaguru, and E. Gonzalez de Mejia, Endocytic mechanism of internalization of dietary peptide lunasin into macrophages in inflammatory condition associated with cardiovascular disease. PloS one, 2013. 8(9): p. e72115.

39. Playford, M.P. and M.D. Schaller, The interplay between Src and integrins in normal and tumor biology. Oncogene, 2004. 23(48): p. 7928-46.

40. Moro, L., et al., Integrin-induced epidermal growth factor (EGF) receptor activation requires $c$-Src and p130Cas and leads to phosphorylation of specific EGF receptor tyrosines. The Journal of biological chemistry, 2002. 277(11): p. 9405-14.

41. Yang, X., et al., Lunasin alleviates allergic airway inflammation while increases antigenspecific Tregs. PloS one, 2015. 10(2): p. e0115330.

42. Tung, C.Y., et al., Activation of dendritic cell function by soypeptide lunasin as a novel vaccine adjuvant. Vaccine, 2014. 32(42): p. 5411-9.

43. $\mathrm{Pu}, \mathrm{C} . Y$. , et al., RGD-modified endostatin fragments showed an antitumor effect through antiangiogenesis. Anti-cancer drugs, 2012. 23(8): p. 788-802.

44. Smolarczyk, R., et al., Antitumor effect of RGD-4C-GG-D(KLAKLAK)2 peptide in mouse B16(F10) melanoma model. Acta biochimica Polonica, 2006. 53(4): p. 801-5.

45. Buerkle, M.A., et al., Inhibition of the alpha-nu integrins with a cyclic RGD peptide impairs angiogenesis, growth and metastasis of solid tumours in vivo. British journal of cancer, 2002. 86(5): p. 788-95.

46. Geiger, B., et al., A chimeric N-cadherin/beta 1-integrin receptor which localizes to both cell-cell and cell-matrix adhesions. Journal of cell science, 1992. 103 ( Pt 4): p. 943-51.

47. Howe, A., et al., Integrin signaling and cell growth control. Current opinion in cell biology, 1998. 10(2): p. 220-31.

48. Persad, S., et al., Inhibition of integrin-linked kinase (ILK) suppresses activation of protein kinase B/Akt and induces cell cycle arrest and apoptosis of PTEN-mutant prostate cancer cells. Proceedings of the National Academy of Sciences of the United States of America, 2000. 97(7): p. 3207-12.

49. Berthet, V., et al., Role of endoproteolytic processing in the adhesive and signaling functions of alphavbeta5 integrin. The Journal of biological chemistry, 2000. 275(43): p. 33308-13.

50. Fu, G., W. Wang, and B.H. Luo, Overview: structural biology of integrins. Methods in molecular biology, 2012. 757: p. 81-99.

51. Hynes, R.O., Integrins: bidirectional, allosteric signaling machines. Cell, 2002. 110(6): p. 673-87.

52. Berrier, A.L. and K.M. Yamada, Cell-matrix adhesion. Journal of cellular physiology, 2007. 213(3): p. 565-73.

53. Pisano, M., et al., In vitro activity of the alphavbeta3 integrin antagonist RGDechi-hCit on malignant melanoma cells. Anticancer research, 2013. 33(3): p. 871-9.

54. McGary, E.C., D.C. Lev, and M. Bar-Eli, Cellular adhesion pathways and metastatic potential of human melanoma. Cancer biology \& therapy, 2002. 1(5): p. 459-65.

55. Hood, J.D. and D.A. Cheresh, Role of integrins in cell invasion and migration. Nature reviews. Cancer, 2002. 2(2): p. 91-100. 
56. Hood, J.D., et al., Differential alphav integrin-mediated Ras-ERK signaling during two pathways of angiogenesis. The Journal of cell biology, 2003. 162(5): p. 933-43.

57. Alavi, A., et al., Role of Raf in vascular protection from distinct apoptotic stimuli. Science, 2003. 301(5629): p. 94-6.

58. Matter, M.L. and E. Ruoslahti, A signaling pathway from the alpha5beta1 and alpha(v)beta3 integrins that elevates bcl-2 transcription. The Journal of biological chemistry, 2001. 276(30): p. 27757-63.

59. Aoudjit, F. and K. Vuori, Integrin signaling inhibits paclitaxel-induced apoptosis in breast cancer cells. Oncogene, 2001. 20(36): p. 4995-5004.

60. Scatena, M., et al., NF-kappaB mediates alphavbeta3 integrin-induced endothelial cell survival. The Journal of cell biology, 1998. 141(4): p. 1083-93.

61. Kuphal, S., R. Bauer, and A.K. Bosserhoff, Integrin signaling in malignant melanoma. Cancer metastasis reviews, 2005. 24(2): p. 195-222.

62. Lee, N., S.R. Barthel, and T. Schatton, Melanoma stem cells and metastasis: mimicking hematopoietic cell trafficking? Laboratory investigation; a journal of technical methods and pathology, 2014. 94(1): p. 13-30.

63. Danen, E.H., et al., Integrin beta 3 cDNA transfection into a highly metastatic alpha $v$ beta 3-negative human melanoma cell line inhibits invasion and experimental metastasis. Biochemical and biophysical research communications, 1996. 226(1): p. 75-81.

64. Desgrosellier, J.S. and D.A. Cheresh, Integrins in cancer: biological implications and therapeutic opportunities. Nature reviews. Cancer, 2010. 10(1): p. 9-22.

65. Schatton, T. and M.H. Frank, Antitumor immunity and cancer stem cells. Annals of the New York Academy of Sciences, 2009. 1176: p. 154-69.

66. Schatton, T., et al., Identification of cells initiating human melanomas. Nature, 2008. 451(7176): p. 345-9.

67. Reardon, D.A., et al., Cilengitide: an RGD pentapeptide alphanubeta3 and alphanubeta5 integrin inhibitor in development for glioblastoma and other malignancies. Future oncology, 2011. 7(3): p. 339-54.

68. Kim, K.B., et al., A randomized phase II study of cilengitide (EMD 121974) in patients with metastatic melanoma. Melanoma research, 2012. 22(4): p. 294-301.

69. O'Day, S., et al., A randomised, phase II study of intetumumab, an anti-alphav-integrin $m A b$, alone and with dacarbazine in stage IV melanoma. British journal of cancer, 2011. 105(3): p. 346-52.

70. Hersey, P., et al., A randomized phase 2 study of etaracizumab, a monoclonal antibody against integrin alpha(v)beta(3), + or - dacarbazine in patients with stage IV metastatic melanoma. Cancer, 2010. 116(6): p. 1526-34.

71. Yamada, S., et al., Effect of the angiogenesis inhibitor Cilengitide (EMD 121974) on glioblastoma growth in nude mice. Neurosurgery, 2006. 59(6): p. 1304-12; discussion 1312.

72. Ruffini, F., et al., Cilengitide downmodulates invasiveness and vasculogenic mimicry of neuropilin 1 expressing melanoma cells through the inhibition of alphavbeta5 integrin. International journal of cancer, 2015. 136(6): p. E545-58.

73. Tentori, L., et al., The integrin antagonist cilengitide increases the antitumor activity of temozolomide against malignant melanoma. Oncology reports, 2008. 19(4): p. 1039-43.

74. (ACS), A.C.S. Skin Cancer Facts. [Online] 2014 3/14/2014 [cited 2014 April 24]; Available from: http://www.cancer.org/cancer/cancercauses/sunanduvexposure/skin-cancerfacts. 
75. Howlader N, N.A., Krapcho M, Garshell J, Miller D, Altekruse SF, Kosary CL, Yu M, Ruhl J, Tatalovich Z,Mariotto A, Lewis DR, Chen HS, Feuer EJ, Cronin KA. SEER Cancer Statistics Review, 1975-2011. 2014 [cited 2014 April 25]; based on November 2013 SEER data submission, posted to the SEER web site, April 2014.]. Available from: http://seer.cancer.gov/csr/1975 2011/.

76. Gandini, S., et al., Meta-analysis of risk factors for cutaneous melanoma: II. Sun exposure. European journal of cancer, 2005. 41(1): p. 45-60.

77. Fountain, J.W., et al., Genetics of melanoma. Cancer surveys, 1990. 9(4): p. 645-71.

78. Piris, A., A.C. Lobo, and L.M. Duncan, Melanoma staging: where are we now? Dermatologic clinics, 2012. 30(4): p. 581-92, v.

79. Crowson, A.N., C.M. Magro, and M.C. Mihm, Prognosticators of melanoma, the melanoma report, and the sentinel lymph node. Modern pathology : an official journal of the United States and Canadian Academy of Pathology, Inc, 2006. 19 Suppl 2: p. S71-87.

80. Ji, Z., et al., Vemurafenib synergizes with nutlin-3 to deplete survivin and suppresses melanoma viability and tumor growth. Clinical cancer research : an official journal of the American Association for Cancer Research, 2013. 19(16): p. 4383-91.

81. Trunzer, K., et al., Pharmacodynamic effects and mechanisms of resistance to vemurafenib in patients with metastatic melanoma. Journal of clinical oncology : official journal of the American Society of Clinical Oncology, 2013. 31(14): p. 1767-74.

82. Davies, H., et al., Mutations of the BRAF gene in human cancer. Nature, 2002. 417(6892): p. 949-54.

83. Chapman, P.B., et al., Improved survival with vemurafenib in melanoma with BRAF V600E mutation. The New England journal of medicine, 2011. 364(26): p. 2507-16.

84. Rizos, H., et al., BRAF Inhibitor Resistance Mechanisms in Metastatic Melanoma: Spectrum and Clinical Impact. Clinical cancer research : an official journal of the American Association for Cancer Research, 2014. 20(7): p. 1965-77.

85. Sun, $\mathrm{C}$., et al., Reversible and adaptive resistance to BRAF(V600E) inhibition in melanoma. Nature, 2014. 508(7494): p. 118-22.

86. Nazarian, R., et al., Melanomas acquire resistance to B-RAF(V600E) inhibition by RTK or NRAS upregulation. Nature, 2010. 468(7326): p. 973-7.

87. Tuma, R.S., Getting around PLX4032: studies turn up unusual mechanisms of resistance to melanoma drug. Journal of the National Cancer Institute, 2011. 103(3): p. 170-1, 177.

88. Reya, T., et al., Stem cells, cancer, and cancer stem cells. Nature, 2001. 414(6859): p. 10511.

89. Clarke, M.F., et al., Cancer stem cells--perspectives on current status and future directions: AACR Workshop on cancer stem cells. Cancer research, 2006. 66(19): p. 9339-44.

90. Clarke, M.F. and M. Fuller, Stem cells and cancer: two faces of eve. Cell, 2006. 124(6): p. 1111-5.

91. Krivtsov, A.V., et al., Transformation from committed progenitor to leukaemia stem cell initiated by MLL-AF9. Nature, 2006. 442(7104): p. 818-22.

92. Sun, B., et al., The minimal set of genetic alterations required for conversion of primary human fibroblasts to cancer cells in the subrenal capsule assay. Neoplasia, 2005. 7(6): p. 585-93.

93. Fang, D., et al., A tumorigenic subpopulation with stem cell properties in melanomas. Cancer research, 2005. 65(20): p. 9328-37.

94. Monzani, E., et al., Melanoma contains CD133 and ABCG2 positive cells with enhanced tumourigenic potential. European journal of cancer, 2007. 43(5): p. 935-46. 
95. Boiko, A.D., et al., Human melanoma-initiating cells express neural crest nerve growth factor receptor CD271. Nature, 2010. 466(7302): p. 133-7.

96. Chaffer, C.L., et al., Normal and neoplastic nonstem cells can spontaneously convert to a stem-like state. Proceedings of the National Academy of Sciences of the United States of America, 2011. 108(19): p. 7950-5.

97. Hoek, K.S. and C.R. Goding, Cancer stem cells versus phenotype-switching in melanoma. Pigment cell \& melanoma research, 2010. 23(6): p. 746-59.

98. Quintana, E., et al., Efficient tumour formation by single human melanoma cells. Nature, 2008. 456(7222): p. 593-8.

99. Kennedy, J.A., et al., Comment on "Tumor growth need not be driven by rare cancer stem cells". Science, 2007. 318(5857): p. 1722; author reply 1722.

100. Gupta, P.B., C.L. Chaffer, and R.A. Weinberg, Cancer stem cells: mirage or reality? Nature medicine, 2009. 15(9): p. 1010-2.

101. Girouard, S.D. and G.F. Murphy, Melanoma stem cells: not rare, but well done. Laboratory investigation; a journal of technical methods and pathology, 2011. 91(5): p. 647-64.

102. Frank, N.Y., et al., VEGFR-1 expressed by malignant melanoma-initiating cells is required for tumor growth. Cancer research, 2011. 71(4): p. 1474-85.

103. Boonyaratanakornkit, J.B., et al., Selection of tumorigenic melanoma cells using ALDH. The Journal of investigative dermatology, 2010. 130(12): p. 2799-808.

104. Luo, Y., N. Nguyen, and M. Fujita, Isolation of human melanoma stem cells using ALDH as a marker. Current protocols in stem cell biology, 2013. 26: p. Unit 38.

105. Prasmickaite, L., et al., Aldehyde dehydrogenase (ALDH) activity does not select for cells with enhanced aggressive properties in malignant melanoma. PloS one, 2010. 5(5): p. e10731.

106. Luo, Y., et al., ALDH1A isozymes are markers of human melanoma stem cells and potential therapeutic targets. Stem cells, 2012. 30(10): p. 2100-13.

107. Visus, C., et al., Targeting ALDH(bright) human carcinoma-initiating cells with ALDH1A1specific CD8(+) $T$ cells. Clinical cancer research : an official journal of the American Association for Cancer Research, 2011. 17(19): p. 6174-84.

108. Carpentino, J.E., et al., Aldehyde dehydrogenase-expressing colon stem cells contribute to tumorigenesis in the transition from colitis to cancer. Cancer research, 2009. 69(20): p. 8208-15.

109. Ginestier, C., et al., ALDH1 is a marker of normal and malignant human mammary stem cells and a predictor of poor clinical outcome. Cell stem cell, 2007. 1(5): p. 555-67.

110. Amann, P.M., et al., Expression and activity of alcohol and aldehyde dehydrogenases in melanoma cells and in melanocytes. Journal of cellular biochemistry, 2012. 113(3): p. 7929.

111. Yue, L., et al., Targeting ALDH1 to decrease tumorigenicity, growth and metastasis of human melanoma. Melanoma research, 2015. 25(2): p. 138-48.

112. Hu, Y., et al., Therapeutic Efficacy of Cancer Stem Cell Vaccines in the Adjuvant Setting. Cancer research, 2016. 76(16): p. 4661-72.

113. Brinckerhoff, C.E., Cancer Stem Cells (CSCs) in melanoma: There's smoke, but is there fire? Journal of cellular physiology, 2017.

114. Volk-Draper, L., et al., Paclitaxel therapy promotes breast cancer metastasis in a TLR4dependent manner. Cancer research, 2014. 74(19): p. 5421-34.

115. Chen, J., et al., A restricted cell population propagates glioblastoma growth after chemotherapy. Nature, 2012. 488(7412): p. 522-6. 
116. Dylla, S.J., et al., Colorectal cancer stem cells are enriched in xenogeneic tumors following chemotherapy. PloS one, 2008. 3(6): p. e2428.

117. Hermann, P.C., et al., Distinct populations of cancer stem cells determine tumor growth and metastatic activity in human pancreatic cancer. Cell stem cell, 2007. 1(3): p. 313-23.

118. Bao, S., et al., Glioma stem cells promote radioresistance by preferential activation of the DNA damage response. Nature, 2006. 444(7120): p. 756-60.

119. Larzabal, L., et al., Differential effects of drugs targeting cancer stem cell (CSC) and nonCSC populations on lung primary tumors and metastasis. PloS one, 2013. 8(11): p. e79798.

120. Pistollato, F., et al., Intratumoral hypoxic gradient drives stem cells distribution and MGMT expression in glioblastoma. Stem cells, 2010. 28(5): p. 851-62.

121. Stepanenko, A.A., et al., Temozolomide promotes genomic and phenotypic changes in glioblastoma cells. Cancer cell international, 2016. 16: p. 36.

122. Gupta, P.B., et al., Identification of selective inhibitors of cancer stem cells by highthroughput screening. Cell, 2009. 138(4): p. 645-59.

123. NCl. Melanoma Treatment 2016 July 11, 2016 [cited 2016 November 2]; Available from: https://www.cancer.gov/types/skin/patient/melanoma-treatment-pdq.

124. Balch, C.M., et al., Final version of 2009 AJCC melanoma staging and classification. Journal of clinical oncology : official journal of the American Society of Clinical Oncology, 2009. 27(36): p. 6199-206.

125. Siddik, Z.H., Cisplatin: mode of cytotoxic action and molecular basis of resistance. Oncogene, 2003. 22(47): p. 7265-79.

126. Quirt, I., et al., Temozolomide for the treatment of metastatic melanoma: a systematic review. The oncologist, 2007. 12(9): p. 1114-23.

127. Hersh, E.M., et al., A randomized, controlled phase III trial of nab-Paclitaxel versus dacarbazine in chemotherapy-naive patients with metastatic melanoma. Annals of oncology : official journal of the European Society for Medical Oncology, 2015. 26(11): p. 2267-74.

128. Chapman, P.B., et al., Phase III multicenter randomized trial of the Dartmouth regimen versus dacarbazine in patients with metastatic melanoma. Journal of clinical oncology : official journal of the American Society of Clinical Oncology, 1999. 17(9): p. 2745-51.

129. Bedikian, A.Y., et al., Bcl-2 antisense (oblimersen sodium) plus dacarbazine in patients with advanced melanoma: the Oblimersen Melanoma Study Group. Journal of clinical oncology : official journal of the American Society of Clinical Oncology, 2006. 24(29): p. 4738-45.

130. Middleton, M.R., et al., Randomized phase III study of temozolomide versus dacarbazine in the treatment of patients with advanced metastatic malignant melanoma. Journal of clinical oncology : official journal of the American Society of Clinical Oncology, 2000. 18(1): p. 158-66.

131. Avril, M.F., et al., Fotemustine compared with dacarbazine in patients with disseminated malignant melanoma: a phase III study. Journal of clinical oncology : official journal of the American Society of Clinical Oncology, 2004. 22(6): p. 1118-25.

132. Vultur, A., J. Villanueva, and M. Herlyn, Targeting BRAF in advanced melanoma: a first step toward manageable disease. Clinical cancer research : an official journal of the American Association for Cancer Research, 2011. 17(7): p. 1658-63.

133. Rosenberg, S.A. and N.P. Restifo, Adoptive cell transfer as personalized immunotherapy for human cancer. Science, 2015. 348(6230): p. 62-8.

134. Fukuhara, H., Y. Ino, and T. Todo, Oncolytic virus therapy: A new era of cancer treatment at dawn. Cancer science, 2016. 107(10): p. 1373-1379. 
135. Shrimali, R.K., et al., Programmed death-1 \& its ligands: promising targets for cancer immunotherapy. Immunotherapy, 2015. 7(7): p. 777-92.

136. Blankenstein, T., et al., The determinants of tumour immunogenicity. Nature reviews. Cancer, 2012. 12(4): p. 307-13.

137. Zimmer, L., et al., Open-label, multicenter, single-arm phase II DeCOG-study of ipilimumab in pretreated patients with different subtypes of metastatic melanoma. Journal of translational medicine, 2015. 13: p. 351.

138. Weber, J.S., et al., Nivolumab versus chemotherapy in patients with advanced melanoma who progressed after anti-CTLA-4 treatment (CheckMate 037): a randomised, controlled, open-label, phase 3 trial. The Lancet. Oncology, 2015. 16(4): p. 375-84.

139. Robbins, P.F., et al., A pilot trial using lymphocytes genetically engineered with an NY-ESO1-reactive T-cell receptor: long-term follow-up and correlates with response. Clinical cancer research : an official journal of the American Association for Cancer Research, 2015. 21(5): p. 1019-27.

140. Schatton, T. and M.H. Frank, Cancer stem cells and human malignant melanoma. Pigment cell \& melanoma research, 2008. 21(1): p. 39-55.

141. Shidal, C., et al., Lunasin is a novel therapeutic agent for targeting melanoma cancer stem cells. Oncotarget, 2016. 7(51): p. 84128-84141.

142. Jeong, H.J., et al., Inhibition of core histone acetylation by the cancer preventive peptide lunasin. Journal of agricultural and food chemistry, 2007. 55(3): p. 632-7.

143. Pinon, P. and B. Wehrle-Haller, Integrins: versatile receptors controlling melanocyte adhesion, migration and proliferation. Pigment cell \& melanoma research, 2011. 24(2): p. 282-94.

144. Guo, W. and F.G. Giancotti, Integrin signalling during tumour progression. Nature reviews. Molecular cell biology, 2004. 5(10): p. 816-26.

145. Mitra, A., L. Mishra, and S. Li, EMT, CTCS and CSCs in tumor relapse and drug-resistance. Oncotarget, 2015. 6(13): p. 10697-711.

146. Mudigonda, T.V., et al., A phase II trial of erlotinib and bevacizumab for patients with metastatic melanoma. Pigment cell \& melanoma research, 2016. 29(1): p. 101-3.

147. Ahluwalia, M.S., et al., Phase II trial of sunitinib as adjuvant therapy after stereotactic radiosurgery in patients with 1-3 newly diagnosed brain metastases. Journal of neurooncology, 2015. 124(3): p. 485-91.

148. Schneider, C.A., W.S. Rasband, and K.W. Eliceiri, NIH Image to ImageJ: 25 years of image analysis. Nat. Methods, 2012. 9(7): p. 671-5.

149. Robinson, J.K., Sun exposure, sun protection, and vitamin D. JAMA, 2005. 294(12): p. 15413.

150. Guy, G.P., Jr., et al., Prevalence and costs of skin cancer treatment in the U.S., 2002-2006 and 2007-2011. American journal of preventive medicine, 2015. 48(2): p. 183-7.

151. Soengas, M.S. and S.W. Lowe, Apoptosis and melanoma chemoresistance. Oncogene, 2003. 22(20): p. 3138-51.

152. Chin, L., L.A. Garraway, and D.E. Fisher, Malignant melanoma: genetics and therapeutics in the genomic era. Genes \& development, 2006. 20(16): p. 2149-82.

153. Helmbach, H., P. Sinha, and D. Schadendorf, Human melanoma: drug resistance. Recent results in cancer research. Fortschritte der Krebsforschung. Progres dans les recherches sur le cancer, 2003. 161: p. 93-110.

154. Yu, Y., G. Ramena, and R.C. Elble, The role of cancer stem cells in relapse of solid tumors. Frontiers in bioscience, 2012. 4: p. 1528-41. 
155. Xia, P., Surface markers of cancer stem cells in solid tumors. Current stem cell research \& therapy, 2014. 9(2): p. 102-11.

156. Sullivan, J.P., et al., Aldehyde dehydrogenase activity selects for lung adenocarcinoma stem cells dependent on notch signaling. Cancer research, 2010. 70(23): p. 9937-48.

157. Charafe-Jauffret, E., et al., Aldehyde dehydrogenase 1-positive cancer stem cells mediate metastasis and poor clinical outcome in inflammatory breast cancer. Clinical cancer research : an official journal of the American Association for Cancer Research, 2010. 16(1): p. 45-55.

158. Silva, I.A., et al., Aldehyde dehydrogenase in combination with CD133 defines angiogenic ovarian cancer stem cells that portend poor patient survival. Cancer research, 2011. 71(11): p. 3991-4001.

159. Jiang, F., et al., Aldehyde dehydrogenase 1 is a tumor stem cell-associated marker in lung cancer. Molecular cancer research : MCR, 2009. 7(3): p. 330-8.

160. Hess, D.A., et al., Selection based on CD133 and high aldehyde dehydrogenase activity isolates long-term reconstituting human hematopoietic stem cells. Blood, 2006. 107(5): p. 2162-9.

161. Gudas, L.J. and J.A. Wagner, Retinoids regulate stem cell differentiation. Journal of cellular physiology, 2011. 226(2): p. 322-30.

162. Chute, J.P., et al., Inhibition of aldehyde dehydrogenase and retinoid signaling induces the expansion of human hematopoietic stem cells. Proceedings of the National Academy of Sciences of the United States of America, 2006. 103(31): p. 11707-12.

163. Tang, X.H. and L.J. Gudas, Retinoids, retinoic acid receptors, and cancer. Annual review of pathology, 2011. 6: p. 345-64.

164. Montales, M.T., et al., Metformin and soybean-derived bioactive molecules attenuate the expansion of stem cell-like epithelial subpopulation and confer apoptotic sensitivity in human colon cancer cells. Genes Nutr, 2015. 10(6): p. 49.

165. McConnell, E.J., et al., The soybean-derived peptide lunasin inhibits non-small cell lung cancer cell proliferation by suppressing phosphorylation of the retinoblastoma protein. Oncotarget, 2014.

166. Bertolini, G., et al., Highly tumorigenic lung cancer CD133+ cells display stem-like features and are spared by cisplatin treatment. Proceedings of the National Academy of Sciences of the United States of America, 2009. 106(38): p. 16281-6.

167. Guan, J.L., Integrin signaling through FAK in the regulation of mammary stem cells and breast cancer. IUBMB life, 2010. 62(4): p. 268-76.

168. Aoudjit, F. and K. Vuori, Integrin signaling in cancer cell survival and chemoresistance. Chemother Res Pract, 2012. 2012: p. 283181.

169. Patrawala, L., et al., Hierarchical organization of prostate cancer cells in xenograft tumors: the CD44+alpha2beta1+ cell population is enriched in tumor-initiating cells. Cancer research, 2007. 67(14): p. 6796-805.

170. van den Hoogen, C., et al., Integrin alphav expression is required for the acquisition of a metastatic stem/progenitor cell phenotype in human prostate cancer. Am J Pathol, 2011. 179(5): p. 2559-68.

171. Ellis, S.J. and G. Tanentzapf, Integrin-mediated adhesion and stem-cell-niche interactions. Cell Tissue Res, 2010. 339(1): p. 121-30.

172. Lathia, J.D., et al., Integrin alpha 6 regulates glioblastoma stem cells. Cell stem cell, 2010. 6(5): p. 421-32. 
173. Lo, P.K., et al., CD49f and CD61 identify Her2/neu-induced mammary tumor-initiating cells that are potentially derived from luminal progenitors and maintained by the integrinTGFbeta signaling. Oncogene, 2012. 31(21): p. 2614-26.

174. Bianchi-Smiraglia, A., S. Paesante, and A.V. Bakin, Integrin beta5 contributes to the tumorigenic potential of breast cancer cells through the SrC-FAK and MEK-ERK signaling pathways. Oncogene, 2012.

175. Devapatla, B., et al., Validation of syngeneic mouse models of melanoma and non-small cell lung cancer for investigating the anticancer effects of the soy-derived peptide Lunasin. F1000Research, 2016. 5: p. 2432.

176. Douville, J., R. Beaulieu, and D. Balicki, ALDH1 as a functional marker of cancer stem and progenitor cells. Stem cells and development, 2009. 18(1): p. 17-25.

177. Carreira, S., et al., Mitf regulation of Dia1 controls melanoma proliferation and invasiveness. Genes \& development, 2006. 20(24): p. 3426-39.

178. Hartman, M.L. and M. Czyz, Pro-survival role of MITF in melanoma. The Journal of investigative dermatology, 2015. 135(2): p. 352-8.

179. Nishimura, E.K., et al., Key roles for transforming growth factor beta in melanocyte stem cell maintenance. Cell stem cell, 2010. 6(2): p. 130-40.

180. Omoni, A.O. and R.E. Aluko, Soybean Foods and Their Benefits: Potential Mechanisms of Action. Nutrition Reviews, 2005. 63(8): p. 272-283.

181. Trock, B.J., L. Hilakivi-Clarke, and R. Clarke, Meta-analysis of soy intake and breast cancer risk. J Natl Cancer Inst, 2006. 98(7): p. 459-71.

182. Yan, L. and E.L. Spitznagel, Meta-analysis of soy food and risk of prostate cancer in men. Int J Cancer, 2005. 117(4): p. 667-9.

183. Rochfort, S. and J. Panozzo, Phytochemicals for health, the role of pulses. Journal of agricultural and food chemistry, 2007. 55(20): p. 7981-94.

184. Larkin, T., W.E. Price, and L. Astheimer, The key importance of soy isoflavone bioavailability to understanding health benefits. Critical reviews in food science and nutrition, 2008. 48(6): p. 538-52.

185. Pabona, J.M., et al., The soybean peptide lunasin promotes apoptosis of mammary epithelial cells via induction of tumor suppressor PTEN: similarities and distinct actions from soy isoflavone genistein. Genes \& nutrition, 2013. 8(1): p. 79-90.

186. de Mejia, E.G., W. Wang, and V.P. Dia, Lunasin, with an arginine-glycine-aspartic acid motif, causes apoptosis to L1210 leukemia cells by activation of caspase-3. Molecular nutrition \& food research, 2010. 54(3): p. 406-14.

187. Dia, V.P. and E.G. Mejia, Lunasin promotes apoptosis in human colon cancer cells by mitochondrial pathway activation and induction of nuclear clusterin expression. Cancer letters, 2010. 295(1): p. 44-53.

188. Santini, R., et al., Hedgehog-GLI signaling drives self-renewal and tumorigenicity of human melanoma-initiating cells. Stem cells, 2012. 30(9): p. 1808-18.

189. Santini, R., et al., SOX2 regulates self-renewal and tumorigenicity of human melanomainitiating cells. Oncogene, 2014. 33(38): p. 4697-708.

190. Plaks, V., N. Kong, and Z. Werb, The cancer stem cell niche: how essential is the niche in regulating stemness of tumor cells? Cell stem cell, 2015. 16(3): p. 225-38.

191. Yun, Z. and Q. Lin, Hypoxia and regulation of cancer cell stemness. Advances in experimental medicine and biology, 2014. 772: p. 41-53.

192. Voog, J. and D.L. Jones, Stem cells and the niche: a dynamic duo. Cell stem cell, 2010. 6(2): p. 103-15. 
193. Roesch, A., Tumor heterogeneity and plasticity as elusive drivers for resistance to MAPK pathway inhibition in melanoma. Oncogene, 2015. 34(23): p. 2951-7.

194. Jiang, Q., et al., Lunasin suppresses the migration and invasion of breast cancer cells by inhibiting matrix metalloproteinase-2/-9 via the FAK/AKt/ERK and NF-kappaB signaling pathways. Oncol Rep, 2016.

195. Sulzmaier, F.J., C. Jean, and D.D. Schlaepfer, FAK in cancer: mechanistic findings and clinical applications. Nature reviews. Cancer, 2014. 14(9): p. 598-610.

196. Ricci, E., et al., Increased expression of putative cancer stem cell markers in the bone marrow of prostate cancer patients is associated with bone metastasis progression. The Prostate, 2013. 73(16): p. 1738-46.

197. Rentala, S., P.D. Yalavarthy, and L.N. Mangamoori, Alpha1 and beta1 integrins enhance the homing and differentiation of cultured prostate cancer stem cells. Asian journal of andrology, 2010. 12(4): p. 548-55.

198. Lee, K.M., et al., The CD49d+/high subpopulation from isolated human breast sarcoma spheres possesses tumor-initiating ability. International journal of oncology, 2012. 40(3): p. 665-72.

199. Nishimura, E.K., S.R. Granter, and D.E. Fisher, Mechanisms of hair graying: incomplete melanocyte stem cell maintenance in the niche. Science, 2005. 307(5710): p. 720-4.

200. Cheli, Y., et al., Mitf is the key molecular switch between mouse or human melanoma initiating cells and their differentiated progeny. Oncogene, 2011. 30(20): p. 2307-18.

201. Perego, M., et al., Heterogeneous phenotype of human melanoma cells with in vitro and in vivo features of tumor-initiating cells. The Journal of investigative dermatology, 2010. 130(7): p. 1877-86.

202. Borrull, A., et al., Nanog and Oct4 overexpression increases motility and transmigration of melanoma cells. Journal of cancer research and clinical oncology, 2012. 138(7): p. 114554.

203. Kumar, S.M., et al., Acquired cancer stem cell phenotypes through Oct4-mediated dedifferentiation. Oncogene, 2012. 31(47): p. 4898-911.

204. Hirata, E., et al., Intravital imaging reveals how BRAF inhibition generates drug-tolerant microenvironments with high integrin beta1/FAK signaling. Cancer cell, 2015. 27(4): p. 574-88.

205. Conner, S.R., G. Scott, and A.E. Aplin, Adhesion-dependent activation of the ERK1/2 cascade is by-passed in melanoma cells. The Journal of biological chemistry, 2003. 278(36): p. 34548-54.

206. Corcoran, R.B., et al., Combined BRAF and MEK Inhibition With Dabrafenib and Trametinib in BRAF V600-Mutant Colorectal Cancer. Journal of clinical oncology : official journal of the American Society of Clinical Oncology, 2015. 33(34): p. 4023-31.

207. Seguin, L., et al., Integrins and cancer: regulators of cancer stemness, metastasis, and drug resistance. Trends in cell biology, 2015. 25(4): p. 234-40.

208. Thang, N.D., et al., Deltex-3-like (DTX3L) stimulates metastasis of melanoma through FAK/PI3K/AKT but not MEK/ERK pathway. Oncotarget, 2015. 6(16): p. 14290-9.

209. Gupta, P.B., et al., The melanocyte differentiation program predisposes to metastasis after neoplastic transformation. Nature genetics, 2005. 37(10): p. 1047-54.

210. Nikolaou, V.A., et al., Melanoma: new insights and new therapies. The Journal of investigative dermatology, 2012. 132(3 Pt 2): p. 854-63.

211. McArthur, G.A., et al., Safety and efficacy of vemurafenib in BRAF(V600E) and BRAF(V600K) mutation-positive melanoma (BRIM-3): extended follow-up of a phase 3, randomised, open-label study. The Lancet. Oncology, 2014. 15(3): p. 323-32. 
212. Hauschild, A., et al., Dabrafenib in BRAF-mutated metastatic melanoma: a multicentre, open-label, phase 3 randomised controlled trial. Lancet, 2012. 380(9839): p. 358-65.

213. Chartrain, M., et al., Melanoma chemotherapy leads to the selection of ABCB5-expressing cells. PloS one, 2012. 7(5): p. e36762.

214. Roesch, A., et al., Overcoming intrinsic multidrug resistance in melanoma by blocking the mitochondrial respiratory chain of slow-cycling JARID1B(high) cells. Cancer cell, 2013. 23(6): p. 811-25.

215. Sosman, J.A., et al., Survival in BRAF V600-mutant advanced melanoma treated with vemurafenib. The New England journal of medicine, 2012. 366(8): p. 707-14.

216. Galluzzi, L., et al., Classification of current anticancer immunotherapies. Oncotarget, 2014. 5(24): p. 12472-508.

217. Redman, J.M., G.T. Gibney, and M.B. Atkins, Advances in immunotherapy for melanoma. BMC medicine, 2016. 14: p. 20.

218. Schwartzentruber, D.J., et al., gp100 peptide vaccine and interleukin-2 in patients with advanced melanoma. The New England journal of medicine, 2011. 364(22): p. 2119-27.

219. Atkins, M.B., et al., High-dose recombinant interleukin-2 therapy in patients with metastatic melanoma: long-term survival update. The cancer journal from Scientific American, 2000. 6 Suppl 1: p. S11-4.

220. Hodi, F.S., et al., Improved survival with ipilimumab in patients with metastatic melanoma. The New England journal of medicine, 2010. 363(8): p. 711-23.

221. Robert, C., et al., Pembrolizumab versus Ipilimumab in Advanced Melanoma. The New England journal of medicine, 2015. 372(26): p. 2521-32.

222. Andtbacka, R.H., et al., Talimogene Laherparepvec Improves Durable Response Rate in Patients With Advanced Melanoma. Journal of clinical oncology : official journal of the American Society of Clinical Oncology, 2015. 33(25): p. 2780-8.

223. Zaretsky, J.M., et al., Mutations Associated with Acquired Resistance to PD-1 Blockade in Melanoma. The New England journal of medicine, 2016. 375(9): p. 819-29.

224. Hamid, O., et al., Safety and tumor responses with lambrolizumab (anti-PD-1) in melanoma. The New England journal of medicine, 2013. 369(2): p. 134-44.

225. Restifo, N.P., M.J. Smyth, and A. Snyder, Acquired resistance to immunotherapy and future challenges. Nature reviews. Cancer, 2016. 16(2): p. 121-6.

226. Zbytek, B., et al., Current concepts of metastasis in melanoma. Expert review of dermatology, 2008. 3(5): p. 569-585.

227. Jiang, Q., et al., Lunasin suppresses the migration and invasion of breast cancer cells by inhibiting matrix metalloproteinase-2/-9 via the FAK/AKt/ERK and NF-kappaB signaling pathways. Oncology reports, 2016. 36(1): p. 253-62.

228. Shidal, C., et al., Lunasin is a novel therapeutic agent for targeting melanoma cancer stem cells. Oncotarget, 2016.

229. Jeong, H.J., et al., Characterization of lunasin isolated from soybean. Journal of agricultural and food chemistry, 2003. 51(27): p. 7901-6.

230. Montales, M.T., et al., Metformin and soybean-derived bioactive molecules attenuate the expansion of stem cell-like epithelial subpopulation and confer apoptotic sensitivity in human colon cancer cells. Genes \& nutrition, 2015. 10(6): p. 49.

231. Yan, G., et al., Selective inhibition of p300 HAT blocks cell cycle progression, induces cellular senescence, and inhibits the DNA damage response in melanoma cells. The Journal of investigative dermatology, 2013. 133(10): p. 2444-52. 
232. Boyle, G.M., A.C. Martyn, and P.G. Parsons, Histone deacetylase inhibitors and malignant melanoma. Pigment cell research / sponsored by the European Society for Pigment Cell Research and the International Pigment Cell Society, 2005. 18(3): p. 160-6.

233. Debeb, B.G., et al., Histone deacetylase inhibitors stimulate dedifferentiation of human breast cancer cells through WNT/beta-catenin signaling. Stem cells, 2012. 30(11): p. 236677.

234. Larue, L. and A. Bellacosa, Epithelial-mesenchymal transition in development and cancer: role of phosphatidylinositol 3' kinase/AKT pathways. Oncogene, 2005. 24(50): p. 7443-54.

235. Kolli-Bouhafs, K., et al., FAK competes for Src to promote migration against invasion in melanoma cells. Cell death \& disease, 2014. 5: p. e1379.

236. Madhunapantula, S.V. and G.P. Robertson, The PTEN-AKT3 signaling cascade as a therapeutic target in melanoma. Pigment cell \& melanoma research, 2009. 22(4): p. 40019.

237. Wang, S. and M.D. Basson, Akt directly regulates focal adhesion kinase through association and serine phosphorylation: implication for pressure-induced colon cancer metastasis. American journal of physiology. Cell physiology, 2011. 300(3): p. C657-70.

238. Nabors, L.B., et al., A safety run-in and randomized phase 2 study of cilengitide combined with chemoradiation for newly diagnosed glioblastoma (NABTT 0306). Cancer, 2012. 118(22): p. 5601-7.

239. Gerstner, E.R., et al., A phase I study of cediranib in combination with cilengitide in patients with recurrent glioblastoma. Neuro-oncology, 2015. 17(10): p. 1386-92.

240. Friess, H., et al., A randomized multi-center phase II trial of the angiogenesis inhibitor Cilengitide (EMD 121974) and gemcitabine compared with gemcitabine alone in advanced unresectable pancreatic cancer. BMC cancer, 2006. 6: p. 285.

241. Vermorken, J.B., et al., Cisplatin, 5-fluorouracil, and cetuximab (PFE) with or without cilengitide in recurrent/metastatic squamous cell carcinoma of the head and neck: results of the randomized phase I/II ADVANTAGE trial (phase II part). Annals of oncology : official journal of the European Society for Medical Oncology / ESMO, 2014. 25(3): p. 682-8.

242. Shechter, D., et al., Extraction, purification and analysis of histones. Nature protocols, 2007. 2(6): p. 1445-57.

243. Greenman, C., et al., Patterns of somatic mutation in human cancer genomes. Nature, 2007. 446(7132): p. 153-8.

244. Sporn, M.B. and A.B. Roberts, Role of retinoids in differentiation and carcinogenesis. Journal of the National Cancer Institute, 1984. 73(6): p. 1381-7.

245. Spanjaard, R.A., et al., Specific activation of retinoic acid receptors (RARs) and retinoid $X$ receptors reveals a unique role for RARgamma in induction of differentiation and apoptosis of $S 91$ melanoma cells. The Journal of biological chemistry, 1997. 272(30): p. 18990-9.

246. Lotan, R., et al., Characterization of the inhibitory effects of retinoids on the in vitro growth of two malignant murine melanomas. Journal of the National Cancer Institute, 1978. 60(5): p. 1035-41.

247. Meyskens, F.L., Jr. and S.E. Salmon, Inhibition of human melanoma colony formation by retinoids. Cancer research, 1979. 39(10): p. 4055-7.

248. Shibata, H., et al., Role of co-activators and co-repressors in the mechanism of steroid/thyroid receptor action. Recent progress in hormone research, 1997. 52: p. 14164; discussion 164-5. 
249. Wang, Z., et al., Differential susceptibility of cultured human melanoma cell lines to enhancement by retinoic acid of intercellular adhesion molecule 1 expression. Cancer research, 1992. 52(17): p. 4766-72.

250. Edward, M., J.A. Gold, and R.M. MacKie, Modulation of melanoma cell adhesion to basement membrane components by retinoic acid. Journal of cell science, 1989. 93 ( Pt 1): p. 155-61.

251. Sengupta, S., et al., Effect of retinoic acid on integrin receptors of B16F10 melanoma cells. Journal of experimental \& clinical cancer research : CR, 2000. 19(1): p. 81-7.

252. Scholer-Dahirel, A., et al., Maintenance of adenomatous polyposis coli (APC)-mutant colorectal cancer is dependent on Wnt/beta-catenin signaling. Proceedings of the National Academy of Sciences of the United States of America, 2011. 108(41): p. 1713540.

253. Anastas, J.N. and R.T. Moon, WNT signalling pathways as therapeutic targets in cancer. Nature reviews. Cancer, 2013. 13(1): p. 11-26.

254. Atkinson, J.M., et al., Activating the Wnt/beta-Catenin Pathway for the Treatment of Melanoma--Application of LY2090314, a Novel Selective Inhibitor of Glycogen Synthase Kinase-3. PloS one, 2015. 10(4): p. e0125028.

255. Kageshita, T., et al., Loss of beta-catenin expression associated with disease progression in malignant melanoma. The British journal of dermatology, 2001. 145(2): p. 210-6.

256. Gallagher, S.J., et al., Beta-catenin inhibits melanocyte migration but induces melanoma metastasis. Oncogene, 2013. 32(17): p. 2230-8.

257. Chien, A.J., et al., Activated Wnt/beta-catenin signaling in melanoma is associated with decreased proliferation in patient tumors and a murine melanoma model. Proceedings of the National Academy of Sciences of the United States of America, 2009. 106(4): p. 11938.

258. Koon, H.B., et al., FOXP1: a potential therapeutic target in cancer. Expert opinion on therapeutic targets, 2007. 11(7): p. 955-65.

259. Ackermann, S., et al., FOXP1 inhibits cell growth and attenuates tumorigenicity of neuroblastoma. BMC cancer, 2014. 14: p. 840.

260. Zhang, K., et al., An ERBB3/ERBB2 oncogenic unit plays a key role in NRG1 signaling and melanoma cell growth and survival. Pigment cell \& melanoma research, 2013. 26(3): p. 408-14.

261. Tiwary, S., et al., ERBB3 is required for metastasis formation of melanoma cells. Oncogenesis, 2014. 3: p. e110.

262. Leivonen, S.K. and V.M. Kahari, Transforming growth factor-beta signaling in cancer invasion and metastasis. International journal of cancer, 2007. 121(10): p. 2119-24.

263. Lasfar, A. and K.A. Cohen-Solal, Resistance to transforming growth factor beta-mediated tumor suppression in melanoma: are multiple mechanisms in place? Carcinogenesis, 2010. 31(10): p. 1710-7.

264. Webster, M.R., C.H. Kugel, 3rd, and A.T. Weeraratna, The Wnts of change: How Wnts regulate phenotype switching in melanoma. Biochimica et biophysica acta, 2015. 1856(2): p. 244-51.

265. Hsu, M.Y., et al., Bone morphogenetic proteins in melanoma: angel or devil? Cancer metastasis reviews, 2005. 24(2): p. 251-63.

266. Gaggioli, C., et al., Tumor-derived fibronectin is involved in melanoma cell invasion and regulated by V600E B-Raf signaling pathway. The Journal of investigative dermatology, 2007. 127(2): p. 400-10. 
267. Puisieux, A., T. Brabletz, and J. Caramel, Oncogenic roles of EMT-inducing transcription factors. Nature cell biology, 2014. 16(6): p. 488-94.

268. Huntington, J.T., et al., Overexpression of collagenase 1 (MMP-1) is mediated by the ERK pathway in invasive melanoma cells: role of BRAF mutation and fibroblast growth factor signaling. The Journal of biological chemistry, 2004. 279(32): p. 33168-76.

269. Zigrino, P., et al., Stromal expression of MMP-13 is required for melanoma invasion and metastasis. The Journal of investigative dermatology, 2009. 129(11): p. 2686-93.

270. Meierjohann, S., et al., MMP13 mediates cell cycle progression in melanocytes and melanoma cells: in vitro studies of migration and proliferation. Molecular cancer, 2010. 9: p. 201.

271. Karin, M., The regulation of AP-1 activity by mitogen-activated protein kinases. The Journal of biological chemistry, 1995. 270(28): p. 16483-6.

272. Urabe, A., et al., Expression of the fos oncogene in B16 melanoma cells exhibiting different metastatic abilities. Journal of dermatological science, 1990. 1(6): p. 455-8.

273. Ramsdale, R., et al., The transcription cofactor c-JUN mediates phenotype switching and BRAF inhibitor resistance in melanoma. Science signaling, 2015. 8(390): p. ra82.

274. Kappelmann, M., A. Bosserhoff, and S. Kuphal, AP-1/c-Jun transcription factors: regulation and function in malignant melanoma. European journal of cell biology, 2014. 93(1-2): p. 76-81.

275. Devapatla B, S.C., Yaddanapudi K and Davis KR, Validation of syngeneic mouse models of melanoma and non-small cell lung cancer for investigating the anticancer effects of the soy-derived peptide Lunasin [version 1; referees: 3 approved with reservations]. F1000Research, 2016(

) .

276. Wennerberg, K., et al., The cytoplasmic tyrosines of integrin subunit beta1 are involved in focal adhesion kinase activation. Molecular and cellular biology, 2000. 20(15): p. 5758-65.

277. Costa, P., et al., Integrin-specific control of focal adhesion kinase and RhoA regulates membrane protrusion and invasion. PloS one, 2013. 8(9): p. e74659.

278. Calderwood, D.A., I.D. Campbell, and D.R. Critchley, Talins and kindlins: partners in integrin-mediated adhesion. Nature reviews. Molecular cell biology, 2013. 14(8): p. 50317.

279. Velling, T., et al., beta1-Integrins induce phosphorylation of Akt on serine 473 independently of focal adhesion kinase and Src family kinases. EMBO reports, 2004. 5(9): p. 901-5.

280. Bianchi-Smiraglia, A., et al., Microphthalmia-associated transcription factor suppresses invasion by reducing intracellular GTP pools. Oncogene, 2016.

281. Arozarena, I., et al., In melanoma, beta-catenin is a suppressor of invasion. Oncogene, 2011. 30(45): p. 4531-43.

282. Javelaud, D., et al., GLI2 and M-MITF transcription factors control exclusive gene expression programs and inversely regulate invasion in human melanoma cells. Pigment cell \& melanoma research, 2011. 24(5): p. 932-43.

283. del Pozo, M.A., et al., Integrins regulate Rac targeting by internalization of membrane domains. Science, 2004. 303(5659): p. 839-42.

284. Maio, M., Melanoma as a model tumour for immuno-oncology. Annals of oncology : official journal of the European Society for Medical Oncology / ESMO, 2012. 23 Suppl 8: p. viii10-4. 
285. Roca-Cusachs, P., et al., Clustering of alpha(5)beta(1) integrins determines adhesion strength whereas alpha(v)beta(3) and talin enable mechanotransduction. Proceedings of the National Academy of Sciences of the United States of America, 2009. 106(38): p. 16245-50.

286. Morgan, M.R., et al., Giving off mixed signals--distinct functions of alpha5beta1 and alphavbeta3 integrins in regulating cell behaviour. IUBMB life, 2009. 61(7): p. 731-8.

287. Venkatesh, S. and J.L. Workman, Histone exchange, chromatin structure and the regulation of transcription. Nature reviews. Molecular cell biology, 2015. 16(3): p. 178-89.

288. Di Martile, M., et al., Histone acetyltransferase inhibitor CPTH6 preferentially targets lung cancer stem-like cells. Oncotarget, 2016. 7(10): p. 11332-48.

289. Vitillo, L., et al., Integrin-Associated Focal Adhesion Kinase Protects Human Embryonic Stem Cells from Apoptosis, Detachment, and Differentiation. Stem cell reports, 2016. 7(2): p. 167-76.

290. Qiao, Y., et al., Dual roles of histone H3 lysine 9 acetylation in human embryonic stem cell pluripotency and neural differentiation. The Journal of biological chemistry, 2015. 290(16): p. 9949.

291. Zhong, X. and Y. Jin, Critical roles of coactivator p300 in mouse embryonic stem cell differentiation and Nanog expression. The Journal of biological chemistry, 2009. 284(14): p. 9168-75.

292. Rose, J.L., et al., Integrin engagement increases histone H3 acetylation and reduces histone H1 association with DNA in murine lung endothelial cells. Molecular pharmacology, 2005. 68(2): p. 439-46.

293. Jeter, C.R., et al., Concise Review: NANOG in Cancer Stem Cells and Tumor Development: An Update and Outstanding Questions. Stem cells, 2015. 33(8): p. 2381-90. 


\section{ABBREVIATIONS}

AA

ABCB5

AEBSF

AKT

ALDH

ALKP

ALT

AST

ATCC

BBI

BCA

BCL-2

BMP2

BMP4

BRAF

BSA

BUN

C

CBC

CD133

CD147

CD20

CD271

CDK
Amino acid

ATP-binding cassette sub-family B member 5

4-(2-aminoethyl)benzenesulfonyl fluoride hydrochloride

V-akt murine thymoma viral oncogene homolog 1

Aldehyde dehydrogenase

Alkaline phosphatase

Alanine transaminase

Aspartate aminotransferase

American Type Culture Collection

Bowman-Birk inhibitor

Bicinchoninic acid assay

B-cell lymphoma 2

Bone morphogenetic protein 4

Bone morphogenetic protein 4

V-Raf murine sarcoma viral oncogene homolog B

Bovine serum albumin

Blood urea nitrogen

Cysteine

Complete blood count

Cluster of differentiation 133 (prominin-1)

Cluster of differentiation 147 (Basigin)

Cluster of differentiation 20 (B-lymphocyte antigen 20)

Cluster of differentiation 271 (low-affinity nerve growth factor receptor)

Cyclin-dependent kinase 


\begin{tabular}{|c|c|}
\hline CIC & Cancer initiating cell \\
\hline $\mathrm{CO}_{2}$ & Carbon dioxide \\
\hline CREA & Creatinine \\
\hline cRGD & cyclic-RGD \\
\hline $\mathbf{D}$ & Aspartic acid \\
\hline DAPI & 4',6-diamidino-2-phenylindole \\
\hline DEAB & N,N-diethylaminobenzaldehyde \\
\hline DI & Drewinko index \\
\hline DMEM & Dulbecco's modified eagle medium \\
\hline DMSO & Dimethyl sulfoxide \\
\hline DTT & Dithiothreitol \\
\hline $\mathbf{E}$ & Glutamic acid \\
\hline ECL & Electrochemiluminescent \\
\hline ECM & Extracellular matrix \\
\hline EDTA & Ethylenediaminetetraacetic acid \\
\hline EGFR & Epidermal growth factor receptor \\
\hline EMT & Epithelial to mesenchymal transition \\
\hline ERBB2 & Erb-b2 receptor tyrosine kinase 2 \\
\hline ERK & Extracellular signal-regulated kinases \\
\hline ES & Embryonic stem \\
\hline ETS1 & ETS proto-oncogene 1 \\
\hline FACS & Fluorescence-assisted cell sorting \\
\hline FAK & Focal adhesion kinase \\
\hline FBS & Fetal bovine serum \\
\hline FITC & Fluorescein isothiocyanate \\
\hline FN1 & Fibronectin 1 \\
\hline FOS & FBJ osteosarcoma oncogene \\
\hline FOSB & FBJ osteosarcoma oncogene B \\
\hline
\end{tabular}




\begin{tabular}{|c|c|}
\hline FOXP1 & Forkhead box P1 \\
\hline $\mathbf{G}$ & Glycine \\
\hline GFP & Green fluorescent protein \\
\hline GI & Gastrointestinal \\
\hline $\mathbf{H}$ & Histidine \\
\hline H\&E & Hematoxylin and eosin \\
\hline $\mathrm{H}_{2} \mathrm{SO}_{4}$ & Sulfuric acid \\
\hline H3 & Histone H3 \\
\hline H4 & Histone H4 \\
\hline HAT & Histone acetyltransferase \\
\hline HBSS & Hank’s balanced salt solution \\
\hline HDAC & Histone deacetylase \\
\hline HPLC & High-performance liquid chromatography \\
\hline HRP & Horseradish peroxidase \\
\hline I & Isoleucine \\
\hline i.p. & Intraperitoneal \\
\hline i.v & Intravenous \\
\hline IGFR1 & Insulin-like growth factor receptor-1 \\
\hline IL & Interleukin \\
\hline ILK & Integrin-linked kinase \\
\hline JAG1 & Jagged 1 \\
\hline JUN & Jun proto-oncogene \\
\hline $\mathbf{K}$ & Lysine \\
\hline КАТ2В & Lysine acetyltransferase $2 B$ \\
\hline KBP & Kentucky BioProcessing \\
\hline $\mathbf{K C l}$ & Potassium chloride \\
\hline $\mathbf{L}$ & Leucine \\
\hline $\mathbf{M}$ & Methionine \\
\hline
\end{tabular}




\begin{tabular}{|c|c|}
\hline МАP2К11 & Mitogen-activated protein kinase kinase 11 \\
\hline МАР2K7 & Mitogen-activated protein kinase kinase 7 \\
\hline MAPK & Mitogen-activated protein kinase \\
\hline $\mathrm{MgCl}_{2}$ & Magnesium chloride \\
\hline MITF & Microphthalmia-associated transcription factor \\
\hline MMP1 & Matrix metallopeptidase 1 \\
\hline MMP13 & Matrix metallopeptidase 13 \\
\hline MS & Mass Spectrometry \\
\hline MTS & $\begin{array}{l}\text { [3-(4,5-dimethylthiazol-2-yl)-5-(3-carboxymethoxyphenyl)-2-(4- } \\
\text { sulfophenyl)-2H-tetrazolium }\end{array}$ \\
\hline $\mathbf{N}$ & Asparagine \\
\hline NANOG & Nanog homeobox \\
\hline $\mathrm{NaOH}$ & Sodium hydroxide \\
\hline NCI & National Cancer Institute \\
\hline $\mathbf{N F - K B}$ & Nuclear factor kappa-light-chain-enhancer of activated B cells \\
\hline NIH & National Institutes of Health \\
\hline NK & Natural killer \\
\hline NOD/SCID & Nonobese diabetic/severe combined immunodeficiency \\
\hline NSAID & Non-steroidal anti-inflammatory drug \\
\hline NSCLC & Non-small cell lung cancer \\
\hline OCT4 & Octamer-binding transcription factor 4 \\
\hline $\mathbf{P}$ & Proline \\
\hline PARP & Poly ADP ribose polymerase \\
\hline PB & Phosphate buffer \\
\hline PBS & Phosphate-buffered saline \\
\hline PCR & Polymerase chain reaction \\
\hline PE & Phycoerythrin \\
\hline PFA & Paraformaldehyde \\
\hline
\end{tabular}




\begin{tabular}{|c|c|}
\hline PI & Propidium iodide \\
\hline PI3K & Phosphatidylinositol-4,5-bisphosphate 3-kinase \\
\hline PLA & Proximity ligation assay \\
\hline PTEN & Phosphatase and tensin homolog \\
\hline PVDF & Polyvinylidene fluoride \\
\hline Q & Glutamine \\
\hline $\mathbf{R}$ & Arginine \\
\hline RAC1 & Ras-related C3 botulinum toxin substrate 1 \\
\hline RAR & Retinoic acid receptor \\
\hline RAS & Rat sarcoma \\
\hline RIN & RNA integrity number \\
\hline RIPA & Radioimmunoprecipitation assay \\
\hline RPC & Reverse-phase chromatography \\
\hline RXR & Retinoid X receptor \\
\hline $\mathbf{S}$ & Serine \\
\hline S.C. & Subcutaneous \\
\hline SA & Senescence-associated \\
\hline SDS-PAGE & Sodium dodecyl sulfate polyacrylamide gel electrophoresis \\
\hline SEER & Surveillance, Epidemiology, and End Results \\
\hline SF & Surviving fraction \\
\hline SKI & SKI proto-oncogene \\
\hline SMAD5 & SMAD family member 5 \\
\hline SMAD6 & SMAD family member 6 \\
\hline SMAD7 & SMAD family member 7 \\
\hline SNAI1 & Snail family transcriptional repressor 1 \\
\hline SNAI2 & Snail family transcriptional repressor 2 \\
\hline $\mathbf{T}$ & Threonine \\
\hline TBS & Tris-buffered saline \\
\hline
\end{tabular}


TCA

TGF- $\beta$

TGF- $\beta 3$

TME

TNF

TP73

TTBS

UV

V

VCAM-1

W

WNT5a
Trichloroacetic acid

Transforming growth factor beta

Transforming growth factor beta 3

Tumor microenvironment

Tumor necrosis factor

Tumor protein p73

Tris-buffered saline with Tween

Ultraviolet

Valine

Vascular cell adhesion protein 1

Tryptophan

Wnt (wingless) oncogene analog 5a 


\section{CURRICULUM VITAE}

Christopher P. Shidal

425 S. Hubbards Lane \#425

Louisville, KY 40207

(270) 519-2207

cshidal@indiana.edu

\section{Personal Statement:}

My personal goal is to generate high quality data that can be easily integrated into and further develop the field of cancer therapeutic drugs. My work as a research fellow in the field of oncology has allowed me to explore and advance several research projects including cigarette smoke induced carcinogenesis and the development of a soy-derived peptide as a chemotherapeutic. My background in the field of pharmacology has allowed me to develop concepts and critical thinking skills necessary to excel throughout my career. I have held several science-related positions since graduating from the University of Kentucky which have allowed me to sharpen my skills working in settings such as industry as well as academia. Furthermore, I was given the opportunity to advance a number of projects independently. As a research fellow, I have acquired a unique skill set aimed toward oncology research; however, learned techniques which could be applied to any life science including flow cytometry, fluorescent microscopy, GC/HPLC, and in vivo models, to name a few.

\section{Education:}

\begin{tabular}{|c|c|c|c|}
\hline $\begin{array}{c}\text { INSTITUTION AND } \\
\text { LOCATION }\end{array}$ & $\begin{array}{c}\text { DEGREE } \\
\text { (if applicable) }\end{array}$ & $\begin{array}{c}\text { DATES } \\
\text { ATTENDED }\end{array}$ & FIELD OF STUDY \\
\hline $\begin{array}{l}\text { Paducah Community College } \\
\text { (Paducah, KY) }\end{array}$ & N/A & $08 / 04-08 / 05$ & Pre-Pharmacy \\
\hline $\begin{array}{l}\text { University of Kentucky } \\
\text { (Lexington, KY) }\end{array}$ & B.S. & $08 / 05-08 / 08$ & Biology \\
\hline University of Louisville & M.S. & $08 / 11-08 / 14$ & Pharmacology/Toxicology \\
\hline & Ph. D (expected) & 08/14 -05/17 & Pharmacology/Toxicology \\
\hline
\end{tabular}

\section{Positions and Honors:}

Employment

$$
\begin{aligned}
& \quad 2003-2006 \\
& \quad 2008 \\
& * 2008-2010 \\
& * \quad 2011-2014 \\
& * \quad 2014-2016 \\
& * 2017-\text { Present }
\end{aligned}
$$

Pharmacy Technician, Lourdes Hospital, (Paducah, KY) Research Technician, University of Kentucky (Lexington, KY) Quality Assurance Technician, Air Products (Calvert City, KY) Predoctoral Researcher, University of Louisville (Louisville, KY) Visiting Researcher Associate, Indiana University (Bloomington, IN) Postdoctoral Research Fellow, University of South Carolina School of Medicine 
$\underline{\text { Volunteerism and Memberships }}$

* $2001-2004$
$* 2004$
$* \quad 2008$ - 2011
$* \quad 2011$ - present

$\underline{\text { Honors }}$

2004-2005
2004-2005
2009-2010
2011-2013
$\quad 2015$
$* \quad 2016$

Volunteer, Relay for Life (Paducah, KY)

Volunteer, Habitat for Humanity (Paducah, KY)

Volunteer, ASPCA (Lexington, KY)

Member, Society of Toxicology (SOT)

Volunteer, Monroe County VITALS Program

\title{
Publications:
}

\section{$\underline{\text { Articles }}$}

\author{
Academic Scholarship, Paducah Community College (Paducah, KY) \\ Deans List, Paducah Community College (Paducah, KY) \\ Governor's Safety and Health Award, Air Products (Calvert City, KY) \\ Graduate Fellowship, University of Louisville (IPIBS) (Louisville, KY) \\ Simon Cancer Center Research Day, $2^{\text {nd }}$ Place Poster Presentation \\ (Indianapolis, IN) \\ CTSI Customer Discovery Program (Indianapolis, IN)
}

Shidal, C.P., Lunasin reduces the melanoma stem cell population in vitro and inhibits tumor proliferation in vivo. (2014). Electronic Theses and Dissertations. Paper 1765.

Shidal C., et. al. Lunasin is a novel therapeutic agent for targeting melanoma cancer stem cells. Oncotarget 2016 (doi: 10.18632/oncotarget.11554)

Devapatla B, Shidal C, Yaddanapudi K and Davis KR. Validation of syngeneic mouse models of melanoma and non-small cell lung cancer for investigating the anticancer effects of the soy-derived peptide Lunasin. F1000Research 2016, 5:2432 (doi: 10.12688/f1000research.9661.1)

Shidal C., Yaddanapudi K., and Keith R Davis. The soy derived peptide Lunasin decreases invasive potential of melanoma initiating cells. Oncotarget, 2016. (Accepted)

Shidal C. et al. Genome-wide microarray analysis reveals the selective effects of Lunasin on melanoma initiating cells. (Manuscript in preparation).

\section{$\underline{\text { Select Presentations }}$}

Shidal, Chris and Keith R. Davis (2012). Lunasin inhibits proliferation of non-small cell lung cancer (NSCLC) in-vitro. J.G. Brown Cancer Center Retreat. University of Louisville, Louisville, KY.

Shidal, Chris and Keith R. Davis (2013). Molecular interactions between cadmium and nitrosamine ketone potentiate carcinogenic potential of cigarette smoke. OVSOT 2013 Spring Meeting, University of Louisville, Louisville, KY.

Shidal, Chris and Keith R. Davis (2013). Profiling Lunasin as an adjuvant treatment in malignant melanoma. J.G. Brown Cancer Center Retreat. University of Louisville, Louisville, KY.

Shidal, Chris, et al. (2015). Lunasin has therapeutic potential against malignant melanoma. Simon Cancer Center Research Day. IUPUI, Indianapolis, IN. 
Shidal, Chris, et al. (2015). Lunasin has therapeutic potential against malignant melanoma. Society of Postdoctoral Scholars Symposium. University of Kentucky, Lexington, KY.

Shidal, Chris, et. al.(2016) Lunasin has therapeutic utility against malignant melanoma. Indiana University Chemistry Department Career Development Seminar. Indiana University, Bloomington, IN.

Shidal, Chris, et. al. (2016) Using the multifaceted peptide Lunasin to combat malignant melanoma. Biochemistry and Molecular Biology (BMB) Research Club, Indiana University-Bloomington.

Shidal, Chris, et. al. (2016) Using the multifaceted peptide Lunasin to combat malignant melanoma. OVSOT 2016 Fall Meeting. Eli Lilly, Indianapolis, IN. 